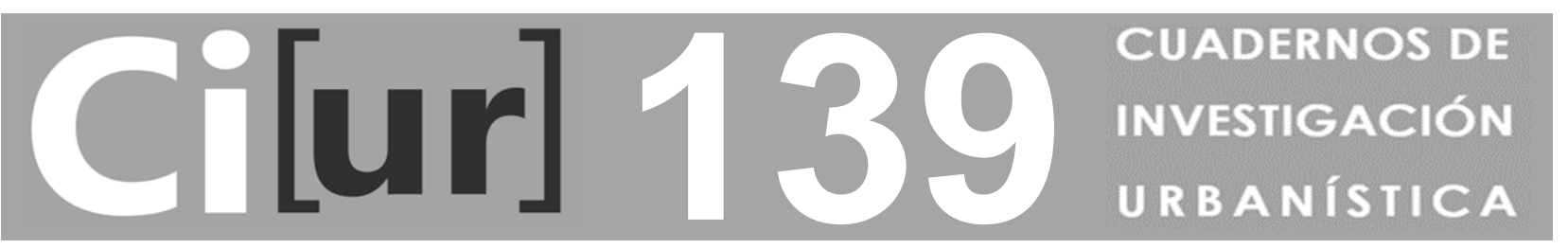

\title{
EL PAISAJE COMO INFRAESTRUCTURA PARA LA RESILIENCIA URBANA FRENTE A DESASTRES. EL CASO DE LOS PARQUES DE MITIGACIÓN EN LA COSTA CENTRO-SUR DE CHILE POST TSUNAMI 2010
}

\section{OSVALDO MORENO FLORES}

Doctor Arquitecto

Este artículo se basa en la tesis doctoral "El paisaje como infraestructura para la adaptabilidad y resiliencia de territorios en riesgo de desastres. El caso de los Parques de Mitigación en localidades de borde costero del centro-sur de Chile post tsunami 2010", dirigida por el Dr. Fernando Aliata y co-dirigida por el Dr. Hermann Mülhausser, presentada por el autor el 11 de diciembre de 2020 para acceder al Grado de Académico de Doctor en Arquitectura y Urbanismo en la Universidad Nacional de La Plata, Argentina.

noviembre / diciembre 2021 


\begin{tabular}{|c|c|}
\hline Directores: & José Fariña Tojo - Ester Higueras García \\
\hline Editora: & María Cristina García González \\
\hline \multicolumn{2}{|c|}{ Consejo de Redacción: } \\
\hline Directora: & María Emilia Román López \\
\hline Comisión ejecutiva: & $\begin{array}{l}\text { Agustín Hernández Aja, José Antonio Corraliza Rodríguez, María Cristina García González, } \\
\text { María Emilia Román López, Eva Álvarez de Andrés. }\end{array}$ \\
\hline Vocales: & $\begin{array}{l}\text { Isabel Aguirre de Urcola (Escola Galega da Paisaxe Juana de Vega, A Coruña), Pilar Chías } \\
\text { Navarro (Univ. Alcalá de Henares, Madrid), José Antonio Corraliza Rodríguez (Univ. } \\
\text { Autónoma de Madrid), Alberto Cuchí Burgos (Univ. Politécnica de Cataluña), José Fariña Tojo } \\
\text { (Univ. Politécnica de Madrid), Agustín Hernández Aja (Univ. Politécnica de Madrid), Francisco } \\
\text { Lamíquiz Daudén (Univ. Politécnica de Madrid), María Asunción Leboreiro Amaro (Univ. } \\
\text { Politécnica de Madrid), Rafael Mata Olmo (Univ. Autónoma de Madrid), Luis Andrés Orive } \\
\text { (Centro de Estudios Ambientales, Vitoria-Gasteiz), Javier Ruiz Sánchez (Univ. Politécnica de } \\
\text { Madrid), Carlos Manuel Valdés (Univ. Carlos III de Madrid) }\end{array}$ \\
\hline Consejo Asesor: & $\begin{array}{l}\text { José Manuel Atienza Riera (Vicerrector de Estrategia Académica e Internacionalización, Univ. } \\
\text { Politécnica de Madrid), Manuel Blanco Lage (Director de la Escuela Técnica Superior de } \\
\text { Arquitectura, Univ. Politécnica de Madrid), José Miguel Fernández Güell (Director del } \\
\text { Departamento de Urbanística y Ordenación del Territorio, Univ. Politécnica de Madrid), } \\
\text { Antonio Elizalde Hevia, Julio García Lanza, Josefina Gómez de Mendoza, José Manuel Naredo, } \\
\text { Julián Salas Serrano, Fernando de Terán Troyano, María Ángeles Querol. }\end{array}$ \\
\hline Comité Científico: & $\begin{array}{l}\text { Antonio Acierno (Univ. Federico II di Napoli, Nápoles, ITALIA), Miguel Ángel Barreto (Univ. } \\
\text { Nacional del Nordeste, Resistencia, ARGENTINA), José Luis Carrillo (Univ. Veracruzana, } \\
\text { Xalapa, MÉXICO), Luz Alicia Cárdenas Jirón (Univ. de Chile, Santiago de Chile, CHILE), Marta } \\
\text { Casares (Univ. Nacional de Tucumán, Tucumán, ARGENTINA), María Castrillo (Univ. de } \\
\text { Valladolid, ESPAÑA), Dania Chavarría (Univ. de Costa Rica, COSTA RICA), Mercedes Ferrer } \\
\text { (Univ. del Zulia, Maracaibo, VENEZUELA), Fernando Gaja (Univ. Politécnica de Valencia, } \\
\text { ESPAÑA), Alberto Gurovich (Univ. de Chile, Santiago de Chile, CHILE), Josué Llanque (Univ. } \\
\text { Nacional de S. Agustín, Arequipa, PERÚ), Angelo Mazza (Univ. degli Studi di Napoli, Nápoles, } \\
\text { ITALIA), Luis Moya (Univ. Politécnica de Madrid, ESPAÑA), Joan OImos (Univ. Politécnica de } \\
\text { Valencia, ESPAÑA), Ignazia Pinzello (Univ. degli Studi di Palermo, Palermo, ITALIA), Julio } \\
\text { Pozueta (Univ. Politécnica de Madrid, ESPAÑA), Alfonso Rivas (Univ. A. Metropolitana } \\
\text { Azcapotzalco, Ciudad de México, MÉXICO), Silvia Rossi (Univ. Nacional de Tucumán, } \\
\text { ARGENTINA), Adalberto da Silva (Univ. Estadual Paulista, Sao Paulo, BRASIL), Carlos } \\
\text { Soberanis (Univ. Francisco Marroquín, Guatemala, GUATEMALA), Carlos A. Torres (Univ. } \\
\text { Nacional de Colombia, Bogotá, COLOMBIA), Graziella Trovato (Univ. Politécnica de Madrid, } \\
\text { ESPAÑA), Carlos F. Valverde (Univ. Iberoamericana de Puebla, MÉXICO), Fernando N. } \\
\text { Winfield (Univ. Veracruzana, Xalapa, MÉXICO), Ana Zazo (Univ. del Bio-Bio, Concepción, } \\
\text { CHILE) }\end{array}$ \\
\hline
\end{tabular}

\section{Realización y maquetación:}

Maquetación: ciur.urbanismo.arquitectura@upm.es

\section{(C) COPYRIGHT 2021}

\section{OSVALDO MORENO FLORES}

Fecha de recepción:

Fecha de aceptación:

I.S.S.N. (edición digital): 2174-5099

DOI: $10.20868 /$ ciur.2021.139.4778

Depósito Legal: M-41356-2011

Año XIII, Núm. 139, noviembre-diciembre 2021, 111 págs.

Edita: Instituto Juan de Herrera 


\section{El paisaje como infraestructura para la resiliencia urbana frente a desastres. El caso de los Parques de Mitigación en la costa centro- sur de Chile post tsunami 2010. \\ Landscape as infrastructure for urban resilience to disasters. The case of Mitigation Parks in central-southern coast of Chile post tsunami 2010.}

DOI: $10.20868 /$ ciur.2021.139.4778

\section{DESCRIPTORES:}

Paisaje / Infraestructura verde / Resiliencia / Reducción de riesgos / Desastres / Tsunami / Chile.

\section{KEY WORDS:}

Landscape / Green Infrastructure / Resilience / Risk Reduction / Disasters / Tsunamis / Chile.

\section{RESUMEN:}

La investigación tiene como propósito estudiar el alcance y contribución de la planificación y diseño del paisaje en la gestión de riesgos, adaptabilidad y resiliencia urbana de territorios afectados por desastres, tomando como caso de estudio el sistema de parques de mitigación de tsunamis proyectado en los años posteriores al terremoto y tsunami de Febrero de 2010, en localidades urbanas costeras del centro-sur de Chile, en las regiones del Maule y Biobío.

En ese marco, el paisaje constituye una plataforma apta para analizar, representar y proyectar las condiciones dinámicas de territorios, con especial atención a aquellos contextos caracterizados por situaciones de exposición a cambios. El desastre en tal sentido, comprendido desde la perspectiva de un cambio abrupto en la trayectoria de un sistema territorial, conforma un ámbito de estudio de alto interés para la arquitectura del paisaje y ésta provee de la sensibilidad para abordar su complejidad en materia de transformación y potencial adaptabilidad. En términos más precisos, la arquitectura del paisaje puede ser entendida como un soporte estructurante del territorio, que permite reconocer y también diseñar sistemas socioecológicos claves para la resiliencia de territorios y comunidades, favoreciendo la prestación de funciones y servicios relacionados con la prevención y/o mitigación de efectos de desastres asociados a inundación o remoción en masa, así como también permitiendo la evacuación y refugio de la población afectada.

Respecto al caso de estudio, la figura de los Parques de Mitigación desarrollados bajo el alero de los Planes de Reconstrucción en el periodo 2010-2015, en la zona centro-sur de Chile, constituye un antecedente relevante en materia de puesta en práctica del enfoque asociado a la arquitectura del paisaje como infraestructura para la mitigación y reducción de riesgos. No obstante, dada su importancia como pieza clave para la resiliencia urbana ante la ocurrencia de desastres de tsunami, es fundamental profundizar en su análisis respecto a los criterios y lineamientos que determinan su formulación, así como también fortalecer el campo de conocimiento referido a las estrategias y técnicas que definen su diseño.

Para ello, el estudio de la experiencia internacional en materia de planificación y diseño de paisaje como infraestructura para la adaptabilidad y resiliencia de territorios afectados por 
desastres permitirá sistematizar lineamientos, estrategias y técnicas orientadas a fortalecer las bases sobre las cuales se desarrollan actualmente los Parques de Mitigación en Chile.

\section{ABSTRACT:}

The main purpose of this doctoral research is to study the scope and contribution of landscape planning and design in the management of risks, adaptability and urban resilience of disasteraffected territories, taking as a case study the projected tsunami mitigation park system in the years after the earthquake and tsunami event of February 2010, in coastal urban areas of the Maule and Biobío regions, in Chile.

Within that framework, the landscape can be understood as an important platform to analyze, represent and project the dynamic conditions of territories, with special attention to those contexts characterized by situations of exposure to changes. In this sense, disasters can be understood as an abrupt change in the evolutionary process of a territorial system, building a high interest field of study of for landscape architecture, that provides the sensitivity to address its complexity in terms of transformation and potential adaptability. The case of the Mitigation Parks developed in the Reconstruction Plans in the period 2010-2015 - in the coastal cities of central-southern Chile - defines a relevant background in the implementation of the landscape architecture approach as infrastructure for risk reduction. Due to its importance as a key piece for urban resilience in the event of tsunami disasters, it is essential to deepen the analysis of the criteria and guidelines that determine its formulation, as well as strengthen the field of knowledge related to the strategies and techniques that defined their design.

The study of international experience in landscape planning and design as an infrastructure for the adaptability and resilience of disaster-affected territories will allow systematizing guidelines, strategies and techniques to strengthen the foundations on which the Mitigation Parks in Chile are currently being developed.

\footnotetext{
* Osvaldo Moreno Flores es Arquitecto de la Universidad de Chile, Doctor en Arquitetura y Urbanismo y Magíster en Paisaje Medioambiente y Ciudad por la Universidad Nacional de La Plata - Red Alfa Pehuén. Actualmente es Profesor y Jefe de Magíster en Arquitectura del Paisaje de la Escuela de Arquitectura, en la Pontificia Universidad Católica de Chile.

Email de contacto: omorenof@uc.cl

ORCID: http://orcid.org/0000-0003-0366-5430 (Osvaldo Moreno Flores)
}

CONSULTA DE NÚMEROS ANTERIORES/ACCESS TO PREVIOUS WORKS:

La presente publicación se puede consultar en la dirección:

This document is available in the following web page:

https://duyot.aq.upm.es/publicaciones 


\section{ÍNDICE}

1 INTRODUCCIÓN: DESASTRES, RIESGO Y RESILIENCIA. APROXIMACIONES DESDE EL PAISAJE.

2 (RE) DEFINIENDO EL PAISAJE COMO INFRAESTRUCTURA PARA LA RESILIENCIA DE TERRITORIOS Y COMUNIDADES VULNERABLES ANTE DESASTRES.

2.1 Desastres, vulnerabilidades y territorios en riesgo. Acepciones y enfoques...12

2.2 El desastre como problema de Paisaje: ecología, representación y proyecto...14

2.3 Resiliencia. Nuevos enfoques asociados a la gestión de territorios en riesgo...22

2.4 Del jardín a la Infraestructura Verde:Planificación y diseño de paisajes resiliente... 26

3 EL DESASTRE COMO ESPACIO DE OPORTUNIDAD PARA REPENSAR LAS DINÁMICAS DE HABITABILIDAD DESDE EL PAISAJE: LOS PARQUES DE MITIGACIÓN EN EL CONTEXTO DE LA RECONSTRUCCIÓN POST TSUNAMI DE 2010 EN CHILE........35

3.1 Caracterización del impacto del tsunami de 2010 en el borde costero del centro sur de Chile. 31

3.2 Planificación territorial y gestión del desastre. Marco normativo y operativo en Chile: definiciones, disposiciones e instrumentos. 38

3.3 Parques de Mitigación, pieza emblemática de los Planes Maestros de Reconstrucción post 27F. 43

3.4 Estrategias, técnicas y operaciones de diseño de los Parques de Mitigación como infraestructura de resiliencia y reclamación del paisaje costero. 54

3.4.1 El caso de Constitución: prototipo de Parque de Mitigación. .56

3.4.2 Otras experiencias: Parques de Mitigación de Pelluhue y Dichato .68

4 HACIA UN MODELO DE RESILIENCIA URBANA DESDE EL PAISAJE: FORMULACIÓN DE LINEAMIENTOS CONCEPTUALES, ESTRATEGIAS DE PLANIFICACIÓN Y CRITERIOS TÉCNICOS PARA EL FORTALECIMIENTO DE LOS PARQUES DE MITIGACIÓN. .75

4.1 Síntesis e integración de referencias asociadas a la experiencia internacional en materia de planificación y diseño de infraestructuras verdes para la resiliencia urbana y reducción de riesgos de desastres.

4.2 Propuesta de lineamientos conceptuales, estrategias de planificación y criterios de diseño del Paisaje para el fortalecimiento de los Parques de Mitigación en contextos de borde costero. 80

4.2.1 Lineamientos conceptuales: definiciones indicativas y normativas de planificación y diseño. 
4.2.2 Estrategias de planificación: articulaciones y sinergias con el mosaico de

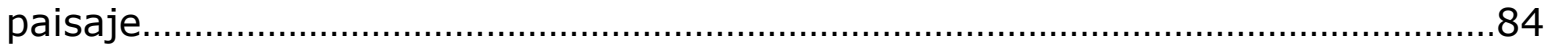

4.2.3 Criterios técnicos de diseño del Parque como sistema integrado de

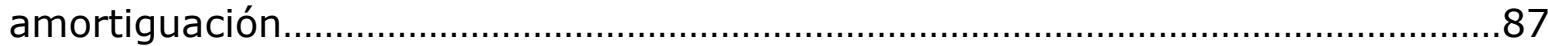

5 CONCLUSIONES Y PROYECCIONES: EL PAISAJE COMO INFRAESTRUCTURA SOCIOECOLÓGICA PARA LA RESILIENCIA Y ADAPTABILIDAD DE TERRITORIOS Y

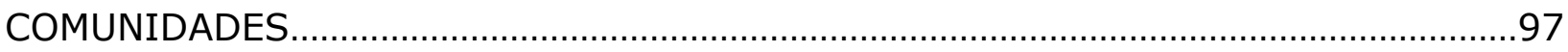

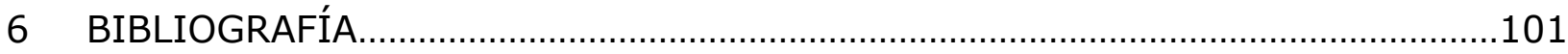




\section{INTRODUCCIÓN: DESASTRES, RIESGO Y RESILIENCIA. APROXIMACIONES DESDE EL PAISAJE}

La arquitectura del paisaje constituye un campo multidisciplinario en el que convergen diversos ámbitos de conocimiento vinculados a las ciencias sociales, las ciencias naturales y las disciplinas del arte, las cuales se integran y sintetizan a partir de técnicas asociadas al diseño y la planificación territorial, en escalas variables de representación y proyecto. Aun cuando el papel tradicional de la arquitectura del paisaje se ha situado históricamente en la producción de escenarios de ocio y esparcimiento en ciudades a través del diseño de jardines y espacios verdes, la compleja realidad contemporánea devela nuevos desafíos y campos de actuación, integrando conceptos que refieren a condiciones de contextos inestables y cambiantes, especialmente relacionadas con territorios vulnerables ante impactos y perturbaciones generadas por desastres. En este panorama reciente $-y$ como se expondrá en el segundo capítulo de esta investigación- resulta interesante constatar también el rol ascendente de la arquitectura del paisaje en las iniciativas de planificación territorial con enfoque de gestión de riesgo y resiliencia, pasando de comparecer como una especialidad vinculada a soluciones específicas de diseño paisajístico, para constituirse como plataforma articuladora de este tipo de instancias.

La ocurrencia de un desastre es posible debido a la propensión de una determinada zona o asentamiento humano al riesgo de afectación derivado de un fenómeno de origen natural o antrópico, determinado por la consumación de un proceso -a veces de larga data- de generación de condiciones de riesgo en la sociedad. Como señala Tapia \& Arteaga (2015), la ocupación desaprensiva de territorios expuestos a amenazas naturales, la falta de estudios profundos de riesgos, que antecedan a la planificación de la localización y crecimiento de las ciudades sobre terrenos seguros, así como los niveles de pobreza y segregación social, constituyen factores sociales, culturales y políticos de los cuales depende el nivel de daño que puede sufrir la población. Mientras los riesgos representan las probabilidades de que ocurran desastres en un determinado lugar, las catástrofes registran su manifestación a través de daños y pérdidas de vidas humanas, bienes y servicios económicos, materiales, psicológicos, culturales y simbólicos, así como de importantes perturbaciones en el comportamiento de las estructuras sociales y de las instituciones encargadas de mantener la normalidad y resiliencia de los grupos humanos que habitan los asentamientos rurales y urbanos (Aravena, Fuentes, \& Guerra, 2010). El desastre, comprendido así como un proceso de cambio abrupto en la trayectoria de los sistemas antrópicos y ecológicos en un determinado contexto territorial, constituye un ámbito de estudio emergente de alto interés para la arquitectura del paisaje, en el contexto de territorios urbanos expuestos a riesgos de desastres. Y ésta -dada su posición intermedia e integradora de diversos ámbitos de conocimiento- puede proveer de la sensibilidad necesaria para abordar su complejidad en materia de transformación y potencial adaptabilidad.

En el marco de esta problemática, el surgimiento del proyecto de paisaje ha estado estrechamente vinculado -en especial en la última década- a experiencias de intervención en territorios afectados por eventos hidrometereológicos, principalmente 
en el contexto norteamericano. El impacto recurrente de tormentas y huracanes en América del Norte -como Katrina en 2005, Ike 2008 y Sandy en 2011- han sido factores desencadenantes de iniciativas de investigación y políticas públicas orientadas a promover instrumentos de planificación y proyectos para la reducción de riesgo ante desastres, principalmente referidos al manejo de inundaciones en ciudades costeras (Lister, 2015). Asimismo, desastres relacionados con tormentas y tsunamis ocurridos en el norte de Europa y Asia, respectivamente, aportan experiencias relevantes en materia de planes y proyectos. En torno a este panorama, que también adopta los lineamientos establecidos por Naciones Unidas a través de diversas instancias intergubernamentales para la gestión del riesgo de desastres, la arquitectura del paisaje ha tenido un emergente espacio de desarrollo teórico y práctico, cuya base conceptual en materia de diseño es informada tanto por el conocimiento ecológico, como las ciencias aplicadas de la ingeniería, la arquitectura y el urbanismo (Waldheim, 2016; Reed \& Lister, 2014; Corner \& Bick, 2014).

Chile, con su amplia extensión de 4.329 kilometros de longitud continental, ubicado en una estrecha franja contenida entre la Cordillera de los Andes y el océano Pacífico, es un territorio esencialmente costero que atraviesa diferentes condiciones climáticas y geográficas, desde el árido desierto en su zona norte, hasta las áreas glaciares y subglaciares del sur austral. Como señala Fernández Galiano, el territorio chileno es un oxímoron geográfico: "del desierto a los témpanos, este país interminable repta por el meridiano para reconciliar el fuego con el hielo, deslizándose entre los Andes y el Pacífico con el aplomo del que a la vez se sabe cordillera y océano." (Fernandez Galiano, 2002:3). Su estructura político-administrativa-dividida jerárquicamente en regiones, provincias y comunas- devela su condición de territorio eminentemente costero: 14 de sus 15 regiones, 33 de sus 54 provincias y 102 de sus 346 municipios, limitan con el oceano Pacífico (SUBDERE, 2011). Asimismo, todas las regiones y provincias de Chile incluyen formaciones geográficas de cordillera ${ }^{1}$, generándose en algunas de ellas hasta 3 cordones cordilleranos que se desarrollan longitudinalmente en forma paralela, como ocurre en las regiones nortinas de Antofagasta y Atacama, donde convergen las cordilleras de Los Andes, de Domeyko y de la Costa.

Debido a la confluencia de las placas tectónicas de Nazca y Sudamericana, Chile constituye un territorio altamente expuesto a múltiples riesgos de carácter geológico, tales como terremotos, tsunamis, remoción en masa y erupciones volcánicas; e hidrometereológico, como inundaciones, aluviones, marejadas, tormentas, lluvias extremas y sequías, entre otros (Arenas et al., 2010). Los impactos relacionados a estos eventos repercuten de manera importante tanto en el medio natural, como en los sistemas antrópicos, debido en gran medida a la presencia de asentamientos humanos, infraestructuras y actividades productivas localizadas en zonas de riesgo, condición agravada además por una débil planificación territorial que se evidencia especialmente en las ciudades regionales de escala intermedia y menor (Martínez,

\footnotetext{
${ }^{1}$ Las cordilleras, en tanto formaciones de relieve del territorio, expresan a su vez las dinámicas geológicas de pliegues de placas tectónicas, procesos sedimentarios y modelamientos derivados de la acción de la hidrología y la erosión eólica, por millones de años (Cereceda \& Errázuriz, 2015).
} 
2013). Al respecto, como señala Arenas et al. (2010), una gran parte de las áreas urbanas en Chile presenta situaciones de riesgo, debido no sólo a la ocupación irregular y desprovista de planificación territorial, sino también a la presión ejercida desde el sector inmobiliario para la construcción en esos espacios. Por lo tanto, más allá de las condiciones físico-naturales, la escasa consideración de la dinámica y recurrencia de procesos naturales extremos, y su relación con el emplazamiento de asentamientos humanos ha incrementando el riesgo de desastre, especialmente en las localidades de borde costero (Lagos et al., 2008).

En este marco, el terremoto y tsunami ocurrido en febrero de 2010 se considera uno de los eventos más relevantes en los registros históricos de actividad sísmica a nivel mundial, tanto desde el punto de vista de la magnitud del fenómeno, de la extensión territorial que abarcó y de la población comprometida -incluyendo a los principales centros urbanos e infraestructuras críticas del centro sur de Chile- con severas consecuencias en las localidades de borde costero en más de 600 kilómetros de extensión (MINVU, 2010). Por otra parte, desde un enfoque prospectivo, este desastre ha permitido, en años posteriores, desarrollar conocimiento científico y técnico en diversas áreas del conocimiento, favoreciendo procesos reflexivos relacionados con la planificación territorial de bordes costeros, contemplando una revisión de los protocolos de gestión de riesgo y un desarrollo de instrumentos especialmente focalizados en la zonificación de áreas de riesgo, en el marco de la actualización de instrumentos de planificación territorial (IPT) a escala comunal y regional.

A partir de este caso de estudio, la investigación abordará la revisión de la figura de los Parques de Mitigación en localidades costeras de las regiones del Maule y Biobío, cuyo planteamiento surge como estrategia de planificación en el contexto post-tsunami de febrero de 2010, en el marco de los procesos de reconstrucción de ciudades afectadas en el centro sur de Chile. La propuesta de los Parques de Mitigación -planteada por primera vez en el plan de reconstrucción de la ciudad de Constitución- emerge como proyecto vinculado a proveer de espacios de amortiguación para disipar parte de los efectos generados por el impacto de tsunamis y marejadas, con el objetivo de favorecer, por un lado, los tiempos de evacuación de la población hacia zonas altas de seguridad y, por otro, de reducir los daños a la propiedad pública y privada. Este nuevo enfoque de infraestructura integra la noción de parque como estrategia que reflexiona sobre las condiciones de habitabilidad en los bordes expuestos a riesgos de desastres, definiendo nuevas posibilidades de encuentro social entre la ciudades litorales y los paisajes costeros, los cuales previos al desastre habían sido progresivamente ocupados, privatizados y subvalorados, en su dimensión cultural y ecológica. De esta manera, el espacio público en la reconstrucción del $27 \mathrm{~F}$ tiene un rol estratégico, dado que se comprende como el ámbito clave a intervenir para revertir las condiciones de vulnerabilidad, promover la reducción de riesgos de desastre y fomentar la resiliencia urbana.

Sin embargo, aun cuando los Parques de Mitigación han conformado un importante ámbito de inversión pública en la última década y sus estrategias han sido implementadas en diversos contextos territoriales, no existe todavía una base 
documental organizada que permita esclarecer los lineamientos conceptuales y criterios técnicos que han sido utilizados en su formulación e implementación. Por el contrario, los antecedentes referidos a estas experiencias se encuentran atomizados en diversos soportes asociados a estudios, informes, memorias y planos, lo cual hasta hoy ha dificultado su análisis y comprensión.

Por tanto, uno de los desafíos que asume esta investigación es visibilizar de manera ordenada y jerarquizada la información encontrada a partir de la consulta a diversas fuentes, sistematizando luego los resultados del análisis para determinar la idoneidad de las principales estrategias y operaciones que dan forma y sentido a la figura de los Parques de Mitigación. Por otra parte, esta base articulada de análisis permitirá identificar aquellos componentes de diseño necesarios de mejorar y fortalecer, nutriéndolos de aquellos lineamientos conceptuales y criterios técnicos que puedan incorporarse a partir de la experiencia internacional, no sólo en materia específica de estrategias de mitigación ante tsunamis, sino en el amplio panorama de casos asociados a otros fenómenos de desastres. Se estima que sólo así será posible aprovechar el enorme esfuerzo del Estado y de diversos actores que han participado de su desarrollo, con el propósito de promover de manera responsable su replicabilidad como parte de una política pública basada en el rol del paisaje como infraestructura para la resiliencia y adaptabilidad de territorios en condiciones de vulnerabilidad ante desastres.

\section{2 (RE) DEFINIENDO EL PAISAJE COMO INFRAESTRUCTURA PARA LA RESILIENCIA DE TERRITORIOS $Y$ COMUNIDADES VULNERABLES ANTE DESASTRES}

Tradicionalmente, el rol de la arquitectura del paisaje ha estado situado en el diseño de jardines, parques, áreas verdes públicas y privadas, centrando la atención en la producción de escenarios de ocio y esparcimiento en ciudades. Sin embargo, la realidad contemporánea devela nuevos desafíos y campos de actuación para esta disciplina, integrando conceptos que refieren a condiciones de contextos inestables y cambiantes. Si durante los últimos veinte años los discursos asociados a la ciudad han instalado la noción de sustentabilidad como principal propósito de investigaciones, estudios y proyectos, en la actualidad es el concepto de resiliencia el que centra la atención de académicos, planificadores, autoridades y, también, de una ciudadanía cada vez más activa y empoderada ante escenarios críticos derivados de la ocurrencia de desastres.

Las áreas urbanas son especialmente vulnerables frente a fenómenos naturales extremos, especialmente en países en vías de desarrollo que cuentan con un gran porcentaje de pobreza e infraestructura no preparada (Kreimer, Arnold, y Carlin, A., 2003). Es así que, en América Latina, la vulnerabilidad se ha incrementado debido a la fuerte expansión urbana sin una planificación efectiva, concretándose en desastres que afectan directamente a la población (Montenegro-Romero y Peña-Cortés, 2010). Este cambio de paradigma -que define el tránsito desde la sustentabilidad a la resiliencia- puede constatarse en diversos informes y reportes oficiales de organismos internacionales tales como el PNUD, el Banco Mundial y la CEPAL, en iniciativas de 
planes y proyectos urbanos en ciudades a nivel global ${ }^{2}$, así como también en el creciente volumen de investigaciones científicas de distintas disciplinas que abordan temáticas de resiliencia en ciudades y asentamientos humanos vulnerables ante desastres.

En términos generales el concepto de resiliencia refiere a la capacidad de un organismo o sistema de adaptarse y asumir flexibilidad en situaciones límite, para sobreponerse a ellas (Emrich \& Tobin, 2018; Moreno 2013; Eckardt, 2011; Holling, 1973). En su alcance territorial, resiliencia es un término utilizado recientemente como estrategia para la reducción de riesgo ante desastres, en su dimensión tanto cultural como material, teniendo la premisa de resistir o generar adaptación de tal forma que ésta siga exhibiendo un nivel aceptable de funcionamiento, determinado por el grado en que cada sistema social es capaz de organizarse a sí mismo y la habilidad de incrementar su capacidad de aprender y adaptarse, incluyendo la capacidad de recuperarse de un desastre (Kreimer et al, 2003). El nivel de presión al cual se encuentran sometidos hoy los territorios urbanos y periurbanos especialmente en nuestro contexto latinoamericano- debido a factores socioculturales, demográficos, económicos y ambientales, argumenta este cambio de énfasis conceptual que asume el tránsito desde la noción de sustentabilidad, hacia la de resiliencia. De esta forma, ya no se habla sólo de articular la dimensión de la equidad social, la integridad ecológica y la competitividad económica en los planes territoriales y proyectos urbanos, sino que ante constantes escenarios de cambios, crisis y desastres, las ideas de adaptabilidad, resistencia y regeneración aparecen como nuevos vectores a gestionar, planificar y proyectar en torno a las ciudades.

El paisaje urbano, entonces, se asume como un paisaje en emergencia, entendido desde una doble consideración: por un lado, la emergencia, asociada al estado de alerta que supone un inmediato riesgo para la salud, la vida o la propiedad de individuos y comunidades, la cual demanda intervención urgente para atender la situación, prevenir y evitar su empeoramiento; por otra parte, la emergencia como concepto vinculado a lo emergente, referido al surgimiento de elementos, sistemas, procesos o actores en un determinado contexto, los que aportan soluciones a problemáticas y demandas existentes (Moreno, 2015). La noción de paisaje, como denominador común para ambas acepciones, se plantea desde una posición intermedia, híbrida y mestiza, que articula lo ecológico y lo sociocultural en una dinámica que posibilita una lectura, interpretación y proyectación del territorio, acorde a los complejos desafíos que supone la atención a las actuales problemáticas asociadas a los cambios, crisis y desastres que afectan a diversos escenarios y contextos. A su vez, permite establecer un diálogo integrador entre disciplinas que por mucho tiempo -incluso siglos mediante- han transitado senderos paralelos e inconexos (Nogué, 2010). Desde el andamiaje teórico, epistemológico y experiencial de lo paisajístico, las ciencias ambientales, las ciencias humanas, las disciplinas del

2 En efecto, la Nueva Agenda Urbana que surge luego de la Cumbre Mundial ONU Habitat III, desarrollada en Quito el 2016, plantea como uno de los principales desafíos la planificación y diseño de ciudades más resilientes. 
arte y del diseño encuentran vasos comunicantes cada vez más trascendentes y sinérgicos.

\subsection{Desastres, vulnerabilidades y territorios en riesgo. Acepciones y enfoques}

Se puede definir desastre como una situación de daño, desencadenada como resultado de la manifestación de un fenómeno de origen natural, socionatural o antrópico que, al encontrar condiciones propicias de vulnerabilidad en una población, causa alteraciones intensas, graves y extendidas en la estabilidad y condiciones de vida de la comunidad afectada (CEPAL, 2005). Generalmente, estas alteraciones implican daños y pérdidas humanas, materiales y ambientales (EPC y TCG International LLC, 2004), cuantificables a nivel de muertes, damnificados y afectación a viviendas, infraestructuras, redes de servicio, áreas productivas e industriales, entre otras categorías. Asimismo, como señala Natenzon \& Ríos (2015), los daños producidos por la ocurrencia de desastres involucran también pérdidas de logros materiales y bienes obtenidos a través de años de vida por parte de las comunidades, generando también pérdidas en el patrimonio físico e inmaterial determinante para la identidad cultural en los territorios afectados (UNESCO, 2014).

Lavell (1996), haciendo una síntesis de los aportes clásicos de diversos autores exponentes de la sociología de desastres norteamericana -entre ellos Fritz (1961), Quarantelli (1987), y Kreps (1984), dados a conocer principalmente a través de la revista Mass Emergencies and Disasters-, define un desastre, desde el punto de vista sociológico, como una ocasión de crisis o estrés social, observable en el tiempo y el espacio, donde las sociedades y sus componentes sufren daños o pérdidas físicas y alteraciones en su funcionamiento cotidiano, excediendo su propia capacidad de autorecuperación y debiendo requerir la intervención o cooperación externa. El autor establece que tanto las causas como las consecuencias de los desastres son producto de los procesos sociales que operan al interior de la sociedad afectada.

La localización de las actividades humanas en territorio - ámbito determinado por razones demográficas, sociales, culturales, económicas y políticas - puede constituir uno de los principales factores determinantes del desastre, cuando la decisión de instalar un asentamiento o actividad humana se establece sin tomar en consideración las amenazas existentes y las vulnerabilidades que se desarrollan, variables que constituyen una situación de riesgo potencial (CEPAL, 2005). Este factor, que interpela la condición de vulnerabilidad de una determinada población ante un potencial riesgo, se complejiza además porque generalmente se encuentra estrechamente vinculada a condiciones de vulnerabilidades sociales ${ }^{3}$, exclusión social y pobreza (Natenzon \& Ríos, 2015; Rojas, 2011), características que se evidencian en nuestras ciudades cuando observamos los escenarios más expuestos ante riesgos

\footnotetext{
${ }^{3}$ La vulnerabilidad social o vulnerabilidad base es definida como la configuración social previa al desastre y abarca aspectos tales como las condiciones materiales de vida, el acceso a infraestructuras y servicios, los marcos normativos que regulan su accionar y las limitaciones en la toma de decisiones, entre otros. (Natenzon \& Ríos, 2015; Ugarte \& Salgado, 2014). Es esta vulnerabilidad previa la que determinará, en gran medida, para quién el riesgo se transformará en catástrofe. (Natenzon \& Ríos, 2015:15).
} 
de remoción en masa, inundaciones, tsunamis e incendios forestales, entre otros fenómenos. Arteaga \& Tapia (2015), en referencia al contexto latinoamericano, señalan que es justamente la vulnerabilidad social ante amenazas naturales lo que en definitiva desencadena los desastres, que cada vez se presentan con mayor frecuencia. Los efectos asociados a estos procesos, agregan los autores, "han develado impactos que se constituyen en desastres una vez que comprometen los bienes y servicios sociales, generando desafíos interdisciplinarios que, para ser simétricos y equilibrados, están requiriendo con mayor énfasis la participación de las diversas ciencias sociales, con el objeto de poder definir y explicar las vinculaciones entre las comunidades humanas y los terremotos, tsunamis, erupciones volcánicas, aluviones e inundaciones, considerando adecuadamente la profundidad y multiescalaridad que les es propia" (Arteaga \& Tapia, 2015:10).

La vulnerabilidad, no obstante, no es sólo sinónimo de pobrezas o desigualdades asociadas a una segregación socio-espacial en la ocupación y acceso a entornos de vida seguros, sino también es expresión de una desvinculación entre las comunidades que habitan los territorios en riesgo y las dinámicas ecosistémicas que determinan los procesos sociales y ambientales que acontecen en dichos territorios. Esta desvinculación, que algunos autores atribuyen a la exacerbación del paradigma de la modernidad relacionado a la disociación Cultura-Naturaleza producto de la instalación global de la sociedad del consumo (Jiménez, 2016; Simonetti \& Figueroa, 2003), ha sido en gran medida institucionalizada por los instrumentos de planificación territorial que históricamente han determinado áreas urbanas en disociación a los sistemas naturales cercanos, invisibilizando sus dinámicas, funciones y potenciales servicios ante fenómenos extremos ${ }^{4}$. En estos términos, según Calderón (2001), la vulnerabilidad es definida como la incapacidad de una comunidad para absorber mediante el autoajuste, los efectos de un determinado cambio en su medioambiente, es decir, constituye su inflexibilidad o incapacidad para ajustarse a ese cambio (Calderon, 2001:67). En tal sentido, el daño generado por un desastre obedece a que el sistema socioecológico ${ }^{5}$ y sus componentes no están en capacidad de protegerse de la fuerza amenazante o de recuperarse de sus efectos (Lavell, 2003), tal como se sintetiza en el siguiente diagrama (fig. 1).

\footnotetext{
${ }^{4}$ Es así, por ejemplo, que la mayoría de los planos reguladores urbanos en Chile siguen contemplando las franjas de borde costero, los humedales y las quebradas - entre otros sistemas naturales existentes en territorio urbano - como zonas de riesgo, excluidas de toda posibilidad para entenderlas como potenciales estructuras urbanas funcionales en términos de regulación y amortiguación ante fenómenos naturales, conservación de biodiversidad, espacio público y movilidad, por nombrar algunos servicios que estos sistemas pueden aportar a la ciudad.

${ }^{5}$ Como se revisará más adelante, es justamente el concepto de sistema socioecológico una clave relevante para ampliar la comprensión de desastre como un cambio abrupto en el sistema social y su soporte ecológico, que posibilita procesos de reorganización y el desarrollo de capacidades adaptativas para superar estados de vulnerabilidad (Berkes; Colding \& Folke, 2003).
} 


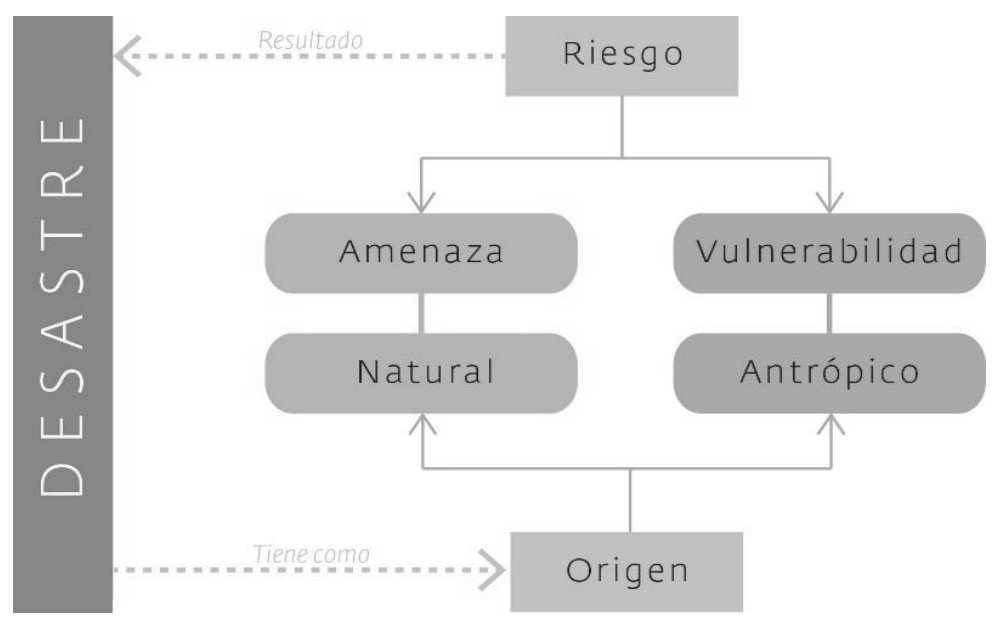

Fig. 1. Diagrama conceptual de los factores contribuyentes al desastre, el cual tiene como origen una condición natural asociada a la amenaza de fenómenos que, en un determinado contexto espaciotemporal, afectan a un sistema antrópico que evidencia condiciones de vulnerabilidad. Ambos factores, amenaza y vulnerabilidad, configuran un escenario de riesgo que deriva en desastre.

Fuente: Elaboración propia en base a Menceyra, 2015.

Si bien los enfoques geográficos han estudiado los riesgos y desastres desde sus tradicionales especializaciones -sísmicos, volcánicos o climáticos, vulnerabilidades sociales- no cabe duda que se trata de sistemas complejos en los cuales no es posible separar sus componentes naturales y sociales, sino que éstos se deben estudiar con perspectivas holísticas (Pigeon, 2005; Romero et al., 2010). Como señala Romero et al. (2010), el estudio de los riesgos naturales, sociales, políticos e institucionales constituye una importante especialización de la geografía contemporánea, que los analiza en sus fases predictivas, en sus materializaciones como catástrofes y en las etapas posteriores o de manejo de las restauraciones y reconstrucciones. Bajo esta perspectiva, el foco de atención de los riesgos y desastres se desplaza desde los fenómenos naturales hacia las estructuras ambientales y socio-territoriales (Arteaga \& Tapia, 2015; Romero et al., 2010), las cuales pueden ser abordadas de manera integral a partir del análisis y evaluación del paisaje, como disciplina concurrente a la dimensión de la gestión de riesgo en territorios susceptibles a ser afectados por desastres.

\subsection{El desastre como problema de Paisaje: ecología, representación y proyecto.}

La ocurrencia de un desastre es posible debido a la propensión de una determinada zona o asentamiento humano al riesgo catastrófico de un fenómeno natural. Desde este punto de vista, el desastre es la consumación de un proceso, a veces de larga data, de generación de condiciones de riesgo en la sociedad. Por lo tanto, un desastre es un riesgo no manejado, la materialización del peligro latente, detonado por un evento "externo" (Chaparro \& Renard, 2005). Mientras los riesgos representan las probabilidades de que ocurran desastres en un determinado lugar, las catástrofes registran su manifestación a través de daños y pérdidas de vidas humanas, bienes y servicios económicos, materiales, psicológicos, culturales y simbólicos, así como de 
importantes perturbaciones en el comportamiento de las estructuras sociales y de las instituciones encargadas de mantener la normalidad y resiliencia de los grupos humanos que habitan los asentamientos rurales y urbanos (Aravena, Fuentes, \& Guerra, 2010). Como señala Tapia \& Arteaga (2015), la ocupación desaprensiva de territorios expuestos a amenazas naturales, la falta de estudios profundos de riesgos, que antecedan a la planificación de la localización y crecimiento de las ciudades sobre terrenos seguros, así como los niveles de pobreza y segregación social, constituyen factores sociales, culturales y políticos de los cuales depende el nivel de daño que puede sufrir la población.
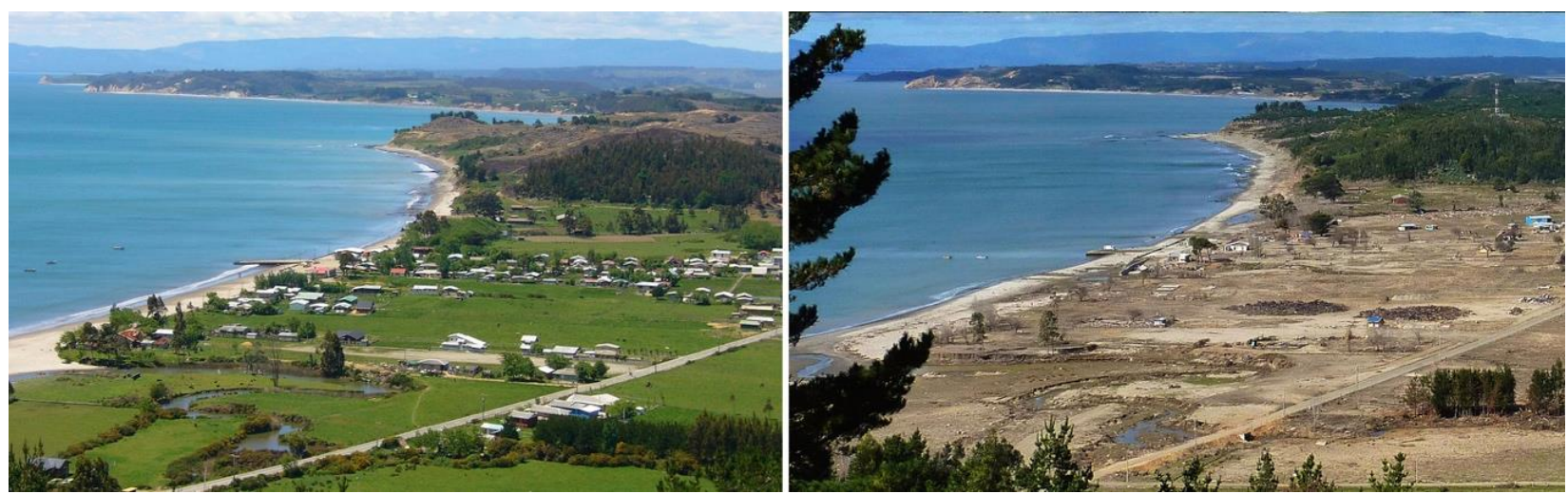

Fig. 2. Registro de Tsunami generado por el terremoto de Febrero de 2010 en la localidad de Llico, Provincia de Arauco, Región del Bío Bío, Chile. En la secuencia de imágenes se observa a la izquierda el paisaje previo a la ocurrencia del evento, y luego a la izquierda los cambios generados por el impacto de las olas.

Fuente: Elaboración propia en base a fotografías de Egon Wolf, 2010.

Distintos autores (Fuchs \& Thaler, 2018; UNISDR, 2015, Tapia \& Arteaga, 2015; Natenzon \& Ríos, 2015; Romero et al., 2010), realizan una necesaria diferenciación entre los desastres y los fenómenos que los provocan. El término "desastre natural" es equívoco, pues los desastres son el resultado de la falta de prevención y planificación ante los fenómenos de la naturaleza. Una de las máximas más profundas de esta concepción es que no existe desastre en la naturaleza; lo que existe son cambios a veces percibidos como peligros y que se transforman en desastres ante la presencia de las actividades y asentamientos humanos en los espacios donde estos cambios y fenómenos acontecen (Tapia \& Arteaga, 2015; Natenzon \& Ríos, 2015; Romero et al., 2010; Chaparro \& Renard, 2005). El desastre, leído desde la perspectiva de un cambio abrupto en la trayectoria de un sistema territorial, constituye un ámbito de estudio de alto interés para la arquitectura del paisaje y ésta provee de la sensibilidad para abordar su complejidad en materia de transformación y potencial adaptabilidad. Gran parte de los fenómenos naturales que devienen en desastres, debido a condiciones de vulnerabilidad de los territorios afectados, 
acontecen en contextos espaciales asociados a sistemas naturales definidos como bordes o ecotonos ${ }^{6}$ : zonas costeras, riberas, cursos hidrológicos y laderas.

El concepto de borde en ecología remite a un espacio territorial de frontera entre dos ecosistemas, cada una de ellos definidos por determinadas características bióticas, abióticas y/o antrópicas, que entran en contacto para generar dinámicas de conflicto o bien sinergias y complementariedades entre sí (Forman, 1995). Por otra parte, el concepto de ecotono se asocia a un espacio de transición cuya escala territorial es más amplia (Odum, 1971; Clements, 1905), como por ejemplo, las zonas de borde costero que generan el encuentro entre los ecosistemas marítimos y terrestres, favoreciendo el intercambio de especies, materia y energía (Weltzin y McPherson, 1999). Los bordes y ecotonos marcan la transición entre diferentes formas de existencia y, como señala Batty \& Longley (1994), mediante la gradiente que determinan transmiten y controlan el intercambio entre los distintos territorios, comprendiéndose a la vez como espacios de amortiguación y adaptabilidad al cambio ante la ocurrencia de fenómenos naturales extremos.

De esta manera, el punto de partida de este enfoque de Paisaje está definido por la propia noción de ecosistema -que identifica al conjunto de relaciones existentes entre comunidades de seres vivos, sus procesos metabólicos y el medio que habitan (Odum, 1971; Holling 1973)- y, más precisamente, por el concepto de estabilidad ecosistémica. Un ecosistema es estable cuando las diversas comunidades, los procesos y componentes que lo conforman logran, en ese contexto cambiante, relaciones de equilibrio que permiten la conservación y evolución de todos ellos en ciclos temporales extensos (Light, 2006; Vargas, 2002). La estabilidad de un ecosistema es dinámica, dado que su soporte -el medio físico-ambiental- está sometido a constantes cambios y transformaciones que se expresan en fenómenos naturales generalmente cíclicos, como el clima, las mareas y los movimientos tectónicos, entre otros. En tal sentido, la estabilidad de los ecosistemas depende de su capacidad para resistir, adaptarse o evolucionar con los fenómenos naturales (Fuchs \& Thaler, 2018; Holling, 1973).

Puede afirmarse entonces, que la ocurrencia de desastres se produce justamente por el desacoplamiento de las capacidades adaptativas de los sistemas antrópicos planificados para permanecer bajo determinados parámetros de estabilidad con escasa flexibilidad a cambios - y los sistemas naturales, capaces de acoger dinámicas de flexibilidad y adaptabilidad en un espectro más amplio (Folke, 2006; Holling, 2002). De acuerdo a lo que indica el tradicional diagrama de Holling y Goldberg (1971), expresado en la figura 3, la estabilidad de un sistema no depende de una situación de equilibrio estático, sino de la flexibilidad que éste puede asumir a lo largo del tiempo. Parte importante de la problemática del desastre subyace de esta forma en la necesidad de conciliar capacidades adaptativas de los sistemas antrópicos y

\footnotetext{
${ }^{6}$ El concepto de ecotono fue usado por primera vez en 1905 por Frederick Clements, en su libro Research Methods in Ecology, para definir el área de encuentro entre dos comunidades biológicas, donde los procesos de intercambio y competitividad entre los sistemas adyascentes podían ser observados. En 1971, Eugene Odum definió ecotono como una zona de transición entre dos o más comunidades, la cual contiene generalmente mayor biodiversidad y dinamismo ecológico que las propias comunidades colindantes.
} 
naturales, en el marco de los procesos de planificación de territorios susceptibles a dinámicas de cambios producidas por fenómenos naturales extremos (Berkes et al. 2003).

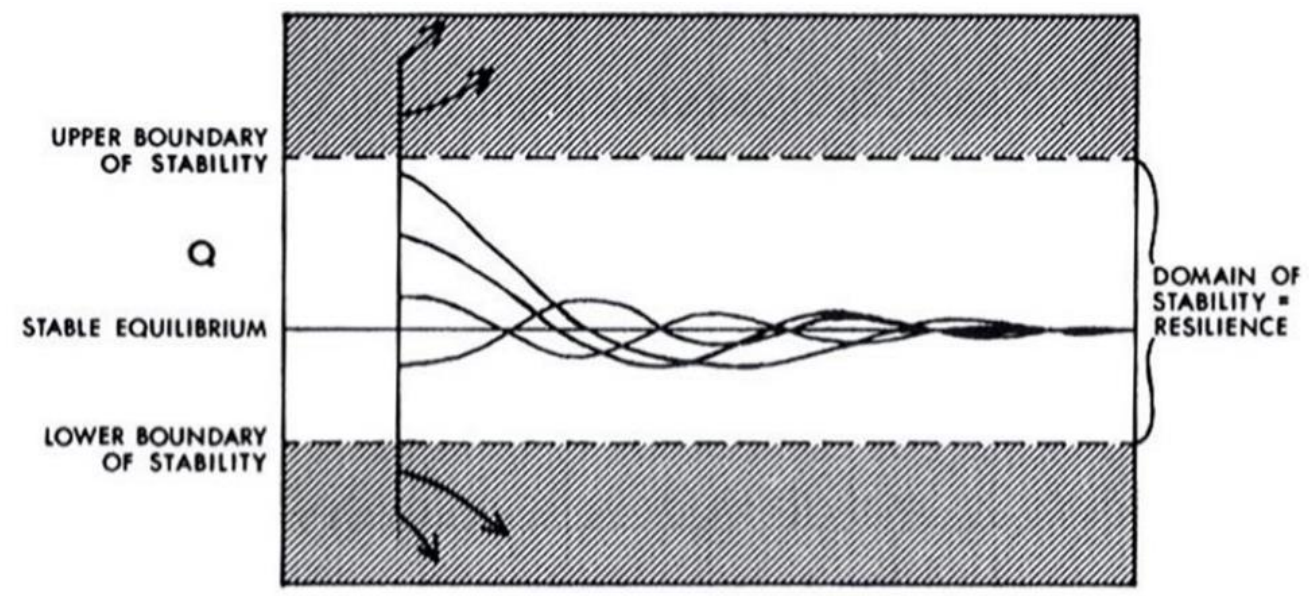

Time

Fig. 3. Diagrama conceptual que expresa la resiliencia de un sistema socioecológico, reconociendo el ámbito de dominio de estabilidad del sistema (franja en blanco) y las capacidades adaptativas que sus componentes pueden adoptar ante pertubaciones (líneas curvas progresivas). La estabilidad por lo tanto no depende de una situación de equilibrio estático, sino de la flexibilidad que el sistema puede asumir en el tiempo.

Fuente: Holling y Goldberg, 1971.

En el campo de la ecología contemporánea y sus derivaciones relacionadas con la ecología urbana, la ecología del paisaje y el paradigma de la socioecología, el concepto de ecosistema incluye a los seres humanos y las dinámicas de vida, ocupación y producción que despliega sobre el territorio, de igual manera que considera a las otras comunidades de seres vivos y sus procesos biológicos, en conjunto con el medio físico (Davidson-Hunt \& Berkes, 2003; Folke, 2006; Holling, 1973; Holling, 2002). La noción de sistema socioecológico se comprende como un sistema territorial complejo y adaptativo, conformado por la combinación de elementos y subsistemas antrópicos y naturales que establece una dinámica ecológica hibrida determinada por un entramado de relaciones en torno a recursos que son necesarios para la vida humana, donde interactúan variables sociales y ambientales (Ostrom, 2009), generando procesos metabólicos relacionados con el intercambio de materia, energía e información. En la medida que los sistemas antrópicos mantengan la integridad de los sistemas naturales, éstos últimos aportarán las funciones necesarias para fortalecer las capacidades adaptativas del sistema en su conjunto (Ostrom, 2009; Folke, 2006; Holling, 2002).

El paisaje, en tanto expresión de niveles de organización de los ecosistemas en un determinado contexto físico-espacial, se constituye como un sistema socioecológico complejo y adaptativo, en el cual los distintos componentes naturales y socioculturales están interactuando en diversos rangos de escalas espaciales y temporales; es la estructura perceptible del sistema de procesos ecológicos localizado 
en un territorio. Conforma así un mosaico de unidades morfológicas y funcionales cada una de ellas caracterizada por una combinación de atributos bióticos y abióticos (Forman, 1995)- modelado también por las dinámicas culturales, económicas y políticas llevadas adelante por las sociedades humanas, en procesos históricos de larga data, comprendido como producto perceptible de la relación cultura-naturaleza configurada sobre la extensión terrestre (Berque, 1994). Cada atributo del paisaje es la expresión de un proceso o un acontecimiento ambiental o cultural y, por ende, configura el palimpsesto de las dinámicas que modelan la realidad física espacial, ambiental y sociocultural de los territorios afectados por desastres.

Entonces, un segundo punto asociado al desastre como problema de paisaje está relacionado con el enfoque de su representación. El paisaje es, esencialmente una forma de ver, encuadrar e imaginar una determinada realidad compleja, conformada por componentes y procesos de diversa naturaleza, que asumen cambios y transformaciones a lo largo de su historia evolutiva, manifestándose en huellas tangibles y formas de habitar que definen el carácter social y cultural de ese paisaje (Nogué, 2010; Corner \& Bick, 2014). La noción de paisaje transita así desde su acepción original de un momento capturado en el tiempo a través de un soporte representativo estático -la pintura paisajista-, hacia una dimensión más compleja de expresión que establece una definición contemporánea estrechamente asociada a

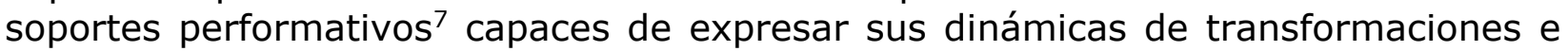
hibridación, como se observa en los ejemplos de las variaciones del Río Mississippi (figs. 4 y 5), documentadas por Mathur \& Da Cuhna, (2001). En tal sentido, como señala Corner (2014), el paisaje puede configurarse tanto a través del discurso, del texto y de la imagen, así como ser construido o reconstruido físicamente a través del diseño.

El paisaje del desastre se puede entender como aquel que evidencia las manifestaciones físicas de fenómenos o eventos extremos acontecidos en los territorios que albergan estas dinámicas de cambios, con consecuencias que impactan tanto en sus estructuras materiales como simbólicas, en las actividades económicas, políticas y sociales, y también en la estructura y ordenamiento demográfico del contexto afectado (Vale \& Campanella, 2005). Como señala Corner (2014), "esta es la razón de porqué mapear nunca es neutral, pasivo o sin consecuencias; al contrario, mapear es quizás el acto más formativo y creativo de cualquier proceso de diseño, primero revelando y luego exponiendo las condiciones para el surgimiento de nuevas realidades" (Corner \& Bick, 2014: 200).

\footnotetext{
7 El filosofo John.L. Austin define lo performativo como aquella expresión de lenguaje que lleva a la realización de una determinada acción. La performatividad se da cuando en un acto del habla o de comunicación no sólo se usa la palabra sino que ésta implica forzosamente a la par una acción (Ausitn, 1965). Diversos autores (Czerniak \& Hargreaves, 2007; Berrizbeitia, 2007; Corner \& Bick, 2014), relacionan lo performativo con las prácticas proyectuales de la Arquitectura del Paisaje.
} 

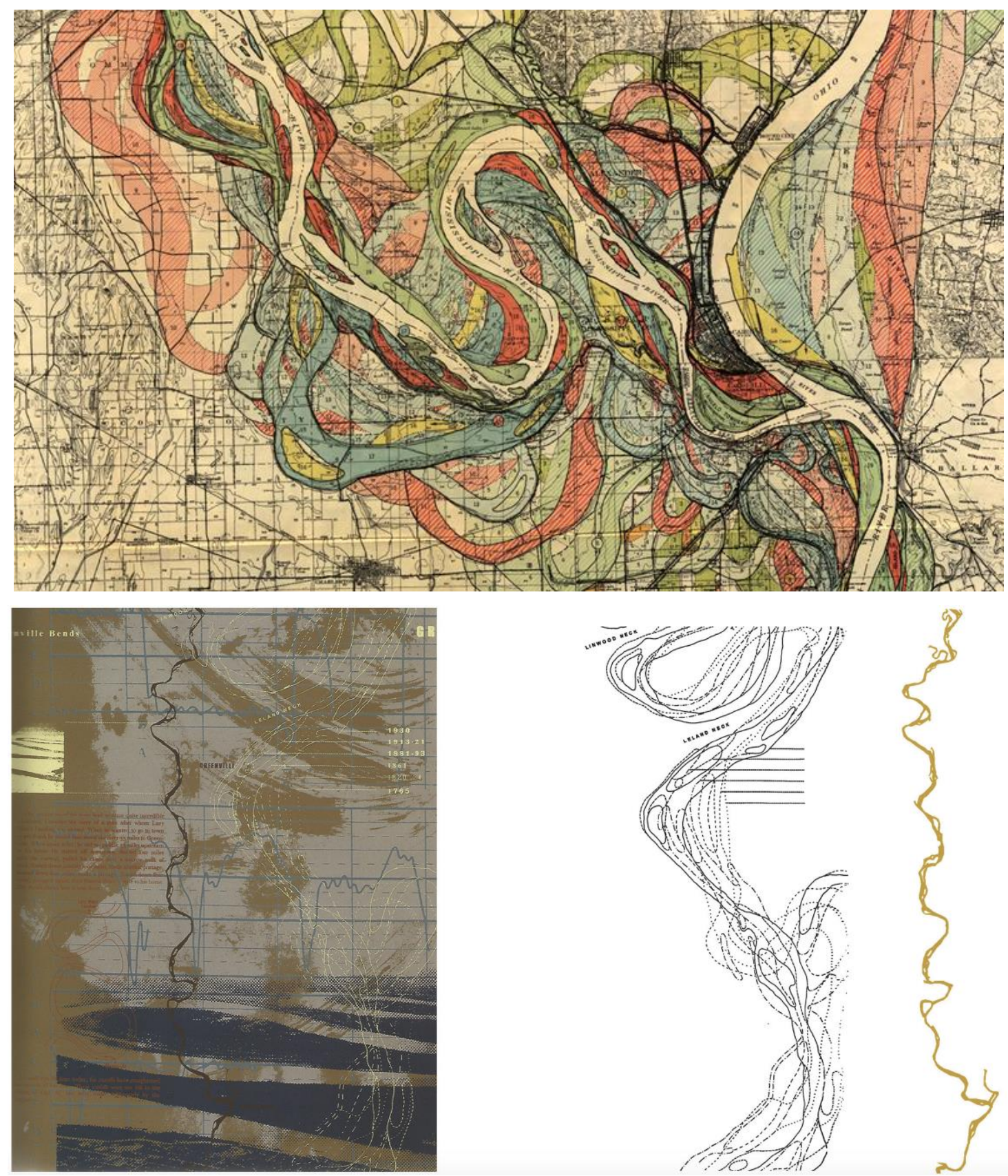

Figs. 4 y 5. Representaciones de las huellas de inundabilidad y variaciones de caudal en el paisaje del Río Mississippi, contenidas en el libro Mississippi Floods (Mathur \& Da Cuhna, 2001). A través de técnicas como la serigrafía, el fotomontaje, los dibujos y la fotografía, se expresan las dinámicas cambiantes del sistema hidrológico, que evidencian las variaciones en el espesor del espacio del agua y las múltiples posibilidades de comprender su ámbito de dominio. En lugar de representar el sistema hidrológico a partir de la clásica definición de una línea que separa agua y la tierra, la consideración de gradientes y ecotonos expresa de manera más certera y precisa los fenómenos del paisaje, trasladando al campo de la representación los datos estadísticos y mediciones matemáticas contenidos en los registros históricos del territorio. El reconocimiento de estas gradientes favorece la planificación de usos y la gestión del riesgo ante inundaciones.

Fuente: Blues Meanders. En, Mathur \& Da Cunha (2001). 
El tercer punto que relaciona las nociones de paisaje y desastre refiere a la dimensión de planificación y proyecto gatillada por la ocurrencia de eventos que cambian abruptamente el estado de un sistema socioecológico. El surgimiento del proyecto de paisaje en contextos de riesgos y vulnerabilidades ante desastres ha estado estrechamente vinculado -en especial en la última década- a experiencias de intervención en territorios afectados por eventos hidrometereológicos, principalmente en el contexto norteamericano. La escala y el impacto de las tormentas y huracanes de América del Norte- como Katrina en 2005, Ike 2018 y Sandy en 2011 -han sido factores desencadenantes de políticas públicas orientadas a promover instrumentos de planificación para a reducción de riesgo ante desastres en general, y planes de manejo de inundaciones, en particular (Lister, 2015). Bajo este contexto institucional, que adopta también los lineamientos establecidos por Naciones Unidas a traves del Marco de Sendai para la reducción del Riesgo de Desastres ${ }^{8}$, la arquitectura del paisaje ha tenido un emergente espacio de desarrollo teórico y práctico, cuya base conceptual en materia de diseño es informada tanto por el conocimiento ecológico, como las ciencias aplicadas de la ingeniería, la arquitectura y el urbanismo (Waldheim, 2016; Reed \& Lister, 2014; Corner \& Bick, 2014).

Una tendencia claramente representada en la iniciativa Rebuid by Design ${ }^{9}$, donde equipos de ingenieros, arquitectos, diseñadores y otros expertos -junto a los gobiernos locales y las comunidades costeras de aquellos territorios impactados por el Huracan Sandy- desarrollaron diez propuestas de planificación y diseño para fortalecer la resiliencia de las costas de metropolis de Nueva York ante el aumento del nivel del mar y la ocurrencia de tormentas severas. El resultado exhibe transversalmente un cuestionamiento hacia los tradicionales enfoques de planificación ante desastres naturales, durante mucho tiempo arraigados en el lenguaje de la resistencia y el control, haciendo referencia a estrategias de defensa costera mediante grandes estructuras de obras civiles diseñadas para contraponerse, generalmente de manera infructuosa, a las fuerzas naturales. Por el contrario, como se expresa en la figura 6 , los enfoques emergentes que evidencian estos planes y proyectos hacen referencia al lenguaje de la resiliencia y el manejo adaptativo, y están asociados con elasticidad y flexibilidad, utilizando ingeniería híbrida de materiales construidos, manejo de topografías y sistemas ecológicos que se adaptan a las condiciones dinámicas del paisaje.

\footnotetext{
${ }^{8}$ El Marco de Sendai para la Reducción del Riesgo de Desastres 2015-2030 se adoptó en la tercera Conferencia Mundial de Naciones Unidas celebrada en Sendai, Japón, en marzo de 2015. Uno de los cambios más importantes que propone el Marco Sendai es el marcado énfasis puesto en la gestión del riesgo de desastres -en lugar de la gestión de desastres- introduciendo la noción de resiliencia, asociada a promover la adaptabilidad como herramienta para la reducción de impactos (UNISDR, 2015a).

${ }^{9}$ Concurso internacional convocado en 2013 por The Rockefeller Foundation y el Gobierno de Estados Unidos a través del Programa Hurricane Sandy Rebuilding Task Force y del U.S. Department of Housing and Urban Development. http://www.rebuildbydesign.org.
} 


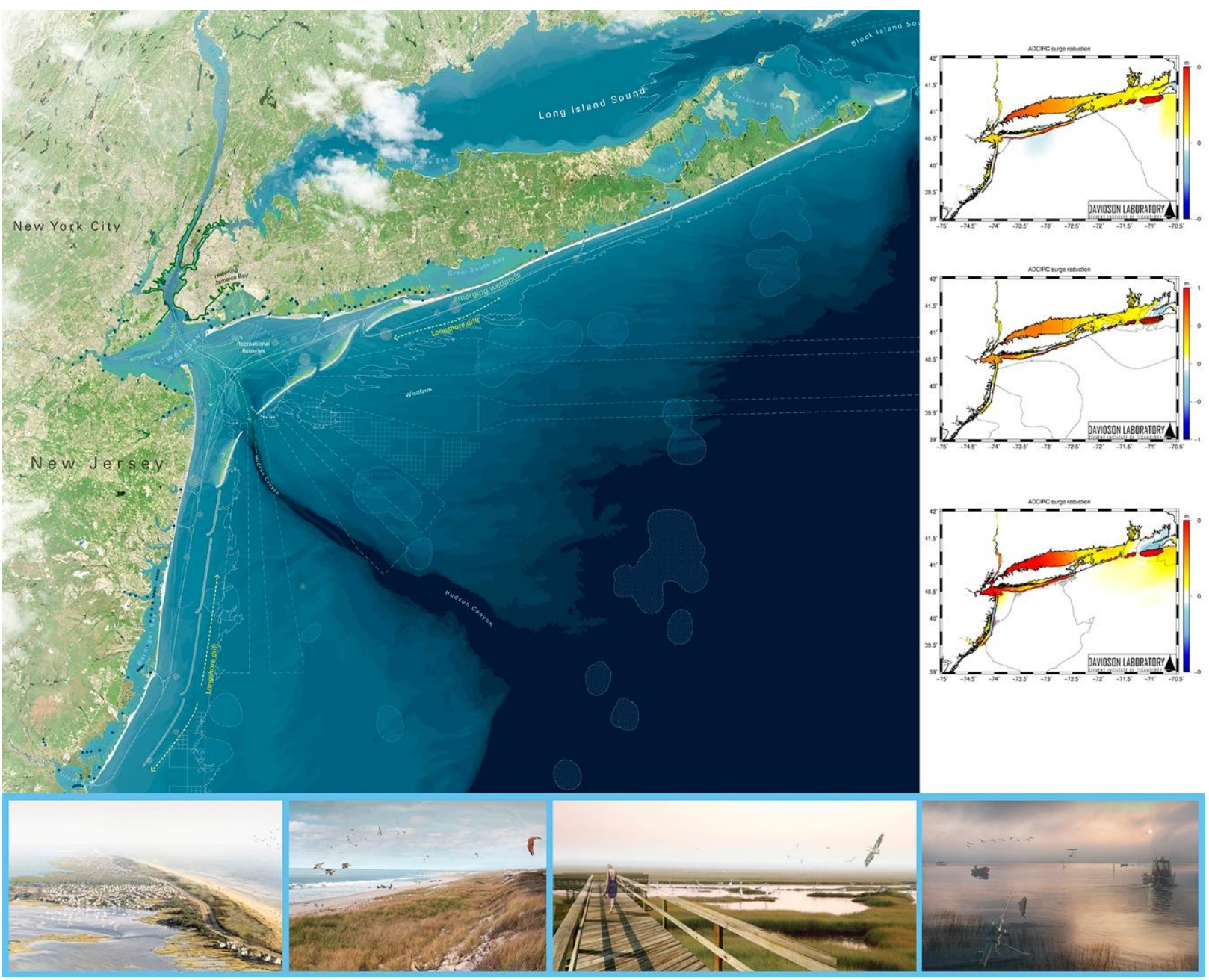

Fig. 6. Blue Dunes, propuesta desarrollada por WXY Architecture + Urban Design y WEST 8 Landscape Architecture para Rebuild by Design Hurricane Sandy Design Competition. A través de una estrategia de planificación y diseño a escala regional, se propone el desarrollo de una infraestructura de amortiguación de tormentas y alza del nivel del mar mediante el modelamiento y la proyección de un sistema de dunas ubicadas en paralelo al litoral de la bahía, costa afuera (offshore). Este sistema natural-artificial, junto con constituirse como infraestructura de defensa ante eventos extremos, como lo expresa la modelación de inundabilidad en la derecha de la imagen, conforma un conjunto de áreas destinadas a la conservacion ecológica, el desarrollo de actividades productivas y turísticas,como se bserva en las imágenes objetivo de la franja inferior.

Fuente: http://www.rebuildbydesign.org.

A la experiencia norteamericana se suman otras iniciativas desarrolladas en los últimos años en contextos tales como el Norte de Europa, Asia y America del Sur, focalizadas principalmente en propuestas de planificación y proyectos orientados a la reducción de riesgo y la reconstrucción post-desastres. Casos como The Sand Engine Project $^{10}$, en las costas holandesas (fig. 7); las propuestas de humedales urbanos y

10 The Sand Engine, defensa costera en la provincia de Zuid Holland, conforma una infraestructura para la mitigación de los efectos de marea basada en la creación progresiva de una peninsula de arena, a modo de duna expandida 
parques inundables en China ${ }^{11}$; o los parques de mitigación en ciudades de borde costero en Chile ${ }^{12}$, conforman un espectro amplio y variado de antecedentes que evidencian -en distintos grados de integración- la comprensión colectiva del urbanismo, el paisaje y la ecología. Si bien en un principio esta integración ha remitido a cuestiones generales de conceptualización y lenguajes formales exploratorios argumentados sobre supuestos, los proyectos en el presente demuestran un permanente búsqueda -abierta y con amplias necesidades de investigación- para avanzar hacia la implementación de estrategias, planes y diseños para la resiliencia fundamentados en la evidencia.
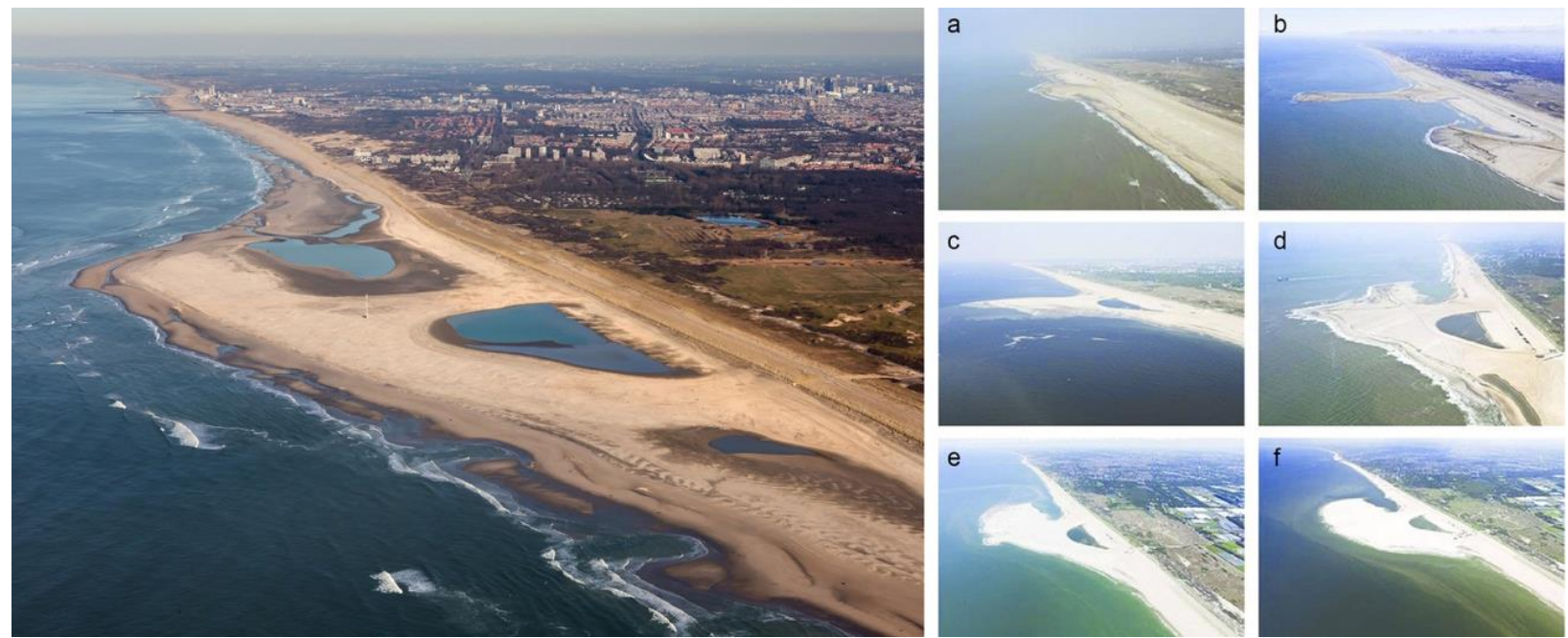

Fig. 7. The Sand Engine, provincia de Zuid Holland. El diseño de la duna expandida en forma de peninsula va modelándose mediante la accion de mareas y vientos, para progresivamente extenderse a lo largo de la costa como buffer de protección ante tormentas y alza del nivel del mar. En la secuencia de fotografías aéreas se observa elproceso de construcción durante: a) 15 de Marzo, 2011; b) 25 de Marzo, 2011; c) 25 de Abril, 2011; d) 17 de Mayo, 2011; e) 14 de Junio, 2011; f) 11 de Julio, 2011.

Fuente: https://www.dezandmotor.nl/

\subsection{Resiliencia. Nuevos enfoques asociados a la gestión de territorios en riesgo}

Los escenarios de cambios y crisis derivados de la ocurrencia de desastres en contextos urbanos plantean importantes desafíos en materia de planificación territorial, donde los conceptos de resiliencia, capacidad adaptativa y transformabilidad conforman un marco relevante que está actualmente guiando la formulación de políticas públicas e instrumentos de planificación, a nivel por ejemplo

que adopta morfologias cambiantes influenciadas por la sedimentación que aporta el océano y el viento. Ver: https://www.dezandmotor.nl/

${ }_{11}$ Proyectos como Wusong Riverfront, en Kunshan, China por el equipo SWA Group, o Yanweizhou Park en la ciudad china de Jinhua por el equipo Turenscape Landscape Architecture dan cuenta del enfoque de diseño integrado que se basa en la articulación de ecología, urbanismo y arquitectura del paisaje.

12 Los Parques de Mitigación de Constitución, Pelluhue y Dichato, documentados en esta tesis, fueron desarrollados en el marco de los planes de reconstrucción de bordes costeros post-tsunami de Febrero de 2010, en la regiones de Maule y Biobío. 
de planes de reducción de riesgo de desastres y estrategias de adaptabilidad al cambio climático. Asimismo, como se ha presentado de manera más específica en la experiencia norteamericana, estos conceptos han motivado el desarrollo de planes y proyectos que promueven la mitigación y amortiguación de eventos extremos en zonas altamente expuestas, tales como bordes costeros y áreas en torno a sistemas hidrológicos en general, mediante soluciones de diseño adaptables y ecológicamente sensibles ante la complejidad, la incertidumbre y la vulnerabilidad.

En un sentido empírico, la resiliencia es la cantidad de cambio o interrupción que un sistema socioecológico urbano puede absorber ante situaciones de desastre $y$, después de estos eventos de cambio, volver a un estado en el cual el sistema conserva la mayoría de sus funciones y procesos metabólicos, aun cuando sus estructuras puedan variar o transformarse. Aquí, como señala Reed (2015), dos puntos son esenciales. Primero, cuando se establece que un sistema socioecológico puede absorber los efectos del cambio, ello implica que el cambio está integrado en el tejido del sistema en cuestión, y no que el cambio es resistido o defendido.

Si este pensamiento se tuviese que aplicar a eventos de inundabilidad en la ciudad -producidas por ejemplo por precipitaciones, crecida de ríos o marejadas- los espacios públicos y las edificaciones se construirían o adaptarían para permitir la entrada de agua, soportar sus efectos temporales y ajustarse fácilmente cuando retroceden las aguas de la inundación. En segundo lugar, cuando se habla de la reorganización del sistema y la transición a un estado alternativo (Emrich \& Tobin, 2018; Eckardt, 2011; Holling, 1973), se está capturando la verdadera esencia de la capacidad de resiliencia y recuperación ante los cambios acontecidos por la ocurrencia de desastres.

Los ecosistemas resilientes incorporan en su ADN la capacidad de cambiar y reorganizar sus componentes para mantener, e incluso fortalecer, el funcionamiento subyacente del sistema, sus estructuras y dinámicas básicas (Lister, 2015). Siguiendo con el ejemplo anterior, el equivalente urbano a esta afirmación sería un diseño de espacios públicos que aprovecha la condición de inundabilidad para producir en ellos nuevos programas, servicios y usos compatibles con esa dinámica; entendida ya no como un problema sino como un atributo de valor para el sistema, desde un punto de vista social, cultural, económico y ecológico, como lo expresa el proyecto relatado en la siguiente figura (fig. 8). En este caso, el sistema no sólo es capaz de absorber los efectos de cambio generados por el fenómeno de inundabilidad, sino que asume una inteligencia tal que aprovecha ese cambio para hacer emerger nuevos valores que fortalecen su funcionalidad y estructura. 

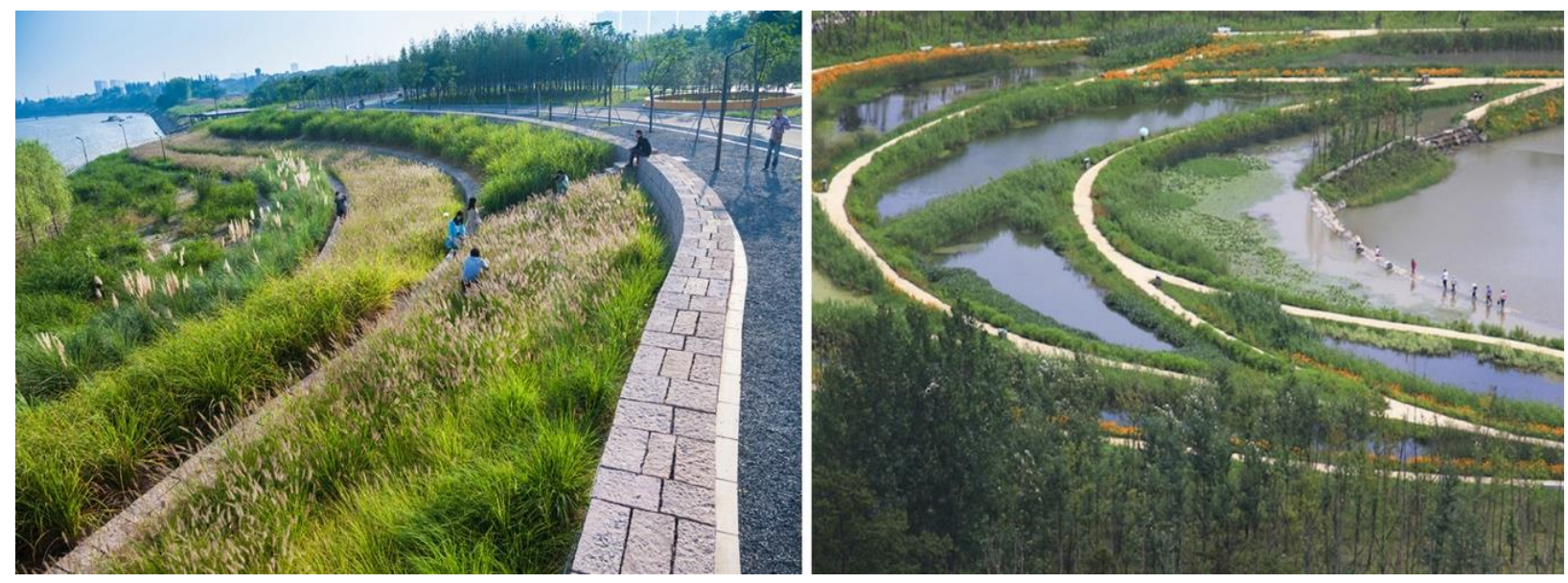

Fig. 8. A la izquierda: Parque Humedal Yanweizhou Park, en la ciudad china de Jinhua, desarrollado por el estudio Turenscape. A la derecha: diseñado por la misma oficina, el Parque Humedal Minghu, en Liupanshui, China. En ambos casos, el proceso de diseño ha contemplado la articulación de ecosistemas, infraestructuras y programas de uso, transformando antiguos márgenes ribereños degradados, en sistemas flexibles orientados a la provisión de espacios públicos de alto valor social, a la restauración ecológica y a la gestión de resiliencia urbana ante inundaciones.

Fuente Turenscape $\odot$ https://www.turenscape.com

Si bien gran parte de las recientes iniciativas de resiliencia abordadas desde el diseño urbano y la arquitectura del paisaje se ha centrado en los efectos de las tormentas y el aumento del nivel del mar en ciudades y regiones costeras, el cambio climático es mucho más diverso que sólo sus efectos en los océanos, y sus impactos se producen en ciudades lejos de las costas continentales (Reed, 2015). El aumento de la intensidad y la frecuencia de los eventos hidrometereológicos afectan a las ciudades de todo el mundo, y los sistemas tradicionales de aguas pluviales urbanas, por ejemplo, no son ya capaces de hacer frente al aumento de los volúmenes de lluvia en períodos cortos de tiempo, así como durante períodos de tiempo más prolongados. Por lo tanto, los incidentes de inundaciones, remociones en masa -y otros desastres en general- están en aumento, comprometiendo no sólo daños materiales a las infraestructuras y edificaciones, sino también afectando la dinámica de los ecosistemas y, de manera particularmente sensible, la salud y seguridad de las comunidades. Volviendo al contexto de los territorios costeros, se prevé que los riesgos aumenten en las próximas décadas debido a las amenazas crecientes del cambio climático -como la subida del nivel del mar y la mayor intensidad en las tormentas- pero también por un mayor desarrollo urbano y productivo de estos territorios, el crecimiento demográfico y los cambios geomorfológicos de las costas (Johnson \& Bayley, 2016; Hallegatte et al., 2013).

Un papel importante para la arquitectura del paisaje a este respecto es aportar soluciones basadas en la naturaleza al discurso de planificación territorial. Este enfoque, traducido del inglés nature-based solutions ${ }^{13}$, abarca a todas las acciones

13 En los primeros años del siglo XXI, emerge el término de nature-based solutions, consolidando un cambio de perspectiva: entendiendo que la población no es solo un beneficiario pasivo de los productos y servicios de la naturaleza, sino que también puede proteger, gestionar y restaurar proactivamente y de forma estratégica los 
que se apoyan en los ecosistemas y los servicios que estos proveen, para responder a diversos desafíos relacionados especialmente con la adaptación al cambio climático y, de manera más reciente, a la reducción del riesgo de desastres (McBreen, 2016). Las áreas de paisaje donde se proporcionan estos servicios -como ocurre por ejemplo en los humedales urbanos (fig. 12)- se pueden gestionar y conservar mediante iniciativas de planificación y diseño basadas ya no sólo en objetivos de preservación ecológica, sino en un afán de comprenderlos como componentes estratégicos para la resiliencia urbana (Reed, 2015), aprendiendo sistemáticamente de las formas en que la naturaleza responde para internalizar ese conocimiento en las propuestas de planes y proyectos. Las estrategias de planificación y diseño de ciudades impulsadas desde el paisaje -mediante soluciones basadas en la articulación de sistemas naturales e infraestructuras urbanas- han demostrado ser exitosas para ayudar a mitigar el cambio ambiental (Hung, 2017; Belanger 2016; Reed, 2015; Batlle, 2011). Si bien la novedad de este enfoque se expresa fuertemente en las propuestas de paisaje contemporáneas, es importante mencionar que abordan, de manera actualizada, el papel tradicional de la arquitectura del paisaje: la mediación entre las dinámicas de la sociedad y los procesos de la naturaleza (Silvestri y Aliata, 2001).

Los sistemas de parques de Frederick Law Olmsted $^{14}$ en ciudades de América del Norte a fines del siglo XIX son algunas de las primeras versiones de soluciones basadas en la naturaleza, donde es posible reconocer la noción de infraestructura verde como un nuevo tipo de proyecto urbano multifuncional; un proyecto que trata tanto de un enfoque paisajístico para la planificación de ciudades, enfatizando la importancia social y cultural de la conservación de los sistemas naturales en la ciudad, como de un sistema infraestructural para la movilidad urbana y la reducción de riesgo ante inundaciones. Abordar estas estrategias implica comprender el alcance de la escala de mosaico de paisaje en su amplia dimensión espacial y ambiental, porque su acción e influencia no se restringe a los límites específicos de una determinada compartimentación territorial administrativa, sino que extienden su influencia espacial hacia lo urbano en su conjunto, o incluso a nivel regional (Belanger, 2016; Reed, 2015; Batlle, 2011). Por lo tanto, planificar la resiliencia significa proyectar a escala territorial, dibujando un campo de actuación interdisciplinario -desde las ciencias naturales, exactas y aplicadas- interescalar e intersectorial, involucrando desafíos en materia de articulación de diversos ámbitos institucionales públicos y privados, marcos técnicos y normativos, actores sociales y comunidades.

ecosistemas, ayudando así a resolver los desafíos de desarrollo, la seguridad alimentaria, la reducción de la pobreza y la mitigación de los efectos producidos por desastres (McBreen, 2016; MEA, 2005)

${ }^{14}$ Frederick Law Olmsted (1822-1903) arquitecto paisajista creador del Central Park en Nueva York, del Sistema de Parques de Boston y de la noción de Parque Nacional, aplicado a Yosemite National Park, entre otras importantes iniciativas especialmente desarrolladas durante la segunda mitad del siglo XIX en Norteamérica. Su labor estableció un nuevo paradigma asociado al proyecto de paisaje, heredero de la tradición pintoresca inglesa, pero superador en términos de escala de intervención y de articulación entre las capas ecológicas y socioculturales del contexto de intervención (Beveridge \& Rocheleau, 1998). 


\subsection{Del jardín a la Infraestructura Verde: Planificación y diseño de paisajes resilientes}

La discusión conceptual sobre la definición de paisaje es tan amplia como su adscripción transversal a diversas disciplinas en distintos momentos históricos, empezando con aquellas que le posicionan como el constructo social y cultural que determina una significación de la mirada sobre el territorio, la cual a su vez deriva de la interpretación y valoración subjetiva de sus características y dinámicas (Nogué, 2010; Bertrand, 2008; Silvestri \& Aliata, 2001; Corner, 1999; Roger, 1997; Berque, 1994). Y que, mediante el establecimiento de soportes representacionales que emergen de esa percepción individual y/o colectiva, expresa diversas jerarquizaciones y valoraciones basadas en formas tangibles o patrones, así como también en procesos o dinámicas intangibles (Corner \& Bick, 2014; Bertrand, 2008; Berrizbeitia, 2007; Mathur \& Da Cunha, 2001; Forman, 1995). Esta construcción de la mirada, por cierto, actualmente se estructura desde múltiples dispositivos, tanto análogos como digitales, ofreciendo a su vez múltiples estímulos en esa percepción. Como señalan distintos autores (Nogué, 2010; Martínez de Pisón, 2008; Roger, 1997) el paisaje puede ser percibido in situ, como forma y objeto geográfico que se expresa como un palimpsesto acumulador del historial de un territorio; y también in visu, como imagen creada en el tiempo, a partir de la suma de vivencias, prácticas, identidades y expresiones artísticas.

En tal sentido, la cualidad infraestructural del paisaje puede ser considerada un atributo inherente a su estructura y funcionalidad, a la vez percibida desde determinada sensibilidad social y cultural que infiere a ese paisaje un cierto rol. En palabras del geógrafo cultural J.B. Jackson, el paisaje puede definirse "como infraestructura o soporte de base para nuestra existencia colectiva (...) aquello que subraya no solo nuestra identidad y presencia, sino también nuestra historia" (Jackson, 1984:8). Se fundamenta justamente en su lectura e interpretación como soporte de resiliencia y sustentabilidad, por parte de un colectivo social que atraviesa esferas ciudadanas, políticas y académicas, situado en un contexto ambiental y geográfico -y por cierto histórico- que interpela esa cualidad infraestructural del paisaje en un marco de discusión multidisciplinaria, asociado a los desafíos de resiliencia ante desastres y sus consecuentes efectos de vulnerabilidades sociales y territoriales. Este enfoque de paisaje se sustenta conceptualmente, por una parte, en la tradición de la ecología del paisaje que lo identifica como mosaico de unidades morfológicas y funcionales (Forman, 2008; 1995; Forman \& Godron 1986), las cuales aportan servicios ecosistémicos claves para la resiliencia y sustentabilidad urbana (Vásquez, 2016; Reed \& Lister, 2014; Benedict \& Mcmahon, 2002) al tiempo que provee de una comprensión del valor social y ecológico de las unidades y componentes que lo conforman (Batlle, 2011; Berrizbeitía, 2007; Berger, 2006; Silvestri \& Aliata, 2001; Corner, 1999).

Frente a los actuales escenarios de perturbaciones, crisis y vulnerabilidades asociadas a procesos de expansión urbana, cambio climático y desastres, la arquitectura del paisaje aborda nuevos desafíos y campos de actuación, asumiendo

el desafío de repensar el rol del proyecto como una plataforma conceptual y operativa 
para la gestión de resiliencia. Sustentado en los paradigmas de la planificación ecológica y la ecología del paisaje, el enfoque de Infraestructura Verde ${ }^{15}$ - que comprende la identificación, gestión y diseño de redes integradas de ecosistemas, espacios verdes, brownfields, áreas productivas e infraestructuras urbanas conforma una aproximación estratégica para repensar los territorios en riesgo. Como sostienen Benedict \& Mcmahon (2006), el paisaje y sus componentes pueden ser concebidos como una potencial red estructurante del territorio y la ciudad, contribuyendo a una planificación integrada de los sistemas naturales y antrópicos tanto a nivel espacial como funcional, en el marco de las actuales políticas e instrumentos de desarrollo urbano y territorial. De esta forma, la idea de paisaje como infraestructura no se remite solamente a la consideración de los sistemas naturales y el aporte que éstos hacen en materia de sustentabilidad y resiliencia, sino que contempla la articulación de sus ecologías con sistemas infraestructurales, productivos y urbanos, ya sea como producto de estrategias y operaciones de diseño concertadas desde un determinado proyecto, o bien derivada de prácticas tradicionales y colectivas destinadas a favorecer el desarrollo económico y cultural de una comunidad.

No obstante, el enfoque de paisaje como infraestructura no es nuevo. En diversos momentos de la historia ha emergido, a veces de manera sutil, otras con más fuerza. Podría remitirse al origen mismo del jardín, que nos devela un espacio multifuncional, configurado y diseñado con alta precisión para favorecer el uso del agua, los cultivos, la produccion animal y el refugio ante el clima, al tiempo que configura un espacio de ocio y recreación. Como señala Batlle (2011), el deseo del ser humano de controlar la naturaleza para fines alimentarios, medicinales o contemplativos, ha producido el desarrollo de diversas técnicas agrícolas y operaciones logísticas al servicio de estos propósitos, desplegando sobre el territorio múltiples sistemas infraestructurales. "Desde los sistemas de riego a las fuentes monumentales, desde los bancales agrícolas a las terrazas de los jardines, desde los sistemas de prtección a las vallas, desde las podas para mejorar la producción a la topiaria decorativa" (Batlle, 2011:25).

Más evidente aun resulta la dimensión infraestructural de Central Park (1863), obra clave de Frederick Law Olmsted y punto de inflexión en la historia del Arquitectura del Paisaje. Heredero del modelo del Jardín Inglés, Central Park se constituye como el primer parque urbano público y democrático ${ }^{16}$, aun cuando en su apariencia sigue remitiendo al paradigma pintoresco. Sin embargo, más allá de las

\footnotetext{
${ }^{15}$ El término infraestructura verde (green infrastructure) fue empleado por primera vez en 1994 en Estados Unidos, por la Comisión de Greenways de Florida, con el objetivo de elevar el valor social y las funciones de las áreas rurales y los sistemas naturales al mismo nivel de importancia que la infraestructura gris. En 2013, la Comisión Europea hizo pública la Estrategia Europea de Infraestructura Verde (Green Infrastructure-Enhancing Europe's Natural Capital, Comisión Europea, Bruselas, 2013), con el objetivo de impulsar el desarrollo de Infraestructuras Verdes en todos los ámbitos territoriales (nacional, regional y local) y garantizar su consideración en la ordenación del territorio.

16 Pionero en tal condición respecto a sus modelos predecesores que en Europa remitían a reductos privados generalmente asociados a principados y monarquías - como los jardines renacentistas y barrocos en Italia y Francia respectivamente - o a aristocracias terratenientes, como el caso del jardín pintoresco inglés.
} 
serpenteantes trazas de circulaciones, las praderas, los belting, clumping \& dotting ${ }^{17}$, Central Park adquiere un rol estructural para la dotar de servicios a la nueva ciudad: un pulmon verde, apto para mitigar la polución de una ciudad industrial; un reservorio de agua dulce para el consumo humano y un área de esparcimiento, recreación y encuentro cultural, en medio de una urbe ya entonces cosmopolita y marcadamente multicultural. Desplazando a su histórica denominación europea como jardín, el nuevo concepto de parque proyectado por Olmsted se transforma entonces en infraestructura de paisaje para la metropolis que lo alberga, articulando la configuración y trazado de espacios verdes con áreas destinadas a programas y equipamientos estratégicos.

Un poco más al norte, en Boston, Olmsted diseña algunos años más tarde un revolucionario proyecto que hasta hoy se puede considerar vigente e innovador en términos de sus propuesta paisajística. Se trata del Sistema de Parques de Boston (fig. 10), conocido también como el Emerald Necklace (1887), que se constituye mediante la articulación y puesta en valor de diversas unidades de paisaje preexistentes de diverso origen y naturaleza -tales como parques, plazas, jardines, cienagas, humedales y esteros- conformando un amplio sistema de espacios verdes. El Emerald Necklace se transforma en un sistema que provee de servicios de regulación de inundaciones y escorrentías, vida saludable, biodiversidad y movilidad, a través de los parkways que circundan y conectan las diversas unidades, cumpliendo hasta hoy un papel fundamental para la resiliencia y sustentabilidad de la ciudad.

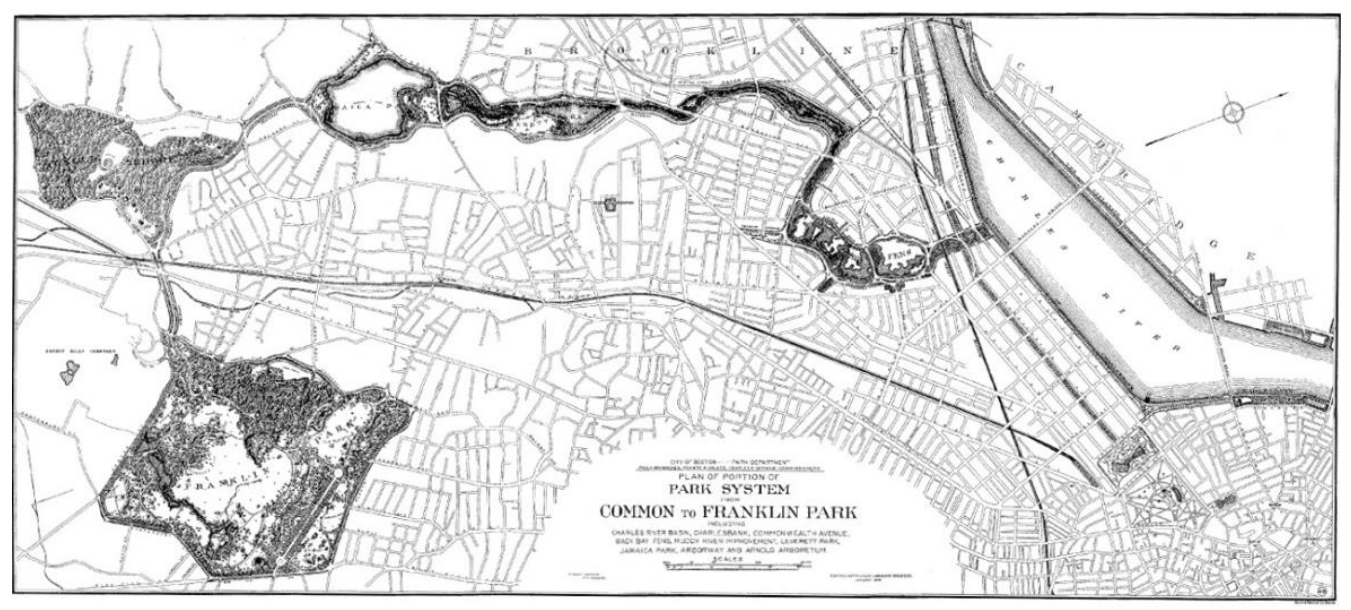

OLMSTED ARCHIVES

Fig. 9. Sistema de Parques de Boston, Emerald Necklace. Plano original desarrollo por Frederick Law Olmsted en 1894.

Fuente: Boston Parks Department \& Olmsted Architects - National Park Service Olmsted Archives.

\footnotetext{
17 Los arquetipos estilisticos del jardín pintoresco, consolidados especialmente en proyectos desarrollados por Lancelot 'Capability' Brown tales como el Plan for Bournehill Cottage (1775) o el Serpentine Plan for Bowood. (1761) señalaban operaciones específicas para las configuraciones de la vegetación: Belting, asociado a la idea de cinturón verde, como telón de fondo para cerrar las vistas; Clumping, como aquellas agrupaciones que aparecen como plano intermedio de visión, conformando masas de árboles distribuidas sobre las praderas; Dotting, como aquellos arboles hitos o landmarks que adquieren valor por su singularidad. (Batlle, 2011; Fariello, 2001; Silvestri \& Aliata, 2001)
} 
En lugar de 'construir' áreas verdes, el proyecto de Olmsted propone 'activar' aquellas unidades de paisaje remanentes que persisten en la emergente urbanización, conectando mediante paseos y 'parkways' las zonas inundables, humedales y esteros con otros espacios abiertos de la ciudad. El Emerald Necklace anticipa en más de un siglo las actuales discusiones acerca del rol de la arquitectura del paisaje en nuestras ciudades, proponiendo una idea de infraestructura paisajística basada en la articulación de sistemas naturales y espacios públicos, orientada a proveer tanto de lugares memorables de encuentro y esparcimiento, como de funciones ecológicas claves para la sustentabilidad y resiliencia urbana.

El ejemplo de Boston fue seguido luego por diversas ciudades norteamericanas ${ }^{18}$, replicando el modelo de articulación espacial y funcional de sistemas de espacios públicos y sistemas naturales existentes. Como señala Batlle (2011), esta estrategia de proyecto no pretende diseñar todo el territorio que abarca, sino que aprovecha lo que ya existe, mejorando el modelo de parque urbano ensayado por Olmsted en Nueva York, "por medio de potenciar la continuidad de los recorridos a través de los diferentes espacios públicos y por conservar los valores ecológicos de determinados lugares." (2011:39-40). Una nueva noción de infraestructura que no remite sólo a la edificación de sistemas antrópicos sobre un soporte natural, sino que justamente se basa en activar los sistemas naturales para transformarlos en parte de una infraestructura híbrida capaz de aportar servicios ecosistémicos orientados al bienestar y resiliencia de territorios vulnerables.

El enfoque de infraestructura verde -cuyo acto fundacional se expone claramente en el trabajo de Olmsted para Boston- expande los parámetros de un paisaje diseñado con fines ornamentales o meramente recreativos, a un sistema multifuncional y de alto rendimiento, incluyendo logísticas y prestaciones originalmente atribuidas a la infraestructura tradicional, como aquellas relacionadas con las dinámicas urbanas de manejo hidrológico y la movilidad (Bélanger, 2016; Hung \& Aquino, 2013), promoviendo la integración de infraestructura y ecología como vectores convergentes en las iniciativas de planificación y proyecto de paisaje a escala urbana y territorial.

\footnotetext{
${ }^{18}$ Se puede destacar el plan de Chicago, de 1908, diseñado por Daniel Burnhm y Edward Bennett; el System Park de New York, de 1928; o el System Park de Washigton -originalmente planteado en 1901 por F.L. Olmsted Jr.- que enlazaba el espacio del Mall con las riberas del río Potomac.
} 


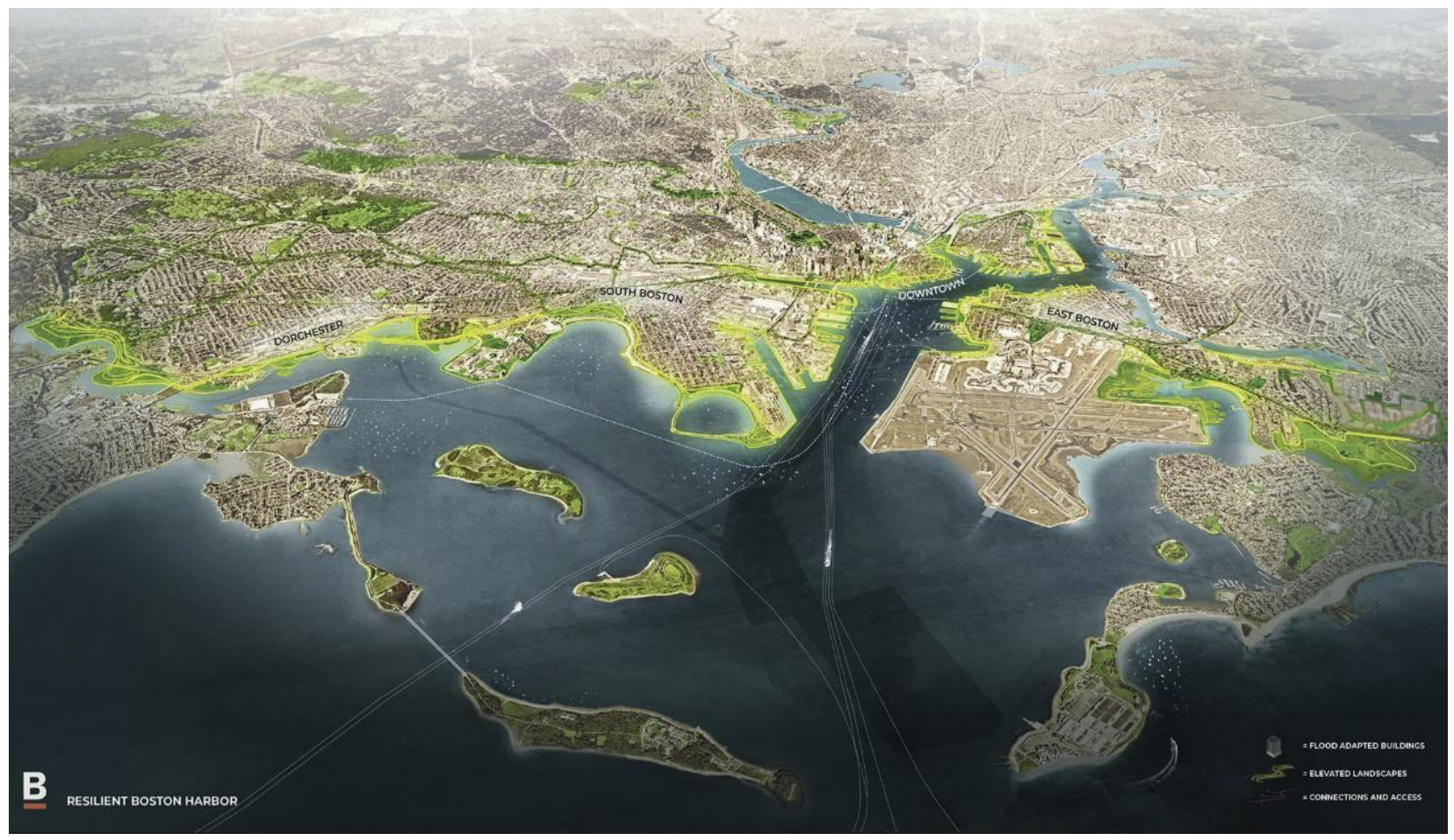

Fig. 10. Resilient Boston Harbor, vista aérea. Iniciativa del gobierno de la ciudad, en desarrollo desde 2017, orientada a generar sistemas integrados de infraestructura verde en las franjas de borde costero y fluvial, mediante la conservación y recuperación gradientes ecotonales para la adaptabilidad y resiliencia ante fenómenos de inundabilidad, marejadas y tormentas. El proyecto amplifica el sistema de parques originalmente proyectado por Olmsted, otorgando una nueva escala de infraestructura verde a nivel urbano-territorial.

Fuente: City of Boston (2018) Resilient Boston Harbor.

Precisando en las definiciones generales previamente expuestas, la infraestructura ecológica ${ }^{19}$ define el sistema de componentes y procesos ecológicos que operan en un determinado contexto con la finalidad de generar, distribuir y aportar servicios ecosistémicos (Carpenter \& Folke, 2006; Davidson-Hunt \& Berkes, 2003; Costanza et al., 1997), a partir del rol activo de ecosistemas remanentes -aquellos que subyacen en el territorio como pre-existencias - y emergentes, es decir, que surgen y se establecen a partir de dinámicas de cambios y transformaciones que acontecen producto de la acción humana o de fenómenos naturales. La infraestructura ecológica incluye también el enfoque de soluciones basadas en la naturaleza, en relación a las acciones estratégicas de conservación y manejo de ecosistemas para responder a desafíos de adaptabilidad al cambio climático, reducción de riesgo y resiliencia ante desastres (McBreen, 2016; Reed, 2015; Steiner, 2012). Esta infraestructura puede estar determinada a su vez por patrones y procesos híbridos, no sólo vinculado a ecosistemas naturales que la definen como infraestructura ecológica subyacente, sino

${ }^{19}$ El concepto de infraestructura ecológica apareció por primera vez en un informe de 1984 del Programa sobre el hombre y la biosfera de la Organización de las Naciones Unidas para la Educación, la Ciencia y la Cultura (UNESCO). Otros autores, la refieren al concepto de capital natural, enfatizando su rol en la generación de servicios ecosistémicos que son necesarios para el bienestar humano (Costanza et al., 1997). 
sumando también ecosistemas resultantes de dinámicas antrópicas en contextos urbanos y/o productivos, bajo una perspectiva de sistema socioecológico complejo (Ostrom, 2009; Carpenter \& Folke 2006; Bolund \& Hunhammar, 1999). Esta hibridación da lugar a la noción de infraestructura verde o infraestructura verdeazul $^{20}$, conformada por ecosistemas naturales remanentes y emergentes, así como también por otras unidades de paisaje resultantes de procesos de antropización.

El concepto de multifuncionalidad asociado a la noción de infraestructura verde ofrece oportunidades para brindar de manera simultánea funciones ambientales, sociales y económicos (Benedict \& Mcmahon, 2006; Faber et al. 2006). Este enfoque sugiere superar el tradicional dilema de elegir entre los objetivos mutuamente excluyentes de la conservación y la urbanización, sino que ambos pueden conducirse a través de la planificación y diseño del paisaje con múltiples objetivos programados de manera integrada. En tal sentido, la multifuncionalidad de la Infraestructura Verde es una de sus principales características y un atributo que le permite atender múltiples necesidades de forma simultánea, lo que la convierte en un instrumento de carácter transversal que puede apoyar el desarrollo de numerosas políticas públicas, en diversos ámbitos de desarrollo territorial asociados a sectores como agricultura, energía, vivienda y espacio público, adaptación al cambio climático y reducción de riesgo ante desastres.

A continuación, a modo de resumen, se exponen las definiciones asociadas a los diferentes enfoques de infraestructura comparados:

${ }^{20}$ Lo azul, en la definición del concepto, refiere a un énfasis que la literatura referida a infraestructura verde otorga al rol que asumen aquellos sistemas del agua -sean de origen natural o antrópicos- en la provisión de funciones y servicios ecosistémicos. 
TIPO DE INFRAESTRUCTURA

\section{Infraestructura Gris}

Grey infrastructure

\section{Infraestructura Multipropósito \\ Multipurpose infrastructure}

Infraestructura Ecológica

Ecological infrastructure

\section{Soluciones basadas en Naturaleza}

Nature - based solutions

\section{Infraestructura Verde Green infrastructure}

\section{DEFINICION Y ALCANCE}

Redes conformadas por partes, piezas, procesos y actores que apuntan a la prestación de servicios esenciales para un determinado territorio, planificadas y disef̉adas desde un enfoque monofuncional, e implementadas con métodos tradicionales de ingenieria civil convencional.

(Bélanger,2016; Sutton-Grier,2015; Shannon \& Smets,2010)

Infraestructura multifuncional que favorece el desarrollo de procesos simultáneos, que apuntan a amplificar y diversificar la prestación de servicios, optimizando la rentabilidad de la inversión Se comprende como un sistema abierto, susceptible de incorporar progresivamente nuevas funciones y externalidades.

(Whaldheim, 2016; Shannon \& Smets, 2010; Mossop, 2006)

Sistema de componentes y procesos ecológicos que operan sinérgicamente en un determinado contexto territorial, con la finalidad de generar, distribuir y aportar servicios ecosistémicos para el bienestar de la población, a partir del rol activo de ecosistemas remanentes.

(Carpenter \& Folke, 2006; Davidson-Hunt \& Berkes, 2003)

Conjunto de estrategias y acciones de ingeniería ecológica que se apoyan en la conservación y manejo de los ecosistemas y los servicios que estos proveen, para responder a desafios de adaptabilidad al cambio climático, reducción de riesgo y resiliencia ante desastres.

(McBreen, 2016; Reed, 2015; Steiner 2012)

Sistema determinado por la integración de patrones y procesos híbridos, no sólo vinculado a ecosistemas naturales que la definen como infraestructura ecológica subyacente, sino sumando también ecosistemas resultantes de dinámicas antrópicas en contextos urbanos y/o productivos, bajo una perspectiva de sistema socioecológico complejo. Se presenta como un sistema interconectado de unidades de paisaje remanentes y emergentes en contextos urbanos, rurales y silvestres, que conservan y aporta servicios claves para la población.

(Anderson et al. 2014; Benedict \& Mcmahon, 2006)

Aporta a la definición de infraestructura verde un énfasis al rol que asumen aquellos sistemas del agua - sean éstos de origen natural o antrópicos - en la provisión de funciones y servicios ecosistémicos.

(Anderson et al. 2014; Benedict \& Mcmahon, 2006)

Tabla 2. Síntesis de definiciones de diferentes enfoques de infraestructura.

Fuente: Elaboración propia en base a autores citados. 
En el contexto europeo, las primeras referencias al concepto de infraestructura verde aparecen en los primeros años de la década del 2000, en documentos de política regional y de cambio climático. No obstante, su verdadero marco de desarrollo es la Estrategia de la Unión Europea sobre la Biodiversidad 2020, aprobada por la Comisión Europea en mayo de 2011. Una de las principales bases de esta Estrategia señala la necesidad proteger y potenciar los procesos naturales para que la sociedad aproveche los múltiples beneficios que le brinda la naturaleza, ante lo cual se compromete a desarrollar una Estrategia de Infraestructura Verde, con la conservación de la biodiversidad como aspecto prioritario. Este enfoque de planificación identifica y analiza el conjunto de espacios abiertos del territorio -áreas verdes urbanas, áreas silvestres, áreas productivas, corredores hídricos, bordes y zonas de riesgo, entre otras tipologías- develando su potencial funcionalidad, conectividad y complementariedad para favorecer la provisión de servicios ecosistémicos, que contribuyen al bienestar general de personas, comunidades y economías ${ }^{21}$.

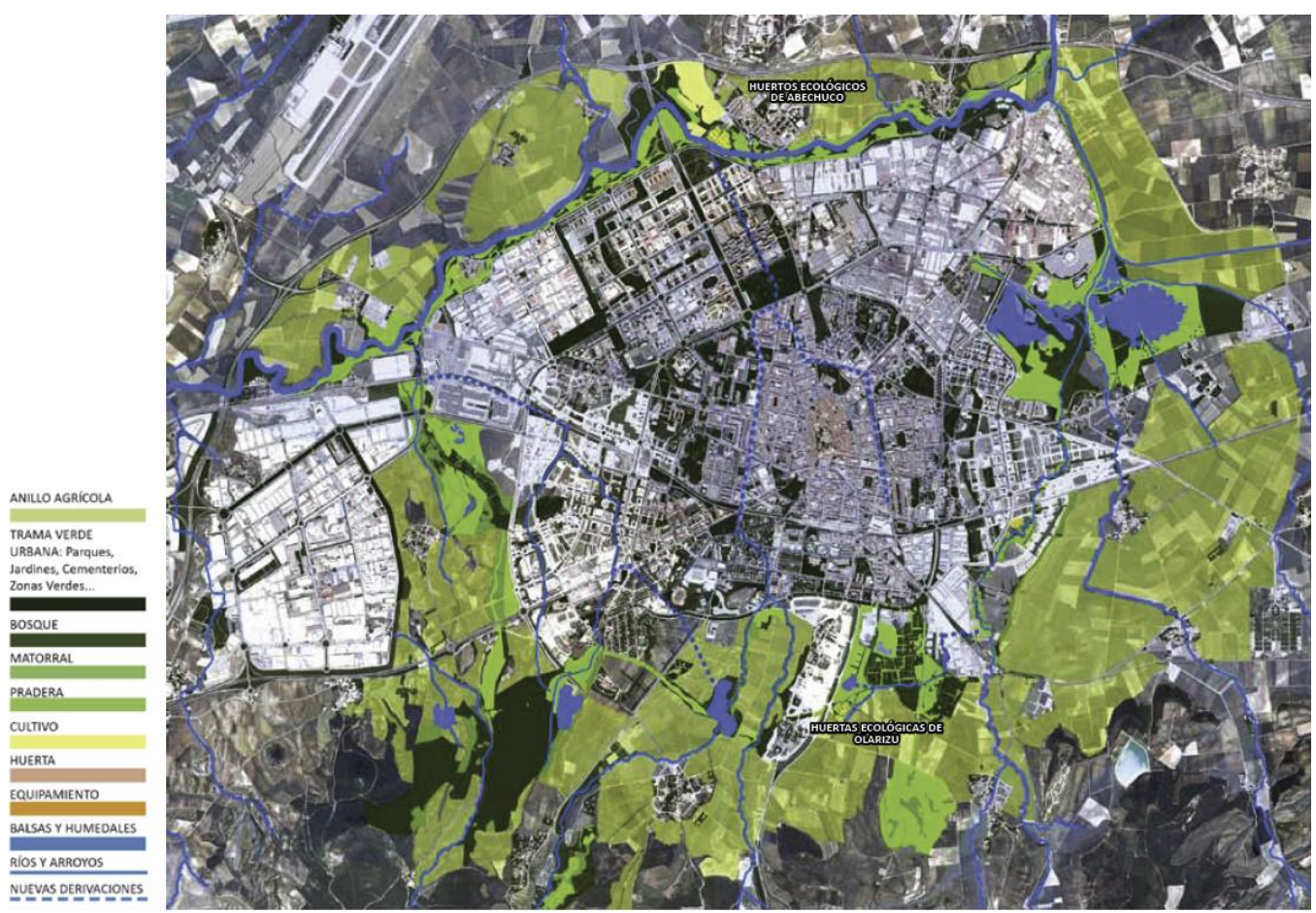

Fig. 11. Plan Anillo Verde de Vitoria Gasteiz, País Vasco. Un sistema de infraestructura verde conformado por diversos enclaves de alto valor paisajístico, enlazados estratégicamente mediante corredores ecológicos, espacios públicos, areas agricolas y sistemas hídricos.

Fuente: Ayuntamiento de Vitoria Gasteiz.

\footnotetext{
${ }^{21}$ Como señala Janez Potocnik, Comisario europeo de Medio Ambiente , "[...] lo que estamos viendo cada vez más en toda Europa es que las soluciones de In-fraestructura Verde son a menudo más rentables, más resistentes y más beneficiosas a largo plazo que una sólida infraestructura artificial". Conferencia del EESC-CoR sobre la Infraestructura Verde, celebrado en Bruselas en noviembre de 2013. (http://www.europa.eu/rapid/press-release_SPEECH-13880_en.pdf).
} 
Actualmente, la incorporación de la infraestructura verde como instrumento de planificación territorial se evidencia en diversas iniciativas a nivel global, especialmente en Europa, Asia y Estados Unidos. Entre ellas, cabe destacar como ejemplo el Plan de Anillo Verde de Vitoria Gasteiz (2010), que se expresa en la gráfica de la figura 11, el Plan de Infraestructura Verde y Paisaje de la Comunitat Valenciana (2011), el Green Infrastructure and Low Impact Development Plan de Nueva York (2012) y el Coastal Roulette-Planning Resilient Communities for Galveston Bay (2012). En el contexto latinoamericano, destaca el Plan Bio 2030 Medellín Valle de Aburrá (2013) y la reciente formulación del Plan de Infraestructura Verde Urbana para Llanquihue en Chile (2017).

De esta forma, el panorama contemporáneo asociado a este enfoque de paisaje como infraestructura ofrece de manera creciente referencias de planes y proyectos situados en el marco de procesos de planificación de ciudades resilientes ante escenarios post-desastre y cambio climático. La conservación y manejo de unidades de paisaje como parte de un sistema de infraestructura verde urbana, considerando áreas naturales y también estructuras de orden antrópico asociadas por ejemplo a zonas productivas y urbanas, conforma un eslabón fundamental para la gestión de resiliencia en territorios vulnerables ante desastres, dadas las capacidades adaptativas que estos sistemas pueden aportar ante riesgos de carácter geológico tales como terremotos, tsunamis, remoción en masa y erupciones volcánicas- e hidrometereológico, como inundaciones, aluviones, marejadas, tormentas, lluvias extremas y sequías. 


\section{EL DESASTRE COMO ESPACIO DE OPORTUNIDAD PARA REPENSAR LAS DINÁMICAS DE HABITABILIDAD DESDE EL PAISAJE: LOS PARQUES DE MITIGACIÓN EN EL CONTEXTO DE LA RECONSTRUCCIÓN POST TSUNAMI DE 2010 EN CHILE}

Debido a su ubicación geográfica, caracterizada por su larga extensión costera en la cuenca del Pacífico suroriental, las costas de Chile se ven afectadas frecuentemente por los efectos de ondas de tsunamis. Estas ondas se desplazan a gran velocidad y, según su magnitud, pueden causar enormes daños materiales y pérdidas de vidas al alcanzar las zonas litorales continentales e islas oceánicas. En el territorio chileno, diversas inundaciones producidas por tsunamis han alcanzado alturas del orden de $25 \mathrm{~m}$ sobre el nivel medio del mar, generando extensa destrucción y pérdidas de vidas (Lockridge, 1985; Lagos, 2000). Esta constante amenaza de tsunami se traduce en un riesgo permanente para los asentamientos humanos localizados en el borde costero, condición que se ve acentuada debido a una ocupación urbana irregular y con una débil planificación territorial, como también por la presión inmobiliaria de construir en zonas de riesgo (Arenas et al., 2010).

La revisión de antecedentes históricos ${ }^{22}$ sobre terremotos y tsunamis, registrados desde 1562, anota más de 30 eventos de magnitud superior a 7.5 en la escala de Richter (Monge, 1993). Las estadísticas relacionadas a ellos contribuyen a comprender la relevancia del fenómeno tsunami en Chile. Los territorios de Chile y Perú son los que sufren más terremotos y erupciones volcánicas por kilómetro cuadrado en todo el planeta. De acuerdo a Lockridge (1985), sólo si se considera el siglo XX, uno de cada tres tsunamis del océano Pacífico se originó en la costa chilena, mientras que el $40 \%$ de los tsunamis más destructivos del mundo se originaron exclusivamente en Chile (Lagos, 2000; Lockridge, 1985). Un terremoto de suficiente magnitud como para generar un tsunami que afecte a toda la cuenca del océano Pacífico ocurre en Chile, como promedio, cada 25 años (Lockridge, 1985). Como precisan diversos autores (Cereceda et al., 2011; Lagos, 2000), la generación de tsunamis en Chile está principalmente asociada a la ocurrencia de grandes terremotos, dada su posición en una zona de subducción denominada fosa chilenoperuana, donde convergen la placa tectónica de Nazca y la placa Americana. Así, como se ha señalado en el anterior capítulo de esta investigación, la localización geográfica de nuestro país, las características tectónicas de su emplazamiento y la generación de tsunamis que potencialmente pueden afectar el litoral chileno y toda la cuenca del océano Pacífico, hacen de Chile una de las principales áreas

\footnotetext{
22 En términos de los registros históricos de tsunamis en Chile, destaca el listado de tsunamis generadores de daño, elaborado por Monge en 1993. Esta lista sintetiza y complementa el trabajo realizado por otras investigaciones desarrolladas en la decada de los 70. En ella se presentan los siguientes campos de información: ubicación (región administrativa), fecha, grado $(\mathrm{m})$ del tsunami y magnitud Richter $(\mathrm{M})$ del sismo en rangos aproximados. El número de registros alcanza 35 eventos, entre 1562 y 1960, a la cual pueden agregarse 2 nuevos registros de historia reciente: el Tsunami de de Febrero de 2010, generado por el sismo de magnitud Richter 8.8 con epicentro en las costas de la región de Biobío; y el Tsunami de Septiembre de 2015, provocado por un sismo de magnitud 8.4 Richter, con epicentro en las costas de la región de Coquimbo.
} 
tsunamigénicas del planeta, junto a las costas pacíficas de Norteamérica, Asia y Oceanía.

En este marco histórico y geográfico, el terremoto y tsunami ocurrido en Febrero de 2010 se considera uno de los eventos más relevantes desde el punto de vista de la magnitud del fenómeno, de la extensión territorial que abarcó - incluyendo a los principales centros urbanos e infraestructuras críticas del centro sur de Chile ${ }^{23}-$ y de la población comprometida. Por otra parte, desde un enfoque prospectivo, este desastre ha permitido, en años posteriores, desarrollar conocimiento científico y técnico en diversas áreas del conocimiento, favoreciendo procesos reflexivos relacionados con la planificación territorial de bordes costeros, contemplando una revisión de los protocolos de gestión de riesgo y un desarrollo de instrumentos especialmente focalizados en la zonificación de áreas de riesgo, en el marco de la actualización de instrumentos de planificación territorial (IPT) a escala comunal y regional.

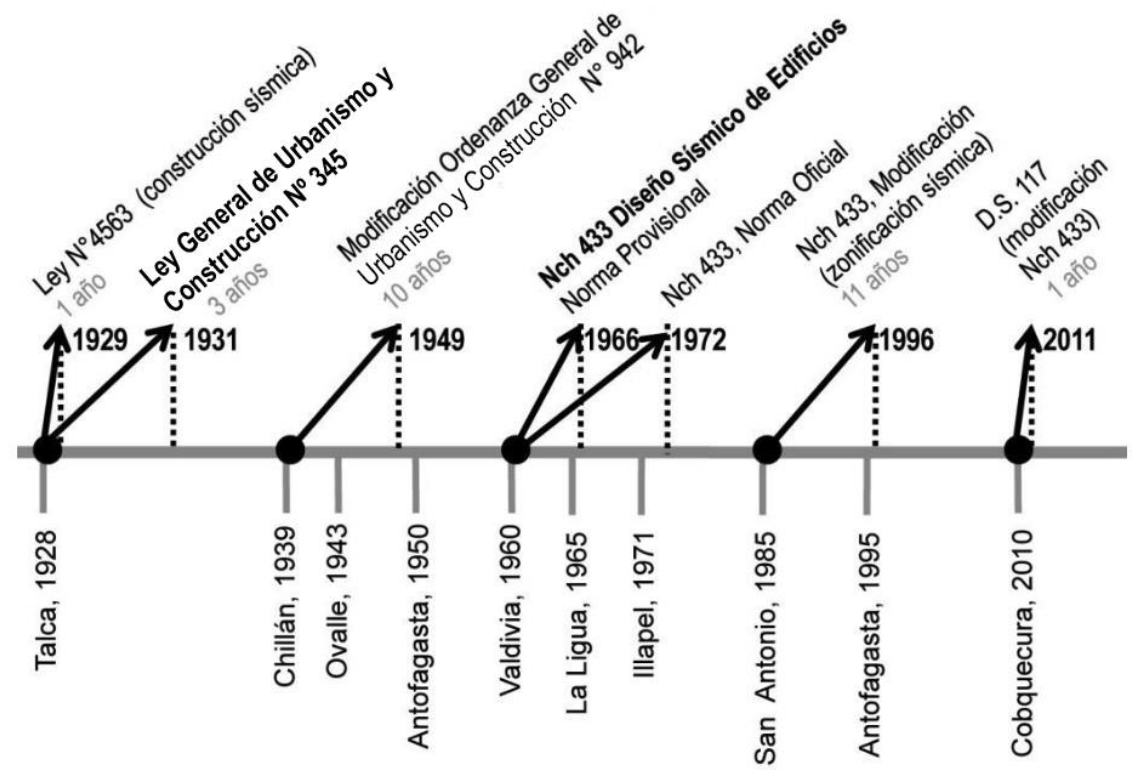

Fig. 12. Diagrama de temporalidad de Normativas creadas a partir de Desastres en Chile. Fuente: Herrmann (2016).

Esta actualización de los protocolos e instrumentos normativos e indicativos observada a continuación del evento de febrero de 2010 , se enmarca en una tradición histórica que vincula directamente la creación o revisión de leyes, normas e insturmentos con la ocurrencia de desastres, principalmente con grandes terremotos que luego han dado paso al desarrollo de regulaciones sismo-resistentes y de planificación territorial, lo cual se grafica en la siguiente figura. En efecto, como señala Herrmann (2016), la primera Ley y Ordenanza General de Urbanización y Construcción de Chile, fue creada como respuesta al terremoto de Talca de 1928. Así,

23 De acuerdo a las estimaciones de impacto de daños, el monto total ascendió a 29 mil 663 millones de dólares equivalentes al $18 \%$ del PIB del mismo año, a nivel país, y la población total afectada superó los 13 millones de habitantes (Gobierno de Chile, 2010) 
el terremoto de Talca inicia en Chile no sólo los estudios en ingeniería antisísmica, conocimiento tomado en gran parte de la tecnología extranjera, sino también la planificación urbana en Chile. (Herrmann, 2016: 22).

A partir de las consecuencias del terremoto y tsunami de 2010, el Estado de Chile visualizó la relevancia de mejorar la incorporación de la gestión del riesgo de desastres en el marco institucional y normativo aplicado a los IPT, con la finalidad de reducir el impacto de futuros eventos (Martínez; Moris; Qüense, 2016). Sin embargo, la dimensión de resiliencia y adaptabilidad se encuentra parcialmente recogida en estos procesos y cuerpos legales. En general, el avance en materia de planificación y gestión post desastre de 2010 se ha situado en actualizar las Cartas de Inundación ${ }^{24}$ de las zonas pobladas ubicadas en el borde costero (fig. 13) y en sensibilizar en términos normativos y operativos, los estudios de riesgo en los procesos de planificación a escala comunal.

Este paso, si bien se entiende como fundamental respecto a definir un conocimiento actualizado para la toma de decisiones en materia de gestión de riesgo, no abarca necesariamente la investigación hacia nuevas formas de habitabilidad de estos territorios de borde con criterios de resiliencia y adaptabilidad, lo cual queda declarado en la ausencia de discusión reflejada en los informes técnicos - e incluso académicos - derivados de la experiencia post Febrero de 2010 y en la exhacerbación de la noción de "reconstrucción" -esto es, 'volver a construir lo que había'- como denominador para determinar las estrategias y acciones sobre el territorio. En efecto, la mayoría de los instrumentos de planificación y gestión post-desastre han utilizado el concepto de reconstrucción para su denominación.

No obstante lo anterior, se estima que aun cuando no existe una referencia explícita a la idea de resiliencia como marco de desarrollo de capacidades adaptativas en el habitar del borde costero, el caso del Plan de Reconstrucción de la ciudad de Constitución -y en particular el proyecto de Parque de Mitigación que se desarrolla bajo su alero- abren un espacio de oportunidad trascendental para repensar formas de actuación desde la planificación y diseño del paisaje en contextos de riesgos y vulnerabilidades.

\footnotetext{
${ }^{24}$ El Servicio Hidrográfico y Oceanográfico de la Armada de Chile (SHOA) es la entidad encargada de la elaboración de las Cartas de Inundación por Tsunami para las principales zonas urbanas y portuarias del borde costero de Chile. Estas Cartas permiten definir los niveles de inundación máximos esperados ante la ocurrencia de eventos sísmicos tsunamigénicos de campo cercano y tienen una aplicación directa en la planificación urbana que ejecuta la autoridad municipal, y en la elaboración de los planes de evacuación y protección civil. En términos generales, las Cartas de Inundación por Tsunami (CITSU) que elabora este Servicio, representan un evento extremo conocido o probable, dependiendo del caso. Actualmente, la simulación numérica es la mejor técnica de análisis geofísico e hidrodinámico disponible para estudiar el riesgo de tsunami en las áreas donde los registros históricos son insuficientes. El modelo que se ha aplicado para desarrollar el proyecto CITSU, se denomina COMCOT (Cornell Multi-grid Coupled Tsunami Model) diseñado por el Dr. S.N. Seo basado en el modelo de Shuto's (Agosto 10, 1993) y Yongsik Cho (Agosto 10, 1993) en la Escuela de Ingeniería Civil y Ambiental, de la Universidad de Cornell.
} 


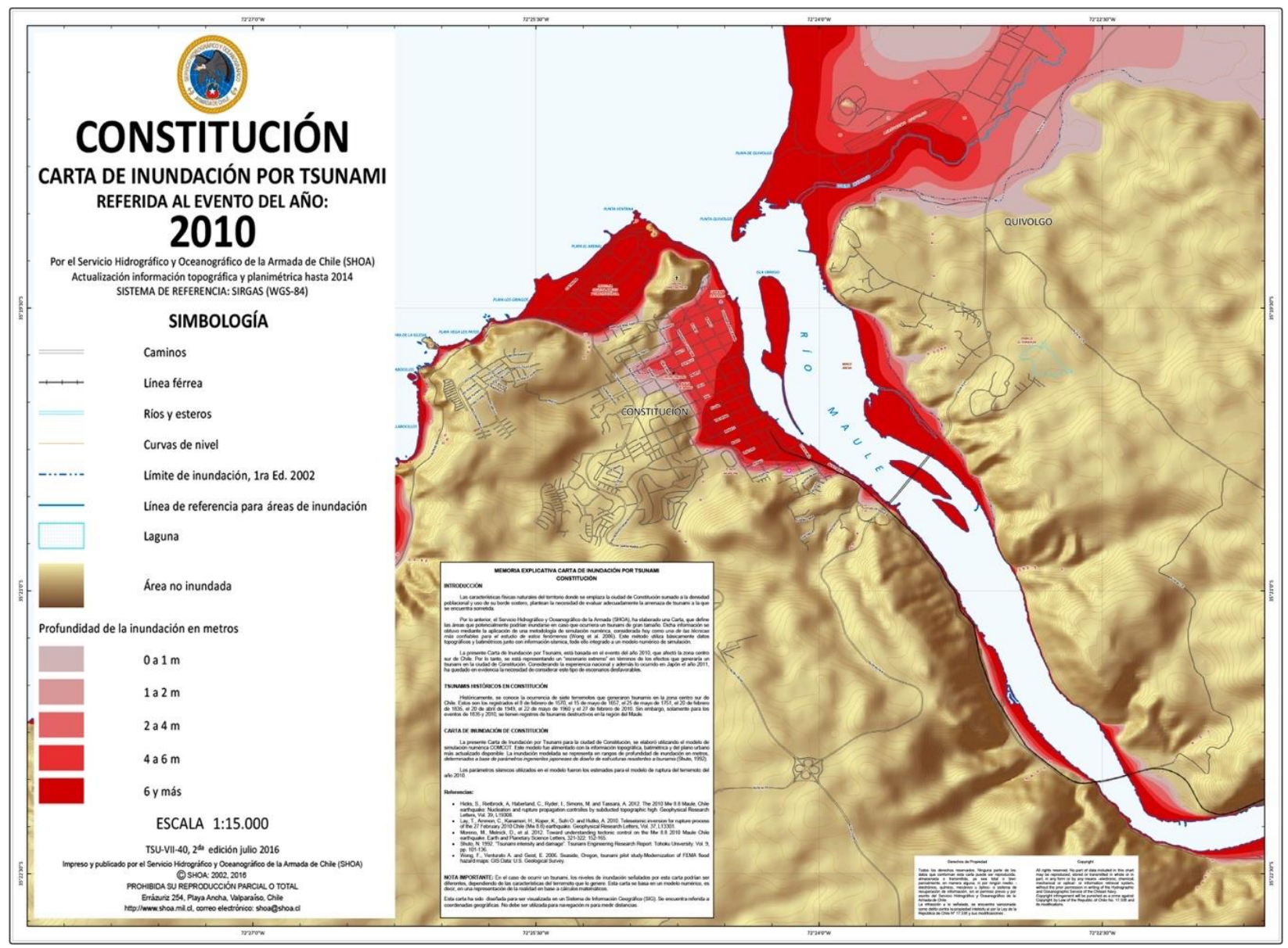

Fig. 13. Cartas de inundación por tsunami (CITSU) para la ciudad de Constitución, Región del Maule afectada severamente por el evento que se generó a continuación del terremoto $8.8 \mathrm{Mw}$ de Febrero de 2010. Las CITSU elaboran utilizando modelos de simulación numérica COMCOT, alimentado con información topográfica, batimétrica y del plano urbano. En términos gráficos, la inundabilidad se expresa en la gradiente de colores de gama roja, en la simbología de la Carta.

Fuente: SHOA, 2016. Disponible en: http://www.shoa.cl/php/citsu.php

Desde su conceptualización como infraestructura urbana para la amortiguación de los fenómenos de inundación derivados de la ocurrencia de tsunamis, la figura de los Parques de Mitigación es replicada luego en diversas localidades costeras afectadas por el desastre de Febrero de 2010, siguiendo el ejemplo de Constitución. En este contexto, el tercer capítulo abordará el análisis de los instrumentos de planificación que surgieron post tsunami de 2010, comprendidos como semillero de un nuevo enfoque de paisaje asociado a la idea de infraestructura verde para la adaptabilidad y resiliencia de territorios en riesgo de desastres.

\subsection{Caracterización del impacto del tsunami de 2010 en el borde costero del centro sur de Chile}

De acuerdo al Servicio Geológico de Estados Unidos, el terremoto que afectó la zona centro sur de Chile el 27 de febrero de 2010 a las 03:34 hora local, alcanzó una magnitud de 8,8 ( $\mathrm{M}_{\mathrm{w}}$ ) y tuvo duración aproximada de tres minutos. El área de ruptura 
comprendió entre Valparaíso (Latitud $33^{\circ} \mathrm{S}$ ) y el sur de la Isla Mocha (Latitud $38,6^{\circ} \mathrm{S}$ ), con una extensión superior a $610 \mathrm{~km}$. (fig. 21). El epicentro se situó aproximadamente a 47 kilómetros de profundidad, en la región de Biobío a 8 kilómetros al oeste de Curanipe y 115 kilómetros al nor-noreste de la segunda ciudad más grande de Chile, Concepción (Bárcena et al., 2010). El mecanismo focal de este sismo es de tipo inverso, es decir, corresponde a un terremoto de subducción producto del hundimiento de la placa de Nazca bajo la Sudamericana (Bárcena et al., 2010; Quezada et al., 2010). Por su magnitud, el desastre provocado incluyó varias otras áreas de la cuenca del Pacífico, pasando a integrar la lista de los cinco mayores terremotos tsunamigénicos del mundo. De este modo, Chile cuenta con dos de los cinco eventos sísmicos más grandes de la historia: 21-22 de mayo de 1960 (de magnitud $M=9,5$ ) y 27 de febrero de 2010 (Martínez et al., 2011).

Según estimaciones de diversos organismos públicos, los habitantes de todas las ciudades afectadas acumularon más de 13 millones de personas, cerca del $80 \%$ de la población del país. Los daños generados superaron las 370.000 viviendas dañadas, $47 \%$ de las cuales tuvieron daños mayores o fueron destruidas, lo que se traduciría en más de 250.000 damnificados (Bárcena et al., 2010; Bresciani, 2010). Aun con estas estadísticas, los daños fueron minimizados gracias a estrictas normas de construcción ${ }^{25}$ vigentes en Chile para la construcción de edificios (INN, 2003, 2009) e industrias (INN, 2003a).

El desastre ocurrido el 27 de febrero del 2010 en Chile -denominado por los medios de comunicación y también por la literatura especializada como $27 \mathrm{~F}-$ se considera el terremoto de mayor cobertura urbana registrado en el país, dada su amplia extensión que afectó gravemente a más de 50 ciudades y 900 pueblos (MINVU, 2010). Sumado a esto, debe considerarse el arribo del tsunami minutos después, que finalmente tuvo severas consecuencias en las localidades de borde costero en más de 600 kilómetros de extensión, por lo cual se declaró como zona afectada por catástrofe al territorio comprendido entre la región de Valparaíso y la región de la Araucanía. Las regiones del Maule y Biobío fueron las zonas más afectadas por el terremoto y posterior tsunami, tanto por las pérdidas de vidas humanas, como por los daños materiales que afectaron diversas ciudades, pueblos y caletas (GSAPP, 2015; Delegación Presidencial para la Reconstrucción, 2014; Gobierno de Chile, 2010). En el valle central de la región del Maule - en las ciudades de Talca, Linares, Cauquenes, Parral y Curicó - se vieron devastadores daños estructurales en infraestructura y vivienda, sobre todo en aquellas construcciones de adobe sobrevivientes a los terremotos precedentes acontecidos en los años 1960 y 1985. El evento del terremoto y tsunami en conjunto dejó un saldo total de 280 Fallecidos en la región (ONEMI, 2010), constituyendo así más de la mitad del total nacional. La mayor cantidad de fallecidos corresponde a victimas del tsunami $(55,2 \%)$, muchas de ellas aún desaparecidas.

\footnotetext{
${ }^{25}$ Estas normas, que refieren a los estándares técnicos de diseño y construcción de edificaciones, son catalogadas por el Instituto Nacional de Normalización (INN), y han ido modificándose tras cada evento de terremoto en la historia reciente, para aumentar los niveles de seguridad de las construcciones (Cisternas, 2011) y se buscó actualizarlas nuevamente para incorporar las lecciones de este sismo (Bitar, 2010; Betanzo, 2010).
} 


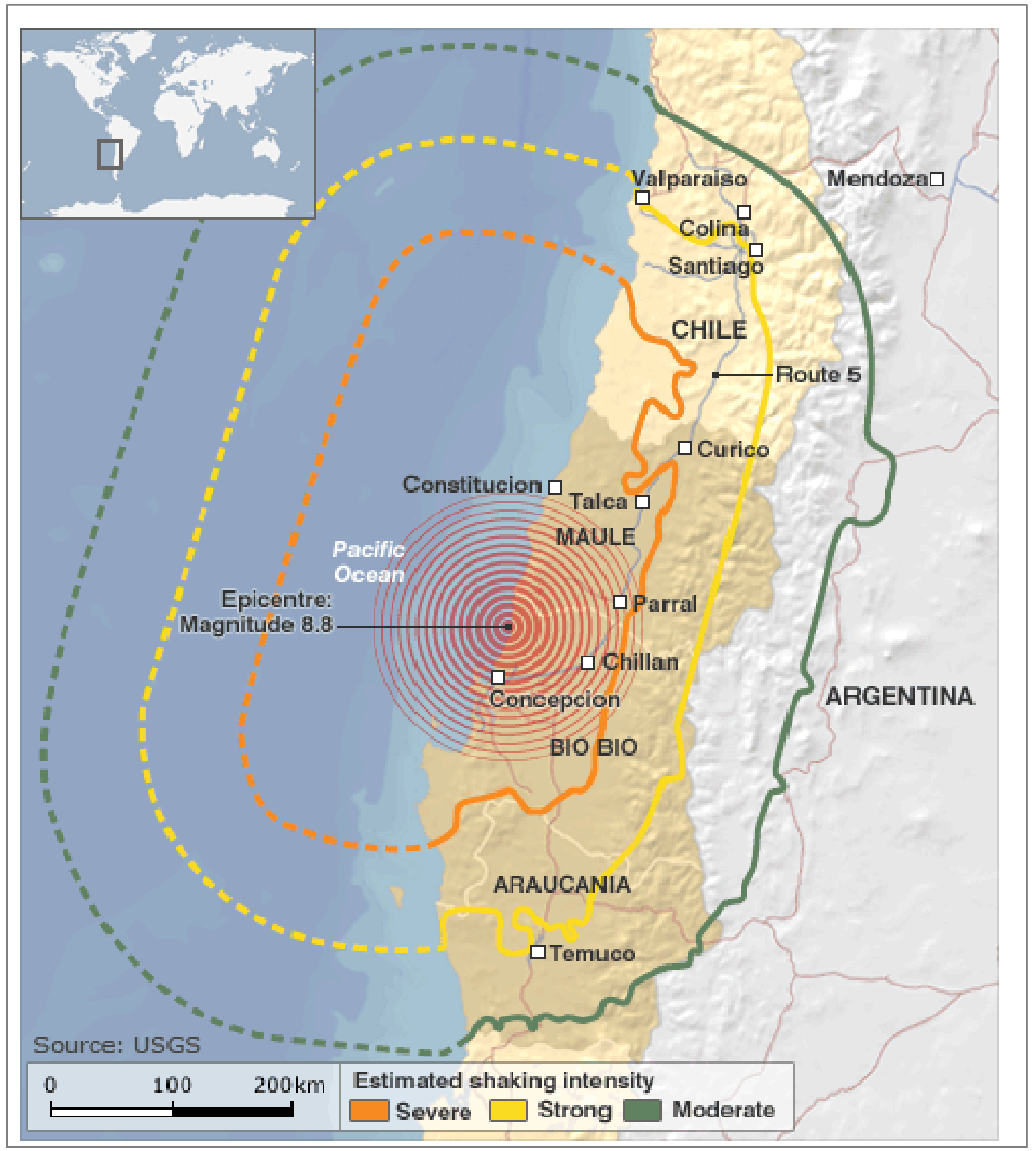

Fig. 14. Mapa con la localización del epicentro del terremoto del 27 de Febrero de 2010, de magnitud 8,8 ( $\mathrm{Mw}_{\mathrm{w}}$, frente a las costas de la región del Biobío. Se indica, mediante la estimación del movimiento telúrico (estimated shaking intensity), el área de afectación que abarca más de 600 kilómetros, incluyendo el sistema de ciudades del centro sur de Chile: desde la región de Valparaíso, al norte, hasta la región de la Araucanía.

Fuente: USGS Earthquake Hazards Program (https://earthquake.usgs.gov/)

Gran parte de la destrucción se concentró en el borde costero, debido principalmente al impacto del tsunami, donde las alturas de las olas fluctuaron entre los 3 y 30 metros (Belmonte et al., 2011) generando episodios de inundación que 
registraron niveles entre los 8 y 11 metros en diversos centros urbanos, características propias de un evento de tsunami grado 3 (USGS, 2010). El ingreso de la ola, correspondiente al momento de flujo, desató en diversas localidades una primera destrucción de infraestructuras y viviendas, escombros que luego incrementaron el poder destructivo de las olas que impactaron posteriormente (Cereceda et al., 2011; Lagos, 2000) y, en la mayoría de los casos, el ingreso del mar se vio favorecido por los cursos de agua, tales como esteros o ríos, en las diferentes localidades litorales. Asimismo, se produjeron cambios geomorfológicos en diversos componentes del territorio costero, tales como alzas o depresiones en los niveles de tierra, aparición de nuevas extensiones de playas o desaparición de otras zonas de playas existentes, así como también cambios en la batimetría de fondos de ríos en los sectores de su desembocadura, con alzas de hasta 2 metros, según Belmonte et al. (2011).

En este contexto generalizado de destrucción, se tuvo información de algunas localidades que sufrieron daños menores, aun cuando sus costas estuvieron expuestas a las olas del Tsunami, condición propiciada por la existencia de sistemas naturales que actuaron como mitigadores y disipadores de impacto. Uno de los casos registrados fue la ciudad de Arauco, en la región del Biobío, la cual vio un efecto mitigador en los humedales del estuario del río Carampangue, como así también en el cordón de dunas ubicado entre la línea de costa y el casco urbano (Belmonte et al., 2011). Cabe destacar que este territorio fue el que presentó una de las mayores áreas de inundación en la región, y sin embargo, daños menores a su infraestructura, demostrando que las condiciones mencionadas - asociadas a la funcionalidad de los sistemas naturales en su rol de infraestructura verde para mitigación y disipación disminuyeron el ingreso del flujo de agua en varios sectores urbanos de la localidad (fig. 16).

Al otro extremo, en términos de afectación, la ciudad de Constitución ${ }^{26}$ en la región del Maule, fue uno de los centros poblados más devastados por el terremoto $y$, especialmente, por el posterior tsunami. Oficialmente fallecieron 55 personas y otras 10 fueron consignadas como desaparecidas (Fiscalía, 2011). En efecto, Constitución es la localidad con el mayor número de víctimas fatales del $27 \mathrm{~F}$. La pérdida de vidas humanas y la devastación física llamó la atención de la opinión pública desde un primer momento sobre esta ciudad. Por otra parte, en materia de infraestructura urbana, se estima que cerca de un $20 \%$ de las viviendas tuvieron algún tipo de daño (GSAPP, 2015). Además, gran parte de las áreas productivas ubicadas en el borde costero- asociadas a la industria de Celulosa- y casi la totalidad de su infraestructura turística fue completamente destruida (GSAPP, 2015; Bárcena, Prado, López, \& Samaniego, 2010).

\footnotetext{
${ }^{26}$ Constitución es una comuna ubicada en la zona costera de la Provincia de Talca, perteneciente a la región del Maule. abarca una superficie de $1.343,6 \mathrm{~km}^{2}$ y una población de 46.068 habitantes (Censo INE Año 2017), correspondientes a un 4,4\% de la población total de la región y una densidad de 34,28 hab/ $\mathrm{km}^{2}$. Del total de la población, 23.063 son mujeres $(50,06 \%)$ y 23.005 son hombres (49,93\%). En febrero de 2010 , según estimaciones censales, la comuna registraba similar cantidad de habitantes.
} 
Es precisamente en esta ciudad, como se verá más adelante, donde se plantea por primera vez y de manera inédita en Chile, la noción de proyecto asociado a la figura de Parque de Mitigación, como componente estructural del Plan de Reconstrucción y como modelo a replicar luego en otras localidades de las regiones afectadas ${ }^{27}$. Experiencias locales referidas al rol activo de los sistemas naturales en la reducción de riesgo, como lo registrado en Arauco, sumado a la influencia de experiencias internacionales, alimentarán los argumentos conceptuales y técnicos que darán paso a su formulación.
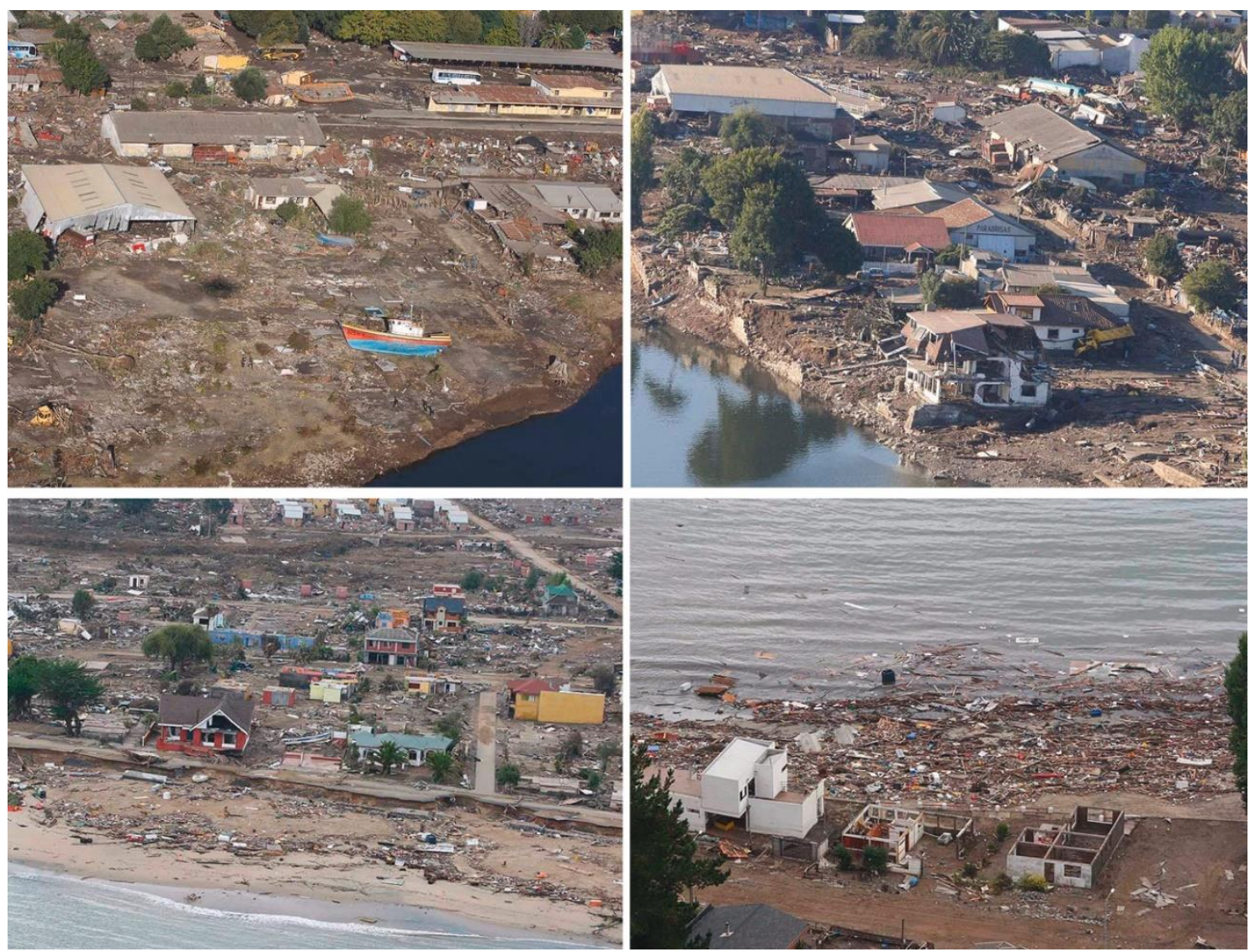

Fig. 15. Arriba: Destrucción en el borde fluvial de Constitución, región del Maule, afectado por el ingreso del tsunami a través de la desembocadura del río Maule. Abajo: Impacto y destrucción producido por el tsunami en el borde costero de Dichato, región del Biobío. Como se observa en ambas secuencias de imágenes, las edificaciones de vivienda y otros usos colindaban con la ribera del río y el borde costero, respectivamente, en una condición de alta vulnerabilidad que finalmente derivó en la destrucción total de ambos frentes urbanos. Actualmente, tal como se observa en las Cartas de Inundación, previamente presentadas, el borde fluvial y costero es declarado zona de riesgo y, como se señala más adelante, es justamente el espacio destinado a los Parques de Mitigación, en ambas localidades.

Fuente: EMOL (https://www.emol.com/especiales/2010/fotos_AD/terremoto_chile_aereas/)

27 La reconstrucción de Constitución fue planteada como la punta de lanza de los planes maestros de reconstrucción para toda la zona afectada por el terremoto y tsunami de 2010, posicionando su proceso desde un primer momento como una gestión territorial innovadora y ejemplar a nivel nacional (GSAPP, 2015). 

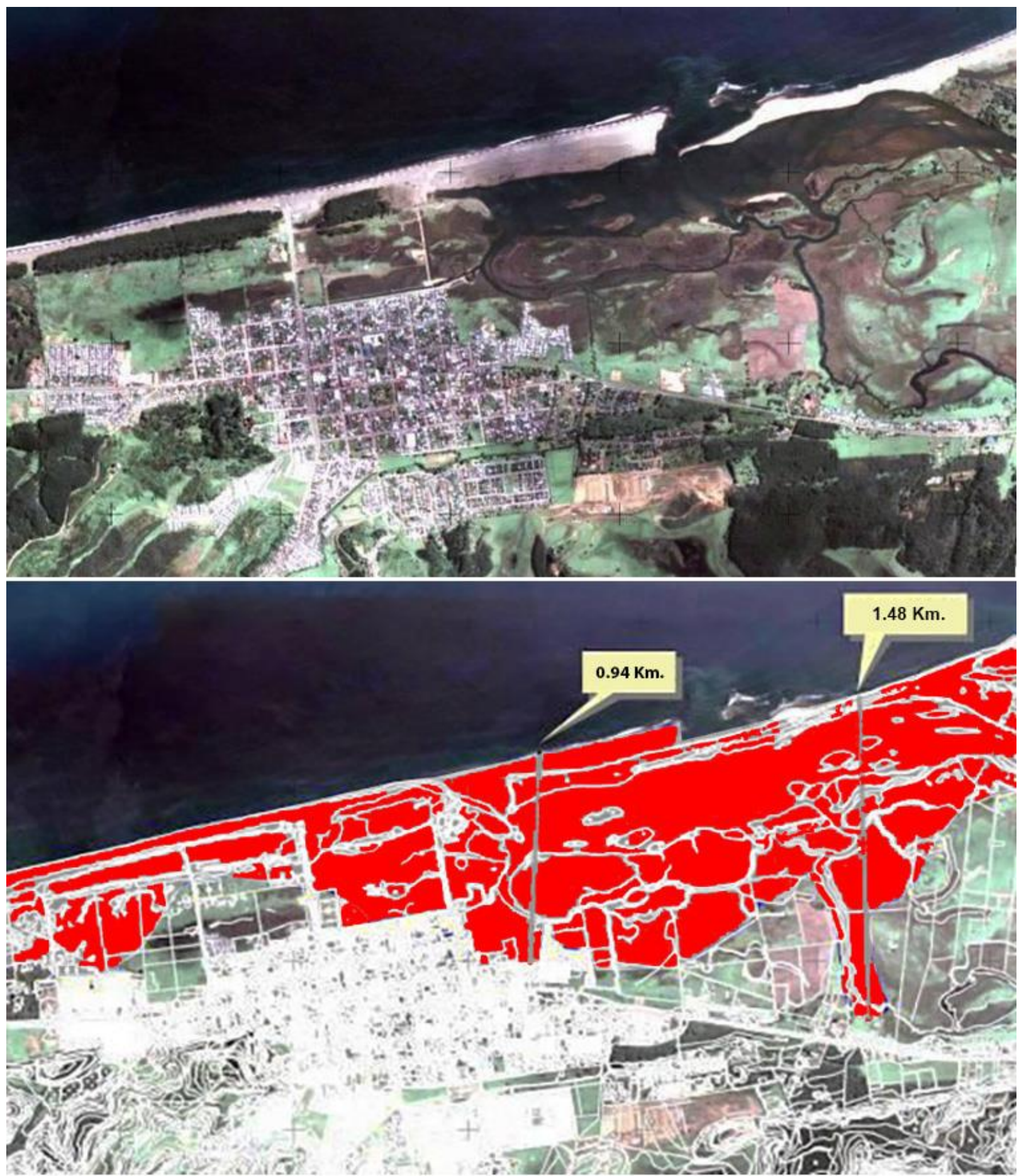

Fig. 16. Carta de inundación modelada en la localidad de Arauco, región de Biobío. Se observa el rol de los humedales costeros y el cordón dunario como infraestructura de amortiguación de los efectos de inundación en el Tsunami del 27F. Arriba, Imagen satelital de la localidad de Arauco. Abajo, Plano con área de inundación del tsunami del $27 \mathrm{~F}$ en la localidad de Arauco.

Fuente: Belmonte et al. (2011). 


\subsection{Planificación territorial y gestión del desastre. Marco normativo y operativo en Chile: definiciones, disposiciones e instrumentos}

El ordenamiento y la planificación territorial en Chile se establece a partir de la definición de Instrumentos de Planificación Territorial (IPT) junto a las denominadas Normas de Ordenamiento Territorial. Estas normas son atingentes jurídicamente a la organización del territorio, de acuerdo con los diferentes usos posibles del suelo y distinguiendo por una parte, entre ordenamiento, planificación y gestión territorial, y por otra, entre normas directas e indirectas de ordenamiento territorial. En el caso chileno, las normas generales están constituidas principalmente por la Ley General y la Ordenanza General de Urbanismo y Construcciones (LGUC), mientras que los instrumentos de planificación que se dictan a partir de ellas son los Planes Reguladores Intercomunales y Comunales, los Límites Urbanos y los Planes Seccionales (Arenas et al., 2010). Como se observa, la totalidad de los instrumentos y cuerpos normativos refieren a zonas urbanas, determinando así una focalización excluyente de la planificación territorial hacia áreas urbanizadas en desmedro de territorios fuera de los límites urbanos.

A partir de las consecuencias del terremoto y tsunami de 2010, como señala Martinez et. al (2011), el Estado visualizó la importancia de avanzar en la incorporación de la gestión del riesgo de desastres al marco institucional y normativo aplicado a los IPT, con el propósito de reducir el impacto de futuros desastres. De esta manera, considerando la necesidad de dotar al Estado con herramientas que le permitieran reaccionar con mayor celeridad en situaciones de emergencia y reconstrucción, se promulgó en mayo de 2012 la Ley $N^{\circ} 20.582$ que modifica las normas legales de la Ley General de Urbanismo y Construcciones, para favorecer los procesos de reconstrucción y las disposiciones sobre planes reguladores existentes en la Ley $\mathrm{N}^{\circ} 16.282$ sobre sismos y catástrofes. Esta nueva normativa da cuenta de un procedimiento excepcional para la formulación y modificación de IPT en zonas declaradas de catástrofe, donde los municipios podrán solicitar su aprobación mediante decreto supremo del Ministerio de Vivienda y Urbanismo, en un periodo de tiempo no superior a dos años a partir de la declaración. Asimismo, como parte de los cambios normativos derivados del desastre de 2010, cabe destacar que en 2011 se incorporó explícitamente el riesgo de inundación por tsunami en la normativa aplicada al artículo 2.1.17 de la OGUC, el cual ya había sido modificado con anterioridad al evento, en 2009.

Hasta febrero de 2010, la única entidad con una misión específicamente orientada a procesos de reconstrucción post desastres dentro de la institucionalidad chilena era la ONEMI, órgano que desde su creación en 1974 había estado a cargo de la coordinación del Sistema Nacional de Protección Civil con la misión de "planificar, impulsar, articular y ejecutar acciones de prevención, respuesta y rehabilitación frente a situaciones de riesgo colectivo, emergencias, desastres y catástrofes de origen natural o provocados por la acción humana"28. No obstante esta amplia

\footnotetext{
${ }^{28}$ Según Decreto D.L. Nº 369 de 1974.
} 
definición, la ONEMI carecía no sólo de capacidades para las labores de prevención, orientando su gestión principalmente al Sistema de Emergencia y Alerta Temprana y el Sistema de Protección Civil, sino que tampoco tenía facultades para la coordinación de las etapas de reconstrucción, las cuales históricamente han dependido de la acción de ministerios sectoriales centralizados como el Ministerio de Vivienda y Urbanismo y el Ministerio de Obras Públicas (Bresciani, 2012: 49).

Con ocasión del desastre del 27F, y luego de una semana caótica en términos de manejo operativo y logístico derivado de la gran magnitud de la devastación, de la amplia destrucción de las vías de comunicación terrestre y de la falta de coordinación entre los actores públicos del nivel central y del nivel local, el Gobierno estableció de manera excepcional un Comité de Emergencia ${ }^{29}$ y al mismo tiempo un Comité Interministerial de Reconstrucción ${ }^{30}$, cuyo organigrama se presenta en la siguiente figura (fig. 17). El Comité de Emergencia contempló tres objetivos principales: abordar la emergencia ciudadana inmediata, concentrándose en la busqueda y rescate de heridos, desaparecidos y fallecidos; restablecer el orden público y garantizar el abastecimiento de servicios básicos como el agua potable, electricidad y alimentos, y; enfrentar la emergencia del invierno en materia de viviendas, educación, salud, infraestructura y en los sectores productivos afectados por la catástrofe. (Gobierno de Chile, 2010).

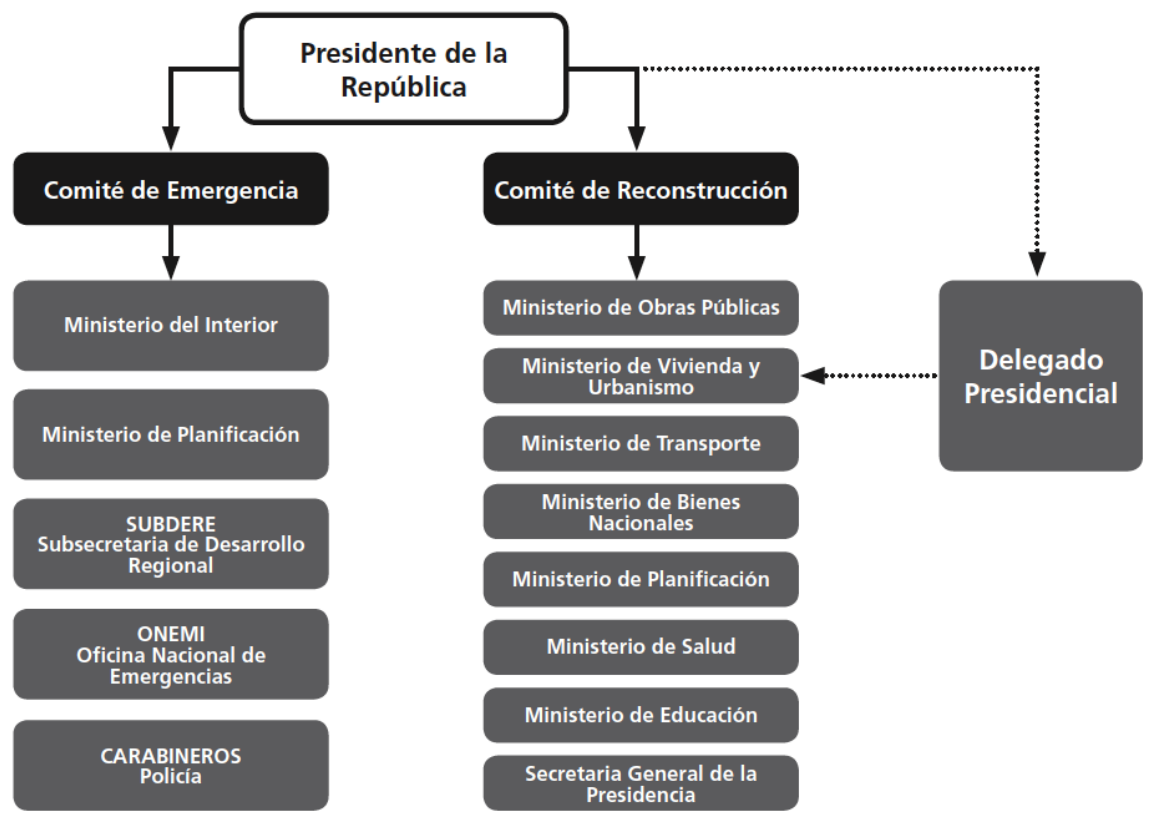

Fig. 17. Organigrama de la institucionalidad creada para la reconstrucción post $27 \mathrm{~F}$. Fuente: Bresciani, 2012.

${ }^{29}$ Creado mediante Decreto Supremo ํo 350 del 22 de marzo de 2010.

${ }^{30}$ Creado mediante Decreto Supremo No 317 del 11 de marzo de 2010. 
Por su parte, el Comité Interministerial para la Reconstrucción existía previo a la catástrofe bajo el nombre de Comité de Ciudad y Territorio y fue reorientado a coordinar las acciones de reconstrucción de los ministerios con mayores competencias en la materia. Tuvo entre sus primeras tareas el levantamiento de las necesidades en cada ministerio por región, centralizar los catastros de daños, definir prioridades y proponer las modificaciones legales o reglamentarias necesarias para avanzar hacia la reconstrucción. Lo anterior, con el objeto de permitir reconstrucción de viviendas, equipamiento y la infraestructura pública destruida.

Debido a la inédita amplitud territorial del daño y de su profundidad, el Gobierno dispuso que los ministerios y la organización territorial del Estado, como las intendencias, gobernaciones y alcaldías, fuesen los brazos ejecutores de planes y programas de emergencia y reconstrucción, elaborados a partir de catastros y diagnósticos. En paralelo, inició la tramitación de la Ley de Financiamiento de la Reconstrucción, con el fin de contar con los recursos financieros necesarios para su ejecución (GSAPP, 2015; Delegación Presidencial para la Reconstrucción, 2014; Gobierno de Chile, 2010).

En la formulación e implementación del denominado Plan de Reconstrucción Chile Unido Reconstruye Mejor (MINVU, 2010), se utilizaron programas e instrumentos de la política urbano habitacional regular, intentando evitar de esta manera la experimentación en un momento de excepcionalidad marcado tanto por la catástrofe, como por la propia instalación de la nueva administración de Gobierno ${ }^{31}$. El Plan de Reconstrucción contempló tres ámbitos generales de desarrollo, denominados: I) Programa de Reconstrucción de Vivienda; II) Programa de Programa de Atención a Aldeas y Condominios Sociales y; III) Programa de Reconstrucción Territorial, Urbana, y Patrimonial (MINVU, 2011). Este tercer programa del Plan de Reconstrucción es el que promovió el desarrollo de las iniciativas de los Planes Maestros de Reconstrucción en las localidades de borde costero afectadas por el tsunami, a partir de lo cual se formulan los Parques de Mitigación como obra emblemática de infraestructura urbana.

\footnotetext{
${ }^{31}$ El terremoto y tsunami del 27 de febrero de 2010 se produjo al término del Gobierno encabezado por la Presidenta Michelle Bachelet, quien el 11 de Marzo de 2010 entrega el mando al nuevo Presidente electo, Sebastián Piñera.
} 

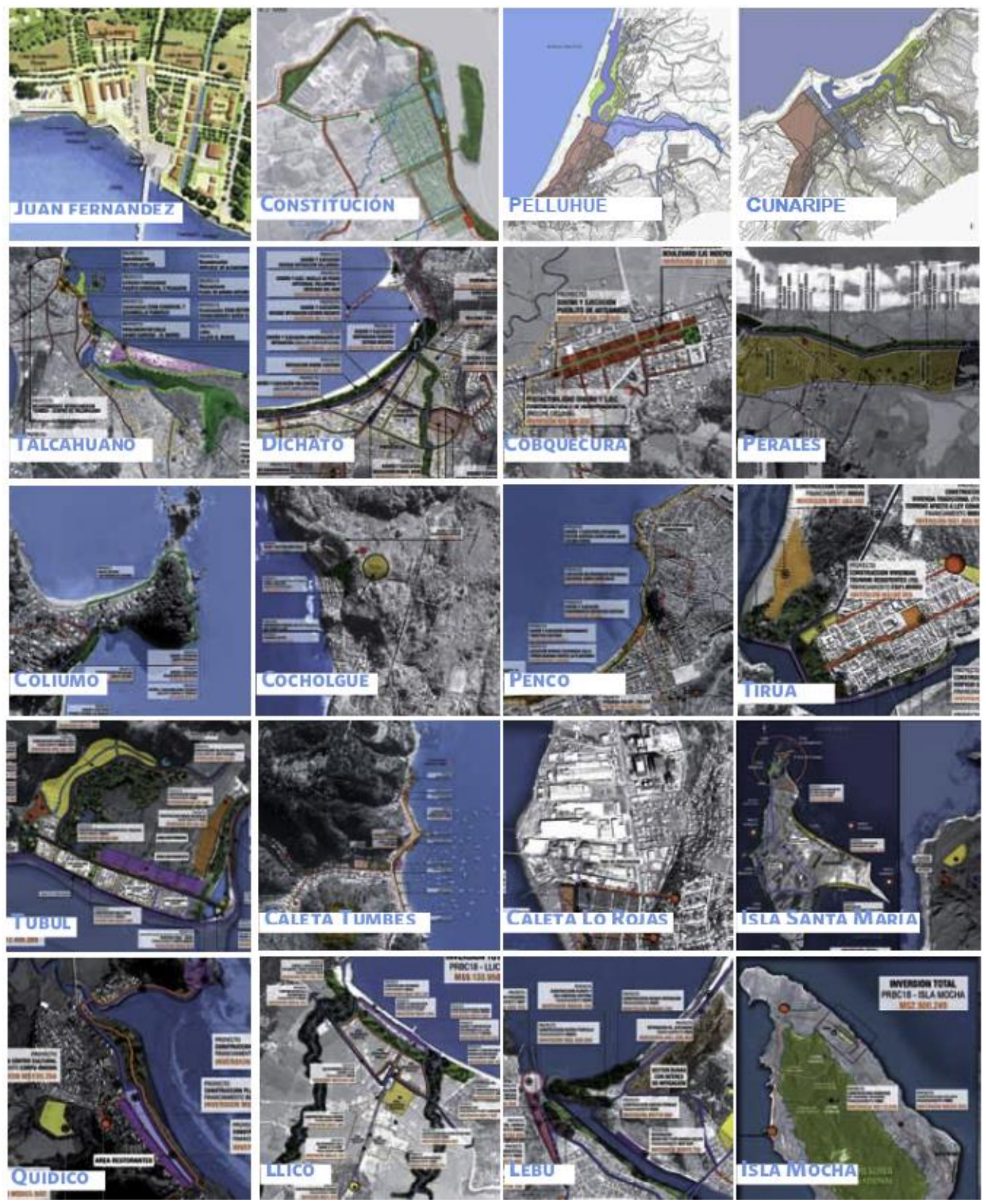

Fig. 18. Infografía de los Planes Maestros de Reconstrucción elaborados en localidades costeras de la región de Valparaíso, Maule y Biobío. Se observan 20 de un total de 25 planes desarrollados en el marco de la reconstrucción post 27F.

Fuente: Elaboración propia en base a MINVU, 2011. 
En el marco de la formulación y desarrollo de estos planes, el diseño e implementación de obras de mitigación y reducción de riesgos de desastre, se focaliza especialmente en la intervención de bordes costeros y fluviales. Una vez definidas las zonas de riesgo en diversas localidades, se establecieron las condiciones para su uso, así como las eventuales obras de mitigación necesarias para permitir retomar las actividades y el regreso de la población. Las obras de protección y mitigación se proponen de manera preliminar en los Planes Maestros a nivel de ingeniería conceptual, y sólo son desarrolladas a nivel de proyectos ejecutivos de ingeniería de detalle si se justifica su rentabilidad social, debido a la alta inversión que suponen. Un aspecto relevante que surge de su formulación, fue la consideración de un enfoque innovador de infraestructura de mitigación, que incorpora -especialmente en el marco de los proyectos de Parques de Mitigación- el aporte del diseño del paisaje y el rol de los sistemas naturales comprendidos como infraestructuras verdes para la reducción de riesgo en las ciudades de borde costero, ante eventos de tsunamis y marejadas (fig. 19).

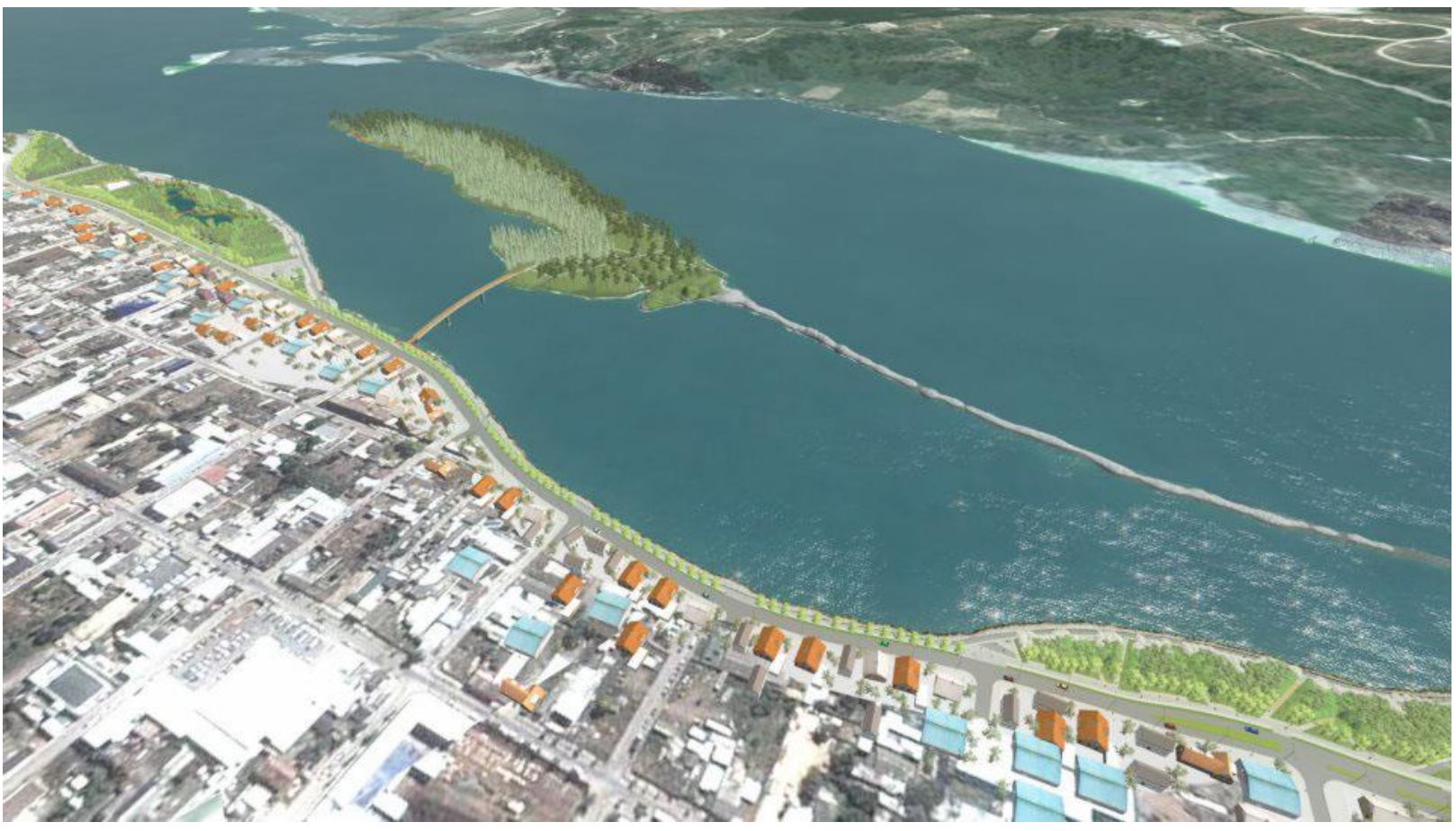

Fig. 19. Imagen objetivo del Parque de Mitigación en la ciudad de Constitución, ubicado en el borde fluvial del estuario del río Maule.

Fuente: SERVIU Región del Maule, 2013.

\subsection{Parques de Mitigación, pieza emblemática de los Planes Maestros de Reconstrucción post 27F}

El espacio público en la reconstrucción del 27F tiene un rol estratégico, dado que se comprende como el ámbito clave a intervenir para revertir las condiciones de vulnerabilidad, promover la reducción de riesgos de desastre y fomentar la resiliencia urbana, concepto que, si bien se menciona escasamente en el Plan de Reconstrucción, 
constituye a la vez el propósito que guiará la implementación de los Parques de Mitigación en las localidades de borde costero y afectadas por el tsunami. Debido a la condición de cercanía de los asentamientos urbanos a cuerpos de agua como el mar, esteros, ríos, lagunas y humedales, la planificación y diseño del ámbito de borde comprendido a la vez como espacio público y ecotono- resulta fundamental en términos de amortiguación ante la probabilidad de ocurrencia de eventos extremos de tsunami, o también ante eventos más recurrentes, como marejadas, inundaciones y crecidas de cauces.

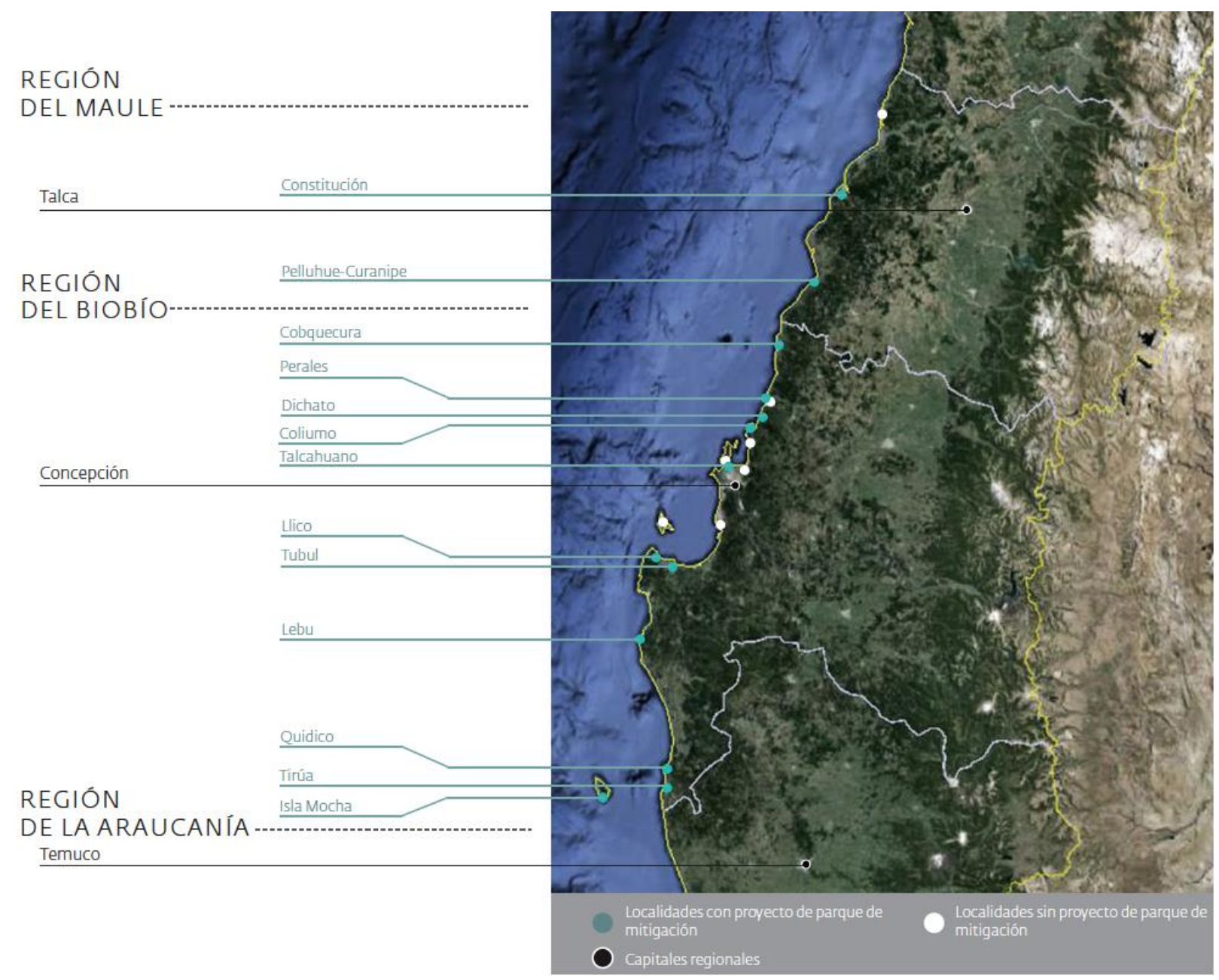

Fig. 20. Mapa de localidades con proyectos de Parque de Mitigación en sus Planes Maestros de Reconstrucción, en las regiones del Maule y Biobío.

Fuente: Elaboración propia a partir de imágenes satelitales de Google Earth e información obtenida de MINVU (2011), PRBC18, PRES Constitución y PRES Pelluhue-Curanipe.

La noción de Parque de Mitigación, en el marco del proceso de reconstrucción post $27 \mathrm{~F}$, surge por primera vez como parte del Plan de Reconstrucción Estratégica Sustentable de Constitución, instrumento conocido como PRES Constitución. El Plan fue formulado y coordinado técnicamente por la oficina Elemental, liderada por el arquitecto chileno Alejandro Aravena, y en su desarrollo participó un consorcio de 
entidades públicas y privadas, instaurando un modelo de gestión inédito en Chile. En gran medida, como se explica a continuación, los lineamientos de diseño del PRES Constitución determinarán los planteamientos que darán forma luego a los distintos planes maestros de reconstrucción de las localidades del centro-sur del país, graficados en la siguiente figura. La replicabilidad de esta estrategia, además, se transforma en un proyecto símbolo de la reconstrucción para las comunidades, por dos motivos principales: la gran inversión económica que supone dentro del plan y la relevancia a nivel de espacio público en localidades que históricamente han evidenciado falencias en ese tipo de equipamientos.

Como se ha señalado, Constitución fue una de las localidades más devastadas por el tsunami de febrero de 2010: con más del 50\% de su superficie urbana destruida, sobre 8.000 damnificados -en una población aproximada de 46.000 habitantes en el año 2010 - y con el mayor número de víctimas fatales del $27 \mathrm{~F}$, contabilizando 55 personas fallecidas y una decena desaparecidos (GSAPP, 2015; Fiscalía, 2011). Asimismo, las instalaciones industriales de Celulosa -principal motor económico de la comuna- y casi la totalidad de la infraestructura y equipamiento turístico fueron destruidas. Aún así, y según se observa en la siguiente figura, la condición geográfica del estuario contribuyó a mitigar parcialmente el ingreso de las olas a la ciudad, disminuyendo en parte su altura, que en territorios más expuestos de la costa norte superaron los 11 metros. La acción de amortiguación fue ejercida principalmente por el cerro Mutrún y por la isla Orrego, ubicada al frente del borde fluvial de la ciudad.

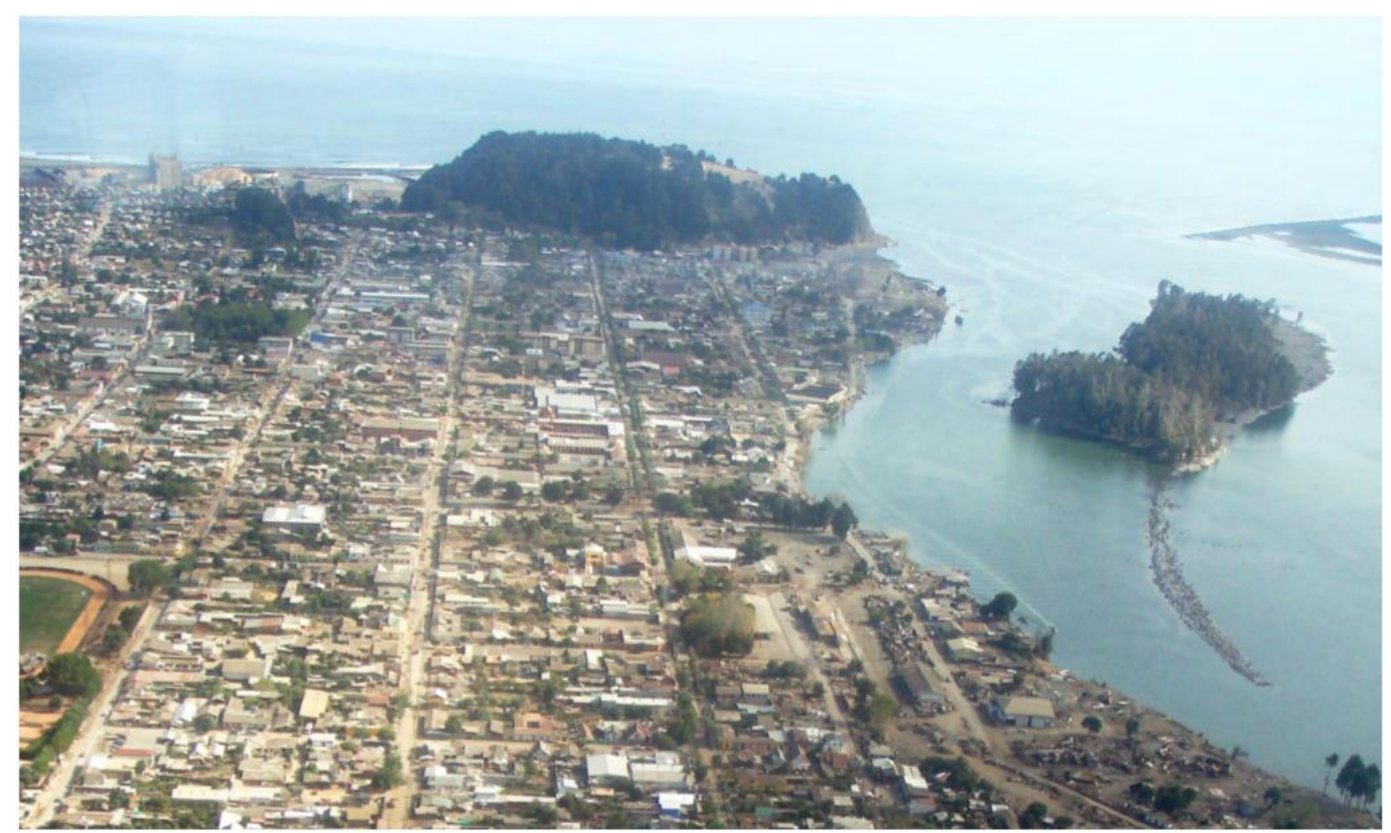

Fig. 21. Vista aérea de Constitución post 27F, 2010. En la imagen tomada hacia el nor-oeste se observa el plano de ciudad parcialmente destruido por el ingreso del tsunami a través de la desembocadura del río Maule, el cual previamente arrasó con la infraestructura turística de Isla Orrego, que aparece a la derecha de la imagen. Parte de los habitantes ubicados en la zona afectada lograron resguardarse en el cerro Mutrún, que se observa en la parte superior, al centro de la fotografía.

Fuente: PRES (2011). 
EI PRES de Constitución surge con la finalidad de orientar la toma de decisiones respecto a los diversos desafíos de reconstrucción que debía enfrentar uno de los centros urbanos más afectados por el tsunami de Febrero de 2010. Tal como señala MINVU (2011), los principales objetivos del plan se vinculaban con asignar los subsidios de reconstrucción y reparación de viviendas; priorizar obras y proyectos de reconstrucción de infraestructura; establecer criterios de inversión a largo plazo y de planificación urbana; incentivar el desarrollo económico, social y ambiental e incorporar instancias de participación ciudadana para consensuar y legitimar la toma de decisiones.

Esta iniciativa nace a partir de un convenio de cooperación firmado por diferentes entidades participantes del ámbito público y privado, dirigido originalmente a desarrollar una cartera de proyectos para guiar la reconstrucción de la ciudad en un horizonte temporal de ocho años. No obstante, dado que el PRES se inserta en un contexto comunal donde el principal instrumento de planificación territorial, como es el Plan Regulador Comunal, databa del año 1987, debió contemplar adicionalmente una serie de estudios técnicos asociados principalmente a determinar zonas de riesgo y a modelar escenarios de inundabilidad para estimar los efectos del tsunami en los nuevos proyectos propuestos.
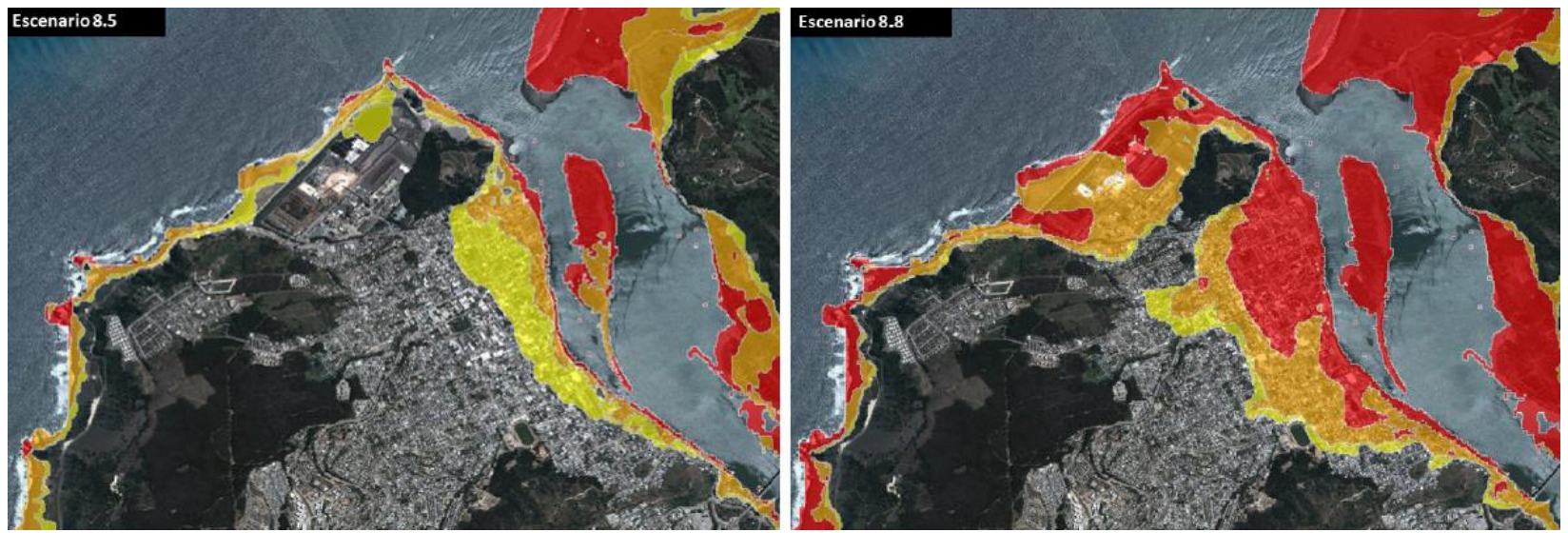

Fig. 22. Zonas de riesgo de Constitución, determinadas por el estudio de riesgos y modelación de tsunami desarrollado de manera paralela al PRES, por el geógrafo Marcelo Lagos. En las imágenes se observa la modelación de los efectos de tsunami, con escenario de un evento de terremoto tsunamigénico grado 8.5 (izquierda) y grado 8.8 . (derecha). Se observan en rojo las áreas severamente dañadas por el fenómeno de inundabilidad por tsunami - derivado del evento de mayor magnitud - que abarcan a prácticamente toda la ciudad.

Fuente: PRES (2011) y Lagos (2010).

El conjunto de decisiones tomadas en el PRES, asociadas al proceso de planificación territorial post desastre en Constitución, se organiza a través de una matriz de 5 ejes estratégicos -Infraestructura, Espacio Público y Equipamiento, Vivienda, Diversificación Económica y Energía- que busca abordar de forma integral todos los aspectos relevantes para la reconstrucción de la ciudad (PRES, 2011), las cuales son conformadas por una serie de planes específicos y proyectos que buscan darle una estructura tangible. Por su parte, los proyectos que componen la matriz apuntan a recuperar el reconocimiento del río Maule como elemento estructurador de la ciudad, hacerse cargo del riesgo de tsunami e inundaciones periódicas, mejorar los 
espacios públicos, lograr una diversificación económica potenciando el turismo y la producción maderera ${ }^{32}$ y, avanzar en la línea de la sustentabilidad a través de la incoporación de energías renovables y la gestión de residuos.

Como se observa en la figura 23 , el ensamblaje espacial que asocia los planes de movilidad, gestión hídrica (aguas lluvias) y mitigación de tsunamis (plan antimaremoto) configuran una superestructura a escala urbana, la cual a su vez integra -en un segundo componente de innovación- la noción de infraestructura verde para atender los requerimientos de drenaje urbano, reducción de riesgo y conectividad. El resultado de esta combinación define una pieza conformada por un gran corredor verde que se plantea en la franja de borde, empezando en la costa y continuando hacia la ribera del Maule, desde el cual se proyectan corredores transversales que conectan espacial y funcionalmente las zonas altas y las áreas del plano urbano.

De esta manera, aun cuando no es explícitamente mencionado, el enfoque de infraestructura verde multipropósito en el PRES de Constitución se evidencia en la gestión integrada de estas carteras de proyectos, destacando dos aspectos:

- En primer lugar, mediante la planificación y diseño integrado de las infraestructuras de drenaje urbano, movilidad y mitigación de tsunamis, se busca a amplificar y diversificar la prestación de servicios ecosistémicos que cada uno de estos componentes genera, concibiéndolos como parte de un sistema de espacios abiertos de uso público, que optimiza la rentabilidad de esa infraestructura.

- En segundo lugar, como se verá en detalle más adelante, otorga prioridad a soluciones basadas en la integración de componentes paisajísticos asociados a sistemas de vegetación pre-existentes y emergentes, combinados con operaciones de manejo topográfico y con soluciones de ingeniería convencional, promoviendo de esta forma la integración de patrones y procesos híbridos orientados a conformar una infraestructura compleja para la mitigación de impactos de desastres.

\footnotetext{
32 En la definición de la matriz de proyectos se evidencia la influencia ejercida por la empresa forestal Arauco para considerar iniciativas orientadas a potenciar a Constitución como ciudad maderera. Destaca en este sentido, dentro del eje de diversificación económica, la propuesta de generar un cluster de la madera y también la incorporación de la madera en la construcción de equipamiento público.
} 

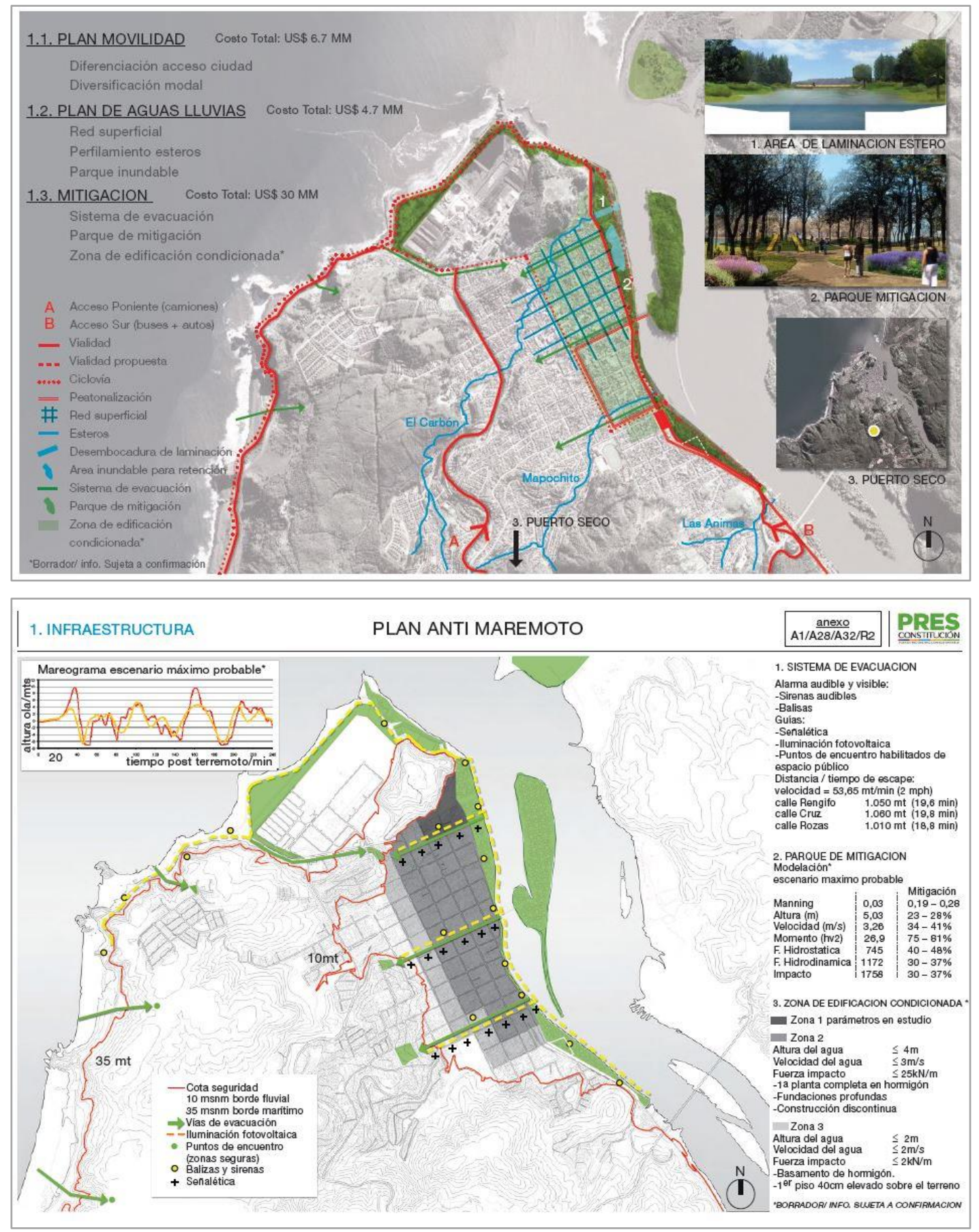

Fig. 23. PRES Constitución, Plan de Infraestructura Urbana. Se observa la integración de los planes sectoriales de movilidad, gestión hídrica y mitigación de tsunamis, en un sistema articulado de infraestructura verde a escala urbana que posiciona al río Maule y sus espacios de ribera como elemento estructurador de la ciudad.

Fuente: PRES (2011)

En términos de diseño, el plan establece por un lado la integración espacial de las redes de drenaje urbano, movilidad y espacio público, mediante el reconocimiento de 
corredores proyectados desde las zonas altas (al oeste) y las zonas bajas hacia el río (este), jerarquizando determinados ejes del trazado urbano que al mismo tiempo sirven para conducir las escorrentías y demarcar las vías de evacuación en caso de tsunami. En la llegada al borde fluvial, estas escorrentías son laminadas mediante lagunas inundables, concebidas como parte del espacio público. Por otro lado, en relación a las estrategias de reducción de riesgo hacia el borde fluvial, el plan establece una franja de amortiguación que denomina Parque de Mitigación, articulando desde un punto de vista conceptual y operativo la dimensión de infraestructura de protección con la dimensión de espacio público. Este parque - que desde un punto de vista espacial y funcional puede comprenderse como un corredor verde que conecta longitudinalmente las áreas del borde costero del norte del territorio, con las zonas ribereñas del río Maule hacia el sur - reivindica también la condición de reclamación de este espacio abierto, históricamente significativo para una cultura ligada al paisaje del agua de este estuario.

\subsection{Estrategias, técnicas y operaciones de diseño de los Parques de Mitigación como infraestructura de reducción de riesgos y reclamación del paisaje costero}

En el marco de los planes de reconstrucción post tsunami de 2010, la propuesta de los Parques de Mitigación emerge como reflexión vinculada directamente a proveer de espacios de amortiguación para disipar parte de los efectos generados por el impacto de las olas, con el objetivo de favorecer, por un lado, los tiempos de evacuación de la población hacia zonas altas de seguridad y, por otro, de reducir los daños a la propiedad pública y privada. Asimismo, este nuevo enfoque de infraestructura integra la noción de parque como estrategia que reflexiona sobre las condiciones de habitabilidad en los bordes expuestos a riesgos de desastres, definiendo nuevas posibilidades de encuentro social entre la ciudades litorales y los paisajes costeros que, en rigor, remiten a la idea de reclamación de un paisaje que fue progresivamente ocupado, privatizado y subvalorado en su dimensión cultural y ecológica.

Desde una visión de infraestrutura multipropósito, según lo ya señalado, la estrategia de hibridar el concepto de infraestructura de mitigación con la idea de parque otorga la posibilidad de optimizar la inversión pública mediante proyectos que apuntan a compatibilizar los objetivos de seguridad y reducción de riesgos, con la necesidad de mejorar la dotación de espacios públicos de calidad, en localidades que presentaban importantes déficit en esta materia, de manera previa al desastre. 

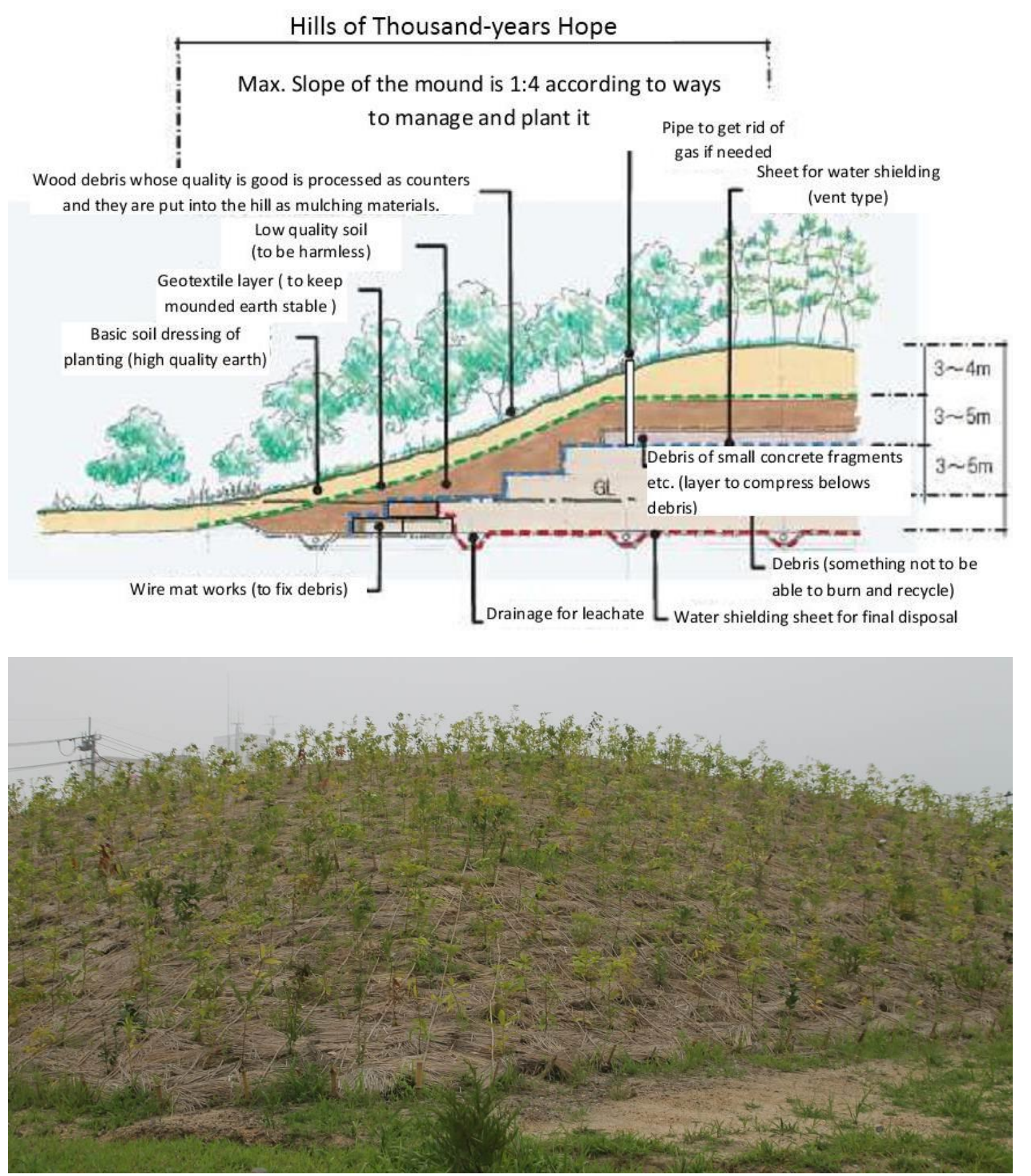

Fig. 24. Bosque de mitigación en la ciudad costera de Iwanuma, Japón. El proyecto forma parte del plan de reconstrucción urbana, post tsunami de 2011. Como se observa en la sección de abajo, el bosque se desarrolla sobre un sistemas de colinas artificiales levantadas a partir de la acumulación de escombros generados por el tsunami, los cuales son estabilizados y luego cubierto por tierra vegetal apta para recibir las plantaciones de árboles.

Fuente: Reconstruction Plan for Iwanuma, en Renaud \& Murti, 2013.

Aun cuando en las descripciones del PRES y del propio Parque de Mitigación de Constitución no se alude directamente a la revisión de casos de estudio de referencias 
o buenas prácticas, la propuesta planteada se puede conectar con experiencias de infraestructuras de mitigación basadas en sistemas de bosques costeros, los cuales constituyen una tradición centenaria en Japón (Tanaka, 2010) y se han utilizado también en diversos contextos litorales a nivel internacional. Como señala Forbes \& Broadhead (2008), las investigaciones sobre el rol de los bosques costeros se incrementaron a partir del tsunami de diciembre de 2004, el cual afectó gravemente las costas de diversos países en el océano Índico ${ }^{33}$. En esos contextos, mediciones realizadas en zonas pobladas que aún conservaban ecosistemas de manglares y bosques litorales demostraron la efectividad ${ }^{34}$ para reducir las fuerzas de impacto y velocidades de flujo, lo que a su vez limitó la extensión de las inundaciones (Op.cit), situación similar a lo observado con la acción de los humedales en el caso de la localidad de Arauco para el tsunami de 2010, como se señaló anteriormente.

En el caso de Japón, los bosques costeros se desarrollan como infraestructura de protección ante eventos climáticos y de mitigación de desastres en zonas costeras desde el siglo XVII (Tanaka, 2010). Si bien en general no contemplan programas de uso público que los asocien a la idea de parque, la larga historia que los precede les otorga una importancia a nivel cultural e identitario para las comunidades, las cuales se han ocupado de gestionar su conservación en el tiempo. A su vez, la ley forestal japonesa establece que los bosques de mitigación deben plantarse en toda la línea litoral para prevenir daños ante desastres. En esa línea, el gobierno estableció que la replantación post-tsunami del 2011 fuese una estrategia prioritaria en las medidas ambientales para la reducción de riesgos, complementándose con otras soluciones estructurales de ingeniería convencional (Renaud \& Murti, 2013). De acuerdo a lo que plantean diversos autores (Renaud \& Murti, 2013; Tanaka, 2010; Forbes \& Broadhead, 2008), la acción de estas infraestructuras verdes ante los impactos de tsunami se basa en la disipación de energía y pérdida de la energía hidrodinámica, en contraposición a la contención limitada que otorgan ciertas medidas estructurales, las cuales por sí solas colapsan debido a la magnitud de los fenómenos a los que enfrentan.

\subsubsection{El caso de Constitución: prototipo de Parque de Mitigación}

En Chile, el punto de partida de esta nueva tipología de infraestructura se genera a partir de la formulación del PRES de Constitución, concibiendo la noción de Parque de Mitigación como proyecto emblemático de la reconstrucción de la ciudad. La superficie propuesta para el parque es la resultante de la aplicación de los criterios de zonificación de riesgo, a partir del estudio modelación de los efectos de tsunami (Lagos, 2010), transformándose también en una estrategia para asegurar la condición de Bien Nacional de Uso Público ${ }^{35}$, logrado mediante un proceso de expropiación

\footnotetext{
${ }^{33}$ El tsunami de 2004, que afectó las costas de Indonesia y Sri Lanka,, se generó a partir de un terremoto grado 9.1, cobrando más de 200.000 víctimas fatales (Forbes \& Broadhead, 2008).

${ }^{34}$ La acción disipadora de los bosques, según Forbes \& Broadhead (2008), dependerá de la idoneidad del sitio para el crecimiento de los árboles, la elevación del suelo y la pendiente de la costa que determina la forma y la fuerza de las olas de altura similar. También serían necesarias distancias de retroceso adecuadas, lo suficientemente grandes como para incorporar el bosque costero

${ }^{35}$ Los Bienes Nacionales de Uso Público (BNUP) constituyen en Chile una catergoría de dominio establecida en el artículo 589 del Código Civil y en la Ley General de Urbanismo y Construcciones, que los define como aquellos
} 
destinado a protegerlo de ocupaciones irregulares. El área dispuesta, que abarca 15 hectáreas, se ubica en paralelo al río Maule en una extensión de casi 3 kilómetros, con un ancho que varía entre los 90 metros, en su parte norte y los 15 metros, en su tramo central.

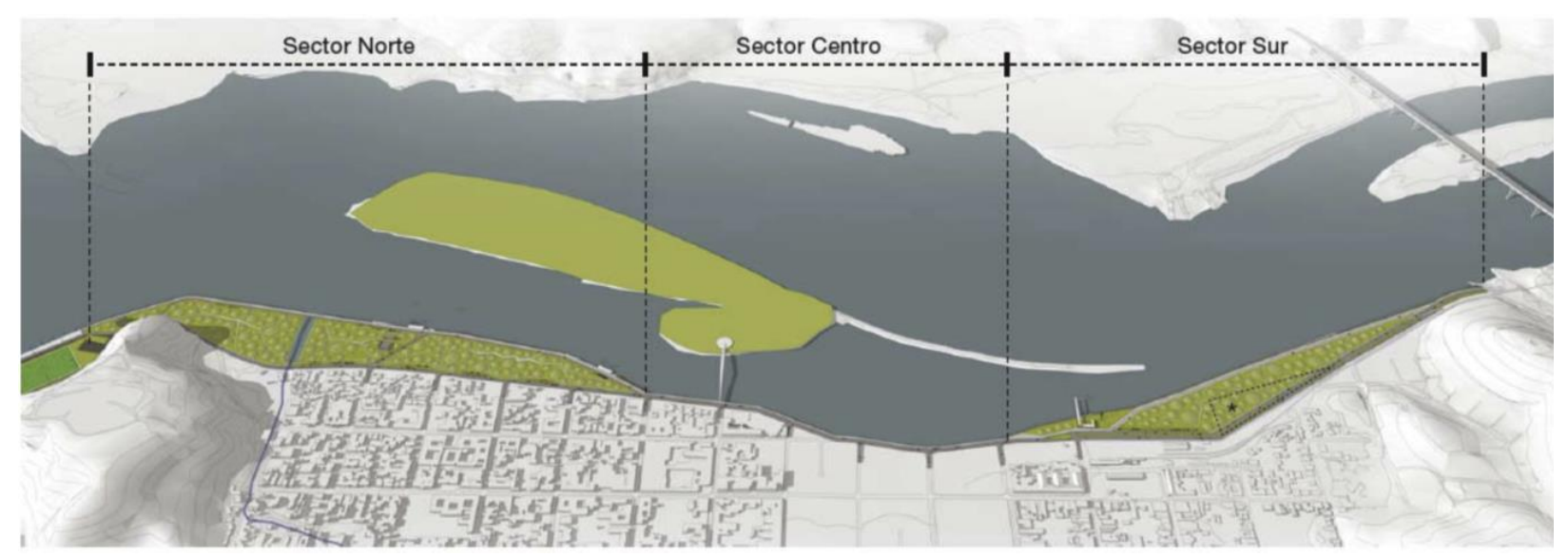

Fig. 25 Parque de Mitigación de Constitución. Sectores de intervención propuestos para el desarrollo del proyecto, totalizando 15,23 hectáreas en el borde fluvial y 19,8 hectáreas en isla Orrego.

Fuente: MINVU (2011a)

En relación al componente de mitigación, la propuesta discute la tradicional aproximación de la infraestructura basada en la creación de barreras que intentan contener impactos de desastres, planteando el concepto de disipación del impacto mediante la descomposición de los vectores de fuerza mediante el uso de un sistema combinado de componentes naturales y construidos conformado principalmente por:

1) movimientos topográficos que aumentan la rugosidad del suelo y generan zonas de inundabilidad controlada ante el ingreso del tsunami;

2) agrupaciones de vegetación, principalmente asociaciones de arbolado que combinan especies de raíces pivotantes y extendidas, que afianzan el terreno y absorben parte del empuje de la masa de agua;

3) defensas construídas, que pueden contemplar muros, gaviones o enrocados, dispuestas en alineaciones que refuerzan zonas críticas.

En suma, el diseño de los componentes de topografía, vegetación y defensas construidas son planteadas como un sistema interdependiente y sinérgico, que opera de manera conjunta para disminuir el impacto del tsunami en su entrada al continente. Desde un punto de vista hidráulico, estas soluciones apuntan a generar una mayor rugosidad en la superficie de desplazamiento del fluido en su recorrido desde el mar hacia la ciudad, aumentando así el roce. Se intenta con ello disminuir por un lado su volumen -asociado a la altura de los niveles de inundabilidad, también denominada run-up- y por otra parte su velocidad, vinculada con la necesidad de otorgar mayor margen temporal para la evacuación de las zonas que se verán

pertenecientes a toda la nación, sin perjuicio que su administración y mantención recaiga sobre determinadas entidades específicas. Para que un proyecto de parque sea financiado por el estado, debe estar localizado en un BNUP. 
afectadas. El manejo de ambos factores contribuye además a disipar el momento de flujo, relacionado con la fuerza destructiva del tsunami al impactar una determinada zona poblada.

Al propagarse un tsunami en aguas someras cada vez menos profundas, y por sobre todo, durante la etapa de inundación, la resistencia de la superficie a través de la cual se desplaza se vuelve cada vez más relevante como elemento de disipación (JICA, 2018; Lagos, 2012; Kotani et al., 1998). Este factor de roce se incluye en los esquemas de modelado numérico a través de un término específico, el cual habitualmente se basa en el coeficiente de Manning ${ }^{36}$ para el cálculo de la pérdida de energía por fricción con la superficie de suelo o fondo. Se puede señalar entonces, que a mayor rugosidad de la superficie base, mayor será la disipación del tsunami en términos de su velocidad, volumen y fuerza de impacto. Según Kotani et al. (1998), el coeficiente de rugosidad estimado para tipos de usos de suelo de áreas verdes urbanas convencionales -con presencia de una baja densidad de vegetación y escasa variación topográfica- es de alrededor de 0.15. En cambio, para los bosques de mitigación -con alta densidad de vegetación- puede llegar a 0.25 o más. Si a ello se suman barreras construidas, como muros de contención y enrocados, el coeficiente aumentará.

En relación a estos parámetros, la Guía para la selección de coeficientes de rugosidad de Manning, para cursos naturales y planicies inundables ${ }^{37}$ preparada por U.S. Geological Survey Water-Supply, establece una serie de criterios técnicos, recomendaciones de cálculo matemático y referencias de casos para incorporar soluciones de mitigación de inundaciones a través de la acción de la vegetación. De forma pionera, esta guía determina de manera gráfica y didáctica la apariencia deseable de bosques de mitigación, mediante la ejemplificación de situaciones reales de densidades vegetacionales existentes en estado natural, que fueron sometidas a fenomenos de inundaciones extremas, en ambientes de clima templado y mediterráneo propios de ambas costas de norteamérica.

A continuación, se presenta una secuencia de dos imágenes, relacionadas cada una con un determinado coeficiente de rugosidad de Manning.

\footnotetext{
${ }^{36}$ El modelo de Manning, o coeficiente de Manning, fue propuesto por el ingeniero irlandés Robert Manning en 1889, para calcular la velocidad del agua y el roce en su desplazamiento, aplicado inicialmente a los flujos hidricos en canales abiertos y tuberías. La expresión matemática del coeficiente de Manning es:

Donde,

$$
V=\frac{1.486}{n} R^{2 / 3} S_{e}^{1 / 2}
$$

$V$ (velocity) es la velocidad del flujo (medida en metros por segundo o pies por segundo)

$R$ (Radius) es el radio hidráulico, en metros o pies

$S_{e}$ (Slope) es pendiente de la línea de grado de energía, en metros o pies

$n$ es el coeficiente de rugosidad de Manning.

Actualmente, esta fórmula es utlizada para estimar la pérdida de energía de un tsunami a medida que avanza sobre el fondo de la costa (JICA, 2018; Kotani et al., 1998).

37 Traducido de Guide for Selecting Manning's Roughness Coefficients for Natural Channels and Flood Plains, editada en 1989 por George Arcement y Verne Schneider para U.S. Geological Survey Water-Supply.
} 

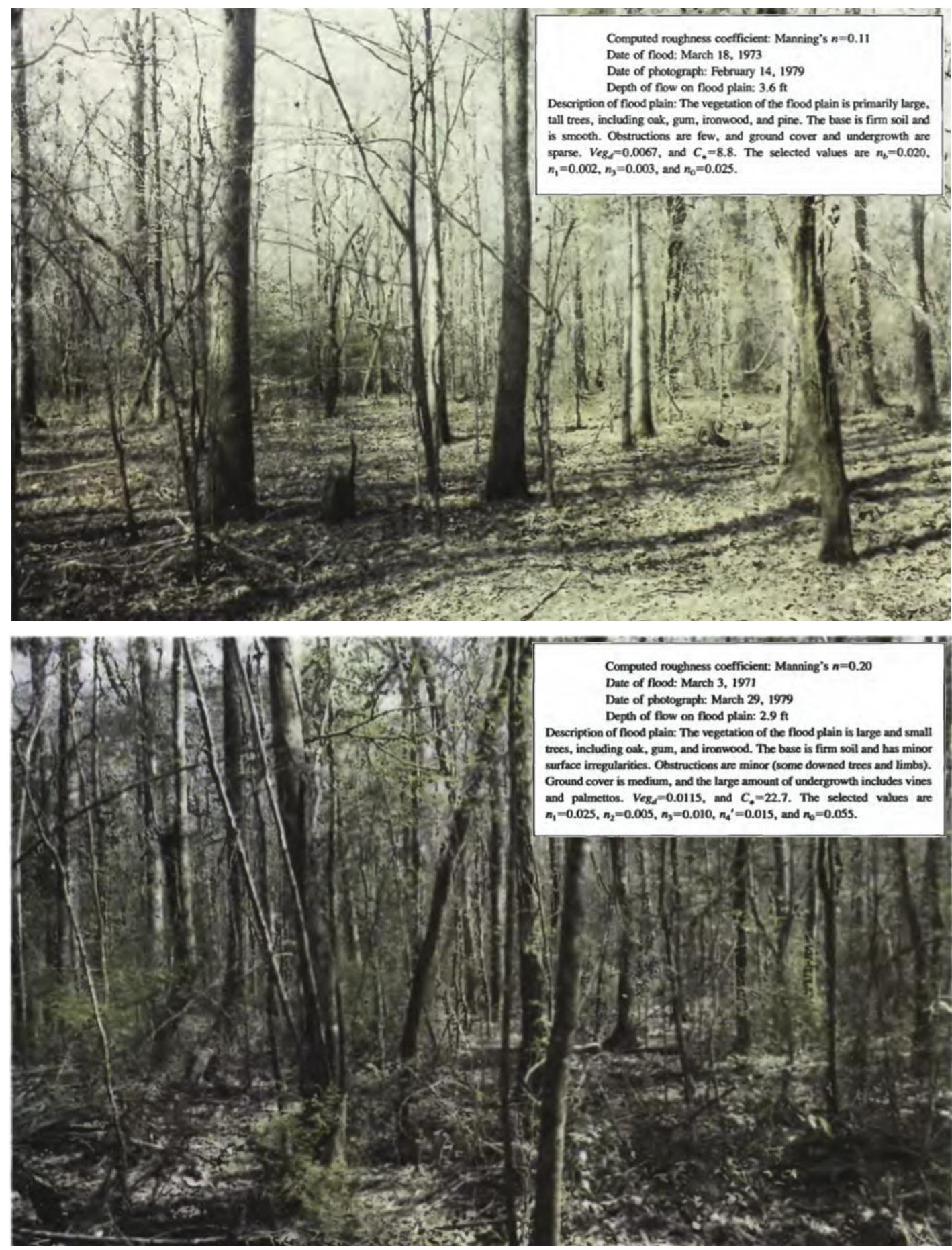

Fig. 26. Estudio de casos para determinar coeficiente de rugosidad de Manning, a partir de dos situaciones de densidades vegetacionales expuestas a inundabilidad. En la imagen superior, el coeficiente de Manning alcanza un valor de 0.11; abajo, alcanza un valor de 0.20. Fuente: Arcement \& Schneider (1989). 
Bajo estos lineamientos se desarrolla una primera versión de proyecto a cargo de Elemental, según la imagen que se presenta a continuación:

\section{ESPACIO PUBLICO Y EQUIPAMIENTO PARQUE FLUVIAL Y COSTANERA}

$\frac{\text { nexo }}{\mathrm{A} 2} \mid \underset{\text { Ponstimución }}{\text { PRES }}$

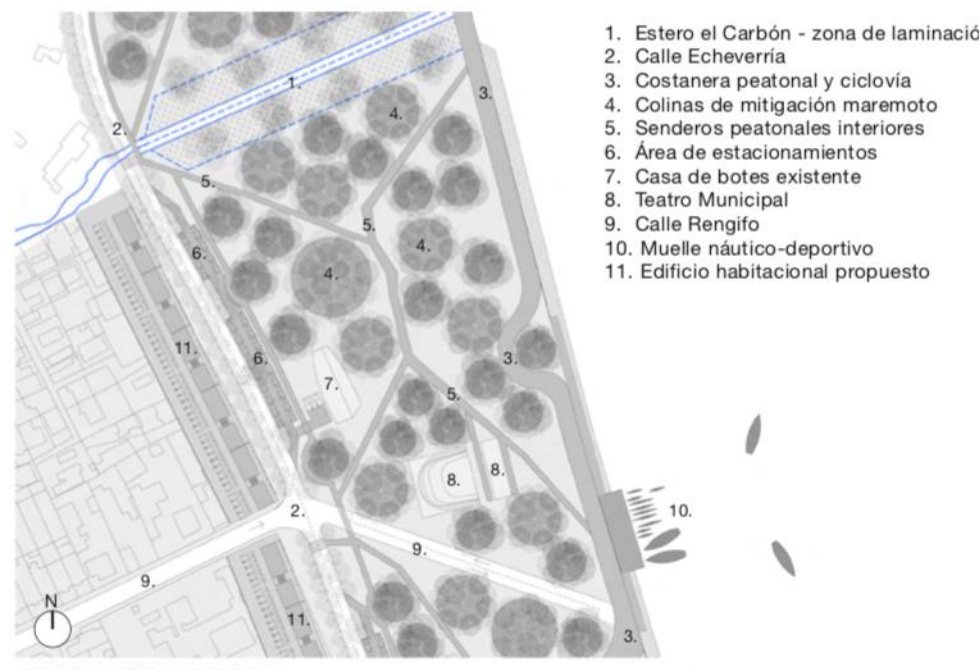

a de laminación

(nes

Casa de botes existente

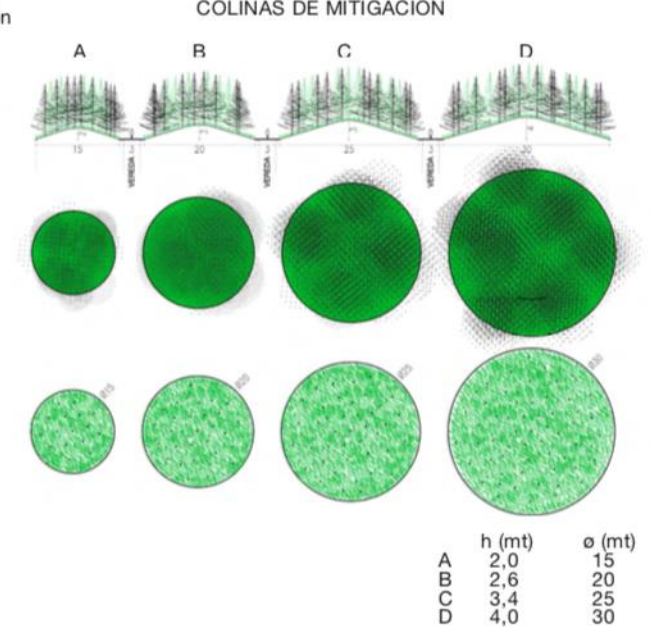

PLANTA DETALLE PARQUE
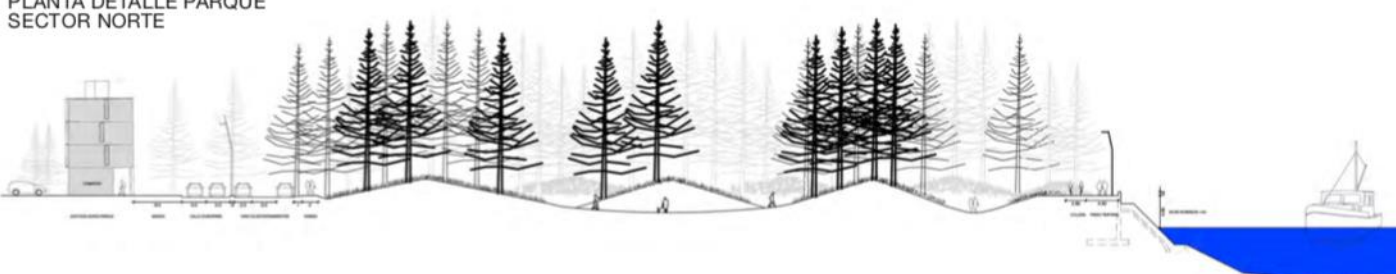

CORTE TIPO

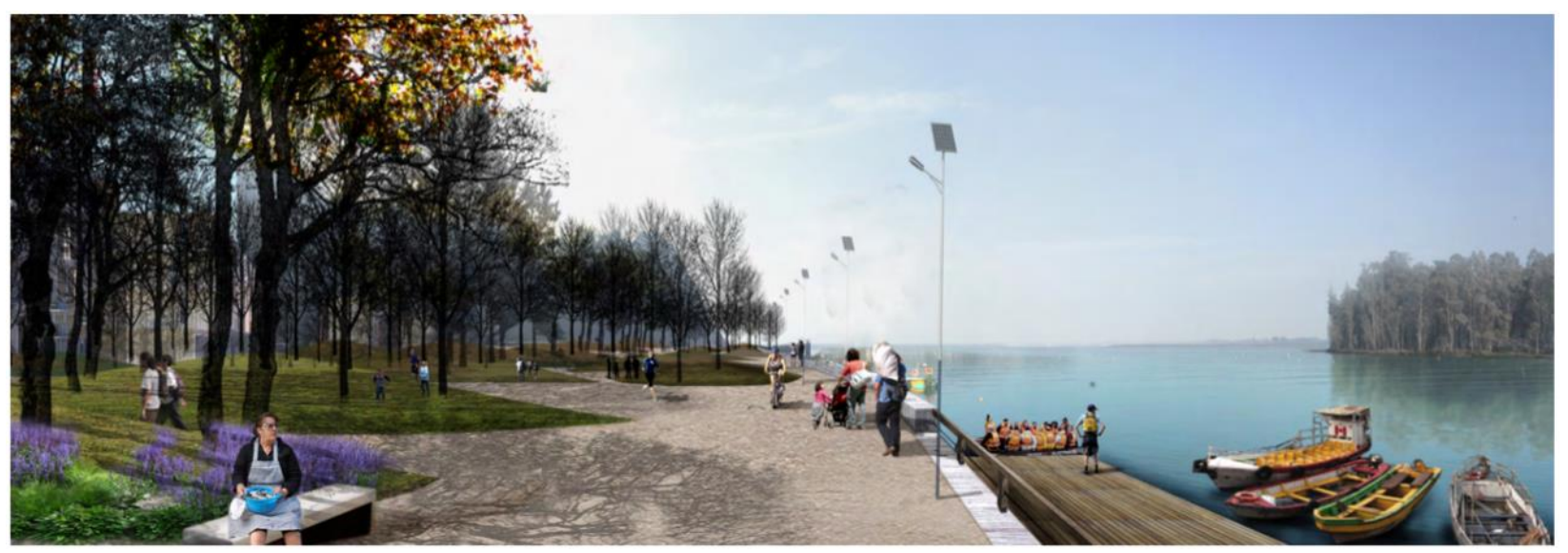

Fig. 27. Anteproyecto del Parque de Mitigación en Constitución, en el marco del PRES. En la parte superior se observa una planta y sección tipo, caracterizada por el modelamiento topográfico, mediante colinas de mitigación que a su vez contienen las plantaciones de bosques, en densidades de 2000 ejemplares por hectárea. En la sección y en la perspectiva se observa también la construcción de defensas fluviales en la costanera, que al mismo tiempo funciona como estructura de paseo y equipamiento náutico. Fuente: PRES (2011). 
Siguiendo los lineamientos establecidos por el diseño preliminar, el proyecto definitivo ${ }^{38}$ se concibe entonces a partir de un sistema infraestructural conformado por la combinación de tres tipos de componentes: soluciones estructurales asociadas a elementos construidos; soluciones topográficas determinadas por operaciones alternadas de rellenos y excavaciones y, por último; soluciones ecológicas relacionadas con la configuración del bosque de mitigación y la cobertura vegetacional del nuevo suelo resultante.

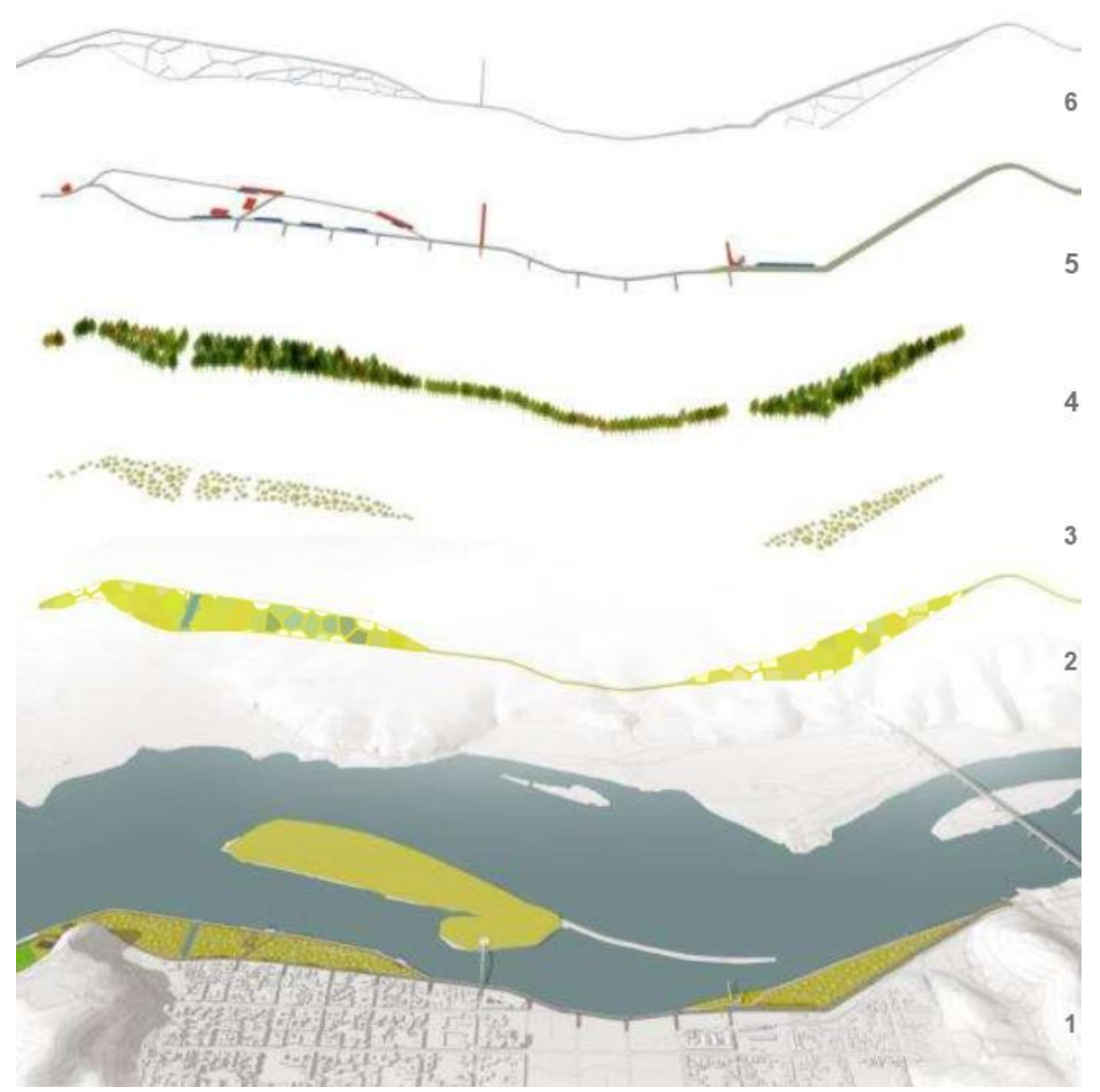

Fig. 28. Diagrama axonométrico del Parque de Mitigación de Constitución. Desde abajo hacia arriba se indican: 1) Situación base del parque en el borde fluvial de la ciudad, incluyendo la isla Orrego; 2) Áreas de manejo topográfico para la elevación de colinas; 3) Cobertura de vegetación para fitoestabilización de suelos; 4) Formaciones de vegetacion árborea; 5) Programas jerarquicos: capitanía de puerto, mercado fluvial y muelles; 6) Infraestructura de defensa fluvial y sistema de circulaciones del parque. Fuente: Elaboración propia en base a MINVU (2011a).

38 El concurso de licitación para la elaboración del proyecto definitivo se adjudica a grupo Moebis, oficina de arquitectura e ingeniería que trabaja durante los años 2012 y 2013 en el diseño de arquitectyra, paisajismo y especialidades del Parque de Mitigación (SERVIU, 2013). 
Respecto a las soluciones estructurales implementadas en el proyecto, cabe señalar que éstas conforman la primera capa del sistema de defensa hacia el río, amortiguando por tanto los aumentos de volumen y velocidad del caudal en el frente fluvial, ya sea en escenarios de crecidas estacionales del río Maule, o en eventos extremos de tsunamis. Sus componentes más importantes, que pueden identificarse en los planos y las imágenes siguientes, son:

- Escollera de protección, también denominada enrocado por su construcción a partir de la disposición de grandes rocas en forma de talud, destinada a evitar que las avenidas del río puedan erosionar las bases de apoyo de la estructura perimetral del parque -determinada por el muro de contencióncomprometiendo su estabilidad.

- Muro de contención, ubicado a continuación de la escollera, que delimita el perímetro del parque y su área de uso hacia el río, confinando a su vez el relleno que se requiere para implementar luego las variaciones topográficas que define el proyecto.

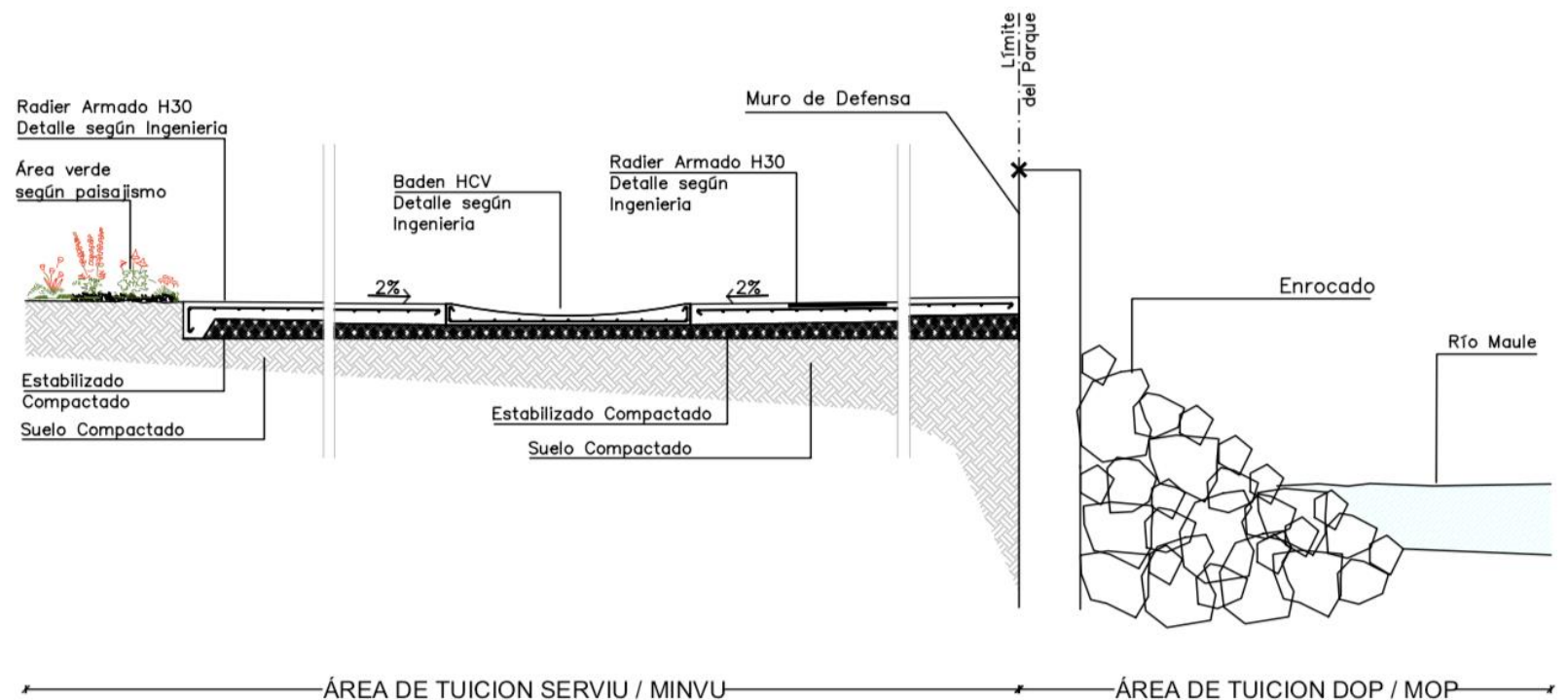

Fig. 29. Sección tipo de las soluciones estructurales para la defensa fluvial. De izquierda a derecha se observa la escollera, el muro de contención y luego el área pavimentada del paseo de la costarena. Se indica también el área tuición -que indica el ámbito de responsabilidad en el diseño y ejecución- que le compete al Servicio de Vivienda y Urbanismo de MINVU, en la zona terrestre, y a la Dirección de Obras Portuarias de MOP, en la zona fluvial, respectivamente.

Fuente: Elaboración propia en base a SERVIU Región del Maule (2013).

Por otra parte, las soluciones topográficas corresponden a aquellas operaciones destinadas a generar un relieve rugoso en la superficie del parque, con el objetivo de aumentar el roce del flujo de la masa de agua que ingresa, para así disminuir su velocidad y fuerza. De esta forma, el suelo del parque se transforma en un sistema de suelos ondulados, que se inspira en la acción de los sistemas dunarios y su rol disipador ante la acción de avance de las mareas. Sus principales componentes, que se expresan graficamente en las siguientes figuras, son: 
- Colinas de mitigación, conformadas por elevaciones del terreno que se diseñan con alturas que fluctuan entre los 2 y 4 metros de altura, generando una pendiente de laderas en torno al $25 \%{ }^{39}$. El relleno necesario para la conformación de las colinas se establece mediante una base de tierra compactada, la cual se cubre con una capa vegetal de fitoestabilización constituida con cubresuelos y especies arbustivas bajas.

- Depresiones topográficas, que acentúan la sinuosidad del relieve del parque e incrementan el efecto de roce mediante sustracciones de terreno en diversos sectores. A su vez, estas operaciones favorecen el drenaje y retención de aguas lluvias provenientes de la ciudad, así como tambien la retención de inundaciones generadas por el aumento del caudal del río.

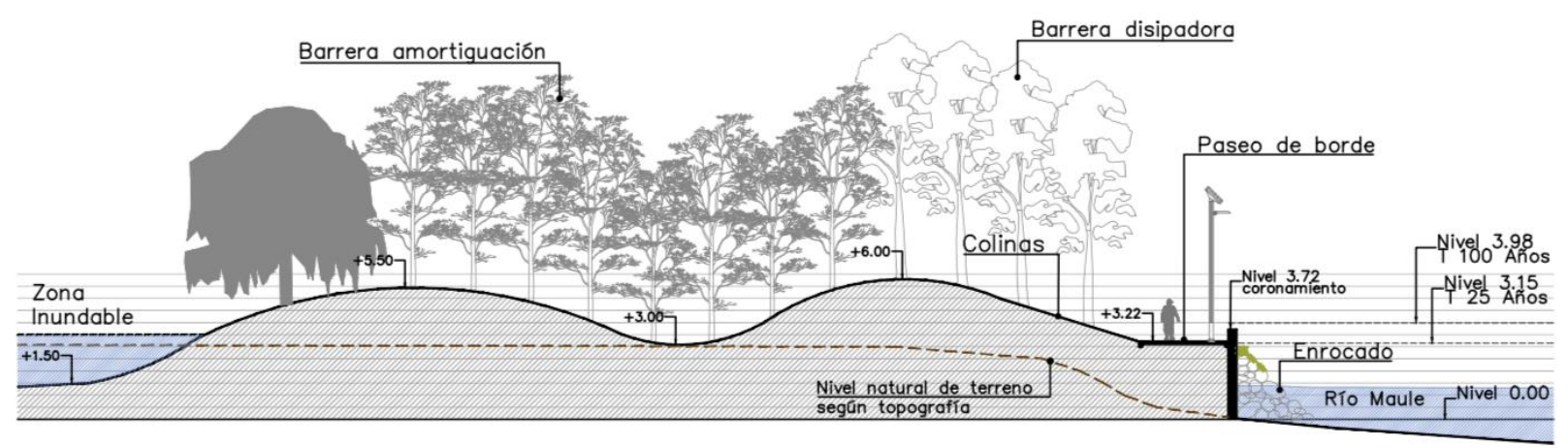

Fig. 30. Sección tipo de las soluciones topográficas para la mitigación del tsunami mediante roce. Se observa la disposición de las colinas y áreas de depresión para inundabilidad controlada.

Fuente: Elaboración propia en base a SERVIU Región del Maule (2013).

Las soluciones ecológicas se definen a partir del diseño de sistemas de vegetación destinados a reducir la energía del tsunami. Para ello, la configuración de bosques en agrupaciones de arbolado con alta densidad de plantación permite disipar el momento de flujo o fuerza de impacto, ya disminuido por la acción de la defensa fluvial y la rugosidad de las colinas. Asumiendo que no se evidencian registros de la existencia de ecosistemas de bosque nativo en la zona de intervención, dado el alto grado de antropización que la ribera ha experimentado desde inicios el siglo XIX, se plantea una asociatividad de especies nativas y exóticas seleccionadas tanto para contribuir con el rol de mitigación, como también con la resiliencia y sustentabilidad de la ecología del parque en su conjunto.

\footnotetext{
39 También denominada pendiente de talud 1 a 4: por cada 1 metro de elevación vertical, se requieren 4 metros de longitud horizontal (SERVIU Región del Maule, 2013).
} 


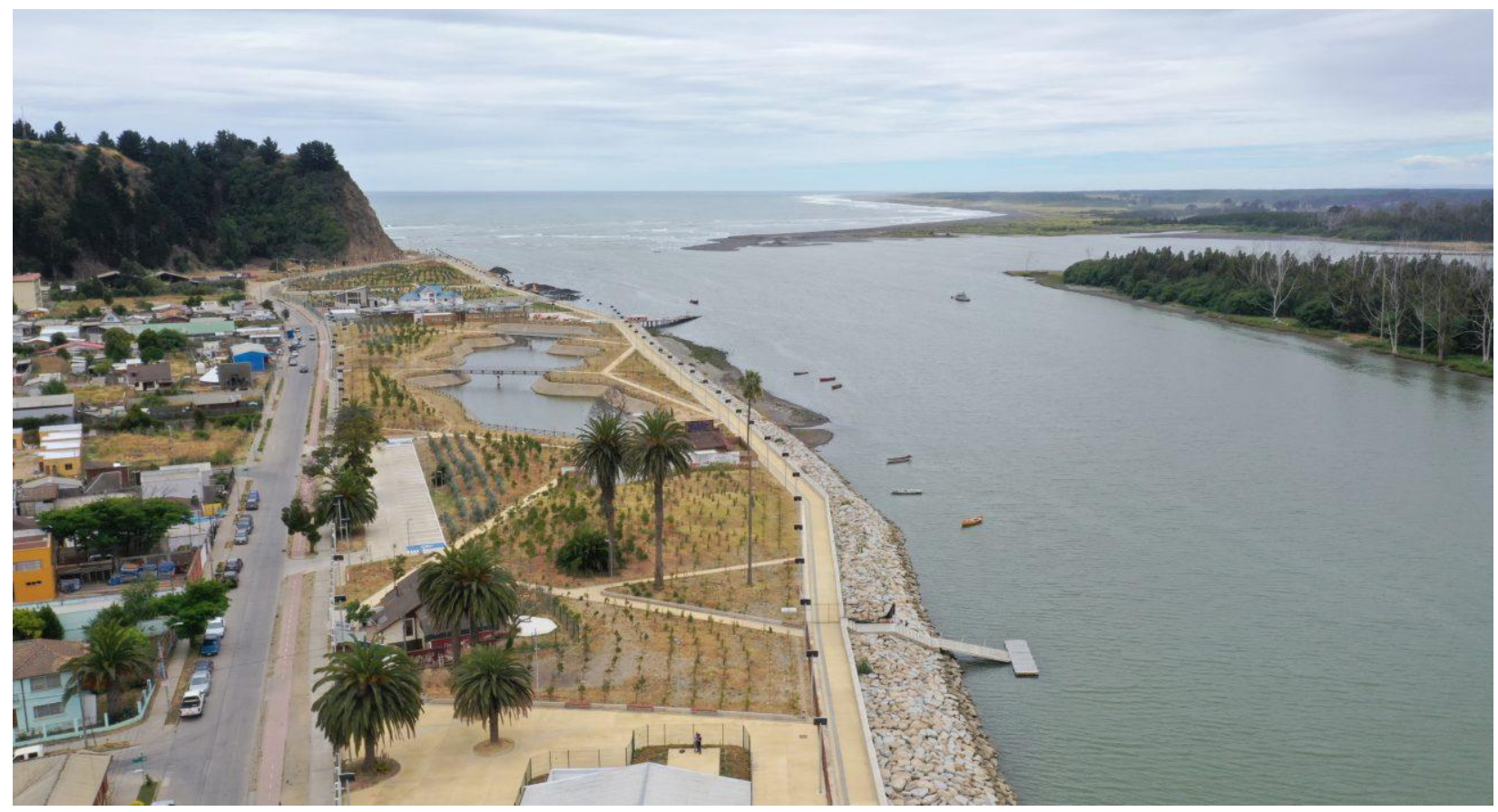

Fig. 31. Vista panorámica del sector norte del Parque de Mitigación de Constitución en fase avanzada de ejecución, donde se observan las soluciones esructurales y topográficas del Parque, anteriormente descritas.

Fuente: Autor (2019).

Además de considerar las recomendaciones generales asociadas a las características de la estructura de raíces, fuste y ramaje del arbolado, establecidas en los términos técnicos de referencia (SERVIU Región del Maule, 2013), puede reconocerse que el bosque de mitigación se estructura en 3 capas secuenciales conformadas por los siguientes componentes:

- Franja verde de disipación, configurada en la primera línea del bosque hacia el frente fluvial. Contempla una densidad de plantación de 1200 árboles por hectárea, utilizando especies resistentes a la brisa salina proveniente del estuario. Para ello se definen alineaciones de Tamarix pentandra, especie halófita propia de zonas ribereñas que forma una cortina para proteger de la salinidad a las filas que se encuentren detrás de ellas. Por otra parte, con el propósito de afianzar los suelos y contribuir a una cobertura vegetacional más densa, se considera el uso de diversas especies arbustivas de mediana y baja altura, priorizando asociaciones de arbustos nativos y exóticos de bajo requerimiento de mantención. Especies como Baccharis concava, Margyricarpus pinnatus, Ribes punctatum y Ribes integrifolium, junto con ejemplares de Rosmarinus officinalis y Myoporum parvifolium, colaboran junto al arbolado como primera barrera de retención y dispersión de la fuerza hidrodinámica, aportando además atributos ecológicos de biodiversidad.

- Franja verde de amortiguación, dispuesta a continuación en la segunda línea del bosque. Tiene una densidad de plantación de 1000 ejemplares por hectárea y está formada por Acacia melanoxylon, Eucalyptus globulus y Casuarina 
cunninghamiana. Las dos primeras son especies que se mostraron resistentes al impacto del tsunami y la tercera que se suma, para incrementar la densidad del ramaje, presenta una alta resistencia al viento y la sequía.

- Franja verde de retención, que constituye la tercera capa del sistema y determina además el borde del bosque hacia la ciudad. Contempla también una densidad de plantación de 1000 árboles por hectárea y está formada por alineaciones densas de Cryptocarya alba, Podocarpus salignus, Maytenus boaria, todas especies nativas, a las que se suman asociaciones de Quercus ilex y Quercus suber, propias de zonas costeras de regiones mediterráneas de clima templado. Esta franja tiene un importante rol, por la estructura y forma de las especies, en la retención de elementos arrastrados por el flujo, como última barrera. Y, además, define la imagen paisajísitca del parque percibido desde el área urbana.

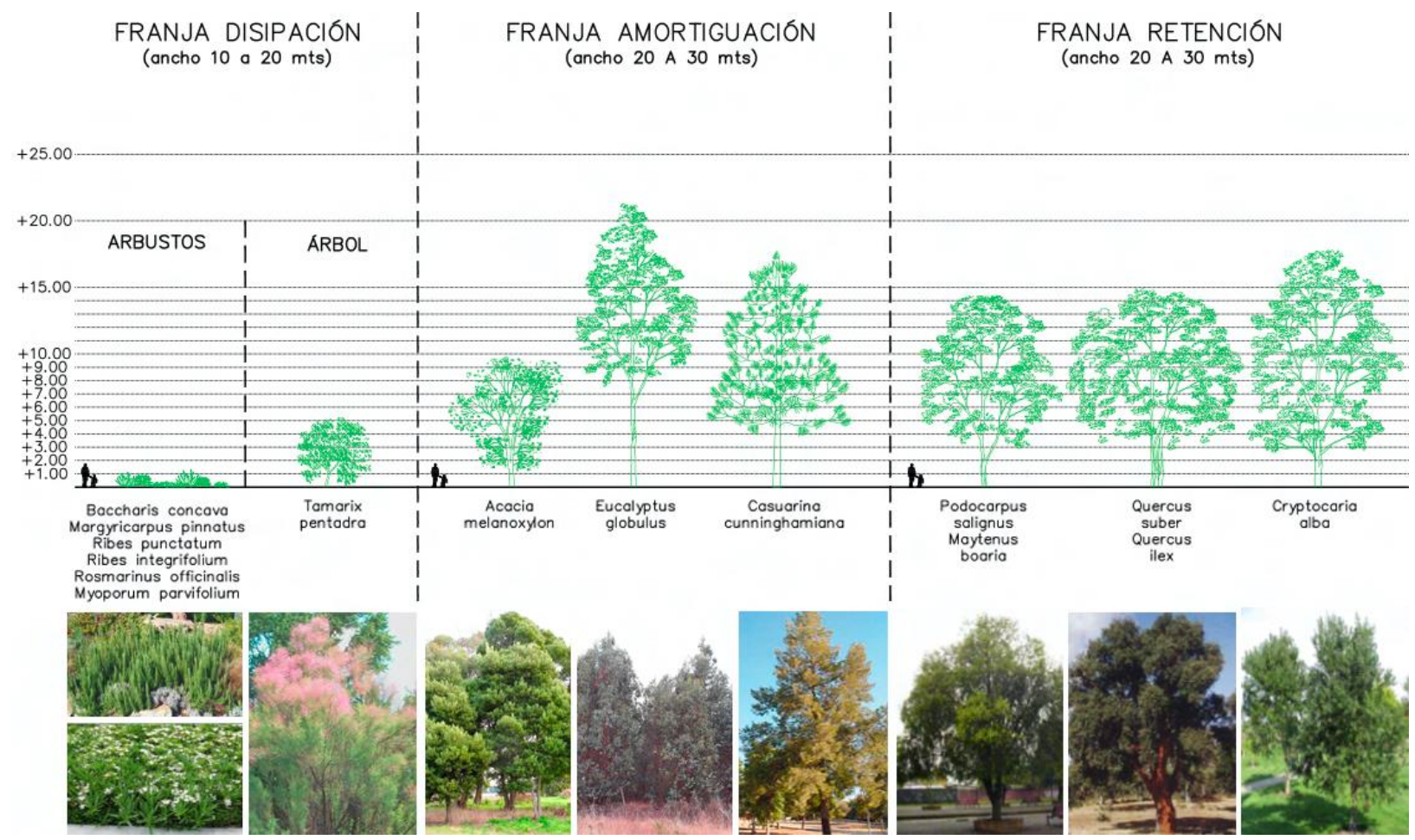

Fig. 32. Esquema de capas secuenciales que conforman el bosque de mitigación. Se observa la magnitud en elevación de las diversas especies propuestas y la complementariedad de densidades de fuste y ramaje. Dado que el parque presenta distintas dimensiones de ancho en su desarrollo longitudinal, el espsor de las franjas va variando según cada tramo.

Fuente: Elaboración propia en base a SERVIU Región del Maule (2013).

Adicionalmente, se propone una cuarta asociación de vegetación se incorpora al bosque, mediante la disposición de bosquetes nativos acompañando el sistema de senderos que atraviesan diagonalmente el parque, conformados por Nothofagus glauca, Luma apiculata, Pitavia punctata y Gomortega keule. Estas agrupaciones, junto con demarcar los ejes de circulación y otorgar biodiversidad al bosque, 
contribuyen a densificar el ramaje en las distintas franjas que lo estructuran. Con el mismo propósito, en torno a las depresiones topográficas que dan forma a las lagunas inundables, se proponen bordes vegetacionales constituidos por Salix humboldtiana.

Para corroborar la efectividad del diseño en el desarrollo del proyecto ejecutivo, el parque se evalúa mediante la modelación de dos escenarios de desastre, considerando la ocurrencia de un evento magnitud $8.5 \mathrm{Mw}$ y $8.8 \mathrm{Mw}$ con epicentro simulado en las costas cercanas a Constitución, utilizando la técnica de modelación numérica de tsunamis ${ }^{40}$. Dentro de los parámetros más importantes, dada su implicancia a nivel de impacto en el sistema urbano-territorial, la modelación permite establecer las alturas de run-up o cota máxima de inundación, así como también las velocidades de ingreso del agua, en una comparación de escenarios sin proyecto y con proyecto (Lagos, 2012). El estudio de evaluación se basa en un valor de coeficiente Manning de 0.23, estimado a partir de la modelación numérica de la rugosidad obtenida por las características del diseño del Parque de Mitigación señaladas anteriormente. Este valor es el resultante de la combinación de densidad de plantación de los árboles, la variación de la rugosidad de la topografía y las condiciones constructivas de la primera defensa fluvial.

La representación gráfica de los escenarios modelados, con los eventos de 8.5 y 8.8 Mw, exhibe el siguiente resultado (figs. 33 y 34 ):
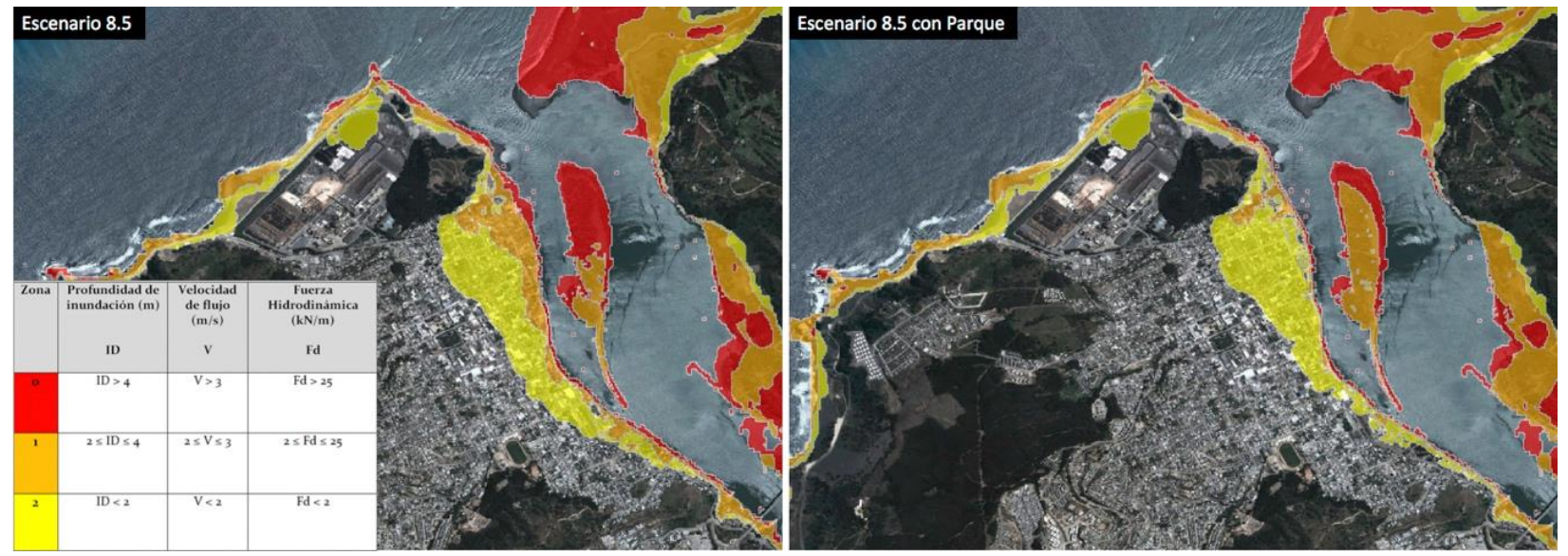

Fig. 33. Modelación escenario de evento 8.5 Mw, que muestra la salida del modelo final de elevaciones de altura de agua para el evento de menor magnitud. En el escenario con Parque de Mitigación, puede observarse una disminución del área inundada en la ciudad, así como también una reducción importante de los valores más críticos (zona 0) en términos de profundidad de inundación y velocidad de flujo. Fuente: elaboración propia a partir de Lagos, 2012.

${ }^{40}$ La técnica de modelación numérica, basada en el código TUNAMI (Siglas de Tsunami Code of Tohoku University), contempla la integración de ecuaciones de movimiento no-lineales para aguas someras o poco profundas (Lagos, 2012). 

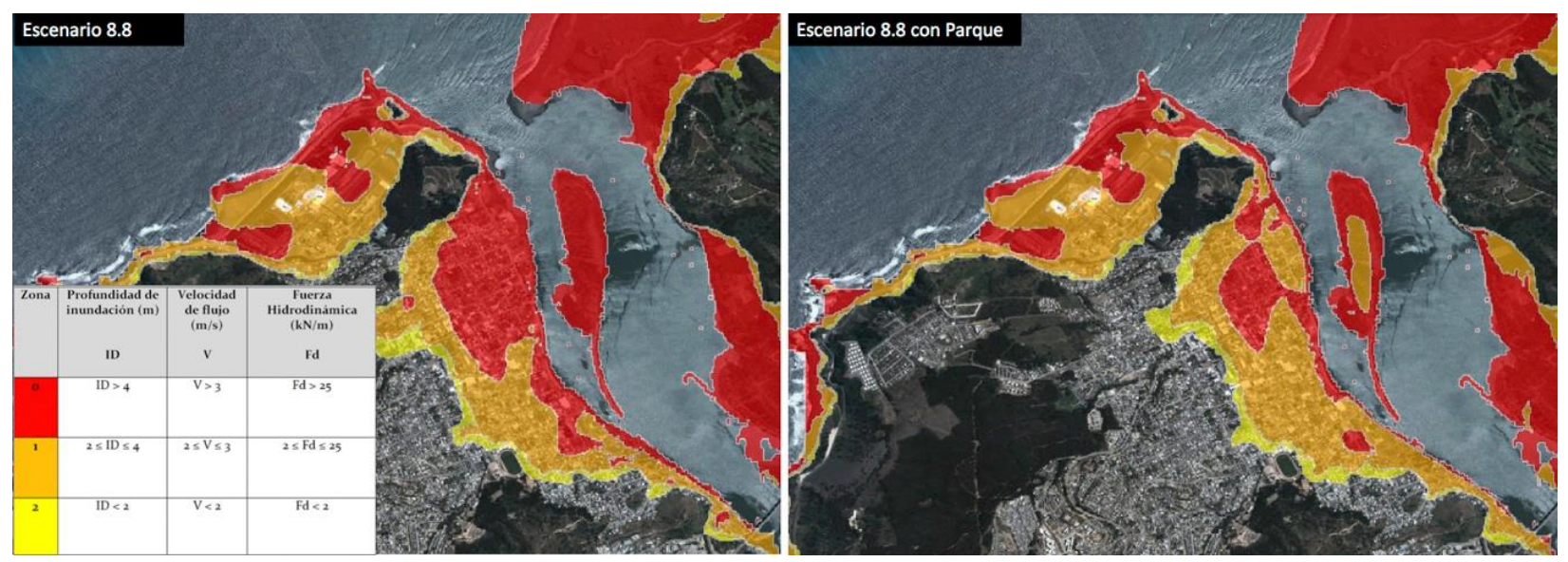

Fig. 34. Modelación escenario de evento 8.8 Mw, que muestra las máximas profundidades de inundación para el evento de mayor potencia. Como puede verse, los valores máximos están generalmente en la línea de costa, siendo más bajos en el límite de la inundación. Si bien en general se observa una reducción de la zona crítica (zona 0), debido a la acción del Parque de Mitigación, éste no evidencia un adecuado comportamiento en su tramo central, que coincide con la sección más angosta en su diseño. Fuente: elaboración propia a partir de Lagos, 2012.

Las simulaciones numéricas en las cuales se basa la evaluación del Parque, han determinado los 3 niveles de riesgo que se observan en el análisis, a partir de las profundidades de inundación estimadas, las velocidades y el momento flujo resultante del tsunami. En la siguiente tabla se presenta el resumen de la modelación de ambos escenarios, en términos del aporte del Parque de Mitigación en la reducción de la superficie de zona urbana en riesgo:

\begin{tabular}{|c|c|c|c|c|c|}
\hline Escenarios & Zona 0 & $\begin{array}{l}\text { Zona } 1 \\
\text { (ha) }\end{array}$ & $\begin{array}{c}\text { Zona } 2 \\
\text { (ha) }\end{array}$ & $\begin{array}{l}\text { Superficie total } \\
\text { en riesgo } \\
\text { (ha) }\end{array}$ & \begin{tabular}{|c}
$\begin{array}{c}\text { Disminución } \\
\text { superficie } \\
\text { total en } \\
\text { riesgo } \\
(\%)\end{array}$ \\
\end{tabular} \\
\hline \multicolumn{6}{|c|}{ SIN Parque Borde Fluvial Costero Constitución } \\
\hline 8.5 (Menor) & 1,2368 & 19,5287 & 39,9656 & 60,7311 & \\
\hline 8.8 (Mayor) & 59,1223 & 53,5353 & 15,8271 & 128,485 & \\
\hline \multicolumn{6}{|c|}{ CON Parque Borde Fluvial Costero Constitución } \\
\hline 8.5 (Menor) & 0,6487 & 5,0162 & 40,8823 & 46,5472 & $23,36 \%$ \\
\hline 8.8 (Mayor) & 27,5373 & 73,4446 & 16,4065 & 117,3884 & $8,64 \%$ \\
\hline
\end{tabular}

Tabla 3. Cuadro resumen de modelación de valores en zonas afectadas por los eventos de magnitud 8.5 y 8.8, en escenarios con y sin proyecto de Parque de Mitigación.

Fuente: Lagos, 2012.

En relación a las variables modeladas, los resultados muestran que el efecto de un terremoto de magnitud $8.8 \mathrm{Mw}$ con epicentro frente a la costa serían significativos, con un área de inundación urbana cercana a las 130 hectáreas. Esta estimación es 
comparable a los registros recogidos en Constitución en febrero de 2010, posterior al arribo del tsunami. Por otra parte, se observa también que el efecto de un terremoto de magnitud 8.5 Mw abarcaría aproximadamente un área de inundación urbana de 60 hectáreas.

En el escenario de mayor magnitud, con un tsunami generado por un evento 8.8 Mw, la propuesta de Parque de Mitigación reduce el área de inundación crítica (zona 0 ) en alrededor de un $50 \%$, dependiendo de las características del diseño establecido en cada tramo respecto a la densidad de plantación de los árboles, la variación de la rugosidad de la topografía y las condiciones constructivas de la primera defensa fluvial. La disminución del área afectada en todo el rango de zonas $(0,1$ y 2$)$ disminuye en poco más de un $8 \%$. El efecto de la fuerza hidrostática es también menor gracias a la acción del Parque, reduciéndose entre un $5 \%$ y un $25 \%$ dependiendo de las suposiciones hechas para la modelación (Lagos, 2012).

\subsubsection{Otras experiencias: Parques de Mitigación de Pelluhue y Dichato}

A partir del análisis de los parques propuestos en las regiones del Maule y Biobío, se pueden identificar 4 tipologías de proyecto, no excluyentes entre síli ${ }^{4}$, determinadas por su localización en el contexto territoral. En general se conforman mediante la disposición de una franja paralela a la línea de costa o ribera, integrando obras de contención y defensa, masas de vegetación y movimientos topográficos, siguiendo las estrategias contempladas en el caso del Parque de Mitigación de Constitución. Las particularidades de cada diseño responden a énfasis que se establecen en consideración a las condiciones geográficas y paisajisticas propias de cada localidad donde se implementan.

De esta manera, se reconocen:

- Parques de borde costero o borde mar: desarrollados por medio de una franja paralela a la línea de la costa, en sectores determinados como zonas de riesgo.

- Parques de borde fluvial o de estero: ubicados en márgenes de esteros y ríos existentes en las localidades afectadas, los cuales facilitaron el ingreso del tsunami.

- Parques de desembocadura: localizados en las áreas de encuentro entre los cursos de agua interiores y el borde costero, que registraron importantes niveles de inundación en el evento de 2010.

- Parques dunarios: ubicados en zonas costeras con presencia activa de sistemas de dunas, comprendidos como infraestructuras de mitigación a potenciar.

\footnotetext{
41 Para el caso del PRBC de Dichato, por ejemplo, las iniciativas propuestas contemplaron un parque de mitigación en la zona de riesgo asociada al frente de la costa y otro parque de mitigación en la zona del Estero.
} 


\begin{tabular}{|c|c|c|c|c|c|}
\hline Plan & Locallidad & Pargue bordemar & $\begin{array}{l}\text { Parque borde } \\
\text { estero }\end{array}$ & $\begin{array}{c}\text { Parque } \\
\text { desembocadura }\end{array}$ & Parque dunario \\
\hline \multirow{2}{*}{ PRES } & Constituob́n & $x$ & $x$ & $x$ & \\
\hline & Pelutue-Curanige & & & & $x$ \\
\hline \multirow[t]{11}{*}{ PRBC18 } & Cobquecura & $x$ & $x$ & $x$ & \\
\hline & Perales & $x$ & & $?$ & \\
\hline & Dichato & $x$ & $x$ & $x$ & \\
\hline & Coliumo & $x$ & & $?$ & \\
\hline & Takahuano & $x$ & $x$ & $x$ & \\
\hline & Tubul & & $x$ & & \\
\hline & Uico & $x$ & $x$ & $x$ & \\
\hline & Lebu & $?$ & $x$ & $x$ & \\
\hline & Quidico & & & $x$ & \\
\hline & Tirúa & & $x$ & $x$ & \\
\hline & Issa Mocha & $x$ & & & \\
\hline
\end{tabular}

Tabla 4. Tipos de parques de mitigación según localidad.

Fuente: Elaboración propia a partir de MINVU (2011), PRBC18, PRES Constitución y PRES Pelluhue-Curanipe.

Como se ha señalado, en la mayoría de los planes maestros estos parques se definen como el proyecto emblemático de la reconstrucción, propuestos como espacios públicos prioritarios para las distintas localidades. Su existencia, en tal sentido, se argumenta no sólo desde un punto de vista técnico funcional asociado a la reducción de riesgo, sino también en la necesidad de cubrir necesidades ya establecidas de manera previa al desastre de 2010, en materia de áreas verdes, equipamiento e infraestructura urbana (GSAPP, 2015; Bresciani, 2012). Por otra parte, dado a que gran parte de las localidades de borde costero constituyen polos de desarrollo turístico (MINVU, 2011), la presencia de estos proyectos tenderá a consolidar su vocación turística a escala regional, tanto en Maule -considerando casos como Constitución y Pelluhue- como en Biobío, con el caso de Dichato.

El impacto del tsunami 2010 en las costas de Pelluhue, en la región del Maule, se produjo aproximadamente 25 minutos después de la ruptura provocada por el terremoto $8.8 \mathrm{Mw}$, con alturas por sobre los 14 metros y con una frecuencia de tres olas u ondas de inundación, siendo cada vez más destructivas, con varios minutos entre cada oleaje, según consta en diversos informes (GSAPP, 2015; SERVIU Región del Maule, 2012; MINVU 2011). El desastre se tradujo en una elevada proporción de víctimas fatales y afectados, respecto de la población existente, comparado con otras localidades de la región, y en un importante número de damnificados en sus viviendas. La afectación de las infraestructuras de servicios críticos en zonas de riesgo fue uno de los aspectos más relevantes del impacto del desastre en estas localidades, incluyendo las plantas de tratamiento de agua potable y algunos servicios públicos como las dependencias del municipio, con sus sistemas de comunicación, bases de datos y redes de información (GSAPP, 2015). 

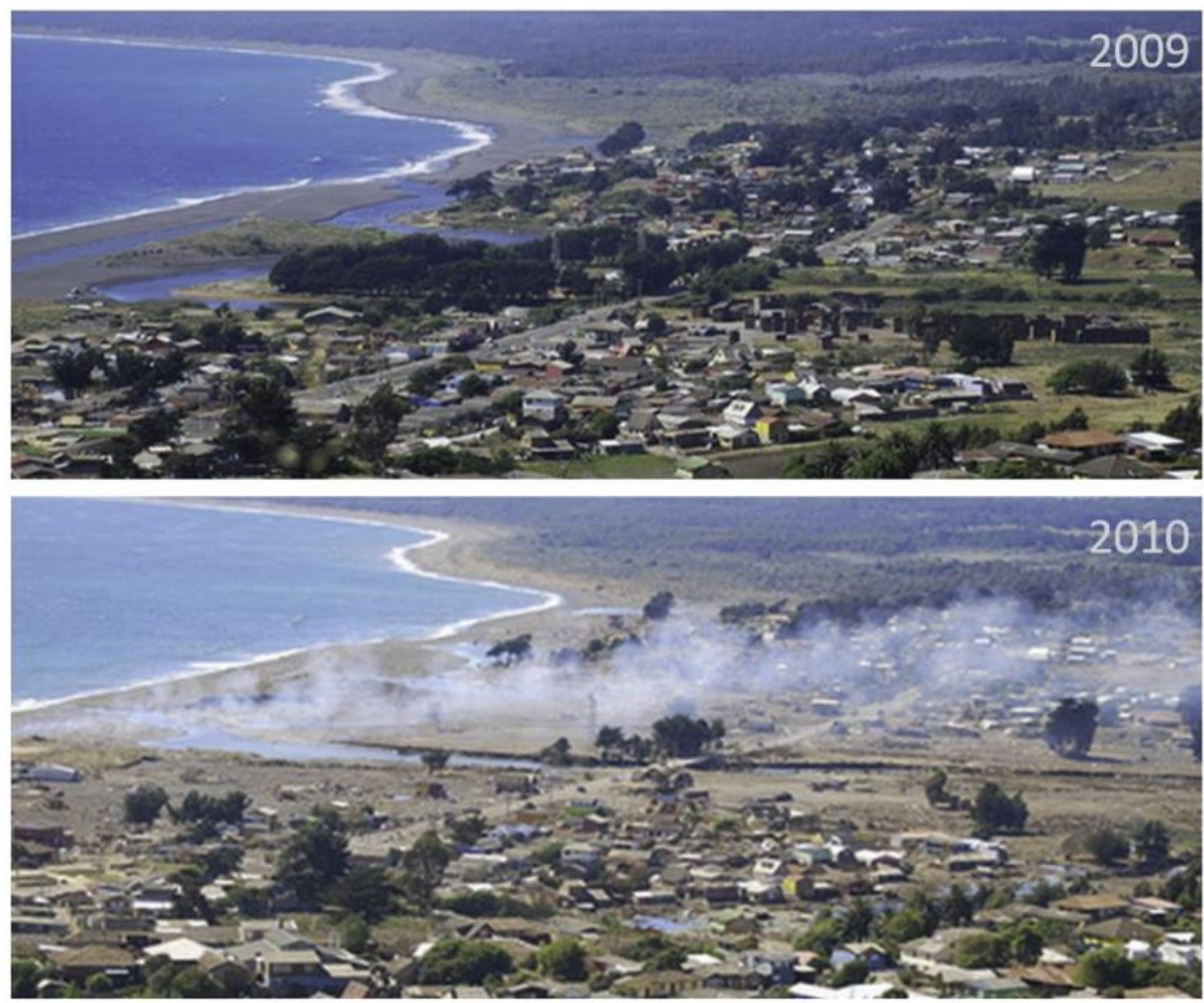

Fig. 35. Vista aérea del área urbana de Pelluhue, antes y después del tsunami de 2010. Fuente: Igualt (2015).

En términos de proveer de infraestructuras urbanas para la reducción de riesgos ante futuros eventos (PRES Pelluhue, 2010), la propuesta del Parque de Mitigación se fundamenta en la integración de sistemas naturales pre-existentes, como las dunas y los humedales ribereños, en conjunto con obras civiles de defensa. Mediante el decreto de zona de riesgo de inundación crítica para la franja urbana de primera línea de costa y el consecuente proceso de expropiación, el borde costero gana mayor espesor y se convierte en una potencial franja mitigadora constituida secuencialmente por el área de playa, el cordón de dunas, la proyección del parque y la consolidación de la vialidad de la costanera. 


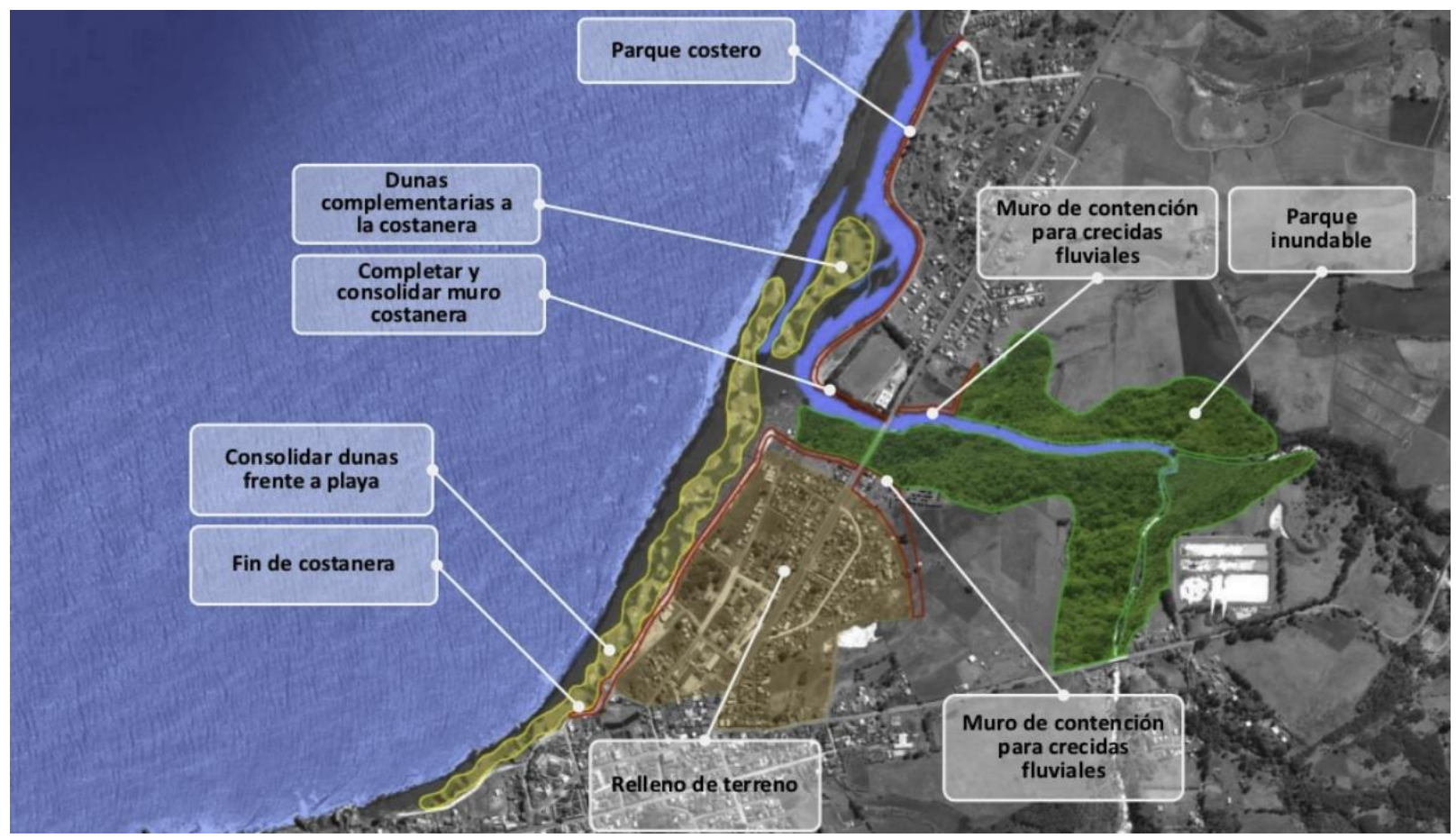

Fig. 36. Infografía con recomendaciones de infraestructuras de mitigación de tsunamis para Pelluhue. Entre ellas, destaca el énfasis en la utilización del campo dunario existente en la zona de playa, reforzado con la proyección de nuevas dunas artificiales en torno a la desembocadura del río Curanilahue. En sus riberas, se propone establecer áreas de inundación controlada, reguladas mediante humedales ribereños existentes.

Fuente: OCUC (2010).

Las estrategias de diseño del Parque de Mitigación consideran, por un lado, el modelamiento topográfico del terreno, acentuando el relieve del sistema dunario existente y prolongándolo longitudinalmente en todo el frente costero del área urbana central. La nueva topografía resultante es estabilizada mediante diversos estratos de vegetación y reforzada con infraestructuras de pilotaje -fundaciones de contención de rollizos de madera- en conjunto con contenciones de gradas de hormigón que a la vez son utilizadas para el desarrollo de programas recreativos.

Por otra parte, el proyecto define estrategias ecológico-paisajisticas asociadas al uso de sistemas de vegetación como parte de la infraestructura de mitigación. Sus componentes se destinan tanto a la conservación y fitoestabilización de las dunas, mediante la disposición de cubresuelos, herbáceas y arbustos rastreros, como al aumento de la rugosidad de la superficie del Parque, con la finalidad de establecer un buffer de amortiguación ante eventos de inundación, a través de alineaciones de árboles. Este arbolado también se destina a proveer de condiciones de protección -a nivel de proyección de sombra, retención de humedad y barrera ante la salinidad del aire- para el crecimiento de otras especies de arbustos y arboles, principalmente nativos (SERVIU Región del Maule, 2012). 


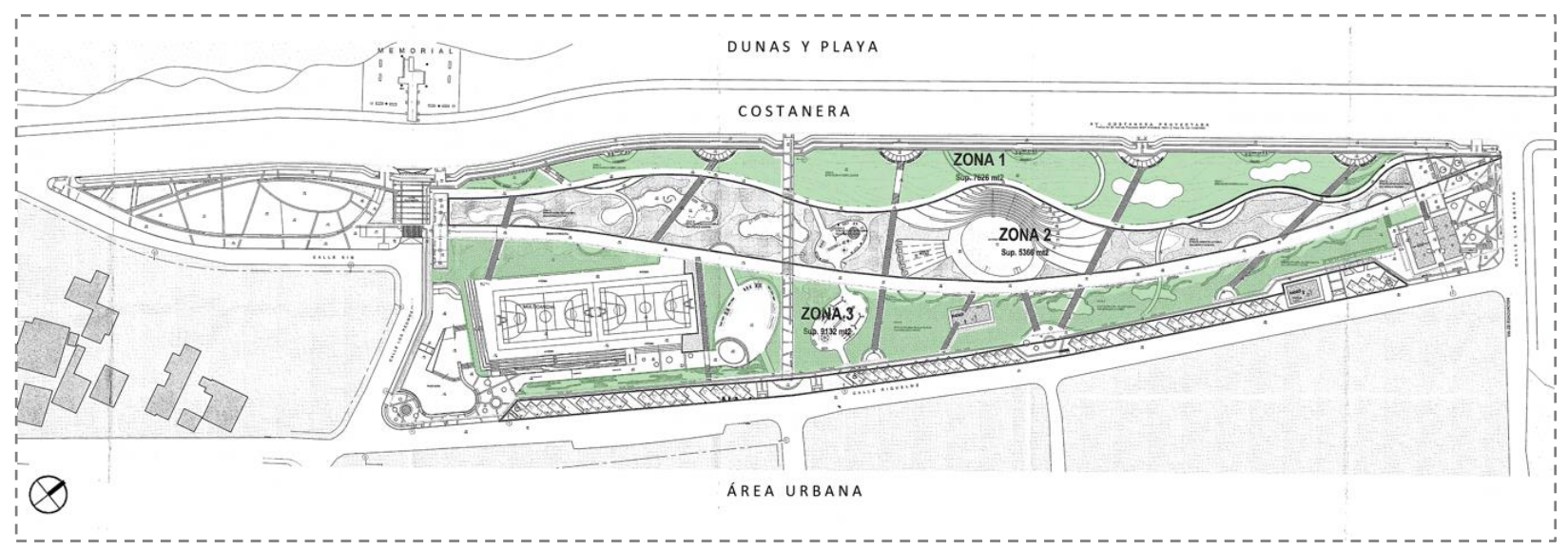

Fig. 37. Planta General del Parque de Mitigación de Pelluhue. Se observan las tres zonas de vegetación establecidas en el proyecto.

Fuente: SERVIU Región del Maule, (2012).

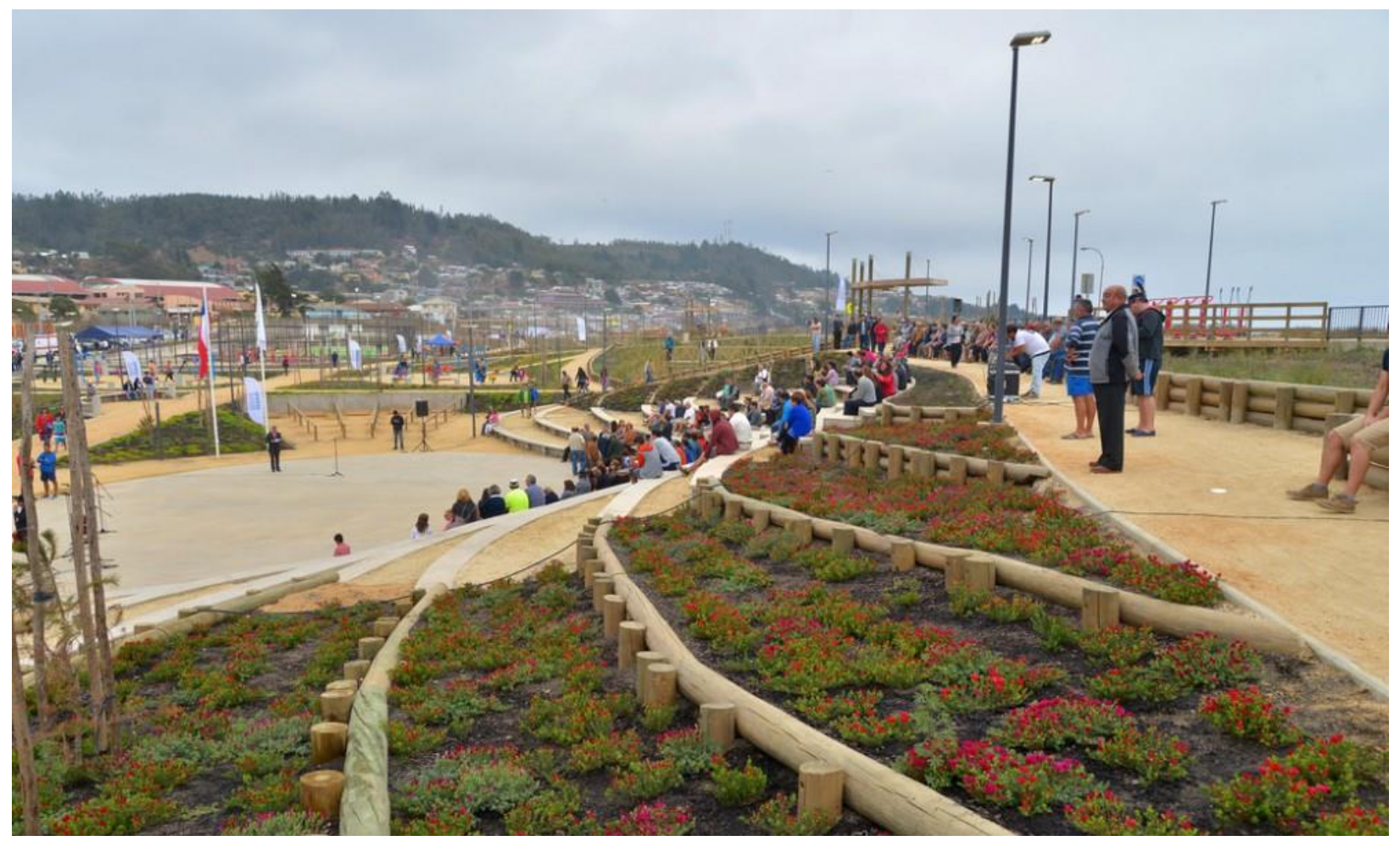

Fig. 38. Modelamiento topográfico y fitoestabilización de dunas en Parque de Mitigación de Pelluhue. Fuente: Autor, 2017.

En el caso de la localidad de Dichato, uno de los principales balnearios de la región del Biobío, los daños producidos por el tsunami de 2010 se concentraron justamente en la primera línea de borde costero y en la llanura aluvial del estero Dichato, cuyas altimetrías mínimas contribuyeron a propagar la inundación hacia tierra adentro, extendiendose hasta el piedemonte de la bahía de Coliumo (PRBC Dichato, 2010). La 
destrucción alcanzó un $80 \%$ en el plano y centro histórico, inundándose más de 80 hectáreas del área urbana, de una superficie total de 112,9 hectáreas.

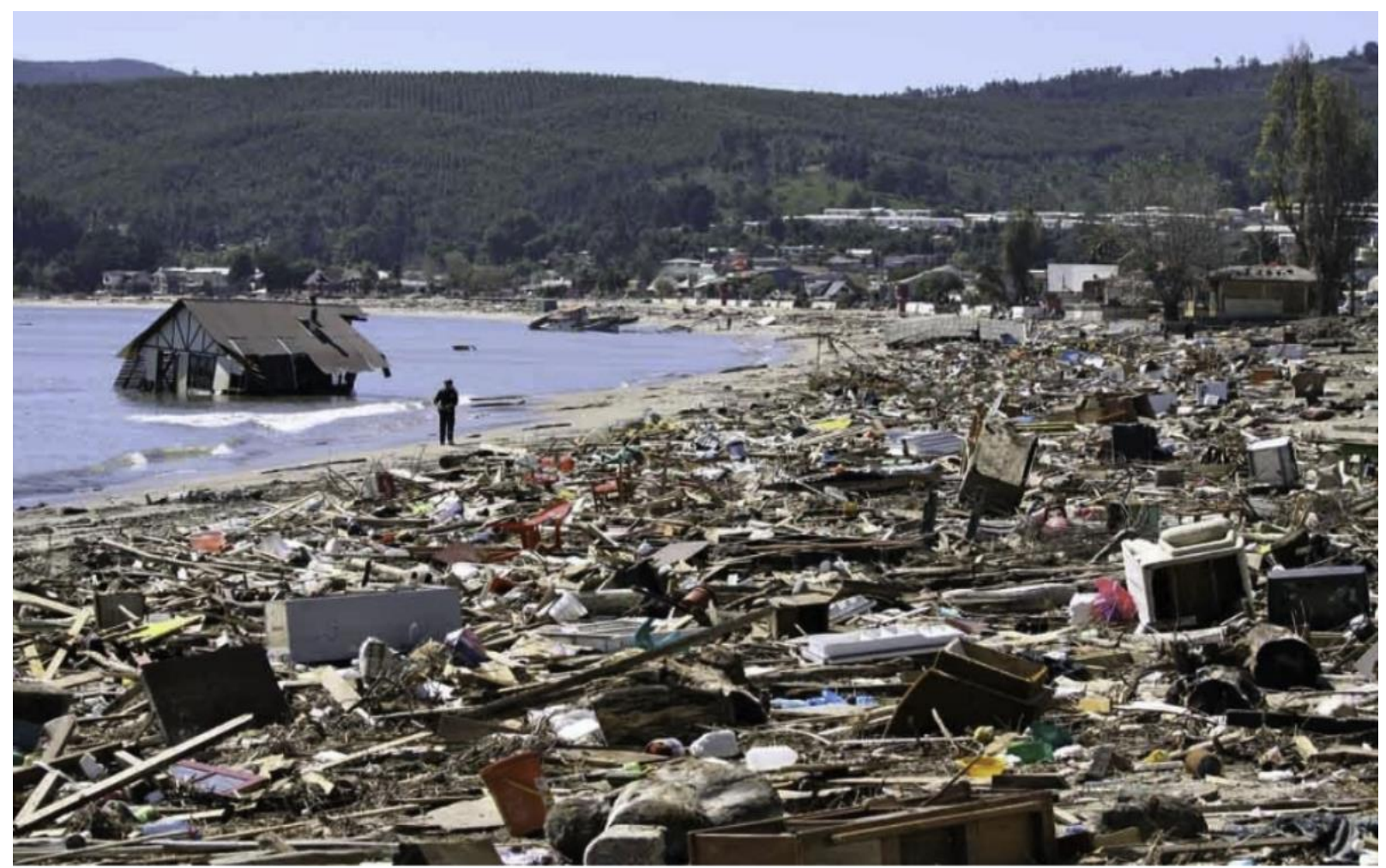

Fig. 39. Borde costero de Dichato, en febrero de 2010, a pocas horas del impacto del tsunami. Fuente: Baeriswyl, Sergio (2010).

En el marco del Plan de Reconstrucción de Dichato, desarrollado por un consorcio de Universidades y entidades privadas lideradas por el Gobierno Regional del Biobío, se establecieron lineamientos conceptuales y técnicos para proponer estrategias de reducción de riesgo ante eventos futuros de similares características al ocurrido (PRBC, 2010). Basadas en la integración de soluciones de ingeniería para la implementación de defensas construidas y de soluciones de infraestructura verde, estas estrategias se reunen bajo el concepto de Parque de Mitigación, en continuidad a la experiencia que ya se desarrollaba en la ciudad de Constitución. Atendiendo a los desafíos planteados por el escenario geográfico determinado por el borde costero de la bahía, la desembocadura y la llanura fluvial del estero Dichato, el plan define de manera simultánea un sistema de mitigación conformado por tres parques:

- Parque Costanera: conformado principalmente por un muro rompeolas de una altura promedio de 5,5 metros sobre el nivel del mar, que se desarrolla a lo largo de todo el frente costero urbano de la localidad, al cual se le anexa un paseo peatonal costanera que se acompaña de una franja arbolada de 20 metros de ancho, en promedio. Abarca una longitud de 1,2 kilómetros y una superficie de 2 hectáreas. 
- Bosque de Mitigación de la Desembocadura: generado a partir del relleno de la cota natural con un terraplén de 3 metros sobre el nivel del mar, sobre el cual se propone una masa de arbolado plantada con alta densidad. Comprende 1,7 hectáreas.

- Parque del Estero Dichato: desarrollado a lo largo del cauce en una superficie de 2 hectáreas, con un ancho de sección de 10 metros por cada ribera, incluye la recuperación de la cobertura vegetacional y la implementación, de una secuencia de lagunas de retención, como medida de protección de las inundaciones por desbordes en eventos de precipitaciones extremas.

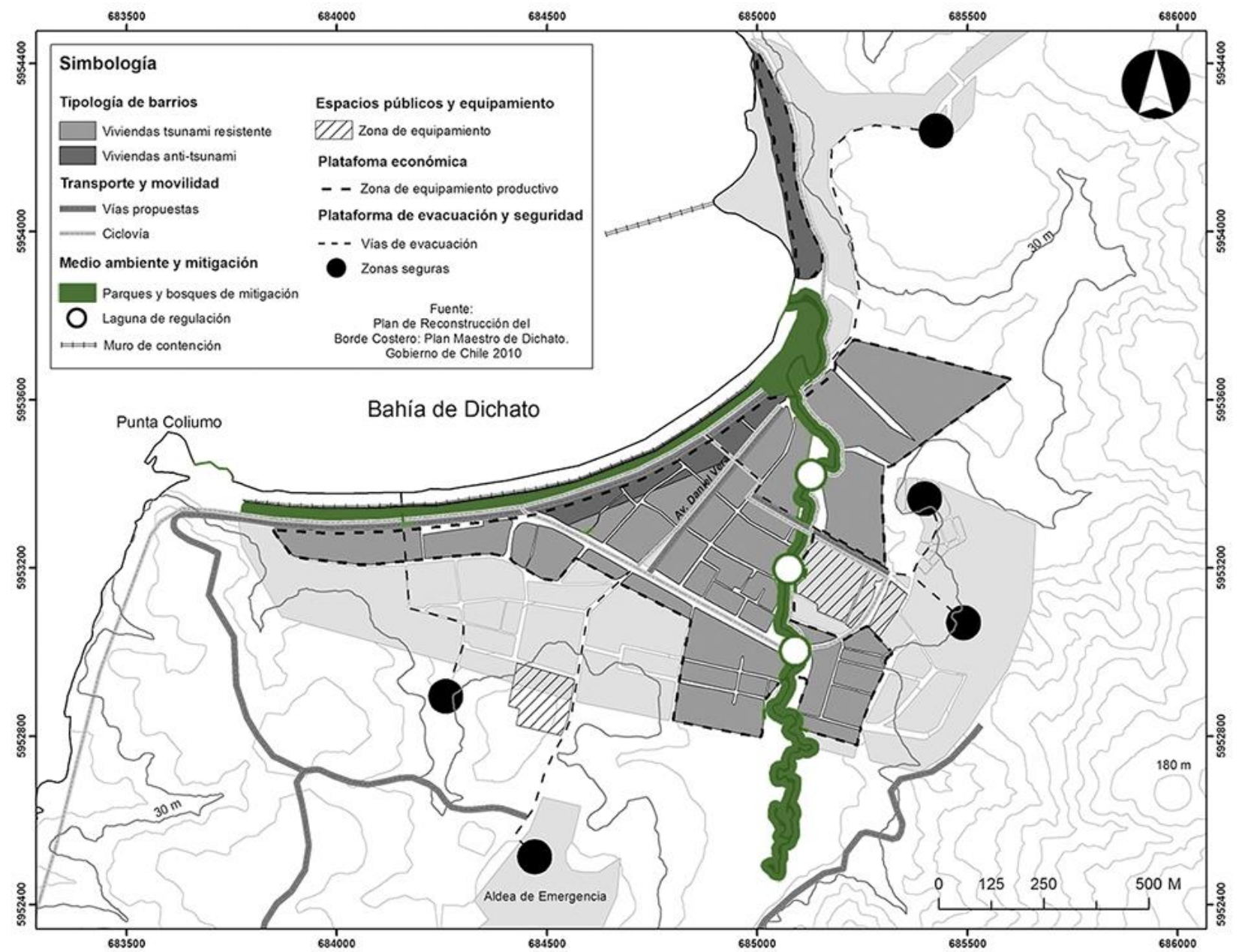

Fig. 40. Mapa síntesis de estrategias de reducción de riesgos para Dichato, desarrolladas en el marco del Plan de Reconstrucción. En color verde se grafica el sistema de parques de mitigación propuestos para el borde costero, la desembocadura y el estero Dichato, que fueron las zonas más afectadas por el tsunami de 2010.

Fuente: Plan de Reconstrucción de Borde Costero, Plan Maestro de Dichato (2010). 


\section{HACIA UN MODELO DE RESILIENCIA URBANA DESDE EL PAISAJE: FORMULACIÓN DE LINEAMIENTOS CONCEPTUALES, ESTRATEGIAS DE PLANIFICACIÓN Y CRITERIOS TÉCNICOS PARA EL FORTALECIMIENTO DE LOS PARQUES DE MITIGACIÓN}

El análisis de los casos de Parques de Mitigación desarrollados en las regiones del Maule y Biobío, expuesto en el capítulo anterior, aporta una serie de estrategias y criterios de diseño asociadas a una concepción de infraestructura híbrida, que combina el despliegue de soluciones construidas junto al manejo de componentes naturales, asociados principalmente al modelamiento de suelos y la configuración de buffers de vegetación en diversos estratos. El sistema en su conjunto, puede comprenderse al mismo tiempo como una operación multipropósito de carácter infraestructural y paisajística, destinada por un lado a otorgar resguardo ante fenómenos extremos de inundaciones generadas por tsunamis, marejadas y otros eventos hidrometereológicos, así como también de proveer de espacios sociales de ocio y esparcimiento en contextos de borde costero, conformando ámbitos públicos de reclamación y accesibilidad hacia un paisaje que -en muchos casos- ha permanecido durante largo tiempo ocupado para fines privados.

No obstante, el análisis de los Parques de Mitigación post 27F devela también una brecha respecto a los actuales lineamientos conceptuales y criterios técnicos de diseño que se evidencian en la experiencia internacional, no sólo en materia específica de estrategias de mitigación ante tsunamis, sino en el amplio panorama de casos asociados a otros fenómenos de desastres, como se ha expuesto en el segundo capítulo de esta investigación. Asimismo, de acuerdo a lo que se explica a continuación, la revisión inédita, detallada y conjunta de los expedientes de proyecto de los Parques de Constitución, Pelluhue y Dichato, exhibe problemas de coherencia entre las estrategias de mitigación y las operaciones de diseño declaradas, respecto a la implementación llevada a cabo, en atención a los rangos de amortiguación de impactos de tsunami esperados para este tipo de infraestructura.

Por un lado, como ya se ha señalado, en los procesos de formulación de los Parques de Mitigación desarrollados en el marco de los planes de reconstrucción de localidades costeras post tsunami de 2010, se ha argumentado el rol del diseño del paisaje concebido como infraestructura verde para la reducción de riesgo ante futuros eventos de desastre. En esta consideración, el énfasis ha estado puesto en la construcción de nuevos paisajes, incluyendo la disposición coordinada de componentes construidos, operaciones topográficas y sistemas de vegetación, configurados en su conjunto como dispositivos complementarios, colaborativos e interdependientes de amortiguación. Sin embargo, la discusión respecto a la conservación, manejo y restauración de sistemas naturales remanentes -tales como humedales costeros, sistemas dunarios y bosques de ribera, entre otros ecosistemasha estado ausente de estos procesos de planificación y diseño.

Comprendidas como importantes infraestructuras verdes en contextos de vulnerabilidad y riesgo de desastres a partir de los servicios ecosistémicos de regulación que aportan, este tipo de sistemas ha sido la base de planes y proyectos 
planteados para la adaptabilidad y reducción de riesgo en territorios costeros, como se ha evidenciado en los diversos casos expuestos en el segundo capítulo de esta investigación ${ }^{42}$. En las localidades costeras del centro sur de Chile, las unidades de paisaje donde se proporcionan estos servicios -que generalmente se encuentran reducidas, fragmentadas y degradadas- se pueden gestionar y conservar mediante iniciativas de planificación y diseño basadas ya no sólo en objetivos de preservación ecológica, sino en un afán de comprenderlos como componentes estratégicos para la resiliencia urbana (Reed, 2015), internalizando su funcionalidad en las propuestas de planes y proyectos de Parques de Mitigación. De acuerdo a lo señalado por diversos autores (Bélanger 2016; Vásquez, 2016; Reed, 2015; Batlle 2011; Carpenter y Folke 2006), abordar esta dimensión ecosistémica implica ampliar el alcance de la escala del proyecto hacia la planificación del mosaico de paisaje en su dimensión espacial y ambiental mayor, expandiendo su influencia hacia un nivel comunal y regional, promoviendo sinergias con las estrategias de diseño y construcción de infraestructuras de mitigación, en conjunto con otras zonas y componentes del territorio, en materia de adaptabilidad y resiliencia ante desastres.

Por otra parte, en relación a aspectos técnicos referidos a las estrategias de mitigación ante tsunamis y las operaciones de arquitectura del paisaje implementadas, su diseño y posterior ejecución exhibe incongruencias que han podido detectarse mediante la revisión sistemática e integrada de los expedientes de anteproyecto, proyecto ejecutivo y registro de obras ejecutadas, cuya documentación se encuentra hasta la fecha dispersa y fragmentada en distintos archivos generados desde el año 2010. Tomando como ejemplo el caso del Parque de Mitigación de Constitución, en él se establecieron principios conceptuales y criterios técnicos en una primera fase de desarrollo de anteproyecto, basados en los fundamentos aportados por la experiencia de infraestructuras de mitigación asociadas a sistemas de bosques costeros, cuya principal referencia se vincula a su tradición histórica en Japón (Tanaka, 2010), siendo su efectividad estudiada en años recientes a partir del evento de tsunami en Indonesia y Sri Lanka el año 2004 (Forbes \& Broadhead, 2008), como también en Japón post tsunami de 2011 (Renaud \& Murti 2013). Asimismo, para la modelación matemática de las estrategias de diseño de los componentes de topografía, vegetación y defensas construidas -planteadas como un sistema interdependiente y sinérgico que opera de manera conjunta para disminuir el impacto del tsunami en su entrada al continente- se utilizó el coeficiente de Manning, factor que establece el grado de rugosidad necesaria para la disipación del tsunami en términos de su velocidad, volumen y fuerza de impacto (JICA, 2018; Kotani et al., 1998; Arcement \& Schneider, 1989).

Si bien estos parámetros de diseño se establecieron desde la experiencia de la efectividad de los sistemas de bosques costeros ante similares eventos y fueron

\footnotetext{
42 Tales como: el proyecto Blue Dunes, desarrollado por WXY Architecture + Urban Design y WEST 8 Landscape Architecture para Rebuild by Design Hurricane Sandy Design Competition; el proyecto Public Sediment, de SCAPE, realizado en el marco de la iniciativa Resilient by Design: Bay Area Challenge; The Sand Engine, implementado en la provincia de Zuid Holland y; Resilient Boston Harbor, desarrollado por la Ciudad de Boston en 2018, ampliando a una escala mayor de infraestructura verde el sistema de parques originalmente proyectado por Frederick Law Olmsted a fines del siglo XIX.
} 
modelados numéricamente en base al coeficiente de Manning, estableciendo un valor esperable de 0.23 (Lagos, 2012), su puesta en práctica en la fase de ejecución del proyecto evidencia falencias en 2 aspectos claves: la densidad de plantación de los sistemas de vegetación y la rugosidad asociada al diseño de las variaciones topográficas.

Respecto a la densidad vegetacional, el proyecto ejecutivo establece una plantación de 1.200 a 1.000 ejemplares por hectárea (SERVIU Región del Maule, 2013), cifra menor a la densidad de 2.000 ejemplares por hectárea recomendada por la propuesta de anteproyecto (PRES, 2011) y lejana a las densidades sobre los 4.000 ejemplares por hectárea observados en bosques de mitigación en Japón ${ }^{43}$. En relación a la topografía diseñada, tanto en los documentos de anteproyecto, como en el expediente de proyecto, se establecen alturas que fluctuan entre los 2 y 4 metros de altura (SERVIU Región del Maule, 2013). No obstante en la realidad del Parque construido se observan alturas que escasamente llegan a los 3 metros, predominando un relieve de colinas de alturas en torno a los 2 metros de elevación ${ }^{44}$. De acuerdo a lo que se puede deducir de la Guía para la selección de coeficientes de rugosidad de Manning, para cursos naturales y planicies inundables (Arcement \& Schneider, 1989) y según lo establecido en las modelaciones de escenarios desarrolladas por Lagos (2012), la reducción de ambos factores -densidad de plantación y alturas del relieve de colinas- genera un coeficiente de Manning inferior a 0.20 , comprometiendo la efectividad de las soluciones propuestas ante futuros eventos de tsunami. Estas observaciones, referidas de manera específica al Parque de Mitigación de Constitución, aplican también a los casos de Pelluhue y Dichato.

En tal sentido, la necesidad de mejorar el rendimiento de ambos componentes del proyecto, mediante la densificación de los ecosistemas de vegetación y la intensificación de una topografía de mayor rugosidad, respectivamente, se plantea como requerimiento fundamental para la operatividad de los Parques comprendidos como infraestructuras verdes para la mitigación de desastres, dado que constituyen iniciativas estratégicas de alto interés público y de alcance nacional.

\subsection{Síntesis e integración de referencias asociadas a la experiencia internacional en materia de planificación y diseño de infraestructuras verdes para la resiliencia urbana y reducción de riesgos de desastres}

En sintonía con la experiencia internacional, documentada a partir de los casos de estudio analizados en Estados Unidos, Europa y Japón, el enfoque de infraestructura híbrida asociada a los proyectos de Parques de Mitigación se fundamenta en el rol activo de los sistemas naturales complementados con sistemas construidos, comprendidos como infraestructuras verdes capaces de absorber y amortiguar los

\footnotetext{
43 Tomando como referencia el proyecto de Bosque de Mitigación implementado post tsunami 2011 en la ciudad costera de Iwanuma, Japón (Renaud \& Murti, 2013).

${ }^{44}$ Altura medida desde el nivel de base del Parque, considerado en el nivel de piso terminado de la costanera paseo peatonal (Nivel +3.22 m. según proyecto, ver figura 118, p. 175)
} 
fenómenos de cambios hidrológicos extremos a través de la adaptabilidad y sinergia de sus componentes (fig. 41), la cual aporta servicios ecosistémicos claves para la protección de zonas urbanas costeras ante desastres .

Si bien la infraestructura gris -aquella construida con sistemas convencionales de ingeniería civil- contribuye a la protección de las comunidades, su efectividad disminuye con el tiempo y carece de la capacidad de adaptarse a las dinámicas cambiantes de las zonas costeras. Como señala Sutton-Grier et al. (2015), la infraestructura construida es funcional inmediatamente después de su ejecución, pero tiene una vida útil establecida, se debilita con el paso del tiempo y se construye según parámetros específicos que no pueden adaptarse a los cambios en el nivel del mar u otras condiciones de variabilidad. Además, aunque las estructuras de defensa costeras construidas -basadas en muros de contención, rompe olas y otros dispositivos similares- pueden ayudar a proteger a las comunidades de los efectos de tsunamis, marejadas y tormentas importantes, éstas pueden tener también impactos negativos en el desarrollo del medioambiente costero, cambiando el transporte de sedimentos y la capacidad de la costa de responder naturalmente a las condiciones dinámicas de diversos factores de fuerza, lo que puede resultar en pérdida de hábitats y pérdida de diversidad de especies (Sutton-Grier et al., 2015; Bilkovic \& Mitchell, 2013; Govarets \& Lauwerts, 2009).

Como se ha señalado, la tendencia mundial apunta a un diseño integral y a una gestión multidisciplinaria de las infraestructuras (Shannon \& Smets, 2010; Mossop, 2006), las cuales necesitan encontrarse e hibridarse con sus componentes ecológicos y culturales para así ser capaces de servir a diferentes propósitos, considerar tanto su contexto físico ambiental, como su espacio de valor cultural y adaptarse a los cambios que supone su operatividad en escenarios inestables y dinámicos, especialmente en materia de infraestructuras de mitigación de impactos de desastres en bordes costeros. Desde su condición multipropósito, la infraestructura verde, favorece el desarrollo de procesos simultáneos que amplían y diversifican la prestación de servicios, comprendiéndose como un sistema abierto apto para incorporar en el tiempo nuevas funciones y externalidades, optimizando de esta manera la rentabilidad social de la inversión en este tipo de proyectos de alto impacto público. 


\section{Mínimas defensas.}

La pérdida y/o degradación de componentes naturales asociados a ecosistemas costeros, producto de la ocupación antrópica, aumenta la vulnerabilidad de los asentamientos urbanos a lo largo del borde costero, con sólo mínimas defensas naturales dependientes generalmente de un margen de playa que los proteje de la acción de las mareas.

\section{Infraestructura ecológica.}

Los ecosistemas costeros que pueden proporcionar protección contra desastres incluyen marismas (salt marsh), arrecifes (oyster beds), manglares, praderas marinas, bordes riparios, dunas e islas de barreras sedimentarias (barrier island) frente a la costa. Como se observa en la figura, la combinación de estos ecosistemas proporciona mayor protección, lo cual puede gestionarse mediante la restauración $y / 0$ creación de estos hábitats naturales. La infraestructura temporal (como el muro rompeolas removible) puede proteger la infraestructura natural, mientras ésta se establece.

\section{Articulaciones entre infraestructura construida y ecológica.}

La infraestructura natural se puede utilizar para proteger la infraestructura construida, con el fin de ayudarla a tener una mayor vida útil y proporcionar más beneficios de protección, actuando como sistemas preventivos de amortiguación. Al relocalizar los muros de defensa (sea wall) más lejos de la costa, hacia el asentamiento, se integran como elementos urbanos y permiten que la infraestructura natural se desarrolle en el frente del borde costero.

\section{Infraestructura Híbrida.}

En el enfoque de infraestructura hibrida, los componentes construidos, tales como muros de defensa (sea wall) y compuertas (flood gate), se despliegan de manera simultánea con ecosistemas naturales restaurados $\mathrm{y} / \mathrm{o}$ creados, como marismas (salt marsh) arrecifes (oyster beds) o barreras sedimentarias (barrier island), favoreciendo sinergias que permiten enfrentar eventos de alta magnitud.
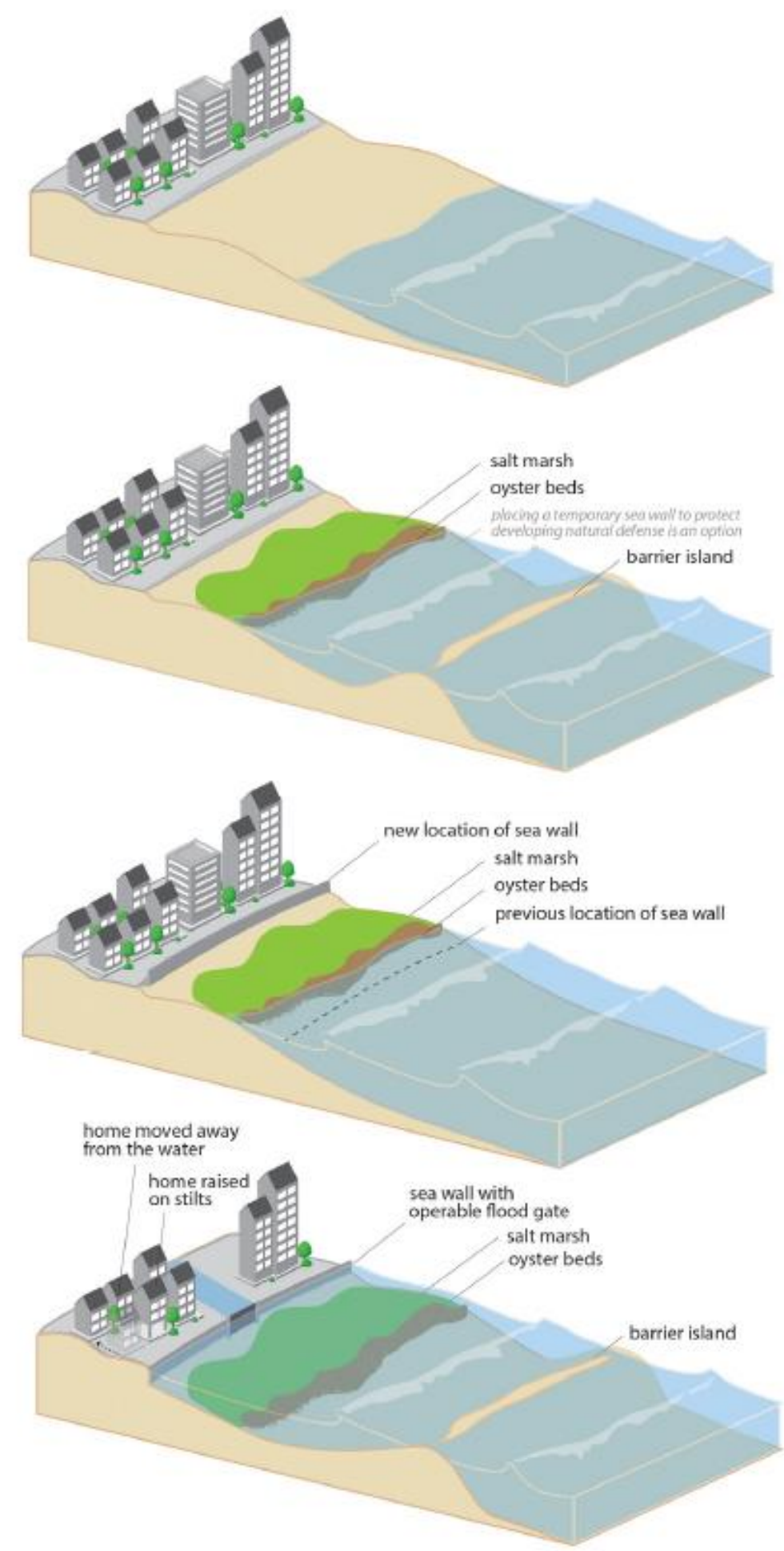

Fig. 41. Esquema síntesis de infraestructuras asociadas a la protección de asentamientos costeros ante desastres, incluyendo el enfoque de infraestructura ecológica e infraestructura verde o híbrida. Fuente: Adaptado de Sutton-Grier et al. (2015). 
El estudio de los diversos casos referenciales de planes y proyectos incluidos en esta investigación, que abarca en términos temporales una década caracterizada por el aumento de la frecuencia e intensidad de eventos de desastres, constituye una importante fuente documental que expone un espacio de desarrollo teórico y práctico emergente e innovador, cuya base conceptual en materia de diseño es informada tanto por el conocimiento ecológico, como por las ciencias aplicadas de la ingeniería, la arquitectura y el urbanismo. El resultado de estas experiencias de investigación y práctica profesional, que se enmarcan en los lineamientos establecidos por Naciones Unidas para la gestión del riesgo de desastres a través de diversas instancias intergubernamentales ${ }^{45}$, abre un renovado ámbito de reflexión en torno al lenguaje de la resiliencia, el manejo adaptativo y la versatilidad, demostrando la operatividad de estos enfoques aplicados a contextos de vulnerabilidad ante desastres, en escalas variables de representación y proyecto. Asimismo, las estrategias y los componentes de diseño aplicados en los distintos casos exhiben una amplia diversidad de tipologías, que transitan desde aquellas vinculadas a soluciones netamente basadas en sistemas naturales -y por tanto relacionadas a la funcionalidad de la infraestructura ecológica de los ecosistemas remanentes- hasta aquellas que contemplan la hibridación entre soluciones de ingeniería ecológica, también denominada soft engineering, con ingeniería tradicional o hard engineering.

Esta base articulada de análisis permitirá, a continuación, sistematizar lineamientos, estrategias y criterios de diseño orientados a fortalecer las bases sobre las cuales los parques de mitigación actualmente se desarrollan en Chile.

\subsection{Propuesta de lineamientos conceptuales, estrategias de planificación y criterios de diseño del Paisaje para el fortalecimiento de los Parques de Mitigación en contextos de borde costero}

La figura de los Parques de Mitigación, desarrollados en el marco de los planes de reconstrucción de localidades costeras del centro sur de Chile afectadas por el tsunami de febrero de 2010, constituye una iniciativa innovadora en materia de puesta en práctica del enfoque asociado a la arquitectura del paisaje como infraestructura verde para la reducción de riesgos, la cual en la última década se ha traducido en un ámbito relevante de inversión pública de alcance nacional, con diversos proyectos diseñados y ejecutados.

\footnotetext{
45 Entre los que destacan la Conferencia Mundial sobre la Reducción de Desastres realizada en Hyogo en 2005, el Marco Sendai para la Reducción del Riesgo de Desastres, en 2015, y la Conferencia Hábitat III, realizada en Quito el año 2016.
} 


\section{PLANIFICACIÓN Y DISEÑO DE PARQUES DE MITIGACIÓN}

1. LINEAMIENTOS CONCEPTUALES.

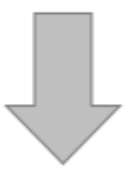

2. ESTRATEGIAS DE PLANIFICACIÓN.

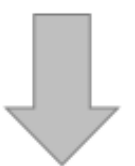

3. CRITERIOS TÉCNICOS DE DISEÑO.
Establecen las definiciones de carácter indicativo y normativo que determinan el desarrollo de los Parques de Mitigación, en tanto iniciativa que se enmarca en políticas públicas e instrumentos de planificación de de resiliencia urbana y gestión de reducción de riesgos. Estos lineamientos favorecen la comprensión del proyecto respecto a su propósito y alcance, a los beneficios y sinergias que considera, a la integración multisectorial que promueve, a la multiescalaridad de su alcance y a la temporalidad de su gestión.

Se conciben como aquellas acciones secuenciales y coordinadas que contribuyen al logro de los lineamientos establecidos, precisando su operatividad desde el reconocimiento e integración de instrumentos y programas multisectoriales, que le otorguen viabilidad en un determinado contexto de intervención. Estas estrategias se estructuran y espacializan en el territorio mediante un plan, que a la vez organiza el conjunto de operaciones que acontecen en un nivel de diseño y/o manejo específico.

Constituyen los parámetros de referencia técnica para la implementación de las estrategias de planificación del Parque de Mitigación, en coherencia con los lineamientos que determinan su formulación, estableciendo una escala y estructura espacial definida para asegurar su operatividad en tanto infraestructura verde para la resiliencia urbana y la reducción de riesgos, mediante la configuración de soluciones basadas en la integración de componentes de infraestructura ecológica e infraestructura construida.

Tabla 5. Estructura de lineamientos conceptuales, estrategias de planificación y criterios de diseño, para el fortalecimiento de las iniciativas de implementación de Parques de Mitigación.

Fuente: Elaboración propia.

La propuesta para el fortalecimiento de los Parques de Mitigación en materia de planificación y diseño de paisaje como infraestructura para la adaptabilidad y resiliencia de territorios afectados por desastres en contextos de borde costero, se organiza en base a la formulación metodológica e instrumental de lineamientos conceptuales, estrategias de planificación y criterios técnicos de diseño.

- En primer lugar, los lineamientos conceptuales establecen las definiciones de carácter indicativo y normativo que determinan el desarrollo de los Parques de Mitigación, en tanto iniciativa que se enmarca en políticas públicas e instrumentos de planificación de resiliencia urbana y gestión de reducción de riesgos. Estos lineamientos favorecen la comprensión de estos proyectos en relación a su propósito y alcance, a los beneficios y sinergias que considera, a la integración multisectorial que promueve en su planificación, diseño e implementación, a la multiescalaridad de su alcance territorial y a la temporalidad de su gestión en el mediano y largo plazo.

- Luego, en segundo lugar, las estrategias se conciben como aquellas acciones secuenciales y coordinadas que contribuyen al logro de los lineamientos 
establecidos para la planificación y diseño de los Parques de Mitigación, precisando su operatividad desde el reconocimiento e integración de instrumentos y programas multisectoriales, que le otorguen viabilidad en un determinado contexto de intervención. Estas estrategias se estructuran y espacializan en el territorio mediante un plan, que a la vez organiza el conjunto de operaciones que acontecen en un nivel de diseño y/o manejo específico.

- Por su parte, los criterios de diseño constituyen los parámetros de referencia técnica para la implementación de las estrategias de planificación del Parque de Mitigación, en coherencia con los lineamientos que determinan su formulación, estableciendo una escala y estructura espacial definida para asegurar su operatividad en tanto infraestructura verde para la resiliencia urbana y la reducción de riesgos, mediante la configuración de soluciones basadas en la integración de componentes de infraestructura ecológica e infraestructura construida.

- En la siguiente tabla se resume la estructura de lineamientos, estrategias y criterios de diseño, como base metodológica e instrumental para el fortalecimiento de las iniciativas de planificación e implementación de Parques de Mitigación.

\subsubsection{Lineamientos conceptuales: definiciones indicativas y normativas de planificación y diseño}

Los Parques de Mitigación constituyen iniciativas de planificación y diseño de infraestructura verde, cuyo propósito es contribuir a la resiliencia urbana y a la reducción de riesgos en territorios vulnerables ante la ocurrencia de desastres, mediante el rol activo e integrado de sistemas naturales complementados con sistemas construidos. De manera sinérgica, esta infraestructura provee, por un lado, espacios de amortiguación para disipar efectos generados por el impacto de eventos telúricos, tsunamigénicos e hidrometereológicos, con el objetivo de favorecer los tiempos de evacuación de la población hacia zonas de seguridad y de reducir los potenciales daños a la propiedad pública y privada. Asimismo, aporta de manera estratégica a la conservación de ecosistemas remanentes asociados a bordes costeros, riberas fluviales, quebradas y laderas, promoviendo también el desarrollo de espacios públicos que albergan programas y funciones sociales compatibles con escenarios de alto valor ambiental y cultural.

Su formulación, diseño y ejecución, por tanto, requiere la gestión integrada de diferentes carteras de inversión pública en los territorios, coordinando iniciativas complementarias en materia de gestión de riesgo, resiliencia, sustentabilidad, infraestructura y espacio público, desde la etapa inicial del proyecto. Ello, con el objetivo de maximizar los beneficios económicos, sociales y ambientales, a través de los costos compartidos y la eficiencia generada por las sinergias basadas en la planificación y gestión multisectorial. Por otra parte, su alcance territorial se establece en relación al desarrollo de instrumentos de planificación de escala urbana y regional, contemplando criterios de multiescalaridad que responden al ámbito de alcance directo de las áreas de intervención del Parque, como así también al ámbito de alcance 
indirecto relacionado con la amplitud de los sistemas naturales que forman parte de la infraestructura verde vinculada al proyecto.

PARQUES DE MITIGACIÓN

1.1. Propósito.

\section{LINEAMIENTOS CONCEPTUALES.}

Los Parques de Mitigación constituyen iniciativas de planificación y diseño de infraestructura verde, cuyo propósito es contribuir a la resiliencia urbana y a la reducción de riesgos en zonas vulnerables ante la ocurrencia de desastres, mediante el rol activo e integrado de sistemas ecológicos remanentes y emergentes, en colaboración con sistemas estructurales construidos en el territorio.

\subsection{Beneficios y sinergias.}

\subsection{Integración multisectorial.}

\subsection{Multiescalaridad.}

\subsection{Temporalidad.}

Tabla 6. Lineamientos conceptuales para la implementación de Parques de Mitigación. Fuente: Elaboración propia.

Desde el punto de vista de la temporalidad de la planificación y su relación con la ocurrencia de eventos de desastre, la articulación a nivel normativo puede generarse con normas e instrumentos de planificación de carácter preventivo ${ }^{46}$, determinados

46 Entre los instrumentos preventivos cabe señalar, entre otros, a: la Ley General de Urbanismo y Construcciones (LGUC); los Planes Regionales de Ordenamiento Territorial PROT); la Política Nacional de Desarrollo Urbano (PNDU); 
por iniciativas que comprenden una visión territorial de resiliencia y gestión de reducción de riesgos a mediano y largo plazo, definida de manera independiente a la contingencia de un evento de desastre específico; o bien con instrumentos de carácter responsivo 47 , los cuales emergen desde la necesidad de implementar iniciativas de planificación complementarias y correctivas derivadas de la ocurrencia de un desastre.

En la siguiente tabla, se sintetizan los lineamientos conceptuales establecidos como base para la planificación y diseño de los Parques de Mitigación.

\subsubsection{Estrategias de planificación: articulaciones y sinergias con el mosaico de paisaje}

Un aspecto fundamental para la funcionalidad de los proyectos de Parques de Mitigación es incorporar el rol activo de patrones y procesos híbridos, no sólo vinculado a ecosistemas naturales, sino sumando también ecosistemas resultantes de dinámicas antrópicas en contextos urbanos y/o productivos. De esta manera, su planificación y diseño necesita articular aquellos ecosistemas remanentes, que subyacen en el territorio como pre-existencias, con aquellos ecosistemas emergentes, que surgen y se establecen a partir de dinámicas de cambios y transformaciones generadas por la acción humana. Integrar esta dimensión ecosistémica requiere ampliar el alcance de la escala del proyecto hacia la planificación del mosaico de paisaje, expandiendo su influencia hacia un nivel comunal y regional.

Con el objeto de otorgar una vialibidad a este enfoque de planificación, la gestión normativa e indicativa de instrumentos de carácter multisectorial -provenientes de diversos ámbitos ministeriales que responden a la gestión de territorios urbanos, rurales y silvestres- se plantea como eslabón fundamental para la promoción y manejo de los Parques de Mitigación comprendidos en el marco de una sistema mayor de infraestructura verde destinada a la resiliencia urbana y a la reducción de riesgos en territorios vulnerables ante la ocurrencia de desastres.

Para ello, se vuelve necesario considerar el aporte de políticas públicas, normas e instrumentos de planificación y gestión territorial que faciliten procesos de conservación de ecosistemas claves para la amortiguación de impactos de tsunamis, marejadas y otros eventos hidrometereológicos. Si bien en la actualidad a nivel nacional no existen definiciones normativas específicas relacionadas con la noción de Infraestructura Verde, se reconocen espacios de oportunidad en la institucionalidad y normativa vigente que pueden contribuir a estructurar este enfoque. En este sentido, cabe destacar el cuerpo legal que establece la regulación de Áreas Silvestres

\footnotetext{
Ios Planes Reguladores Comunales (PRC) y los Planes de Adaptación y Mitigación ante el Cambio Climático, tanto aquellos de alcance nacional asociados a diversos Ministerios, como aquellos de escala comunal.

47 Respecto a instrumentos responsivos o correctivos, se puede mencionar al conjunto de iniciativas que se desarrollaron en el contexto post desastre de 2010, los cuales siguen vigentes y han sido aplicados en otros territorios afectados por desastres de diverso tipo: los Planes de Reconstrucción Estratégicos (PRES), los Planes de Reconstrucción de Borde Costero (PRBC), los Planes de Regeneración Urbana (PRU) y los Planes Urbanos Estratégicos (PUE).
} 
Protegidas ${ }^{48}$, sobre las cuales se puede ampliar el espectro de argumentación que las define, considerando ya no sólo aquellos valores ecológicos intrínsecos -tales como naturalidad, endemismo o biodiversidad-sino también valores asociados a los servicios ecosistémicos que aportan en materia de regulación, resiliencia y reducción de riesgos ante desastres. Sumado a lo anterior, se puede mencionar también el aporte en materia de protección y conservación de ecosistemas que promueve la suscripción -por parte del Estado de Chile- de convenciones y acuerdos internacionales, tales como el Convenio $R A M S A R^{49}$, especialmente enfocado en la conservación de humedales, incluyendo aquellos que se localizan en zonas costeras y que constituyen piezas relevantes de infraestructura ecológica para la amortiguación de impactos de tsunamis, marejadas y otros eventos hidrometereológicos.

Otro aspecto fundamental en la planificación estratégica de los Parques de Mitigación tiene relación con la necesidad de coordinación de las carteras de infraestructura urbana y territorial asociada a ámbitos de gestión sectorial en materia de vialidad, obras portuarias, obras hidráulicas y espacio público, cuya gestión se concentra principalmente en los Ministerios de Obras Públicas (MOP) y el Ministerio de Vivienda y Urbanismo (MINVU). Desde el año 2018, la Subsecretaría de Desarrollo Regional (SUBDERE) en conjunto con diversos Gobiernos Regionales han impulsado la conformación de Mesas Regionales de Infraestructura ${ }^{50}$, las cuales constituyen instancias técnicas de coordinación para el desarrollo de infraestructura regional que operan mediante la participación del MOP, MINVU y la Cámara Chilena de la Construcción, agrupación que reúne a las principales empresas constructoras en

48 La ley 18362, del año 1984, establece el Sistema Nacional de Áreas Silvestres Protegidas del Estado de Chile (SNASPE), el que tiene los siguientes objetivos de conservación:a) Mantener áreas de carácter único o representativas de la diversidad ecológica natural del país o lugar con comunidades animales o vegetales, paisajes o formaciones geológicas naturales, a fin de posibilitar la educación e investigación y de asegurar la continuidad de los procesos evolutivos, las migraciones animales, los patrones de flujo genético y la regulación del medio ambiente; b) Mantener y mejorar recursos de la flora y la fauna silvestres y racionalizar su utilización; c) Mantener la capacidad productiva de los suelos y restaurar aquellos que se encuentren en peligro o en estado de erosión; d) Mantener y mejorar los sistemas hidrológicos naturales, y e) Preservar y mejorar los recursos escénicos naturales y los elementos culturales ligados a un ambiente natural.Actualmente, existe un proyecto de ley para modernizar la regulación de las áreas silvestres, el cual crea el Servicio de Biodiversidad y Areas Protegidas, en tramitación desde 2011, definiendo modificaciones orientadas a mejorar la gestión intersectorial e interescalar, asumiendo que el problema de conservación también depende principalmente de actores y componentes que se encuentran fuera de las áreas protegidas como tal.

49 La Convención Ramsar sobre los Humedales es la principal autoridad intergubernamental sobre los humedales y procura velar para que las contribuciones, hechas por los humedales al bienestar humano, en todos sus aspectos, se reconozcan y fortalezcan en todos los sectores y niveles de la sociedad. La Convención impulsa su ámbito de acción en humedales, en el contexto de manejo de cuencas hidrográficas, zonas designadas como Sitios Ramsar. Chile a la fecha cuenta con 13 Sitios Ramsar, de los cuales 9 están dentro de áreas del SNASPE y el resto cuenta con diversas figuras de protección y administración. Este tratado se aprobó como Ley de la República en septiembre de 1980 y promulgada por DS No 771 de 1981 por el Ministerio de RREE. El Ministerio de RREE, a través de la Dirección de Medio Ambiente (DIMA) es la autoridad administrativa ante la Convención.

50 Las Mesas Regionales de Infraestructura constituyen iniciativas de carácter público-privada, en las cuales participan representantes del Gobierno Regional, de la Subsecretaría de Desarrollo Regional, de los Ministerios de Obras Publicas, Vivienda y Urbanismo y de la Cámara Chilena de la Construcción. Tiene como objetivo fomentar la cooperación e incorporar una visión integral y consensuada entre los actores relevantes del territorio, buscando elaborar, implementar y hacer un seguimiento de las medidas que promuevan una mayor eficiencia en la inversión de infraestructura considerando el desarrollo sostenible de la región. Desde el 2018, estas Mesas se han establecido en diversas regiones, mediante convenios de colaboración que suscriben las instituciones participantes. 
Chile. Estas mesas, de carácter público-privada, constituyen un importante e innovador espacio de articulación multisectorial, que puede favorecer la visión de la infraestructura multipropósito requerida para la planificación e implementación de los Parques de Mitigación, en tanto infraestructura clave para el desarrollo socioeconómico y productivo de territorios vulnerables ante la ocurrencia de desastres.

PARQUES DE MITIGACIÓN

2.1. Integración normativa e indicativa de instrumentos y programas de carácter multisectorial.
2.2. Conservación estratégica de ecosistemas y unidades de paisaje claves para la conformación de una red infraestructura verde a partir de instrumentos de protección de áreas silvestres.
2.3. Coordinación multisectorial de la infraestructura urbana $y$ territorial asociada a la noción de infraestructura verde para la resiliencia y reducción de riesgos de desastres.
2.4. Gestión de recursos para planes y proyectos de infraestructura verde de mitigación mediante instrumentos de articulación público - privada.

\section{ESTRATEGIAS DE PLANIFICACIÓN.}

\begin{abstract}
La gestión normativa e indicativa de instrumentos de carácter multisectorial provenientes de diversos ámbitos ministeriales que responden a la gestión de territorios urbanos, rurales y silvestres - se plantea como eslabón fundamental para la promoción y manejo de los Parques de Mitigación comprendidos en el marco de una sistema mayor de infraestructura verde destinada a la resiliencia urbana y a la reducción de riesgos en territorios vulnerables ante la ocurrencia de desastres
\end{abstract}

Si bien en la actualidad a nivel nacional no existen normativas especificas relacionadas con la noción de Infraestructura Verde, se reconocen espacios de oportunidad en la institucionalidad y normativa vigente que pueden contribuir a estructurar este enfoque. Destaca la figura legal de las Áreas Silvestres Protegidas, sobre las cuales se puede ampliar el espectro de argumentación que las define, considerando valores asociados a los servicios ecosistémicos que aportan a la resiliencia y reducción de riesgos ante desastres. También es relevante la existencia del Convenio RAMSAR, enfocado en la conservación de humedales, incluyendo aquellos que se localizan en zonas costeras y que son piezas relevantes de infraestructura ecológica para la amortiguación de impactos de tsunamis, marejadas y otros eventos hidrometereológicos.

La conformación de las Mesas Regionales de Infraestructura - instancias técnicas de coordinación para el desarrollo de infraestructura regional que operan mediante la participación del MOP, MINVU y la Cámara Chilena de la Construcción - constituyen un importante e innovador espacio de articulación multisectorial que puede favorecer la visión de la infraestructura multipropósito requerida para la planificación e implementación de los Parques de Mitigación, en tanto infraestructura clave para el desarrollo socioeconómico y productivo de territorios vulnerables ante la ocurrencia de desastres.

Destaca la Ley de Aportes al Espacio Público (Ley 20.958), que conduce las mitigaciones y compensaciones ambientales derivadas del desarrollo de proyectos inmobiliarios públicos y privados hacia aquellas zonas que - previo a un plan definido a nivel comunal - puedan recibir cesiones de terrenos y aportes monetarios para conformar sistemas de infraestructura verde. Sumando a lo anterior, estas zonas y los planes vinculados a infraestructuras verdes de mitigación ante desastres que en ellas se formulen, pueden capturar aportes de recursos provenientes de compensaciones ambientales determinadas por el Sistema de Evaluación Ambiental (Ley 20.417), desde aquellos desarrollos industriales y productivos que generen impactos ambientales en esas comunas o regiones.

Tabla 7. Estrategias de planificación para la implementación de Parques de Mitigación.

Fuente: Elaboración propia.

Por otra parte, en relación al ámbito urbano, se reconocen disposiciones normativas e instrumentos que pueden contribuir a consolidar la figura de los Parques de Mitigación. Destaca en tal sentido la promulgación de la Ley de Aportes al Espacio 
Público ${ }^{51}$, que conduce las mitigaciones y compensaciones ambientales derivadas del desarrollo de proyectos inmobiliarios públicos y privados hacia aquellas zonas que previo a un plan definido a nivel comunal- puedan recibir cesiones de terrenos y aportes monetarios para conformar sistemas de espacios públicos. Sumando a lo anterior, estas zonas y los planes vinculados a infraestructuras verdes de mitigación ante desastres que en ellas se formulen, pueden capturar aportes de recursos provenientes de compensaciones ambientales determinadas por el Sistema de Evaluación Ambiental ${ }^{52}$, desde aquellos desarrollos industriales y productivos que generen impactos ambientales en esas comunas o regiones. De esta forma, las áreas definidas en los instrumentos de planificación como zonas de riesgo -asociadas a bordes y ecotonos determinados por el encuentro de los asentamientos urbanos con los sistemas naturales costeros y ribereños, entre otros- pueden constituirse en receptoras de aportes provenientes de estas normas e instrumentos de gestión y planificación, conformando un capital base para la implementación de proyectos de Parques de Mitigación. En la tabla 7 se resumen las estrategias de planificación propuestas.

\subsubsection{Criterios técnicos de diseño del Parque como sistema integrado de amortiguación}

La funcionalidad de los Parques de Mitigación, asociada a su rol de infraestructura verde proyectada para promover la resiliencia urbana y la reducción de riesgos ante desastres, depende fundamentalmente de la articulación de dinámicas colaborativas y sinérgicas entre los componentes naturales y construidos que conforman el sistema en su conjunto. En tal sentido, la propuesta de fortalecimiento para su implementación comprende cinco ámbitos de diseño que se presentan a continuación, los cuales configuran subsistemas secuenciales y coordinados para estructurar, por un lado, capas de protección ante fenómenos extremos de inundaciones generadas por tsunamis, marejadas y otros eventos hidrometereológicos y, por otro, proveer de espacios sociales en contextos de borde costero, conformando ámbitos públicos de reclamación y accesibilidad hacia el paisaje.

La efectividad de su diseño debe ser verificado en las fases tempranas de su formulación, mediante el modelamiento numérico de tsunamis y/o marejadas, siguiendo los procedimientos técnicos de TUNAMI ${ }^{53}$ u otro de similares características.

\section{i) Diseño de componentes off-shore}

51 La Ley 20.958, promulgada en 2016, establece un sistema de aportes al espacio público que modifica la Ley General de Urbanismo y Construcciones (LGUC), reemplazando a los Estudios de Impacto sobre el Sistema de Transporte Urbano (EISTU) por un nuevo sistema basado en mitigaciones sobre la base que todos los proyectos inmobiliarios sean públicos o privados generan externalidades en su entorno, las cuales deberán ser mitigadas de manera directa en las áreas de influencia del proyecto, o bien transferidas como aportes a otras zonas urbanas.

52 El Sistema de Evaluación Ambiental (SEIA) está regulado por la ley 20.417 y por Reglamento del Sistema de Evaluación Ambiental, que determinan los procedimientos y objetivos de compensación aplicables a proyectos de inversión que generan impactos ambientales.

53 Siglas de Tsunami Code of Tohoku University, cuyas técnicas de modelación numérica fueron utilizadas para evaluar el diseño de anteproyecto y proyecto ejecutivo de los Parques de Mitigación de Constitución, Pelluhue y Dichato, revisados en esta investigación. 
La mayoría de los asentamientos urbanos en Chile ubicados en bordes costeros se desarrollan en contextos de bahías o estuarios determinados por la desembocadura de ríos, constituyendo paisajes que en su estado natural se caracterizan por la presencia de humedales, praderas marinas, campos dunarios y zonas de depósito sedimentarios, provenientes desde la corriente fluvial y las corrientes marinas (Da Cunha, 2018). Como se ha señalado, los procesos de antropización de estos territorios, sumado a dinámicas de cambio climático, han derivado en la reducción, fragmentación y deterioro de estos sistemas naturales, comprometiendo de esta forma su potencial rol como infraestructuras ecológicas para la reducción de riesgos ante inundaciones y otros desastres.

Este primer criterio de diseño reflexiona acerca de la necesidad de estructurar sistemas de mitigación mediante componentes que contribuyan al establecimiento de infraestructuras ecológicas en paralelo al litoral, costa afuera u offshore, en aquellos casos de localidades ubicadas en zonas de estuario y/o bahías cerradas, contemplando la restauración y propagación de ecosistemas remanentes y emergentes. De esta manera, se plantea que los Parques de Mitigación consideren la proyección y manejo de zonas de depósito sedimentarios acompañados de estructuras de defensa construidas para su estabilización en los espacios marinos y/o fluviales que preceden la línea de borde costero. Esta propuesta busca ampliar el rango de actuación de los Parques de Mitigación hacia un campo operativo mayor, contemplando intervenciónes que permitan robustecer el sistema de amortiguación hacia el espacio marítimo o fluvial -según corresponda, en contextos de bahías o estuarios, respectivamente- aprovechando las potenciales sinergias que pueden activarse a través de la conservación, planificación y eventual diseño de ecosistemas remanentes y emergentes.

En continuidad con las definiciones conceptuales identificadas en el diseño de los proyectos analizados en la experiencia internacional, la propuesta de estrategias offshore se estructura en base a tres operaciones:

- Operaciones de infraestructura construida, mediante la proyección de diques espigones estructurados de manera perpendicular a la línea de costa o ribera, los cuales contribuyen a capturar los flujos sedimentarios provenientes desde la corriente del estuario, conformando una primera capa de defensa basada en la combinación de métodos estructurales - los diques espigones - con métodos no estructurales referidos a la progresiva acumulación y modelamiento de los bancos sedimentarios. En términos de diseño, los diques pueden contemplar una base de enrocado natural o bloques de hormigón prefabricados, conformando taludes con pendientes en relación $1: 4$, considerando alturas de coronación similares a los niveles de terreno de las costaneras y muros de contención proyectados en el borde costero.

- Operaciones topográficas, a través de la configuración y modelamiento de bancos sedimentarios contenidos por la acción de los diques espolones, desarrollando superficies de rugosidad de alturas y anchos variable, las cuales son modeladas y compactadas para evitar fenómenos de erosión o sobreenbancamiento. La rugosidad y porosidad de estos bancos, que se refuerzan también con coberturas vegetacionales, aporta en el aumento del coeficiente 
de Manning y, por tanto, en las capacidades de amortiguación del Parque en su conjunto.

- Operaciones ecológicas, por medio de la restauración de ecosistemas riparios sobre los bancos sedimentarios, transformándose en ámbitos susceptibles para la implantación y/o recuperación de vegetación de ribera, cuya propagación aporta a la fitoestabilización de los nuevos suelos.

Junto con favorecer la conformación de una primera línea de defensa del sistema de mitigación que establece el Parque, estas estrategias pueden articularse con iniciativas de programas sociales recreativos, turísticos y productivos, así como también con la restauración de ecosistemas riparios y marinos. En la siguiente imagen (fig. 42) se grafica una propuesta de imagen objetivo de las estrategias off-shore aplicadas al caso del Parque de Mitigación de Constitución.

\section{ii) Defensas construidas}

Los componentes asociados a las defensas construidas constituyen un importante dispositivo de los Parque de Mitigación, cuando su funcionalidad es complementada y apoyada por soluciones basadas en la acción de componentes naturales. De esta forma, la proyección de muros de contención, enrocados, escolleras y diques debe ser coordinada para actuar de manera conjunta con sistemas de vegetación y suelos. Las defensas construidas cumplen con el rol de descomponer parte de la fuerza de impacto en los procesos de inundación generados tsunamis, marejadas y otros eventos hidrometereológicos, amortiguando por tanto los aumentos de volumen y velocidad del flujo de ingreso.

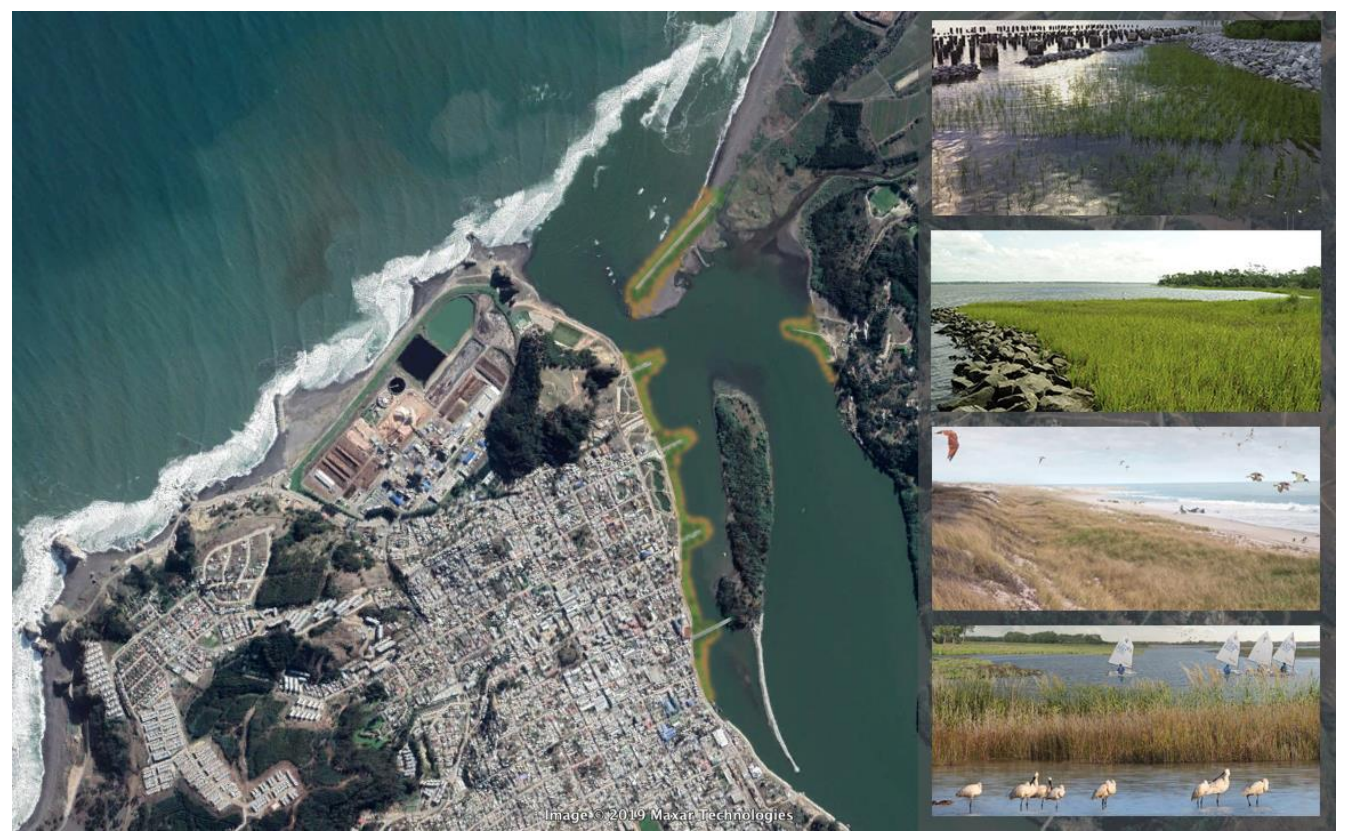

Fig. 42. Imagen Objetivo de las estrategias off-shore aplicadas al caso del Parque de Mitigación de Constitución, a través de espigones perpendiculares a la ribera para promover captura de sedimentación proveniente del río, generando bancos de amortiguación a través de la acumulación progresiva de suelo para establecimiento de vegetación riparia. Las estructuras de captura, sostenidas mediante taludes de 
enrocado, conforman también dispositivos de rehabilitación de ecosistemas de ribera y de soporte para el desarrollo de actividades recreativas y productivas.

Fuente: Elaboración propia en base a imágenes Google Earth (c).

En términos de innovación respecto a los componentes ya utilizados en los Parques de Mitigación, se propone articular el diseño de este tipo de defensas construidas con otras iniciativas de proyecto de infraestructuras urbanas, relacionadas principalmente con vialidad, obras portuarias y drenaje urbano, concibiéndolas desde la perspectiva de planificación y diseño de infraestructuras multipropósito que, por un lado, atiendan los requerimientos específicos propios de su función $y$, por otro, adquieran operatividad como mecanismos de protección ante desastres.

Según lo analizado en la experiencia internacional, entre los componentes de infraestructura que adquieren un sentido multifuncional, se pueden mencionar:

- En el caso de las infraestructuras de obras portuarias: muros costeros, enrocados rompeolas, molos de abrigo, espigones, muelles y rampas de acceso tierra-mar.

- Respecto a las infraestructuras viales y ferroviarias: terraplenes, muros de contención y muros de seguridad.

- En relación a las infraestructuras de drenaje: canales de escorrentía, lagunas de retención y pozos absorbentes.

En la siguiente figura se identifican ejemplos de defensas construidas para la mitigación de impactos de desastres en bordes costeros, basadas en la operatividad de infraestructuras multipropósito asociadas a vialidad, obras portuarias y drenaje urbano.
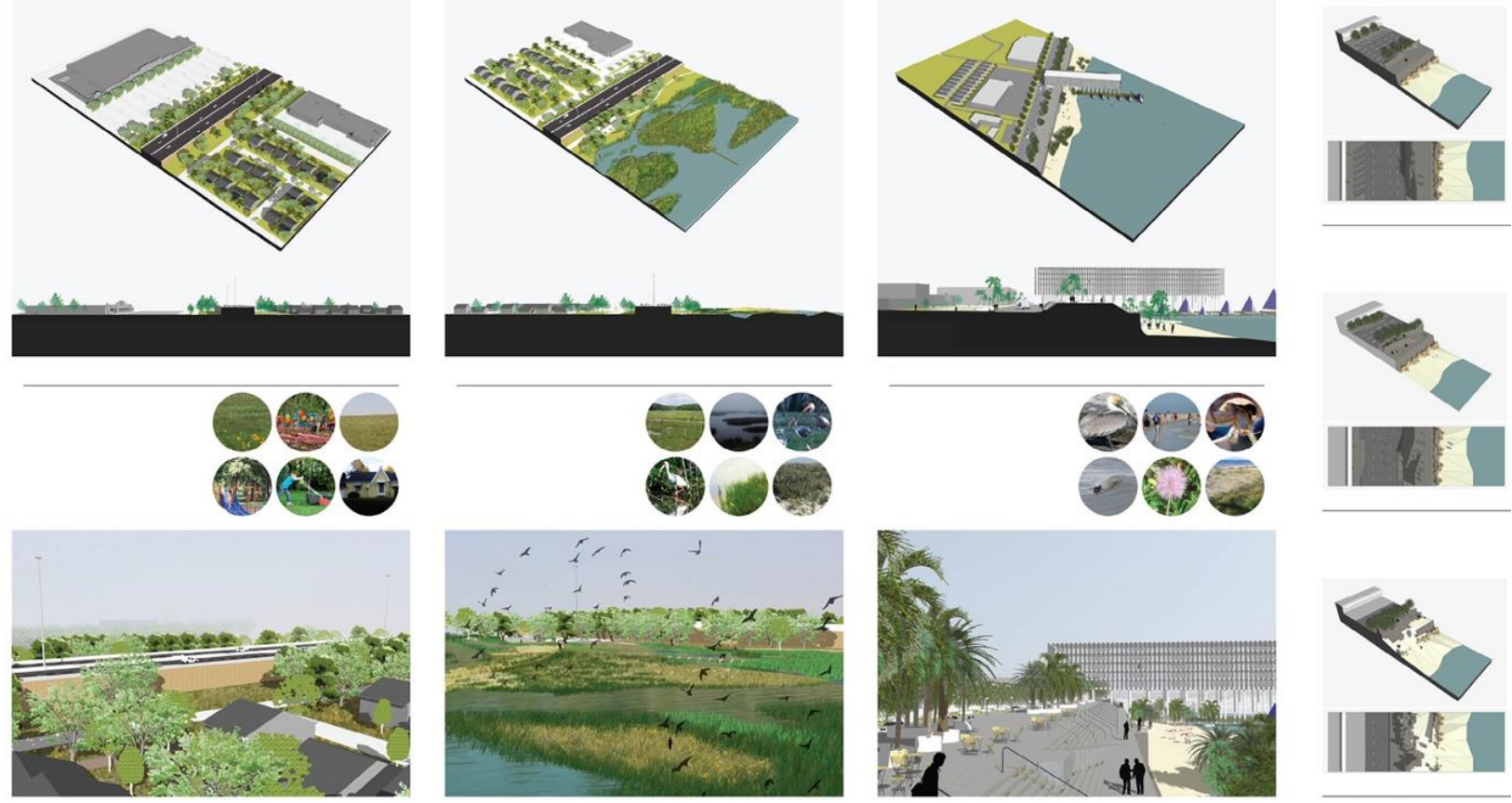
Fig. 43. Ejemplo de planificación y diseño de infraestructuras verdes para la mitigación de impactos de desastre, basadas en la operatividad de sistemas ecológicos - de humedales y bosques costeroscombinados con infraestructuras construidas.

Fuente: Elaboración propia en base al proyecto Houston Coastal Roulette Planning Resilient Communities for Galveston Bay (SWA Group y ASLA, 2012).

\section{iii) Sistemas de circulación / evacuación}

Los sistemas de circulación en los Parques de Mitigación deben contemplar su conectividad con las vías de evacuación definidas a partir de los planes de emergencia desarrollados en ciudades litorales y en otras localidades afectas a riesgos de desastres $^{54}$. Para ello, resulta necesario que la configuración de las circulaciones peatonales favorezca un desplazamiento expedito y claro hacia las vías de evacuación, las cuales a su vez conducen a la población hacia zonas seguras.

En términos de diseño, se propone estructurar una red principal de infraestructura pavimentada, la cual conecte los diversos sectores del Parque en sentido longitudinal y transversal, constituyéndose como matriz ordenadora de los recorridos. Esta red debe asegurar la accesibilidad universal, el desplazamiento y la conexión desde la franja de costero o fluvial, según sea el caso, hacia la vialidad que alberga las vías de evacuación. Como refuerzo referido a la legibilidad de esta estructura, se plantea el uso de pavimentos podotáctiles o texturados, la disposición de señalética informativa y la dotación de luminarias que posean autonomía energética, idealmente a través de energía solar.

\section{iv) Modelamiento topográfico}

En los Parques de Mitigación, el diseño del suelo implica un factor relevante y crítico para la disipación del impacto mediante la descomposición de los vectores de fuerza del desastre, especialmente cuando éste supera la barrera vinculada a las defensas off-shore. Operando de manera conjunta con los sistemas de vegetación que complementan las operaciones de suelo, los movimientos topográficos aumentan la elevación natural del terreno en las zonas de planicies litorales y ribereñas donde se desarrolla el Parque, generando también depresiones que favorecen la inundabilidad controlada ante el ingreso del tsunami.

Estas soluciones definen un manto variable -que basa su funcionalidad en los sistemas de dunas y colinas costeras- el cual produce una mayor rugosidad en la superficie de desplazamiento del fluido en su recorrido desde el mar hacia tierra adentro, aumentando el coeficiente de roce. Se intenta con ello disminuir por un lado su volumen - asociado a la altura de los niveles de inundabilidad o run-up- y por otra parte s velocidad, vinculada con la necesidad de otorgar mayor margen temporal para la evacuación de las zonas que se verán afectadas.

\footnotetext{
54 Los planes de emergencia se desarrollan a nivel comunal, en aquellos territorios susceptibles de ser afectados por la ocurrencia de desastres. Su objetivo es proveer las herramientas y los procedimientos para atender la emergencia post-desastre y, de manera particular, generar las condiciones para implementar la evacuación de las zonas de riesgo, hacia zonas seguras. Su formulación e implementación dependen de ONEMI y MINVU respectivamente.
} 
De acuerdo a lo constatado en la experiencia japonesa post tsunami 2011, así como también en los casos nacionales de los parques de mitigación desarrollados en los planes de reconstrucción post tsunami de 2010, los criterios de diseño topográfico requieren contemplar:

- Coeficientes de rugosidad del modelamiento topográfico con valores de Manning no inferiores a 0.20 , en aquellos proyectos que cuenten además con Bosques de Mitigación. Para los casos que no contemplen estos sistemas de vegetación, el coeficiente de Manning no debería ser inferior a 0.23.

- Extensiones de amplitud idealmente superiores a 100 metros de ancho, considerando para aquellos casos de amplitud reducida complementar estas estrategias topográficas con defensas construidas y sistemas de bosques de mitigación.

- Dimensionamiento de alturas de elevación -modelamiento "hacia arriba"- y profundidades de depresión -"hacia abajo"- generando diferencias de nivel de 5 o más metros, entre la cota inferior de depresiones y la cota superior de elevaciones.

- Pendientes de elevación de laderas no superiores a la relación 1:4, para prevenir procesos erosivos y, por otra parte, facilitar el establecimiento de vegetación sobre las dunas o colinas.

- Reutilización y reciclaje de escombros para generar elevaciones en el terreno, promoviendo iniciativas de economía circular, sobre los cuales se implementan coberturas de suelos estabilizados con mecanismos físicos (membranas) y fitoestabilización para prevenir erosión de origen eólico o hídrico.

- Coberturas y composición de sustrato del suelo compatibles con las condiciones ambientales del contexto de intervención, en términos de su procedencia, granulometría, erodabilidad, capacidad de infiltración y perfil bioquímico.

\section{v) Bosques de mitigación}

Los sistemas de vegetación en los parques de Mitigación constituyen el eslabón más importante de su estructura, no sólo respecto al aporte en materia de disipación y amortiguación de los impactos ante desastres, sino también a su presencia como componente ecológico y paisajístico clave para la provisión de servicios ecosistémicos de provisión, regulación, culturales y de soporte.

Desde el punto de vista de su origen, las estrategias de vegetación consideran:

- Conservación y propagación de sistemas de vegetación de ecosistemas remanentes como parte de la infraestructura verde del Parque, especialmente de aquellos estratos arbustivos y herbáceos propios de praderas marinas o hidrófilas, zonas riparias, humedales costeros y cordones dunarios.

- Introducción de sistemas de vegetación compatibles con las condiciones ambientales del contexto de intervención, determinadas por una selección de especies nativas y/o exóticas aptas para establecer comunidades resilientes ante las características de clima y suelos, con especial atención en la salinidad de ambientes costeros y estuarinos.

- Hibridación de sistemas de vegetación remanentes e introducidos o emergentes, mediante criterios de diseño y manejo que favorezcan sinergias y 
complementariedades interespecies. Un ejemplo de ello refiere al rol que pueden asumir las especies nativas o introducidas halófitas de primera línea de costa, para proteger las alineaciones posteriores ante la influencia de la salinidad en aire y suelos.

Por otra parte, las estrategias contemplan el uso combinado de vegetación en diversos estratos, los cuales colaboran con las funciones de mitigación mediante la densidad del sistema en su conjunto. De esta manera se proponen:

- Especies de estrato de cubresuelos, resistente a sustratos rústicos y - según el contexto de intervención - a bajo requerimiento hídrico, cuya función es, por un lado, proveer de estabilización a la cobertura de suelos modelados en las pendientes de colinas o dunas, según sea el caso. Por otro, al desarrollarse como primera capa de cobertura vegetal, contribuye a mejorar las condiciones de humedad y fijación de nutrientes en los suelos.

- Especies de estrato herbáceo, principalmente asociada a zonas riparias de primera línea de costa, o bien a zonas inundables vinculadas a depresiones en el sistema de modelamiento topográfico del Parque, cuyo rol es contribuir a la fitoestabilización de los movimientos topográficos, retener volúmenes de agua ante eventos de inundación y colaborar en su infiltración. En particular, cuando se dispone en zonas inundables de retención y laminación, colabora también en procesos de oxigenación y fitorremediación de aguas.

- Especies de estrato arbustivo, con raíces pivotantes y extendidas, de ramaje denso y horizontal, de hoja idealmente perenne, su función es colaborar junto al arbolado como barrera de retención y disipación de la fuerza hidrodinámica, aportando además atributos ecológicos de biodiversidad. Por otra parte, el uso de alineaciones de especies halófitas propias de zonas ribereñas, forman cortinas que protegen de la salinidad a las filas que se encuentren detrás de ellas.

- Especies de estrato arbóreo, de raíz profunda y pivotante que conforman junto al estrato arbustivo la barrera de disipación del flujo entrante, la cual tiene un importante rol, por la mayor envergadura de las especies, en la retención de elementos arrastrados por las aguas.

En términos de densidades de plantación, siguiendo el ejemplo de las iniciativas estudiadas en Japón (Renaud \& Murti, 2013), las recomendaciones de la Guía para la selección de coeficientes de rugosidad de Manning (Arcement \& Schneider, 1989) y los supuestos establecidos en las modelaciones de escenarios desarrolladas por Lagos (2012), se propone definir rangos mínimos de 4000 especies de arbustos por hectárea y 3000 especies de árboles por hectárea, con el objetivo de alcanzar coeficientes de rugosidad de Manning superiores a 0.20, para asegurar la efectividad de las soluciones propuestas.

El logro de estas densidades de plantación no sólo plantea un desafío ambiental y técnico vinculado a las capacidades bioquímicas y mecánicas de los suelos que las soportan, o a la propias condiciones de asociatividad ecológica de las especies, sino que demanda una nueva concepción de parque referida a la espacialidad y a la estética resultante, más cercana a la imagen de ecosistemas silvestres auto- 
organizados y evolutivos, que a sistemas de plantación determinados por grillas geométricas predefinidas. Asimismo, desde el punto de vista de su uso y valoración social, estos componentes se definen ya no sólo como ámbitos programáticos o socialmente funcionales, sino más bien como reductos ecológicos que contienen y aportan importantes servicios ecosistémicos asociados a la conservación de la biodiversidad y, especialmente, a la adaptabilidad y resiliencia de las localidades costeras ante la ocurrencia de desastres.

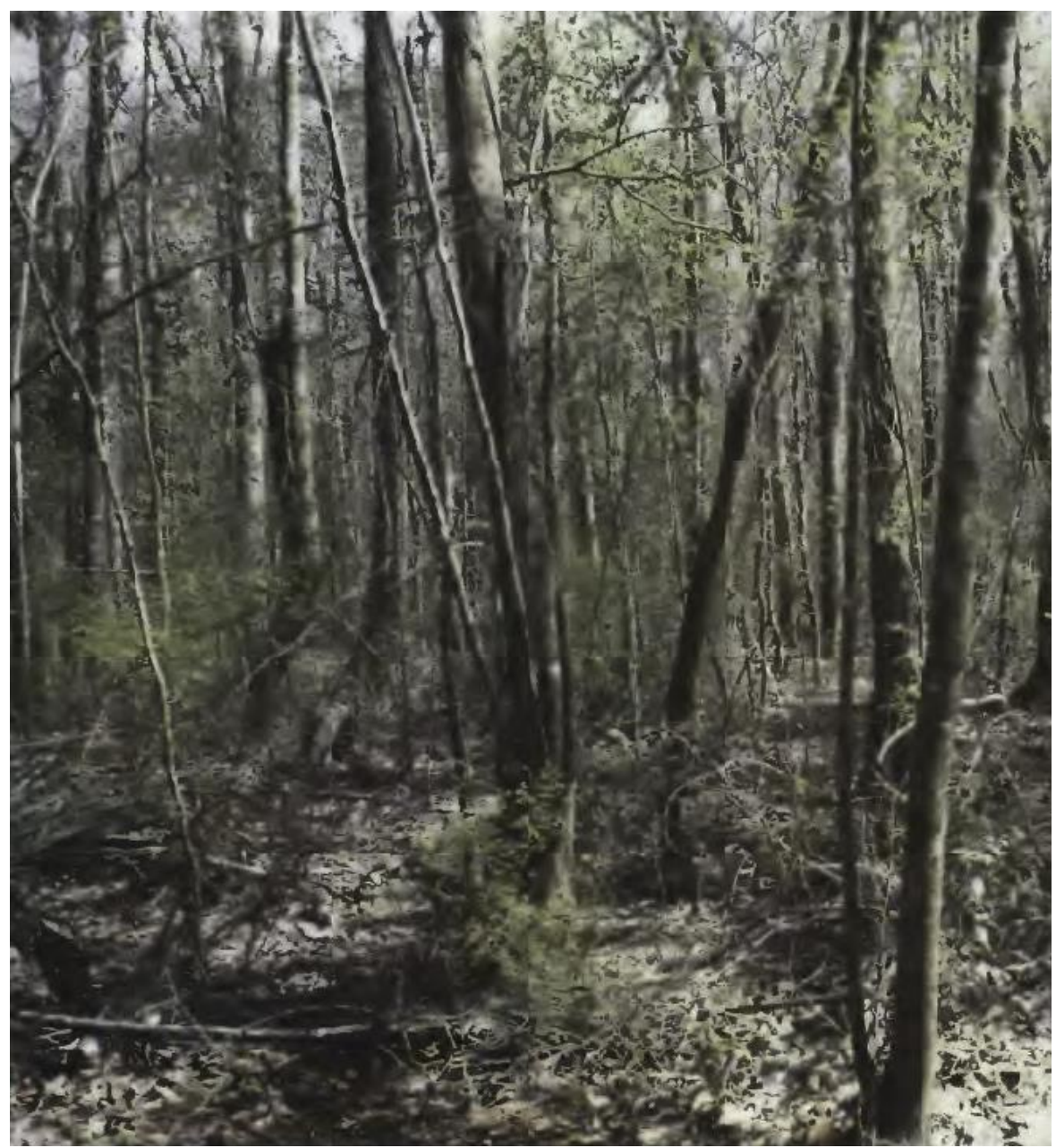

Fig. 44. Estudio de caso para determinar coeficiente de rugosidad de Manning de 0.20 , a partir de densidad vegetacional expuesta a inundabilidad.

Fuente: Arcement \& Schneider (1989).

En la siguiente tabla se sintetizan los criterios técnicos de diseño expuestos: 
PARQUES DE MITIGACIÓN

3.1. Establecimiento de sistemas de mitigación mediante infraestructuras ecológicas off-shore
3.2. Diseño de defensas construidas mediante infraestructura de carácter multipropósito.

\section{CRITERIOS TÉCNICOS DE DISEÑO.}

Configuración de sistemas de mitigación mediante componentes que contribuyan al establecimiento de infraestructuras ecológicas en paralelo al litoral, costa afuera (offshore), contemplando la restauración y propagación de ecosistemas remanentes y emergentes. Para ello se considera la proyección y manejo de zonas de depósito sedimentarios acompañados de estructuras de defensa construidas para su estabilización en los espacios marinos y/o fluviales que preceden la línea de borde costero, robusteciendo el sistema de amortiguación.

3.1.1. Operaciones de infraestructura construida.

3.1.2. Operaciones topográficas.

3.1.3. Operaciones ecológicas.

Los componentes asociados a defensas construidas conforman un importante dispositivo de los Parque de Mitigación, cuando su funcionalidad es complementada por soluciones basadas en la acción de ecosistemas. Se propone articular el diseño de este tipo de defensas con otras iniciativas de infraestructuras urbanas, relacionadas principalmente con vialidad, obras portuarias y drenaje urbano, concibiéndolas desde la perspectiva de planificación y diseño de infraestructuras multipropósito que, por un lado, atiendan los requerimientos específicos propios de su función y, por otro, adquieran operatividad como mecanismos de protección ante desastres.

3.2.1. Operaciones de infraestructura portuaria.

3.2.2. Operaciones de infraestructura vial y ferroviaria.

3.2.3. Operaciones de infraestructura hidráulica.

Los sistemas de circulación en los Parques de Mitigación deben contemplar su conectividad con las vías de evacuación definidas en los planes de emergencia desarrollados en localidades afectas a riesgos de desastres, favoreciendo un desplazamiento expedito hacia las vias de evacuación que conducen hacia zonas seguras. Por un lado, se propone estructurar una red principal de infraestructura pavimentada, la cual conecte los diversos sectores del Parque, constituyéndose como matriz ordenadora de los recorridos. Como refuerzo referido a la legibilidad, se plantea el uso de pavimentos podotáctiles o, la disposición de señalética informativa y la dotación de luminarias con autonomía energética, idealmente a través de energía solar.

3.2.1. Red principal de accesibilidad universal, ordenadora de recorridos.

3.2.2. Señalética horizontal y vertical.

3.2.3. Luminaria con autonomía energética. 
3.4. Modelamiento topográfico de los suelos del Parque para aumentar el coeficiente de roce.
3.5. Configuración de sistemas de vegetación multiestrato como dispositivo ecológico de disipación.
Operando de manera conjunta con los sistemas de vegetación que complementan las operaciones de suelo, los movimientos topográficos aumentan la elevación natural del terreno en las zonas de planicies litorales y ribereñas donde se desarrolla el Parque, generando también depresiones que favorecen la inundabilidad controlada ante el ingreso del tsunami. Estas soluciones definen un manto variable que produce una mayor rugosidad en la superficie de desplazamiento del fluido en su recorrido desde el mar hacia tierra adentro, aumentando el coeficiente de roce.

3.4.1. Amplitud de extensión transversal y complementariedad con otros sistemas.

3.4.2. Dimensionamiento de alturas de elevación y pendientes de laderas.

3.4.3. Reciclaje de escombros y estabilización de sustratos para conformación de suelos.

Los bosques de mitigación, conformados por sistemas de vegetación de diversos estratos, constituyen el eslabón más importante de la estructura del Parque, no sólo respecto al aporte en materia de disipación y amortiguación de los impactos ante desastres, sino también a su presencia como componente ecológico y paisajístico clave para la provisión de servicios ecosistémicos de provisión, regulación, culturales y de soporte.

3.5.1. Conservación y propagación de sistemas de vegetación remanentes .

3.5.2. Introducción de sistemas de vegetación compatibles con el contexto.

3.5.3. Hibridación de sistemas de vegetación remanentes e introducidos o emergentes.

3.5.4. Uso combinado de vegetación en diversos estratos y en alta densidad.

Tabla 14. Criterios de diseño para la implementación de Parques de Mitigación. Fuente: Elaboración propia. 


\section{CONCLUSIONES Y PROYECCIONES: EL PAISAJE COMO INFRAESTRUCTURA SOCIOECOLÓGICA PARA LA RESILIENCIA $Y$ ADAPTABILIDAD DE TERRITORIOS Y COMUNIDADES}

En los últimos años, la arquitectura del paisaje ha desarrollado un importante ámbito de reflexión teórica y práctica asociado a la problemática de la planificación y diseño de territorios vulnerables ante desastres, gran parte de los cuales acontecen en contextos determinados por la presencia de asentamientos urbanos en espacios colindantes a sistemas naturales, definidos como bordes o ecotonos. En tal sentido, los territorios costeros representan un foco de atención relevante en materia de estudios y proyectos orientados a la reducción de riesgo y la gestión de resiliencia, dada su alta exposición a fenómenos tales como marejadas, tsunamis y alza del nivel del mar, acentuados en las pasadas décadas debido a los efectos del cambio climático global. Desde el lenguaje de la resiliencia, el manejo adaptativo y la versatilidad, el proyecto de paisaje ha estado estrechamente vinculado al diseño de infraestructuras verdes conformadas por ingenierías híbridas de elementos construidos, manejo de topografías y sistemas ecológicos, los cuales se adaptan a las condiciones dinámicas del territorio, contemplando sus múltiples naturalezas y fenómenos. El impacto recurrente de tormentas y huracanes en América del Norte -como Katrina en 2005, Ike 2018 y Sandy en 2011- han sido factores desencadenantes de iniciativas de investigación y políticas públicas orientadas a promover instrumentos de planificación y proyectos para la reducción de riesgo ante desastres, principalmente referidos al manejo de inundaciones en ciudades costeras. Asimismo, desastres relacionados con tormentas, marejadas y tsunamis ocurridos en el norte de Europa y Asia, respectivamente, aportan experiencias destacadas en materia de planes y proyectos de paisaje e infraestructuras verdes.

En relación al caso de estudio, el terremoto y posterior tsunami ocurrido el 27 de febrero del 2010 en Chile -denominado comúnmente como 27F- se considera el desastre de mayor cobertura urbana registrado en su historia y uno de los más grandes eventos acontecidos a escala global, dada su amplia extensión que afectó gravemente las localidades de borde costero en más de 600 kilómetros de longitud, incluyendo a los principales centros urbanos e infraestructuras críticas del centro sur de Chile. Las regiones del Maule y Biobío fueron las zonas más devastadas, tanto por las pérdidas de vidas humanas, como por los daños materiales generados en diversas ciudades, pueblos y caletas. Más allá de las condiciones físico-naturales, la escasa consideración de la dinámica y recurrencia de procesos naturales extremos, y su relación con el emplazamiento y expansión de asentamientos humanos, incrementó el riesgo de desastre especialmente en las localidades de borde costero, debido no sólo a la ocupación irregular y desprovista de planificación territorial, sino también a la presión ejercida desde el sector inmobiliario para la construcción en esos espacios.

Pese al complejo escenario de destrucción que este evento produjo, ha sido posible entenderlo también como un importante espacio de oportunidad para repensar las dinámicas de habitabilidad en contextos de borde. Este enfoque prospectivo ha permitido en años posteriores desarrollar conocimiento científico y técnico en diversas áreas del conocimiento, favoreciendo procesos reflexivos relacionados con la 
formulación de una serie de instrumentos de planificación e iniciativas de proyectos enfocados no sólo en la necesidad de promover la reconstrucción de las localidades afectadas, sino también de fomentar la discusión acerca de nuevos enfoques de actuación ante los desafíos de resiliencia urbana y gestión del riesgo en ciudades costeras, en el marco de la actualización de instrumentos de planificación territorial a escala comunal y regional. Aun cuando en estos instrumentos no existen referencias explícitas a la idea de resiliencia como marco de desarrollo de capacidades adaptativas en el habitar del borde costero, el caso del Plan de Reconstrucción de la ciudad de Constitución -y en particular el proyecto de Parque de Mitigación que se desarrolla bajo su alero- abren un espacio de reflexión sobre las formas de actuación desde la planificación y diseño del paisaje en contextos de riesgos y vulnerabilidades. Desde su conceptualización como infraestructura urbana para la amortiguación de los fenómenos de inundación derivados de la ocurrencia de tsunamis, la figura de los Parques de Mitigación como proyecto es replicada luego en diversas localidades costeras afectadas por el desastre de febrero de 2010, siguiendo el ejemplo de Constitución.

Este nuevo enfoque de infraestructura integra la noción de parque como estrategia que especula sobre las condiciones de habitabilidad en los bordes expuestos a riesgos de desastres, proponiendo nuevas posibilidades de encuentro social entre la ciudades litorales y los paisajes costeros, los cuales previos al desastre habían sido progresivamente ocupados, privatizados y subvalorados, en su dimensión cultural y ecológica. De esta manera, el espacio público en la reconstrucción del $27 \mathrm{~F}$ adquiere un rol estratégico, dado que se comprende como el ámbito clave a intervenir para revertir las condiciones de vulnerabilidad, promover la reducción de riesgos de desastres y fomentar la resiliencia urbana. Desde esta visión de infraestrutura multipropósito, la estrategia de hibridar el concepto de infraestructura de mitigación con la idea de parque permite optimizar la inversión pública mediante proyectos intersectoriales que apuntan a compatibilizar los objetivos de seguridad civil y reducción de riesgos, con la necesidad de mejorar la dotación de espacios públicos de calidad, en localidades que presentaban importantes déficit en esta materia, de manera previa al desastre.

No obstante, aun cuando su desarrollo ha significado un inédito esfuerzo de política pública, gobernanza e inversión multisectorial, los proyectos de Parques de Mitigación han sido escasamente analizados y la información asociada a su formulación, diseño y ejecución ha permanecido archivada y fragmentada en diversas reparticiones gubernamentales. Ante ello, esta investigación ha aportado justamente en establecer una búsqueda, sistematización y análisis crítico de la documentación de anteproyecto, proyecto ejecutivo y registro de obras ejecutadas, evaluando su planificación y diseño en términos de coherencia y efectividad, en tanto dispositivos claves para la reducción de riesgos ante desastres. Asimismo, la profundización de su análisis comparado respecto a casos relevantes que aporta la experiencia internacional, ha permitido identificar brechas que refieren tanto a la necesidad de ampliar el alcance de la escala del proyecto hacia la planificación del mosaico de paisaje en una dimensión espacial y ambiental mayor, como también a precisar aspectos específicos de diseño en 
congruencia con parámetros técnicos requeridos para la disipación del tsunami, en términos de su velocidad, volumen y fuerza de impacto.

En base a este análisis, la propuesta para el fortalecimiento de los Parques de Mitigación en tanto infraestructura verde para la adaptabilidad y resiliencia de territorios afectados por desastres en contextos de borde costero, se organiza a partir de la formulación de lineamientos conceptuales, estrategias de planificación y criterios técnicos de diseño. Comprendidos en primer lugar como iniciativas que se enmarcan en políticas públicas e instrumentos de planificación de resiliencia urbana y gestión de reducción de riesgos, los lineamientos favorecen la comprensión de los Parques de Mitigación en relación a su propósito y alcance, a los beneficios y sinergias que considera, a la integración multisectorial que promueve su planificación, diseño e implementación, a la multiescalaridad de su alcance territorial y a la temporalidad de su gestión en el mediano y largo plazo. Por su parte, las estrategias que se proponen permiten precisar su operatividad desde el reconocimiento e integración de instrumentos y programas multisectoriales, que favorecen su viabilidad en un determinado contexto de intervención. Estas estrategias se estructuran y espacializan en el territorio mediante un plan, que a la vez organiza el conjunto de operaciones que acontecen en un nivel de diseño y/o manejo concreto. Por último, en términos más específicos, los criterios de diseño establecen los parámetros de referencia técnica que definen la escala y estructura espacial del Parque de Mitigación, asegurando su operatividad mediante la configuración de soluciones basadas en la integración de componentes de infraestructura ecológica e infraestructura construida.

Sin perjuicio de lo anterior, resulta importante concluir que este enfoque de infraestructura verde de mitigación plantea un desafío ambiental y cultural que trasciende su dimensión operativa y técnica, el cual refiere a la sociabilización de una nueva concepción de parque, estética y espacialmente más cercana a la imagen de ecosistemas silvestres auto-organizados y evolutivos, que a sistemas construidos y manejados como áreas verdes urbanas convencionales. Asimismo, desde el punto de vista de su uso y valoración social, estos componentes se definen ya no sólo como ámbitos programáticos o socialmente funcionales, sino más bien como reductos ecológicos que contienen y aportan importantes servicios ecosistémicos para la adaptabilidad y resiliencia ante potenciales desastres.

En relación a las proyecciones de la investigación, se plantea promover su transferencia y aplicabilidad mediante el desarrollo de soportes que favorezcan la implementación de una política pública asociada a la promoción de iniciativas de planificación y diseño de infraestructuras verdes para el fortalecimiento de la resiliencia urbana y la reducción de riesgos de desastres, incluyendo:

- La definición de un cuerpo normativo orientado a regular aspectos técnicos de diseño y ejecución de proyectos, contenido tanto a nivel de ley y ordenanzas, como también a nivel de reglamentos que colaboren en su operatividad técnica.

- La adscripción de este tipo de proyectos a los marcos normativos e indicativos de los instrumentos de planificación a escala comunal y regional, transformándolos en piezas fundamentales de la infraestructura urbana. 
- La determinación de modelos de gestión intersectoriales destinados por un lado a facilitar su evaluación social y económica que permita acceder a fondos públicos $y$, por otra parte a reconocer e integrar diversas fuentes de financiamiento para la implementación y mantención de los proyectos.

- La estructuración de instancias de participación ciudadana abiertas y vinculantes, establecidas desde las fases tempranas de su planificación, que permitan integrar los requerimientos, visiones y objetivos de desarrollo de las comunidades locales y los actores relevantes del territorio.

- El desarrollo de guías técnicas de planificación y diseño de proyectos, que contribuyan a apoyar el desarrollo de este tipo de iniciativas y colaboren en la divulgación de buenas prácticas documentadas a nivel nacional e internacional.

En términos del alcance potencial de estas proyecciones, su ámbito de acción puede expandirse hacia otros contextos territoriales relacionados con diversas situaciones y factores de riesgo, tales como remociones en masa, inundaciones por eventos hidrometereológicos e incluso incendios generados en la interfaz urbanoforestal. Las múltiples interacciones que este abanico de fenómenos establece con los territorios habitados constituye un campo fértil para la formulación y desarrollo de iniciativas de planificación y diseño de Parques de Mitigación. 


\section{BIBLIOGRAFÍA}

Arcement, George; Schneider, Verne (1989). Guide for Selecting Manning's Roughness Coefficients for Natural Channels and Flood Plains. U.S. Geological Survey Water-Supply.

Arenas, Federico; Lagos, Marcelo; Hidalgo, Rodrigo (2010). Riesgos naturales y planificación territorial. Revista Centro de Políticas Públicas UC, 5 (39), 1-11.

Arteaga, Catalina; Tapia, Ricardo (2015). Vulnerabilidades y Desastres Socionaturales. Editorial Universitaria, Santiago de Chile.

Batlle, Enric (2011). El Jardín de la Metrópoli. Del paisaje romántico al espacio libre para una ciudad sostenible. Editorial Gustavo Gili, Barcelona.

Bélanger, Pierre (2016). Landscape as infrastructure: a base primer. Taylor \& Francis / Routledge, Londres.

Belmonte, Jesus (2016). Registro de representaciones y discursos proyectuales en paisajes del desastre Redibujando el borde costero chileno afectado por tsunamis. Constitución y el 27 de febrero de 2010. Tesis para optar al grado de Magister en Arquitectura del Paisaje. Escuela de Arquitectura, Pontificia Universidad Católica de Chile.

Berkes, Fikret; Colding, Joahn; Folke, Carl (2003). Navigating Social-Ecological Systems: Building Resilience for Complexity and Change. Cambridge University Press, Londres.

Berrizbeitia, Anita. (2007) Re- Placing process. En Large Parks, ed. Czerniak, Julia; Hargreaves, George (eds.). Princeton Architectural Press, Nueva York.

Berque, Augustín. (ed.) (1994) Cinq Propositions pour une Théorie du Paysage. Seyssel: Editions Champ Vallon, París.

Bertrand, George (2008). Un paisaje más profundo. De la epistemología al método. Cuadernos Geográficos, 43 (2), 17-27.

Beveridge, Charles; Paul Rocheleau (1998). Frederick Law Olmsted: Designing the American Landscape. Universe Publishing, Nueva York.

Bilkovic, D.; Mitchell, M. (2013). Ecological tradeoffs of stabilized salt marshes as a shoreline protection strategy: effects of artificial structures on macrobenthic assemblages. Journal of Ecological Engineering, 61, 469-481.

Bresciani, Luis (2012). En, Brain, I. \& Mora, P. (eds.) Emergencia y Reconstrucción: el antes y después del terremoto y tsunami del 27-F en Chile. Aprendizajes en materia habitacional, urbana y de seguros. Ediciones Pontificia Univeridad Católica de Chile, Centro de Políticas Públicas UC, Santiago de Chile.

Carpenter, S. R.; Folke Carl (2006). Ecology for transformation. Trends in Ecology and Evolution 21, 309-315.

CEPAL (2012). La economía del cambio climático en Chile. Documento de Proyecto. Comisión Económica para América Latina y el Caribe. Santiago de Chile.

Cereceda, Pilar; Errázuriz, Ana M. (2015). Geografía. Chile y el mundo. Editorial Vicens Vives, Santiago de Chile.

Cereceda, Pilar; Errázuriz, Ana M.; Lagos, Marcelo (2011). Terremotos y tsunamis en Chile: Para prevenir y conocer. Origo Ediciones, Santiago de Chile.

Clements, Frederick (1905). Research methods in ecology. The University Publishing Company, Lincoln Nebraska. Consulta online en: https://archive.org/details/researchmethodsi00clemuoft

COI - Comisión Oceanográfica Intergubernamental (2012) Tsunamis: Las grandes olas, 2da edición revisada. UNESCO, París. 
Comisión Europea (2013). Estrategia Europea de Infraestructura Verde / Green InfrastructureEnhancing Europe's Natural Capital, Bruselas.

Contreras, Manuel, \& Winckler, Patricio (2013). Pérdidas de vidas, viviendas, infraestructura y embarcaciones por el tsunami del 27 de febrero de 2010 en la costa central de Chile. Obras y proyectos, (14), 6-19.

Corner, James; Bick, Alison (2014). The Landscape Imagination. The Collected Essays of James Corner 1990-2010. Princeton Architectural Press, Nueva York.

Corner, James (1999). Recovering Landscape: Esays in Contemporary Landscape Theory. Princeton Architectural Press, Nueva York.

Costanza, Robert; d'Arge, R.; de Groot, R.; Farber, S.; Grasso, M.; Hannon, B.; Limburg, K.; Naeem, S.; O'Neill, R. V.; Paruelo, J.; Raskin, R. G.; Sutton, R.; van den Belt, M. (1997) The value of the world's ecosystem services and natural capital. Nature, 387, 253-260.

Czerniak, Julia; Hargreaves, George (2007). Large Parks. Princeton Architectural Press, Nueva York.

Da Cunha, Dilip (2018). The Invention of Rivers: Alexander's eye and Ganga's Descent. University of Pennsylvania Press, Pensilvanya.

Davidson-Hunt, Ian \& Berkes, Fikret (2003). Nature and society through the lens of resilience: toward a human-in-ecosystem perspective. En, Berkes, Fikret; Colding, Joahn; Carl Folke. Navigating Social-Ecological Systems: Building Resilience for Complexity and Change. Cambridge University Press, Cambridge.

Eckardt, F. (2011) Landscapes of Disaster. Symbolic Spaces of Orientation. Topos Internatiional Review of Landscape Architecture and Urban Design, 76, 51-54.

Elkin, Rosetta; Tsing, Anna (2018). The Politics of the Rhizosphere. Harvard Design Magazine, 45 / Into the Woods, Cambridge.

Emrich, C., \& Tobin, G. (2018). Resilience: An Introduction. En Fuchs \& Thaler (Eds.), Vulnerability and Resilience to Natural Hazards, 124-144. Cambridge University Press, Cambridge.

EPC -Environmental Planning Collaborative \& TCG International LLC (2004). Participatory Planning Guide for Post-Disaster Reconstruction. Ahmedabad.

Farber, S.; Costanza, R.; Childers D. L.; Erickson, J.; Gross, K.; Grove, M.; Hopkinson, C. S.; Kahn, J.; Pincelt, S.; Troy, A.; Warren, P.; Wilson, M. (2006). Linking ecology and economics for ecosystem management. BioScience, 56, 121-133.

Fariello, Francesco (2001). La arquitectura de los jardines. De la antigüedad al siglo XX. Editorial Reverte, Madrid.

Fernández Galiano, Luis (2002). Último Chile. Arquitectura Viva, 85, 3.

Finney, S. C. \& Edwards, L. E. (2015). The "Anthropocene" epoch: Scientific decision or political statement?. GSA Today, 26(3-4), 4-10.

Forbes; Keith \& Broadhead, Jeremy (2008). The Role of Coastal Forests in the Mitigation of Tsunami Impacts. Main report. FAO - Food and Agriculture Organization of the United Nations. Regional Office for Asia and the Pacific, Bangkok.

Folke, Carl (2006). Resilience: The emergence of a perspective for social-ecological systems analyses. Global Environmental Change, 16 (3), 253-267.

Forman, Richard TT. (1995). Landmosaics: the ecology of landscape and regions. Cambridge University Press, Cambridge.

Forman, Richard TT.; Godron, Michel (1986). Landscape Ecology. Wiley and Sons, Nueva York.

Fritz, H., Petroff, C., Catalán, P., Cienfuegos, R., Winckler, P., Kalligeris, N., Weiss, R., Barrientos, S., Meneses, G., Valderas-Bermejo, C., Ebeling, C., Papadopoulos, A., Contreras, M., Almar, R., 
Domínguez, J. and Synolakis, C. (2011). Field Survey of the 27 February 2010 Chile Tsunami. Pure and Applied Geophysics, 168: 1989-2010.

Fuchs, Sven; Thaler, Thomas (2018). Vulnerability and Resilience to Natural Hazards. Cambridge University Press. Reino Unido.

Gobierno de Chile (2010). Programa de Reconstrucción Terremoto y Maremoto del 27 de febrero de 2010. Resumen Ejecutivo. Ministerio Secretaría General de la Presidencia.

Govarets, A.; Lauwerts, B. (2009) Assessment of the impact of coastal defence structures. Biodiversity Series, The Convention for the Protection of the Marine Environment of the North-East Atlantic (OSPAR Commission), pp. 29.

GSAPP - Graduate School of Architecture Planning and Preservation (2015) Learning from 27F: A Comparative Assessment of Urban Reconstruction Processes After The 2010 Eathquake In Chile. Proyecto de investigación financiado por el Columbia-Chile Fund de Columbia Global Center Santiago y CONICYT. Dirigido por el Latin Lab, GSAPP Columbia University y Santiago Research Cell.

Hallegatte, S.; Green C.; Nicholls, R.J.; Corfee-Morlot, J. (2013). Future flood losses in major coastal cities. Nature Climate Change, 3, 802-806.

Herrmann, Marie (2016). Planificación territorial y mitigación de impacto de tsunami en Chile después del 27 febrero 2010. Revista de Urbanismo, 34, 20-33.

Holland, Marjorie; Risser, Paul; Naiman, Robert (1991). Ecotones. The role of landscape boundaries in the management and restoration of changing environments. Routledge, Chapman \& Hall.

Holling, Crawford S. (2002). Understanding the Complexity of Economic, Ecological and Social Systems. Ecosystems, 4 (5), 390-405.

Holling, Crawford S. (1992). Cross-scale Morphology, geometry, and dynamics of ecosystems. Ecological Monographs, 62 (4) 447-502.

Holling, Crawford S. (1973). Resilience and stability of ecological systems. Annual Review of Ecology and Systematics, 4, 1-23.

Igualt, Felipe; Breuer, Wolfgang; Contreras, Manuel \& Winckler, Patricio (2017). Rehabilitación de centros urbanos afectados por el Tsunami 2010 en la Comuna de Pelluhue. Latin American Journal of Aquatic Research, 45, 659-674.

Igualt, Felipe (2015). Urban Waterfront Rehabilitation in Pelluhue County, Chile, affected by the Chile 2010 Earthquake and Tsunami. Doctoral Thesis. School of Architecture University of Hawai'i at Manoa.

INE (2017). Censo Nacional, año 2017. Instituto Nacional de Estadísticas G.obierno de Chile.

INE (2006). Compendio estadístico 2006: Características de los climas de Chile. Instituto Nacional de Estadísticas. Gobierno de Chile.

INE (2002). Censo Nacional, año 2002. Instituto Nacional de Estadísticas. Gobierno de Chile.

Jackson, John Brinckerhoff (1984). Discovering the Vernacular Landscape. Yale University Press, New Haven.

JICA (2018). Guía para la estimación del peligro de tsunami. Proyecto de Investigación para el Mejoramiento de Tecnología para desarrollar una Comunidad Resiliente ante los Tsunamis. Proyecto SATREPS Tsunami, Agencia de Cooperación Internacional del Japón.

Jiménez, Francisco (2016). Antropología ecológica. Editorial Dykinson, Madrid.

Johnson, Marcha; Bayley, Amanda (2016) Coastal Change, Ocean Conservation and Resilient Communities. Springer International Publishing, Ginebra.

Kreimer, A.; Arnold, M. \& Carlin, A. (eds.) (2003) Building Safer Cities. The Future Of Disaster Risk. The World Bank Disaster Management Facility, Washington, D.C. 
Kotani, M., Imamura, F. \& Shuto, N. (1998) Tsunami run-up simulation and damage estimation by using geographical information system. Proc. Coastal Engineering, JSCE 45, 356-360.

Lavell, Allan (1996). Degradación ambiental, riesgo y desastre urbano. Problemas y conceptos: Hacia la definición de una agenda de investigación. Red de Estudios Sociales en Prevención de Desastres en América Latina (La Red). Lima.

Lagos, Marcelo (2012). Modelación de tsunami proyecto: Parque Borde Fluvial ciudad de Constitución. Documento técnico. Laboratorio de Investigación de Tsunami UC.

Lagos, Marcelo (2010). Modelación de tsunami proyecto: Parque Borde Fluvial ciudad de Constitución. Documento técnico. Facultad de Geografía Pontificia Universidad Católica de Chile.

Lagos, Marcelo; Cisternas, Marco; Mardones, María. (2008) Construcción de viviendas sociales en áreas de riesgo de tsunami. Revista de la Construcción, 7 (2), 4-16.

Lagos, Marcelo (2000) Tsunamis de origen cercano a las costas de Chile. Revista de Geografía Norte Grande, 27, 93-102.

Lister, Nine-Marie (2015) Resilience: Designing the New Sustainability The need for an evidencebased approach to adaptivity. Topos The international Review of Landscape Architecture and Urban Design, 90, 14-21.

Lockridge, P. (1985): "Tsunamis in Peru - Chile". Report SE-39, World Data Center A for Solid Earth Geophysics.

Martínez, Carolina; Moris, Roberto; Qüense, Jorge (2016). Valoración de las áreas de riesgo por tsunami y potencial de evacuación: propuestas para la reducción del riesgo de desastres a escala local. En Propuestas para Chile. Concurso de Políticas Públicas 2016, Centro de Políticas Públicas Pontificia Universidad Católica de Chile, 243-278.

Martínez, Carolina (2013). Vulnerabilidades y desastres socio- naturales: aportes desde la geografía al proceso de reconstrucción en la región del Biobío. Revista Geográfica del Sur, 3, 33-58.

Martínez, C., Rojas, O.; Jaque, E.; Quezada, J.; Vázquez, D.; Belmonte, A. (2011). Efectos territoriales del tsunami del 27 de febrero de 2010 en la costa de la región del Biobío, Chile. Revista Geográfica de América Central, 47 E(2), 1-16.

Martínez de Pisón, E. (2008). La experiencia del paisaje. E, Mateu Bellés, J. y Nieto Salvatierra, M. (eds.) Retorno al Paisaje, pp. 21-69. Editorial EVREN, Evaluación de Recursos Naturales, S.A., Valencia.

Mathur, Anuradha; Da Cunha, Dilip (2001) Mississipi Floods: Designing a Shifting Landscape. Yale University Press, New Haven.

McBreen, J. (2016). Regional Assessment on Ecosystem-based Disaster Risk Reduction and Biodiversity in South America. A report for the Resilience through Investing in Ecosystems - knowledge, innovation and transformation of risk management (RELIEF Kit) project. International Union for Conservation of Nature.

MEA - MILLENIUM ECOSYSTEM ASSESSMENT (2005) Ecosystem and Human Well-being: Current State and Trends. Island Press. Washington D.C.

MINVU (2010). Plan de Reconstrucción MINVU "Chile Unido Reconstruye Mejor". Ministerio de Vivienda y Urbanismo, Gobierno de Chile, 3era edición.

MINVU (2011). Plan de Reconstrucción MINVU "Chile Unido Reconstruye Mejor". Ministerio de Vivienda y Urbanismo, Gobierno de Chile, 4ta edición.

MINVU (2011a). Terminos de Referencia para el Diseño de Arquitectura, Paisajismo y Especialidades de Construccion Parque Borde Fluvial Ciudad de Constitucion. Plan de Reconstrucción Estratégico Sustentable de Constitución (PRES) IDI.: 30104703-0.

Moreno, Osvaldo (2013). Paisaje, riesgo y resiliencia. La arquitectura del paisaje en la modelación sustentable del territorio. Revista Forum de Sustentabilidad, Cátedra UNESCO, 6, 17-30. 
Moreno, Osvaldo (2015). Paisajes en emergencia: transformación, adaptación, resiliencia. Revista INVI, 30 (83), 9-17.

Monge, J. (1993). Estudios de riesgo de tsunami en costas chilenas. Santiago, Chile. Jornadas chilenas de Sismología en ingeniería antisísmica, 2, 3-22.

Mossop, Erick (2006). Landscapes of infraestructure. En: Waldheim, C. (ed). Landscape as Urbanism Reader. Princeton Architectural Press, Nueva York.

Natenzon, Claudia; Ríos, Diego (2015). Riesgos, catástrofes y vulnerabilidades. Aportes desde la geografía y otras ciencias sociales para casos argentinos. Ediciones Imago Mundi, Buenos Aires.

Nogué, Joan (2010). El retorno al paisaje. Enrahonar: Quaderns de filosofía, 45.

OCUC (2010). Estudio de Riesgo de Sismos y Maremoto para Comunas Costeras de las Regiones de O'Higgins y del Maule. Documento técnico desarrollado por el Observatorio de Ciudades y el Instituto de Estudios Urbanos de la Pontificia Universidad Católica de Chile.

Odum, Eugene P. (1971). Fundamentals of ecology. W.B. Saunders Company, Philadelphia.

ONEMI (2014). Política Nacional para la Gestión de Riesgo de Desastres. Oficina Nacional de Emergencia del Ministerio del Interior y Seguridad Pública. Gobierno de Chile.

Ostrom, Elinor (2009). A General Framework for Analyzing Sustainability of Social-Ecological Systems. Science, Vol. 325, n5939, pp: 419-422.

PRBC Dichato (2010). Plan de Reconstrucción del Borde Costero. Plan Maestro de Dichato. Informe Final. Gobierno Regional del Biobío.

PRES (2011). Book PRES - Plan de Reconstrucción Estratégica Sustentable. Recuperado de: https://es.slideshare.net/presconstitucion/presbook-presentacion

PRES Pelluhue (2010). Plan de Reconstrucción Estratégico-Sustentablede de Pelluhue. Memoria explicativa. Consorcio para la Reconstrucción de Pelluhue.

Reed, Chris (2015). Absorb, Adapt, Transform. USA: Urban landscapes and climate adaptation strategies. Topos The International Review of Landscape Architecture and Urban Design, 90, 60-69.

Reed, Chris; Lister Nine-Marie (2014). Projective Ecologies. Harvard University Graduate School of Design, Cambridge.

Reed, Chris; Lister Nine-Marie (2014a). Parallel Genealogies. En Projective Ecologies. Harvard Graduate School of Design, Cambridge.

Renaud, Fabrice \& Murti, Radhika (2013). Ecosystems and disaster risk reduction in the context of the Great East Japan Earthquake and Tsunami - a scoping study. International Union for Conservation of Nature. Publication Series of UNU-EHS $\mathrm{N}^{\circ} 10$.

Roger, Alain (1997). Court traité du paysage. Éditiones Gallimard, Paris.

Rojas, Jorge (2011). Vulnerabilidad social, neoliberalismo y desastre: sueños y temores de la comunidad desplazada/ damnificada por el terremoto/tsunami. En, Revista Sociedad Hoy, número 19. Departamento de Sociología y Antropología, Universidad de Concepción. Chile.

Romero, H.; Fuentes, C.; Smith, P. (2010). Dimensiones geográficas territoriales, institucionales y sociales del terremoto de Chile del 27 de febrero del 2010. Cuadernos de Geografía - Revista Colombiana de Geografía, 19, 137-152.

SERVIU Región del Maule (2013). Proyecto de Arquitectura, Paisajismo y Especialidades de Construccion Parque Borde Fluvial Ciudad de Constitución. Expediente técnico.

SERVIU Región del Maule (2012). Proyecto de Arquitectura, Paisajismo y Especialidades de Construccion Parque Costanera Comuna de Pelluhue. Expediente técnico. 
SERVIU Región del Biobío (2012). Licitación Pública Construcción Parque de Mitigación de Dichato. Servicio de Vivienda y Urbanismo. Región del Biobío.

Shannon, K.; Smets, M., (2010). The Landscape of Contemporary Infrastructure. Nai Publishers, Rotterdam.

Silvestri, Graciela; Aliata, Fernando (2001). El paisaje como cifra de armonía. Editorial Nueva Visión, Buenos Aires.

Simonetti, Javier; Figueroa, Eugenio (2003). Globalización y Biodiversidad: oportunidades y desafíos para la sociedad chilena. Editorial Universitaria, Santiago de Chile.

Steiner, Frederick (2012). The living landscape: an ecological approach to landscape planning. Island Press, West Palm Beach.

SUBDERE (2011). Guía de zonificación costera para el Ordenamiento Territorial. Santiago de Chile: Gobierno de Chile.

Sutton-Grier, Ariana; Wowk, Kateryna; Bamford, Holly (2015). Future of our coasts: The potential for natural and hybrid infrastructure to enhance the resilience of our coastal communities, economies and ecosystems. Journal of Environmental Science \& Policy, 51, 137-148.

Tanaka, Shigenobu (2010) Planning and design of tsunami-mitigative coastal vegetation belts. En, ICHARM n.18, UNESCO. Public Works Research Institute, Tsukuba, 3-5.

Ugarte, Ana María; Salgado, Marcela (2014). Sujetos en emergencia: acciones colectivas de resistencia y enfrentamiento del riesgo ante desastres; el caso de Chaitén. Revista INVI, 29 (80), pp.143168.

UNESCO (2014) Gestión del riesgo de desastres para el patrimonio mundial. París.

UCSUSA - Union of Concerned Scientists (2013). Causes of Sea Level Rise. Documento en línea:https://www.ucsusa.org/sites/default/files/legacy/assets/documents/global_warming/Causes-ofSea-Level-Rise.pdf

UNISDR - United Nations Office for Disaster Risk Reduction (2015). Proposed Updated Terminology on Disaster Risk Reduction: A technical review. Agosto. Ginebra, Suiza.

UNISDR - United Nations Office for Disaster Risk Reduction (2015a) Sendai Framework for Disaster Risk Reduction 2015-2030. Ginebra, Suiza.

Vargas, Jorge (2002). Políticas Públicas para la reducción de la vulnerabilidad frente a los desastres naturales y socio-naturales. CEPAL, Naciones Unidas, Santiago de Chile.

Vásquez, Alexis (2016) Infraestructura verde, servicios ecosistémicos y sus aportes para enfrentar el cambio climático en ciudades: el caso del corredor ribereño del río Mapocho en Santiago de Chile. Revista de Geografía Norte Grande, 63, 63-86.

Waldheim, Charles (2016). Landscape as Urbanism. Princeton Architectural Press. Nuev York.

Zelst, I. van.; Brizzi, S.; Dinther Y. van; Funiciello F.; Heuret, A. (2018). The influence of subduction zone tectonics on earthquake-generated tsunamis. Poster. EGU, Vienatria. 
LOS CUADERNOS DE INVESTIGACIÓN URBANÍSTICA. El Departamento de Urbanística y Ordenación del Territorio de la Escuela Técnica Superior de Arquitectura de Madrid, lleva publicando desde el año 1993 la revista Cuadernos Investigación Urbanística, (Ci[ur]), para dar a conocer trabajos de investigación realizados en el área del Urbanismo, la Ordenación Territorial, el Medio Ambiente, la Planificación Sostenible y el Paisaje. Su objetivo es la difusión de estos trabajos. La lengua preferente utilizada es el español, aunque se admiten artículos en inglés, francés, italiano y portugués.

La publicación presenta un carácter monográfico. Se trata de amplios informes de la investigación realizada que ocupan la totalidad de cada número sobre todo a aquellos investigadores que se inician, y que permite tener accesibles los aspectos más relevantes de los trabajos y conocer con bastante precisión el proceso de elaboración de los mismos. Los artículos constituyen amplios informes de una investigación realizada que tiene como objeto preferente las tesis doctorales leídas relacionadas con las temáticas del Urbanismo, la Ordenación Territorial, el Medio Ambiente, la Planificación Sostenible y el Paisaje en las condiciones que se detallan en el apartado "Publicar un trabajo".

La realización material de los Cuadernos de Investigación Urbanística está a cargo del Departamento de Urbanística y Ordenación del Territorio de la Escuela Técnica Superior de Arquitectura de Madrid. EI respeto de la propiedad intelectual está garantizado, ya que el registro es siempre en su totalidad propiedad del autor $y$, en todo caso, con autorización de la entidad pública o privada que ha subvencionado la investigación. Está permitida su reproducción parcial en las condiciones establecidas por la legislación sobre propiedad intelectual citando autor, previa petición de permiso al mismo, y procedencia.

Con objeto de verificar la calidad de los trabajos publicados los originales serán sometidos a un proceso de revisión por pares de expertos pertenecientes al Comité Científico de la Red de Cuadernos de Investigación Urbanística (RCi[ur]). Cualquier universidad que lo solicite y sea admitida por el Departamento de Urbanística y Ordenación del Territorio de la Universidad Politécnica de Madrid (DUYOT) puede pertenecer a esta red. Su único compromiso es el nombramiento, como mínimo, de un miembro de esa universidad experto en el área de conocimiento del Urbanismo, la Ordenación Territorial, el Medio Ambiente, la Planificación Sostenible y el Paisaje para que forme parte del Comité Científico de la revista y cuya obligación es evaluar los trabajos que se le remitan para verificar su calidad.

A juicio del Consejo de Redacción los resúmenes de tesis o partes de tesis doctorales leídas ante el tribunal correspondiente podrán ser exceptuados de esta revisión por pares. Sin embargo, dicho Consejo tendrá que manifestarse sobre si el resumen o parte de tesis doctoral responde efectivamente a la aportación científica de la misma.

\section{NORMAS DE PUBLICACIÓN}

Las condiciones para el envío de originales se pueden consultar en la página web:

Manuscript Submission Guidelines:

http://polired.upm.es/index.php/ciur 


\section{CONSULTA DE NÚMEROS ANTERIORES/ACCESS TO PREVIOUS ISSUES}

La colección completa se puede consultar en siguiente página web:

The entire publication is available in the following web page:

http://polired.upm.es/index.php/ciur

\section{ÚLTIMOS NÚMEROS PUBLICADOS:}

138 Eduardo De Santiago Rodríguez e Isabel González García: "Planeamiento urbanístico durante la burbuja y la posterior resaca inmobiliaria: de los excesos del neodesarrollismo a las dificultades de un urbanismo corrector. El caso del área urbana de León", 102 páginas, octubre, 2021.

137 Javier Zulategui Beñarán: "Hacia un diálogo entre ciudad y naturaleza. Una revisión histórica para fundamentar un futuro ambiental menos incierto", 58 páginas, agosto, 2021.

136 Augusto Tovar Numpaque: "Red de autopistas urbanas. Estimación de los efectos territoriales en la Ciudad de Buenos Aires", 104 páginas, junio, 2021.

135 María Teresa Baquero Larriva: "Salud urbana, confort térmico y acústico en espacios públicos exteriores, en el marco de las ciudades amigables con los mayores", 92 páginas, abril, 2021.

134 Sonia De Gregorio Hurtado, Virginia Do Santos Coelho y Amina Baatti Boulahia, "La europeización de la política urbana en España en el periodo 2014-2020. análisis de las estrategias de desarrollo urbano sostenible integrado (EDUSI)", 100 páginas, febrero,2021.

133 Eduardo De Santiago Rodríguez y Isabel González García: "Planes urbanísticos y asentamientos tradicionales en el medio rural: el tratamiento del suelo de núcleo rural en Asturias", 102 páginas, diciembre 2020.

132 Carlos Bustamante Oleart: "La historia del viento en las ciudades", 63 páginas, octubre 2020.

131 José Jorge Peralta Arias: "Sostenibilidad urbana en el contexto latinoamericano y en el europeo", 128 páginas, agosto 2020.

130 Álvaro Cerezo Ibarrondo: "La actuación sobre el medio urbano de regeneración y renovación integrada. El nuevo paradigma de la gestión urbanística en suelo urbanizado" 95 páginas, junio 2020.

129 Emilia Román López (editora): "Seminario Internacional. Paisajes culturales de la sal artesanal en España e Iberoamérica. Estrategias e instrumentos para la planificación y gestión del patrimonio cultural [I/II]. II. Sal y cultura", 109 páginas, abril 2020.

128 Ester Higueras García (editora): "Seminario Internacional. Paisajes culturales de la sal artesanal en España e Iberoamérica. Estrategias e instrumentos para la planificación y gestión del patrimonio cultural [I/II]. I. Sal y cultura", 86 páginas, febrero 2020. 


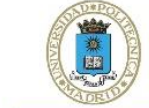

POLITÉCNICA

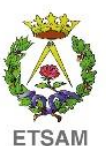

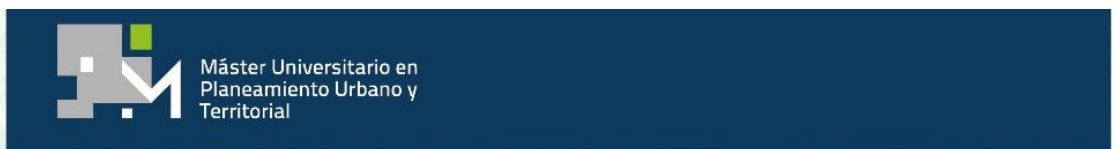

XIII MASTER UNIVERSITARIO EN PLANEAMIENTO URBANO Y TERRITORIAL POR LA UNIVERSIDAD POLITÉCNICA DE MADRID

\section{MÁS DE 20 AÑOS FORMANDO EN LA INVESTIGACIÓN Y LA PRÁCTICA PROFESIONAL DEL URBANISMO PARA RESPONDER A LOS DESAFÍOS DEL DESARROLLO URBANO Y TERRITORIAL, LA SOSTENIBILIDADY LA JUSTICIA SOCIOESPACIAL.}

Nuestras ciudades están cambiando a un ritmo acelerado ante los retos cada vez más apremiantes de la crisis climática, la desigualdad social, la reestructuración económica y el desarrollo de nuevas tecnologias. Junto a estos desafíos, estrategias emergentes como la Agenda 2030, la Agenda Urbana Mundial o la reconstrucción post-COVID demandan una respuesta urgente por parte de los agentes implicados en la producción y ordenación del territorio. EI MUPUT prepara al alumnado para enfrentarse a estas transformaciones con un programa que combina una mirada interdisciplinar con la especialización técnica y una larga experiencia en la incorporación de enfoques innovadores, adaptados a las nuevas demandas sociales, dando también respuesta a los conflictos y oportunidades derivados de la actual pandemia.

El máster se apoya en las fortalezas del DUyOT, la ETSAM, y la UPM para ofrecer la formación de postgrado en urbanismo con mayor trayectoria en España. Durante más de 20 años el Departamento de Urbanística y Ordenación del Territorio ha formado en la investigación y la práctica profesional a un alumnado de más de 30 países, procedentes de las diversas áreas de conocimiento que se articulan en nuestra visión multidisciplinar del urbanismo. EI MUPUT cuenta con certificados de calidad de AESOP (Association of European Schools of Planning) y la Fundación para el Conocimiento MADRI+D, es reconocido por la AETU (Asociación Española de Técnicos Urbanistas) y colabora con numerosas administraciones públicas y empresas para el desarrollo de sus prácticas de formación. La plantilla docente incluye a urbanistas e investigadores/as de reconocido prestigio y una prolongada experiencia a nivel nacional internacional.

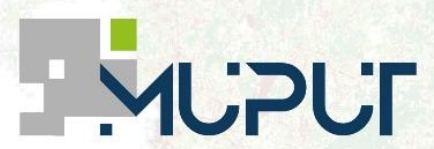

Máster Universitario en Planeamiento Urbano y Territorial

\section{Especialidad en Planeamiento Urbanístico}

Este itinerario tiene una orientación profesional y capacita al alumnado en el uso de instrumentos de análisis, nuevas tecnologías y criterios de planificación y diseño para ejercer el oficio de urbanista en organismos públicos y empresas de consultoría.

Se ofrece la oportunidad de desarrollar prácticas de formación en empresas y administraciones públicas como parte del programa lectivo. El título del MUPUT es reconocido para la admisión como miembro de AETU.

\section{Especialidad en Estudios Urbanos}

Este itinerario está orientado a la formación de investigadores/as, dotándoles de destrezas para examinar críticamente y dar respuesta a los principales retos urbanos contemporáneos a través de metodologías y marcos conceptuales avanzados.

La titulación da acceso al programa de doctorado del DUyOT. El alumnado tiene la oportunidad de continuar sus carreras en el mundo académico, en observatorios urbanos y en departamentos de investigación de organismos públicos.

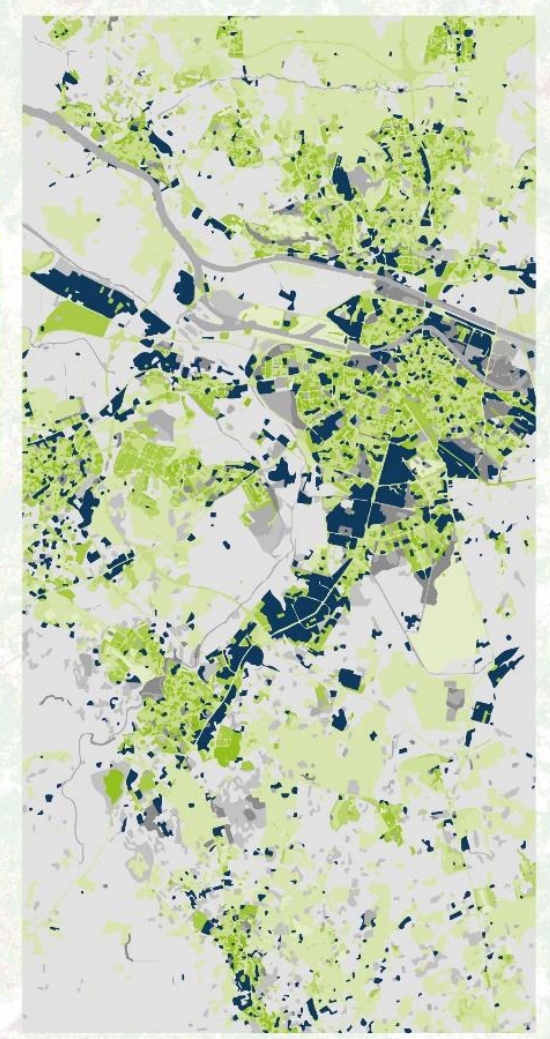

Créditos: 60 ECTS

Equipo de dirección: Directora: Ester Higueras García Secretaría académica: María Cristina García Gonzálezz Responsable en marketing y comunicación: Inmaculada Mohino Sanz

Profesorado: Agustin Hernández: José Miguel Fernández-Güell; José María Ezquiaga; Ester Higueras; Javier Ruizi; Inés Sánchez de Madariaga; Alvaro Sevilla; Andrea Alonso: Eva Alvarez; Cristina Garcia; Isabel Gonzalez; Sonia De Grecorio; Francisco Lamiquiz; Emilia Román: Carmen Andrés; Llanos Masiá

Lugar de impartición: Escuela Ténica Superior de Arquitectura de Madrid

Tipo de enseñanza: Presencial

Calendario: Malriculación 1 1" semestre / Periodo de desmatriculación: consullar web Inicio de las clases: 13 de septiembre de 2021

Web oficial: attps://duyot:aq.upm.es/master/muput Contacto: masterplaneamiento arc 
Otros medios divulgativos del Departamento de Urbanística y Ordenación del Territorio: Web del Departamento de Urbanística y Ordenación del Territorio: https://duyot.aq.upm.es/, donde figuran todas las actividades docentes, divulgativas y de investigación que se realizan en el Departamento con una actualización permanente de sus contenidos.

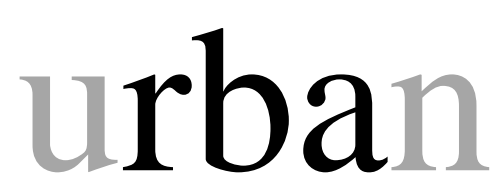

\title{
REVISTA del DEPARTAMENTO de URBANÍSTICA Y ORDENACIÓN del TERRITORIO
}

\author{
ESCUELA TÉCNICA SUPERIOR DE ARQUITECTURA
}

\section{Presentación Segunda ÉPoca}

DESDE el año 1997, URBAN ha sido vehículo de expresión de la reflexión urbanística más innovadora en España y lugar de encuentro entre profesionales y académicos de todo el mundo. Durante su primera época la revista ha combinado el interés por los resultados de la investigación con la atención a la práctica profesional, especialmente en el ámbito español y la región madrileña. Sin abandonar dicha vocación de saber aplicado y localizado, la segunda época se centra en el progreso de las políticas urbanas y territoriales y la investigación científica a nivel internacional.

\section{CONVOCATORIA PARA LA RECEPCIÓN DE ARTÍCULOS:}

Urban mantiene abierta una convocatoria permanente para la remisión de artículos de temática relacionada con los objetivos de la revista: Para más información:

http://www2.aq.upm.es/Departamentos/Urbanismo/institucional/publicaciones/urban/ns/instruccionesparaautores/

Por último, se recuerda que, aunque La revista URBAN organiza sus números de manera monográfica mediante convocatorias temáticas, simultáneamente, mantiene siempre abierta de forma continua una convocatoria para artículos de temática libre.

\section{DATOS DE CONTACTO}

Envío de manuscritos y originales a la atención de Javier Ruiz Sánchez:

urban.arquitectura@upm.es Página web: http://polired.upm.es/index.php/urban 4

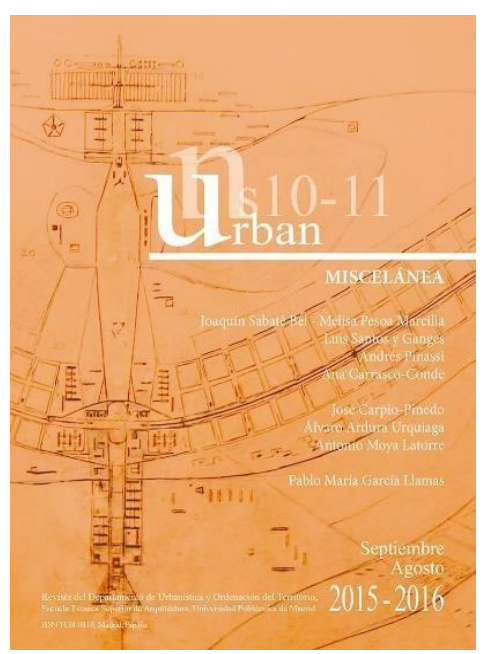




\section{territorios}

\section{en formación

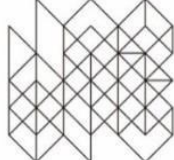 \\ NE RE AS \\ NET RESEARCH \\ ASSOCIATION \\ ETSAM UPM}

\section{ESCUELA TÉCNICA SUPERIOR DE ARQUITECTURA}

Territorios en formación constituye una plataforma de divulgación de la producción académica relacionada con los programas de postgrado del Departamento de Urbanística y Ordenación del Territorio de la ETSAM-UPM proporcionando una vía para la publicación de los artículos científicos y los trabajos de investigación del alumnado y garantizando su excelencia gracias a la constatación de que los mismos han tenido que superar un tribunal fin de máster o de los programas de doctorado del DUyOT.

Así, la publicación persigue dos objetivos: por un lado, pretende abordar la investigación dentro del ámbito de conocimiento de la Urbanística y la Ordenación del Territorio, así como la producción técnica de los programas profesionales relacionados con ellas; por otro, promueve la difusión de investigaciones o ejercicios técnicos que hayan sido planteados desde el ámbito de la formación de postgrado. En este caso es, principalmente, el Departamento de Urbanística y Ordenación del Territorio el que genera esta producción, gracias a la colaboración con la asociación Ne.Re.As. (Net Research Association / Asociación Red Investiga, asociación de investigadores de urbanismo y del territorio de la UPM), que, por acuerdo del Consejo de Departamento del DUyOT, es la encargada de la edición de la revista electrónica.

\section{DATOS DE CONTACTO}

http://polired.upm.es/index.php/territoriosenformacion
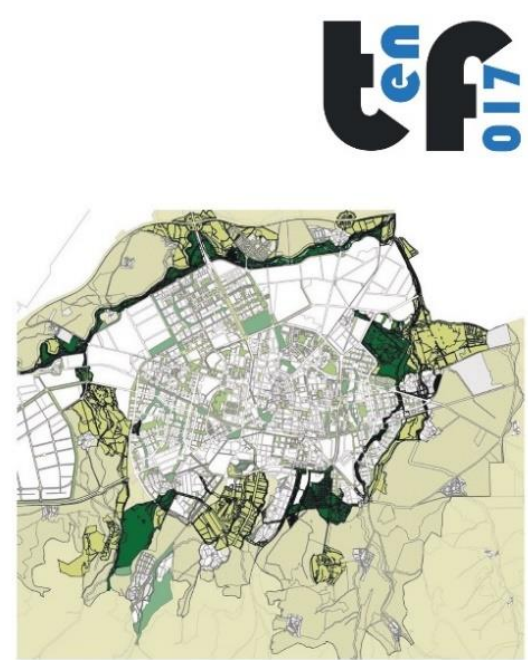

territorios en formación

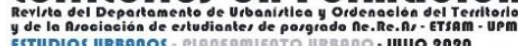

